
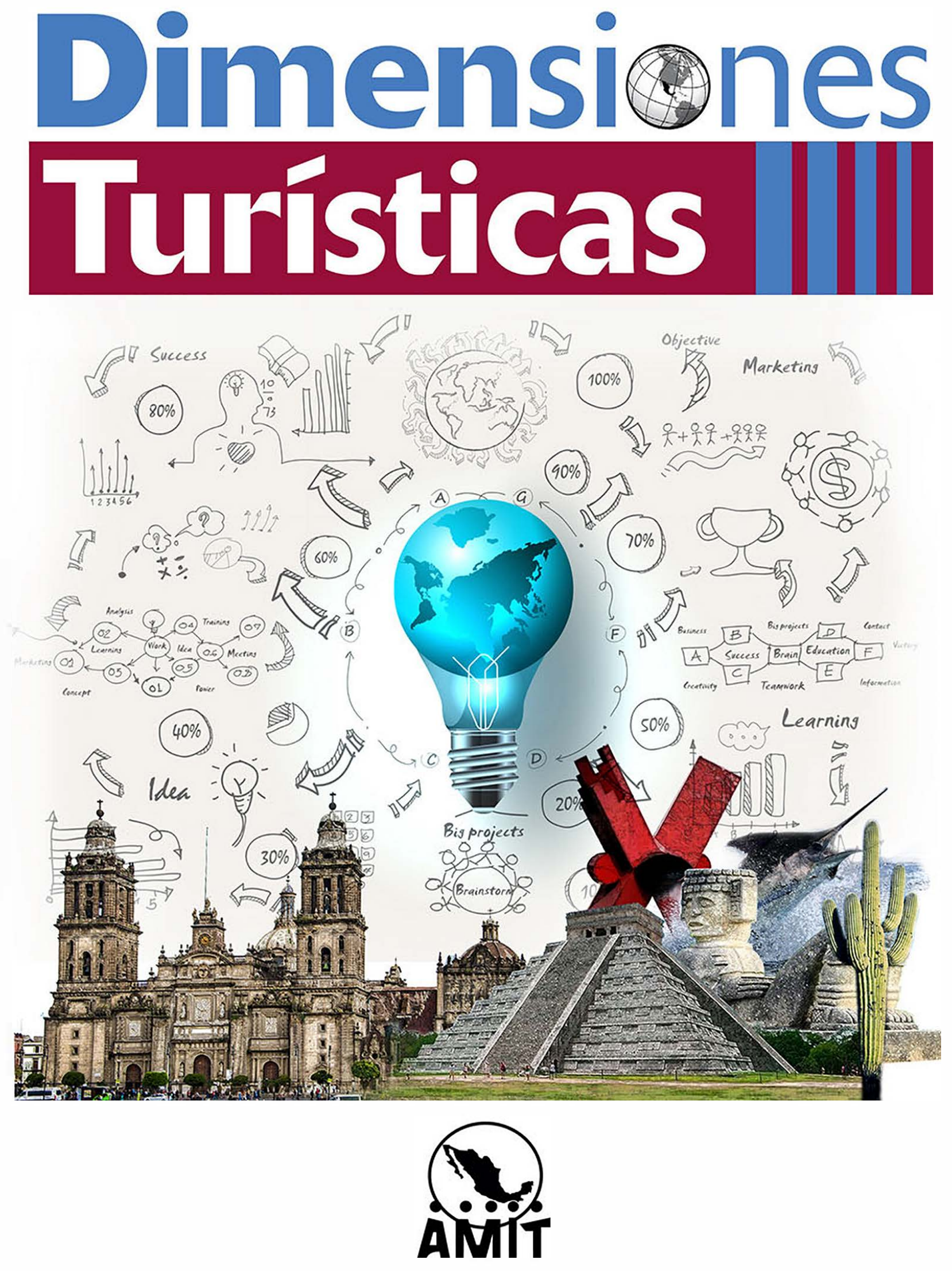

Publicación semestral • Vol. 2 ○ Núm. 3 Julio-diciembre 2018 e-ISSN 2594-2069

Academia Mexicana de Investigación Turistica, A. C. https://doi.org/10.47557/HMQK2952 

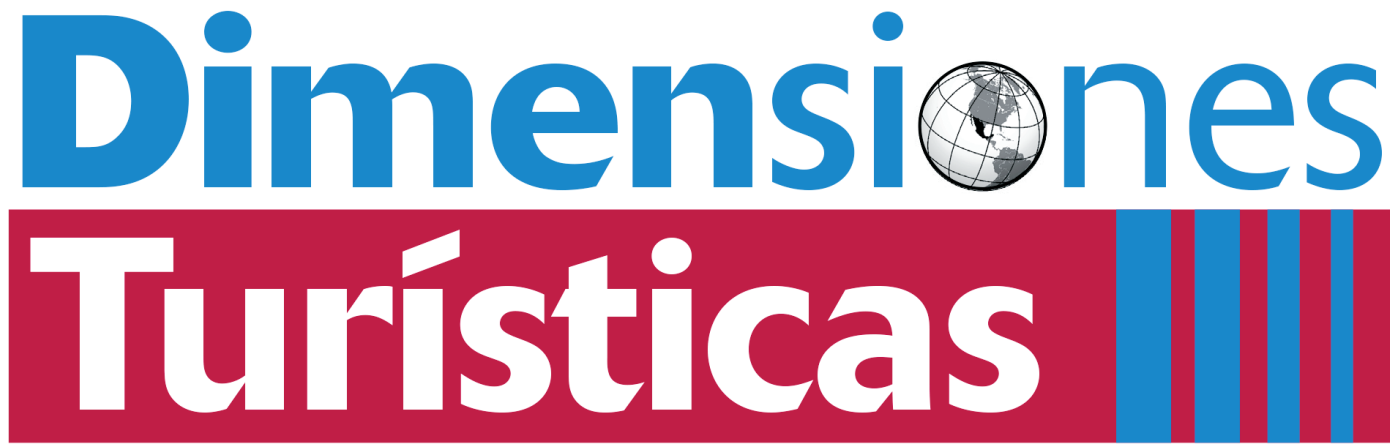

Publicación semestral • Vol. 2 • Núm. 3 • Julio-diciembre 2018 e-ISSN 2594-2069

https://doi.org/10.47557/HMQK2952

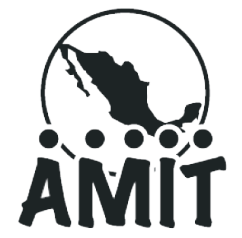

Academia Mexicana de Investigación Turística, A. C. 


\section{Academia Mexicana de Investigación Turística, A. C.}

La Academia Mexicana de Investigación Turística, A.C. (АMIт), de acuerdo con sus estatutos es una sociedad sin fines de lucro cuyos miembros, adscritos a universidades, centros de investigación u otro tipo de entidades públicas y privadas, proceden del campo de estudio del turismo así como de disciplinas como la geografía, economía, sociología, comunicación, antropología, psicología, administración, ciencia política, demografía, ecología, entre otras. La Aміт pretende generar un espacio de trabajo colegiado entre los investigadores(as) dedicados a los estudios del turismo.

Directora de Dimensiones Turísticas

Nora Leticia Bringas Rábago

Teléfono: +52 (664) 6316300 ext. 1306

Correo electrónico: amit.dimentur@gmail.com

Contacto de asistencia

Teresa López Avedoy

Teléfono: +52 (664) 6316300 ext. 1315

Correo electrónico: amit.dimentur@gmail.com

Diseño, formación y cuidado de la edición: Alfa/Zeta

Ma. Eugenia Varela Carlos

zet.alfa@gmail.com

Dimensiones Turísticas, Vol. 2, Núm. 3, año 2, julio-diciembre 2018, es una publicación semestral, editada por la Academia Mexicana de Investigación Turística, Villa Costa Azul núm. 55, Mediterráneo Club Residencial, Mazatlán, Sinaloa, C. P. 82113, tel.: + 52 (664) 6316300 ext. 1306, https://dimensionesturisticas.amiturismo. org, amit.dimentur@gmail.com. Editora responsable: Nora Leticia Bringas Rábago. Reserva de Derechos al Uso Exclusivo: 04-2018-082217054200-203, ISSN:2594-2069, ambos otorgados por el Instituto Nacional de Derechos de Autor. Responsable de la última actualización de este número, administrador web de la Academia Mexicana de Investigación Turística: Carlos Vladimir Ruelas González, Carretera Escénica Tijuana-Ensenada Km 18.5, San Antonio del Mar, Tijuana, Baja California, C. P. 22560, fecha de última modificación, 11 de julio de 2018.

Las opiniones expresadas por los autores no necesariamente reflejan la postura del editor de la publicación. 


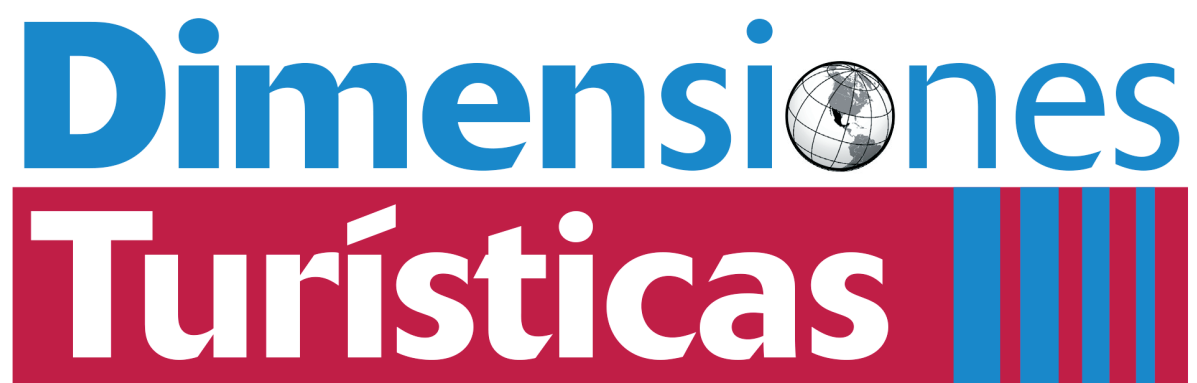

Publicación semestral • Vol. 2 • Núm. $3 \bullet$ Julio-diciembre $2018 \bullet$ e-ISSN 2594-2069

Nora Leticia Bringas Rábago

DiRECTORA

\section{Consejo científico}

Salvador Gómez Nieves • Universidad de Guadalajara, México

Daniel Hiernaux-Nicolas • Universidad Autónoma de Querétaro, México

Raquel Huete Nieves • Universidad de Alicante, España

Antonina Ivanova Boncheva • Universidad Autónoma de Baja California Sur, México

Alfonso de Jesús Jiménez Martínez • Universidad Autónoma de Guerrero, México

Tomás López Guzmán • Universidad de Córdoba, España

Alejandro Palafox Muñoz • Universidad de Quintana Roo, México

Agustín Santana Talavera • Universidad de La Laguna, Canarias, España

Regina G. Schlüter • Centro de Investigación y Estudios Turísticos, Argentina

Rocío del Carmen Serrano Barquín - Universidad Autónoma del Estado de México

Pablo Szmulewicz, Universidad Austral de Chile, Chile

Miguel Ángel Troitiño Vinuesa, Universidad Complutense de Madrid, España

José Fernando Vera Rebollo • Universidad de Alicante, España

\section{COMITÉ EDITORIAL}

Andrea Muñoz Barriga • Pontificia Universidad Católica del Ecuador, Ecuador Alfonso González Damián • Universidad de Quintana Roo, México Maximiliano Korstanje • Universidad de Palermo, Argentina Álvaro López López • Universidad Nacional Autónoma de México Ana Pricila Sosa Ferreira - Universidad del Caribe, Quintana Roo, México Basilio Verduzco Chávez • Universidad de Guadalajara, México Lilia Zizumbo Villarreal • Universidad Autónoma del Estado de México, México 


\section{Dimensiones Turísticas ||||}

Biannual publication

Vol. 2, No. 3

July-december 2018

e-ISSN 2594-2069
Nora Leticia Bringas Rábago

Articles

Claudia Inés Martínez

Pedro Moncada Jiménez

Ana Pricila Sosa Ferreira

Graciela Cruz Jiménez

Cecilia Cadena Inostroza

Carlos Jesús González-Macías

Tomás Jesús Cuevas-Contreras

ISABEl ZizaldRa-HeRnÁNDEZ

Alba E. Gámez

EdUARDO JUÁREZ

José Alfredo Guevara-Franco

Rafael Guerrero Rodríguez

Mónica Pérez Sánchez

Ilia Alvarado Sizzo

EsSAY

Noemí Wallingre

BOOK REVIEW

ÁlVARO LóPEZ LóPEZ

\section{Congress ReView}

Sonia Guadalupe Zermeño

FLORES

AOut

Dimensiones TURÍSTICAS
6-7 Presentation

8-24 Airbnb's supply and demand overview in Cancun, Quintana Roo and its implications for tourism

25-47 The start of Ixtapan de la Sal as a tourism emporioum

48-74 Feminine empowerment and competitiveness: the case of the Tierra y Cielo restaurant in San Cristóbal de las Casas, Chiapas, México

75-90 Distinctive signs in rural communities of Baja California Sur, Mexico: a strategy to promote rural tourism

91-110 What do our tourists think? A thematic analysis in TripAdvisor about tourist attractions in the city of Guanajuato

111-116 Questions on tourism academic production

117-120 Osorio, M. y Bringas Rábago, N.L. (2017) Residential tourism in Mexico. Socio-spatial behaviours

121-124 2018 Forum on Creativity, Innovation and Copetitiveness in Tourism. Between business reality and academia

125-137 


\section{Dimensiones Turísticas |||| \\ Publicación semestral \\ Vol. 2, Núm. 3 \\ Julio-diciembre 2018 \\ e-ISSN 2594-2069}

\section{ÍNDICE}

Nora Leticia Bringas Rábago

Artículos

Claudia Inés Martínez

Pedro Moncada Jiménez

Ana Pricila Sosa Ferreira

Graciela Cruz Jiménez

Cecilia Cadena Inostroza

Carlos Jesús González-Macías

Tomás Jesús Cuevas-Contreras

Isabel ZizaldRa-HeRnándeZ

Alba E. Gámez

EDUARDO JuÁreZ

José Alfredo Guevara-Franco

Rafael Guerrero Rodríguez

Mónica Pérez Sánchez

Ilia Alvarado Sizzo

NOTA CRÍTICA

Noemí Wallingre

ReseñA

Álvaro López López

\section{Reseña de congreso}

Sonia Guadalupe Zermeño

FLORES

Acerca de

Dimensiones TURÍSTICAS
117-120

Osorio, M. y Bringas Rábago, N.L. (2017)

Turismo residencial en México.

Comportamientos socio-espaciales

8-24 Panorama de la oferta y la demanda de la plataforma Airbnb e implicaciones para el turismo en Cancún, Quintana Roo, México

25-47 El inicio de Ixtapan de la Sal como emporio turístico

48-74 Empoderamiento femenino y competitividad: caso restaurante Tierra y Cielo, en San Cristóbal de Las Casas, Chiapas, México

75-90 Signos distintivos en comunidades rurales de Baja California Sur, México: una estrategia para impulsar el turismo rural

91-110 ¿Qué opinan nuestros turistas? Un análisis temático en TripAdvisor sobre atractivos turísticos de la ciudad de Guanajuato

111-116 Interrogantes sobre producciones y publicaciones académicas en turismo

121-124 2018 Foro de Creatividad, Innovación y

Competitividad en Turismo

Entre la realidad empresarial y la academia

125-137 


\section{Presentación}

$\mathrm{E}$ n esta edición, Dimensiones Turísticas reúne los resultados de investigación vinculados al desarrollo de centros turísticos, a la gestión y promoción que hacen de los servicios del sector plataformas electrónicas como Airbnb y TripAdvisor. También convergen dos temas relacionados con la gastronomía, uno en relación con el empoderamiento femenido mediante un estudio de caso en este sector, y el otro acerca del potencial económico que representa la constitución de los alimentos locales como signos distintivos para impulsar el turismo rural en dos comunidades de Baja California Sur.

El primer artículo parte de la economía colaborativa y lo que representa como marco de las plataformas de alojamiento, para analizar la oferta y la demanda de hospedaje en Cancún a partir del lanzamiento de la plataforma Airbnb. Claudia Inés Martínez, Pedro Moncada y Ana Pricila Sosa exponen cómo gracias a los avances tecnológicos y al uso de las redes sociales, esta nueva forma de negocio ha transformado la industria de los viajes y la hospitalidad y se ha convertido en una competencia para la hotelería tradicional, impulsada principalmente por los denominados millenials, quienes acceden de esta manera a una amplia oferta, desde habitaciones en desuso en viviendas hasta servicios profesionales de empresas inmobiliarias e incluso hoteles pequeños.

Graciela Cruz Jiménez y Cecilia Cadena Inostroza abordan la evolución del desarrollo turístico de Ixtapan de la Sal, Estado de México, y mediante el enfoque de redes en política pública, analizan los vínculos entre los diferentes actores que contribuyeron a moldear el perfil turístico de este importante destino de salud y bienestar del centro del país, ampliamente conocido por sus aguas termales curativas. Las autores destacan que las asimétricas relaciones de poder entre los actores con mayores recursos han marcado su trayectoria actual.

En otra contribución, Carlos Jesús González, Tomás Jesús Cuevas e Isabel Zizaldra, estudian las acciones empresariales de empoderamiento femenino y competitividad en el área gastronómica, a través de un estudio de caso de un restaurante ubicado en San Cristóbal de las Casas, Chiapas. El estudio se basa en el modelo tridimensional de Rowlands, que explora tres dimensiones: la personal, la colectiva y la de las relaciones cercanas. Los autores concluyen que el empoderamiento femenino impulsa la competitividad y la sustentabilidad en el restaurante, además de la innovación.

Alba E. Gámez, Eduardo Juárez y José Alberto Guevara, con un acercamiento desde el turismo rural y con un estudio de caso de dos comunidades rurales 
de Baja California Sur, estudian las posibilidades de reactivación económica a través de la gastronomía como un signo distintivo que rebasa lo puramente económico y pone en valor lo sociocultural; de la argumentación se desprende la propuesta de llevar a cabo el rescate de productos agroalimentarios tradicionales como mecanismo para promover la diversificación de las actividades productivas locales y elevar el nivel de vida de estas comunidades.

Rafael Guerrero, Mónica Pérez e Ilia Alvarado Sizzo revisan el contenido de las principales opiniones vertidas en el foro digital de Tripadvisor sobre los atractivos turísticos más importantes de la ciudad de Guanajuato para analizar cómo comunican los usuarios sus experiencias de viaje e identificar elementos que son más o menos agradables de los atractivos visitados. Estas opiniones on-line de viaje, como se les conoce, son cada vez más importantes para el análisis de la imagen del destino e influyen directamente en las decisiones de viajar y en la valoración de la experiencia de viaje, como lo muestran los autores.

Pilar Espeso-Molinero profundiza en el proceso de investigación acción participativa mediante una revisión de enfoques y un ejemplo práctico en turismo con comunidades indígenas de la Selva Lacandona (México), con el cual muestra la necesidad de colaboración investigador-comunidades locales para avanzar en el conocimiento del turismo.

El trabajo presentado por Basilio Verduzco Chávez aborda el tema del diseño de políticas turísticas a partir del análisis de las implicaciones teóricas y prácticas de orientar las políticas a mejorar la experiencia del turista, entre los que destaca la necesidad de considerar los aspectos geopolíticos de la planeación de destinos turísticos y el desarrollo de capacidades para diseñadores de política turística.

El trabajo de Noemí Wallingre nos invita a reflexionar sobre el desvío que ha sufrido la investigación en las últimas décadas, en la que ha prevalecido la presión por publicar cada vez más rápido, a costa incluso de la calidad del contenido, lo que ha dado como resultado investigaciones hechas al vapor, sin profundizar, con datos débiles y sin realmente hacer aportaciones a la generación de nuevo conocimiento, sino atendiendo la lógica del mercado y del Estado.

Finalmente se incluyen dos reseñas: una preparada por Álvaro López López sobre el libro coordinado por Maribel Osorio García y Nora L. Bringas Rábago, titulado Turismo residencial en México. Comportamientos socio-espaciales, publicado por El Colegio de la Frontera Norte en 2017; otra, realizada por Sonia Guadalupe Zermeño Flores sobre el encuentro académico denominado 2018 Foro de Creatividad, Innovación y Competitividad en Turismo: Entre la realidad empresarial y la academia, celebrado en Acapulco, Guerrero.

Nora Leticia Bringas Rábago

Directora de Dimensiones Turísticas 


\title{
Panorama de la oferta Y LA Demanda DE LA PLATAForma AIRBNB E IMPLICACIONES PARA EL TURISMO en Cancún, Quintana Roo, México
}

\author{
Claudia InÉs Martínez \\ cmartinez@ucaribe.edu.mx \\ Pedro Moncada Jiménez \\ pmoncada@ucaribe.edu.mx \\ Ana Pricila Sosa Ferreira \\ psosa@ucaribe.edu.mx \\ Universidad del Caribe
}

\begin{abstract}
Las diversas modalidades de economía colaborativa que permean a los distintos servicios tienen en el hospedaje la faceta más visible y también la más controvertida. Entre las plataformas existentes destaca Airbnb, la cual desde su surgimiento, y en un breve lapso, se ha extendido de forma significativa en prácticamente todo el mundo y generado diversas reacciones. Este trabajo examina cómo se presenta tal fenómeno en el caso de Cancún, para lo cual se analizan las características de la oferta y la demanda alojada a través de dicha plataforma. La importancia de esta investigación radica en que brinda información amplia y confiable sobre esta creciente modalidad, invisible aún en las estadísticas oficiales, para permitir una discusión seria, así como tomar decisiones y medidas que redunden en un mayor beneficio para la comunidad.
\end{abstract}

Palabras clave: Airbnb, economía colaborativa, huéspedes, anfitriones, Cancún.

\section{Airbnb's supply and demand overview in Cancun, QUINTANA ROO AND ITS IMPLICATIONS FOR TOURISM}

Hosting services are the most visible and controversial service within the many which function under the collaborative economy modality. Among the existing virtual platforms, Airbnb has been known, since its creation, for its significant and rapid growth around the world, and for the different types of reactions it generates. This work examines its development in Cancun by analyzing the supply and demand characteristics hosted in this platform, and it is considered relevant because of the vast and reliable information it provides. This growing modality is still invisible in official statistics, so it is difficult to hold a formal discussion, take decisions, and implement measures that can benefit the community.Keywords: Airbnb, share economy, guests, hosts, Cancun.

Keywords: Airbnb, share economy, guests, hosts, Cancun.

Fecha de recepción: 3 de enero de 2018. Fecha de aceptación: 16 abril de 2018

CÓMO CITAR: Martínez, C. I., Moncada, P. y Sosa-Ferreira, A. P. (2018). Panorama de la oferta y la demanda de la plataforma Airbnb e implicaciones para el turismo en Cancún, Quintana Roo, México. Dimensiones Turísticas, 2(3), 8-24 https://doi.org/10.47557/CGEW6811 
A partir del concepto economía colaborativa se ha creado un nuevo sistema socioeconómico que permite la producción, distribución y consumo compartido de bienes, servicios y recursos entre los individuos. Gracias a los avances tecnológicos, como la Web 2.0, el aumento del uso de las redes sociales y los teléfonos inteligentes, las personas pueden compartir diversos servicios y productos entre sí. Esto ha dado paso al nacimiento de empresas como Uber, Couchsurfing, Carpooling y Airbnb, que, a través de plataformas tecnológicas, están transformando la industria de viajes y hospitalidad al constituir verdaderos negocios disruptivos.

No obstante el reciente surgimiento de las plataformas de alojamiento entre particulares, estas se han extendido de forma acelerada en los destinos turísticos. Fundada en 2008, Airbnb, cuya marca nace del acrónimo de "air bed and breakfast” (Álvarez, 2016), hoy está presente en más de 65000 ciudades de 191 países y posee una oferta de más de tres millones de sitios de alojamiento, ninguno de su propiedad (https://www.airbnb. $\mathrm{mx} /$ ). En México, durante 2016, hubo cerca de 33000 anfitriones que hospedaron a 974000 visitantes en sus propiedades (Blanco, 2017). Estas cifras son un reflejo del fuerte crecimiento de Airbnb en México en los últimos años y muestran las características de un negocio disruptivo con un crecimiento exponencial que empieza a ser investigado en otros países, pero con escasa y nula atención en México. En este contexto, resulta de gran trascendencia revelar las peculiaridades de la oferta y la demanda de la plataforma de hospedaje Airbnb en Cancún, así conocer las principales implicaciones que conllevan para el mercado turístico local. Cancún es el principal destino de playa de México y el primero a nivel nacional en recepción de turistas, con casi cinco millones en 2016, además de estar bien posicionado internacionalmente, junto con la Riviera Maya (Secretaría de Turismo del Estado de Quintana Roo [Sedetur], 2017), por lo que resulta relevante examinar la dimensión y los rasgos propios del uso de servicios de hospedaje realizados a través de plataformas.

\section{Algunas consideraciones teórico-conceptuales}

La economía colaborativa irrumpió en la sociedad mundial al finalizar la primera década del siglo XXI, provocando una transformación radical en el modelo de negocio conocido hasta el momento. Definida como aquella economía construida sobre redes dispersas de individuos y comunidades conectados, que transforma la manera en la cual se puede producir, consumir, obtener financiamiento y aprender. Lo que la distingue es que traslada el foco de atención de la propiedad de los bienes y servicios al acceso temporal de los mismos; todo posibilitado por las nuevas tecnologías de la información y la comunicación que permiten que el consumo colaborativo sea altamente accesible, flexible y fácil de compartir (Botsman y Rogers, 2011).

Si bien las distintas experiencias y formas de economía colaborativa permean diferentes ámbitos, la venta de servicios ocupa un lugar importante; y entre ellos se observa un 
crecimiento ininterrumpido en el sector turismo. El consumo colaborativo o intercambio turístico entre iguales se ha adscrito al término turismo peer to peer ( 2 2p), donde se traslada el concepto de consumidor a prosumidor, entendido como el usuario que no solo consume información sino también la produce y la comparte en una comunidad de usuarios (Pizam, 2014 cit. por Guillén e Íñiguez, 2016; Reinhold y Dolnicar, 2018). Este cambio de modelo transforma la relación entre empresa y cliente y, en lo que atañe al turismo, empodera al turista por su papel en la generación y difusión de información sobre experiencias en hoteles, excursiones o incluso el destino; o bien en la búsqueda y comprobación de la veracidad de opiniones de otros usuarios. Todas estas acciones resultaban imposibles antes del desarrollo de la Web 2.0 y las redes sociales.

El caso de Aribnb resulta controversial y son múltiples las perspectivas desde las que se requiere analizarlo (Dolnicar, 2018). Existe un enfoque que lo considera un ejemplo emblemático de consumo colaborativo, al tratarse de una empresa que posee únicamente una plataforma tecnológica donde se comercializa alojamiento ofrecido por particulares a precios muy competitivos; además, no se limita a unir a los usuarios con los propietarios del servicio sino que posibilita su contacto para construir confianza mediante su comunicación, primero por medios tecnológicos y luego personal, lo cual permite al visitante vivir la experiencia turística como si fuera local (Karlsson y Dolnicar, 2016). Sin embargo, existe otra postura que señala que no se trata de consumo colaborativo en su sentido más puro, dado que no cumple con el fin principal que es compartir o pedir prestado, sino que se produce un intercambio monetario (Gansky, 2010). Este es el caso de las plataformas que ofrecen el alquiler de habitaciones o viviendas actuando como intermediarias entre el propietario que quiere ganar dinero por su vivienda y el turista que busca un alojamiento. A lo anterior se suma que, la mayoría de las veces, la plataforma cobra comisión. Desde este punto de vista, el modelo Airbnb resulta ser un híbrido, porque a pesar de compartir atributos del consumo colaborativo, como la confianza y la comunicación entre las partes, la existencia del fin comercial y la creciente incorporación de viviendas gestionadas por empresas inmobiliarias, promueve la pérdida del sentido de la colaboración y la idea de compartir propias del turismo p2p, convirtiéndose en mero intermediario turístico (Guillén e Iñiguez, 2016 y Pacheco, 2016). Reihold y Dolnicar (2018) afirman que lo que caracteriza a los intercambios en la economía colaborativa es que se crea un sentido de propiedad mutua o compartida y, sobre todo, un sentido de comunidad, sentido al que se ajustarían los servicios de hospedaje a través de plataformas; sin embargo, que se mantengan en o se alejen del concepto de la economía colaborativa depende de la operación de las mismas.

Para otros autores (Oskam y Boswijk, 2016), ciertamente la operación de Airbnb no corresponde al sentido de la economía colaborativa y -aunque con cierto contenido de innovación- podría generar consecuencias negativas para la actividad si no se establecen algunas regulaciones. Los análisis sobre el impacto de esta plataforma en hotelería encuentran, a través del análisis de caso, una afectación en el retorno de la inversión en la hotelería, principalmente para ciertas categorías y dimensiones (Zervas, Proserpio y Byers, 2017). 


\section{Estrategias metodológicas de la investigación}

La investigación posee un carácter exploratorio y fue realizada desde una aproximación de análisis mixto, cuantitativo y cualitativo. La dificultad para localizar a los usuarios de Airbnb en el destino le otorgó una mayor complejidad metodológica al levantamiento de entrevistas semiestructuradas. Por lo tanto, se decidió completar el muestreo con la revisión de antecedentes estadísticos de la oferta de Aribnb y organizar un grupo focal con anfitriones de Airbnb en Cancún. De esta forma fue posible obtener información, en cantidad y calidad, acorde al objetivo del estudio.

El levantamiento se realizó entre el 27 de junio y el 7 de agosto de 2017, durante las seis semanas del receso estival. La entrevista semiestructurada indagaba 30 variables aplicadas a turistas hospedados en Cancún por medio de Airbnb. Puesto que las estadísticas obtenidas de Airbnb no incluyen el número de huéspedes, sino el número de anuncios, se determinó definir una muestra con base en el total de turistas de Cancún N: 4622286 (Asociación de Hoteles de Cancún, 2016), utilizando la fórmula de muestra probabilística para proporciones de poblaciones infinitas. El tamaño de la muestra quedó fijado en $\mathrm{N}$ : 384 entrevistas semiestructuradas, con los parámetros de $95 \%$ de confianza y $5 \%$ de error.

La entrevista semiestructurada se configuró en dos partes: al inicio del cuestionario se indagaron dos preguntas como filtro para detectar el sujeto de análisis. Las preguntas fueron: ¿Dónde está alojado? y ¿Ha usado alguna vez la plataforma Airbnb?

Estas dos preguntas se hicieron a 2003 turistas alojados en Cancún, bajo un muestreo aleatorio simple, realizado en trece lugares de levantamiento, los cuales cubrieron la zona hotelera, el centro urbano de Cancún e Isla Mujeres, reconocidos por Airbnb como Cancún. De este modo se intentó obtener la proporción de turistas de Cancún que son usuarios de plataformas de alojamiento. Sin embargo, la cantidad de entrevistas no fue proporcional en las tres zonas turísticas, existió un predominio de las realizadas en la zona Centro de Cancún (71\%). Por esta razón, los resultados no pueden extrapolarse al total de turistas de Cancún. Además, el número de entrevistas efectuadas a usuarios de Airbnb fue de 238, cantidad menor al tamaño fijado como muestra, que, no obstante, otorga al levantamiento un carácter de sondeo y genera valiosa información sobre este segmento de turistas desconocido hasta el momento.

El cuestionario para grupo focal de anfitriones se diseñó mediante 22 preguntas abiertas, organizadas en cuatro grandes dimensiones temáticas enfocadas en: la oferta de alojamiento, la propia plataforma Airbnb, el perfil de huéspedes, sus hábitos y comportamiento vacacional y las repercusiones asociadas al uso de la plataforma de alojamiento. El trabajo con el grupo focal se realizó el 13 de julio y participaron siete anfitriones cuya antigüedad en la oferta de alojamiento a través de Airbnb variaba entre uno y cinco años. Fueron cuatro mujeres y tres hombres; tres con una edad entre 30 y 40 años, dos entre 40 y 50 y dos de más de 50 años. El ejercicio fue grabado. Esta técnica de recolección de aproximación cualitativa dio la posibilidad de conocer, además de los atributos visibles 
de la demanda, las percepciones y opiniones del anfitrión sobre la interacción huéspedanfitrión-residente, y también las repercusiones de esta modalidad de alojamiento para ellos como anfitriones y para el destino.

Para analizar la oferta de Airbnb se revisaron antecedentes estadísticos principalmente a través del reporte del mercado de Airbnb en Cancún realizado por Airbnb Data and Analytics (AirDNA, 2017), cuyos datos se estiman a partir de la oferta de anuncios en el destino. Es importante señalar que, en el caso de Cancún, los datos además de incluir el municipio de Benito Juárez, donde se ubica el centro urbano de Cancún y la zona hotelera, considera alojamientos ubicados en Isla Mujeres, tanto en su área insular como continental.

\section{Análisis de resultados y discusión}

\section{Panorama general de la oferta de Airbnb en Cancún}

Airbnb nació en 2008 (Álvarez, 2016) y dos años después aparecieron los primeros siete anuncios de alojamiento en Cancún. Los primeros cuatro años registró un crecimiento constante pero lento, el periodo 2015-2016 fue el que presentó mayor porcentaje (160\%) de incremento de anuncios (figura 1). Entre 2016 y mayo de 2017, creció $58 \%$ comparado con el total del año anterior; lo cual indicaría que esta modalidad ha sido descubierta hace poco por los anfitriones y se prevé un crecimiento mayor dado el aumento de publicidad en México y su reciente apertura de oficinas en el país.

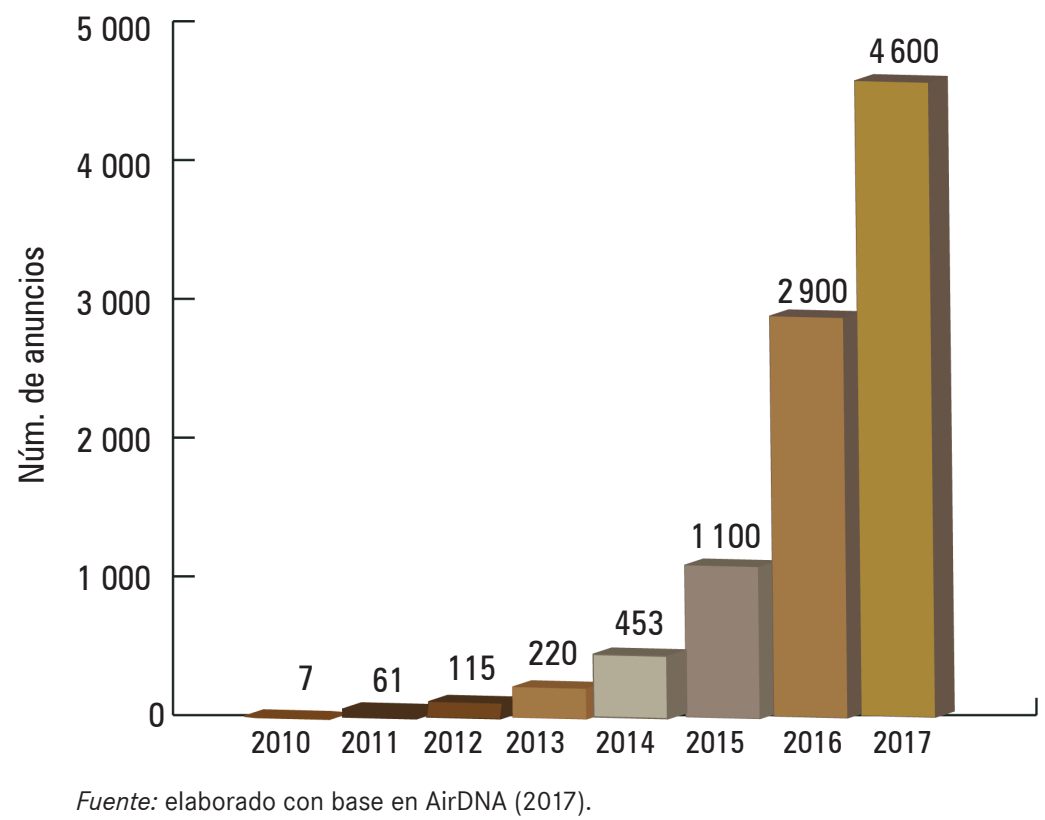

Figura 1. Evolución de la cantidad de anuncios en Cancún entre 2010-2017 (mayo) 
A través del análisis de la cantidad de anuncios gestionados por anfitrión se puede evidenciar el uso de la plataforma por parte del sector inmobiliario para renta turística de sus propiedades. Cancún todavía mantiene más de dos tercios de sus anuncios $(70 \%)$ gestionados por un anfitrión (AirDNA, 2017) y el porcentaje restante considera entre dos y cinco anuncios operados por un mismo anfitrión, que pudiera ser un agente inmobiliario o bien personas que se dedican a administrar propiedades de terceros como salida laboral.

Las modalidades más ofertadas de alojamiento se concentran en habitación privada en vivienda compartida (42\%) y vivienda completa (56.2\%), de la cual predominan las propiedades con dos cuartos, seguidas de las de un cuarto (cuadro 1). Estas cifras permiten estimar que existen al menos 6378 cuartos disponibles a través de Airbnb en Cancún.

CuADRo 1. Cantidad de anuncios por tipo de alojamiento, mayo 2017

\begin{tabular}{|c|c|c|c|c|}
\hline \multicolumn{2}{|c|}{ Tipo de alojamiento } & $\begin{array}{l}\text { Cantidad de } \\
\text { anuncios }\end{array}$ & $\%$ & $\begin{array}{c}\text { Estimación de } \\
\text { cuartos }{ }^{*}\end{array}$ \\
\hline \multicolumn{2}{|c|}{ Habitación compartida } & 78 & 1.8 & \\
\hline \multicolumn{2}{|c|}{ Habitación privada } & 1754 & 42 & 1754 \\
\hline \multirow{6}{*}{ 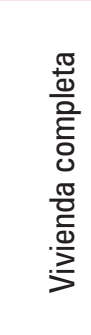 } & Estudio & 271 & 6.5 & 271 \\
\hline & 1 cuarto & 631 & 15.1 & 631 \\
\hline & 2 cuartos & 810 & 19.4 & 1620 \\
\hline & 3 cuartos & 442 & 10.6 & 1326 \\
\hline & 40 más cuartos & 194 & 4.6 & 776 \\
\hline & Subtotal & 2348 & 56.2 & 4624 \\
\hline \multicolumn{2}{|l|}{ Total } & 4180 & 100 & 6378 \\
\hline
\end{tabular}

* El número de cuartos estimados se determinó con base en el número de cuartos que ofrecen los anuncios.

Fuente: elaborado con base en AirDNA (2017).

Una última variable de la oferta importante a destacar es la tarifa diaria promedio que reporta Airbnb para 2017 (en dólares estadounidenses, usD) por habitación: 32 dólares para la habitación privada; significativamente menor a la tarifa promedio de los hoteles del centro de Cancún, 45 usD (Asociación de Hoteles de Cancún, 2016). Los precios de vivienda completa resultan también bajos en proporción si se considera que poseen más servicios y mayor capacidad: vivienda con dos cuartos 86 usD y con tres, 122 usD (figura 2). Las cifras reflejan una de las ventajas competitivas más reconocidas de la plataforma: sus precios competitivos $\mathrm{y}$, a su vez, principal queja del sector hotelero, en especial en destinos donde no está regulado. 


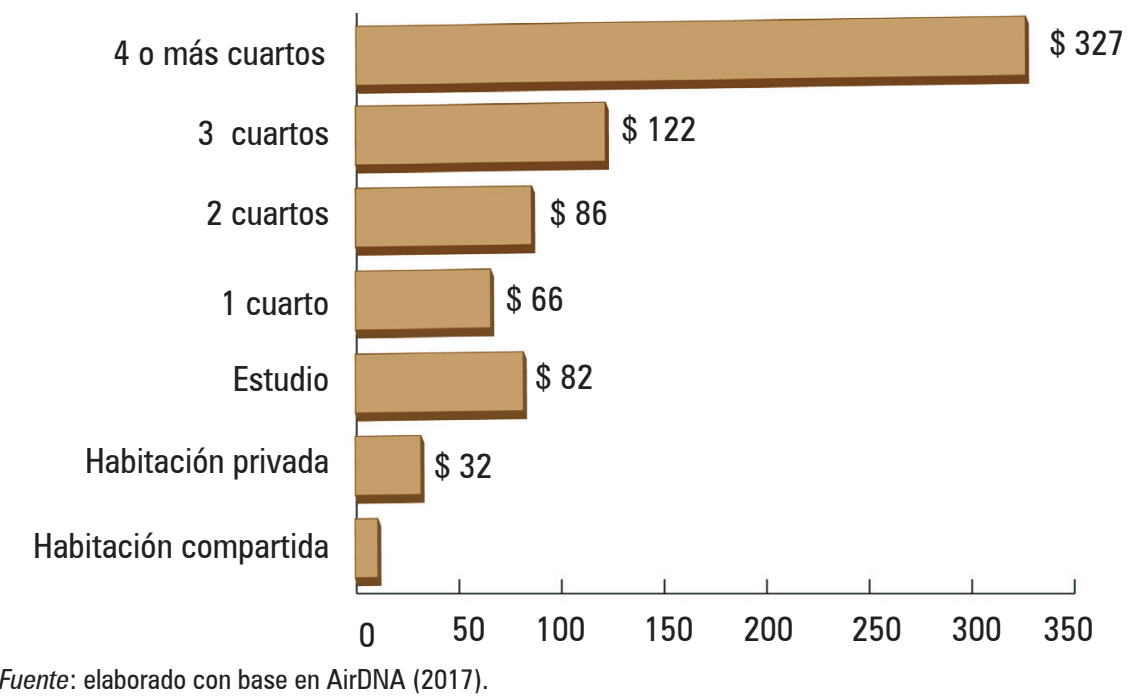

Figura 2. Tarifa diaria promedio en dólares por cantidad de habitaciones

\section{La oferta de alojamiento en Airbnb desde los anfitriones}

La información obtenida en el grupo focal resultó muy amplia y fructífera; una parte fue utilizada para el análisis de la demanda en combinación con los resultados del levantamiento. En este apartado se presentan pormenores destacados sobre su papel como anfitriones y, paralelamente, como gestores de la plataforma.

Al consultar los motivos de los anfitriones para rentar habitaciones o viviendas en Airbnb se reconocieron tres razones: 1) el fin exclusivamente económico; 2) la combinación de búsqueda de ingresos extras y tener compañía (la mayoría), y 3) quienes manifiestan hacerlo solo para tener compañía y compartir. Los anfitriones motivados por fines exclusivamente económicos ya contaban con experiencia en renta convencional de propiedades para turistas, por inmobiliarias o anuncios en páginas web; sin embargo, coincidían en preferir Airbnb por su baja comisión de gestión y porque percibían ingresos crecientes. Respecto a la ocupación, todos los anfitriones coincidieron en que la temporada más alta es invierno, principalmente diciembre. Sin embargo, al comparar la ocupación del último año con los anteriores, todos coinciden en que ha disminuido la ocupación y las tarifas. Esto lo atribuyen a la sobreoferta de alojamiento usando Airbnb que perciben en Cancún en los últimos años (figura 1) y a la activación de los precios inteligentes, un mecanismo que orienta en la fijación de la tarifa y siempre la disminuye. Con todo, reconocen que en temporada alta juegan con sus tarifas y las incrementan debido a la alta demanda. Dos de ellos manifiestan incluso que buscaron alternativas para las bajas temporadas usando redes sociales para promocionarse, páginas de internet o plataformas como Mercado Libre y Booking.com. 
La interacción huésped-anfitrión ha sido el argumento inicial de esta plataforma etiquetada dentro de las economías colaborativas y es el atributo más promovido en las publicidades de la marca alrededor del mundo. Empero, la mayoría de los anfitriones manifiesta que prefiere evitar tener interacción con los huéspedes. Las razones enunciadas son: que la estadía más frecuente es de una sola noche y que quieren brindarles privacidad a sus huéspedes. No obstante, concuerdan en que la interacción más fuerte se da en la charla del check in, o bien en la hora de desayuno o comida cuando coinciden con sus huéspedes alojados en su vivienda. En esos momentos se les brinda toda la información necesaria sobre el destino, se responden sus preguntas y se entrega folletería de restaurantes, excursiones, mapas y guías turísticas. Una minoría reconoció que en sus primeras experiencias como anfitriones de Airbnb realizaba actividades con ellos (salidas a restaurantes o atractivos turísticos), pero con el tiempo lo ha dejado de hacer y siente que no todos los huéspedes desean esas atenciones; esto indicaría un posible cambio en la motivación por usar la plataforma por parte del huésped.

\section{Análisis de la demanda turística usuaria de Airbnb}

Los resultados del levantamiento de entrevistas semiestructuradas muestran turistas alojados en hoteles que han usado la plataforma en otras ocasiones (35\%), esta significativa proporción parece indicar que el uso de las plataformas responde a las necesidades derivadas del tipo de viaje que se realiza, lo cual contradice la idea de que el turista deja de utilizar alojamiento tradicional una vez que ha experimentado con las plataformas.

Llama la atención que los turistas alojados en casa de familiares y amigos presenta mayor participación (22\%) que los usuarios de la plataforma. Dicho porcentaje es mayor que en otros estudios (Sosa, Martínez, Moncada, Beltrán y Álvarez, 2015) que analizaron el segmento de visitas a familiares y amigos (cuadro 2). También destaca la nula experiencia en el uso de la plataforma, tanto entre quienes se hospedaron en alojamiento comercial como en casa de familiares y amigos, con porcentajes superiores al $60 \%$ (cuadro 2). Incluso, se detectaron 27 nuevos usuarios de alojamiento por plataforma que lo harían por primera vez en Cancún, lo que indica que se trata aún de una modalidad en crecimiento.

Cuadro 2. Uso de plataforma de Airbnb según tipo de alojamiento

\begin{tabular}{llllll}
\multirow{2}{*}{ Tipo de alojamiento } & \multicolumn{2}{c}{ Uso de plataforma Airbnb } & \multirow{2}{*}{ Total } & $\%$ \\
\cline { 2 - 3 } & Sí ha usado & No ha usado & & \\
Hotel o alojamiento comercial & $439(35 \%)$ & $801(65 \%)$ & & 1240 & $62 \%$ \\
Casa de familiares y amigos & $170(38 \%)$ & $279(62 \%)$ & 449 & $22 \%$ \\
\hline Plataforma de renta alojamiento & $287(91 \%)$ & $27(9 \%)$ & 314 & $16 \%$ \\
\hline Total & 896 & 1107 & 2003 & 100 \\
\hline
\end{tabular}

Fuente: Elaboración propia con base en las entrevistas realizadas. 
Al analizar las características sociodemográficas de los usuarios de plataformas de alojamiento, sobresale la concentración en tres variables: $91 \%$ de los entrevistados cuenta con estudios técnicos y superiores (cuadro 3); $91 \%$ gana menos de 3800 uSD, $60 \%$ tiene ingresos entre 300 y 1500 usD; y, en cuanto a la edad, $88 \%$ tiene entre 21 y 40 años, $63 \%$ tiene entre 21 y 30 años y la edad promedio es de 29 años. Una amplia mayoría corresponde al perfil de millenials (personas nacidas después de 1980 y hasta 1995 y que empezaron a llegar a la mayoría de edad en el 2000).

CuAdRo 3. Características sociodemográficas del sondeo

\begin{tabular}{lclllc}
\multicolumn{2}{c}{ Variables } & $\%(\mathrm{n})$ & \multicolumn{2}{c}{\begin{tabular}{c} 
Variables \\
\multicolumn{2}{c}{ Edad }
\end{tabular}} & \multicolumn{2}{c}{$\begin{array}{c}\text { Nivel de estudios } \\
\text { (n) }\end{array}$} & \multicolumn{2}{c}{$\begin{array}{c}\text { Variables } \\
\text { Ingreso mensual en dólares }\end{array}$} \\
\hline <20 años & $2 \%(5)$ & Secundaria & $1.3 \%(3)$ & $<300$ usd & $16 \%(39)$ \\
$21-30$ años & $63 \%(151)$ & Preparatoria & $7.1 \%(17)$ & $300-700$ usd & $29 \%(70)$ \\
$31-40$ años & $25 \%(60)$ & Técnico & $23.1 \%(55)$ & $700-1500$ usd & $31 \%(73)$ \\
$41-50$ años & $7 \%(16)$ & Licenciatura & $51.3 \%(122)$ & $1500-3800$ usd & $15 \%(35)$ \\
$>51$ años & $2 \%(4)$ & Posgrado & $16.8 \%(40)$ & $3800-7600$ usd & $5 \%(11)$ \\
N/R & $1 \%(2)$ & Sin estudio & $0.4 \%(1)$ & $>7600$ usd & $1 \%(3)$ \\
& & & & N/R & $3 \%(7)$ \\
\hline
\end{tabular}

N/R: no respondió.

Fuente: Elaboración propia con base en las entrevistas realizadas.

Respecto a su lugar de residencia, los porcentajes de México y Europa son similares a la demanda del destino Cancún (cuadro 4). Destaca el caso de Estados Unidos (principal emisor de turistas a Cancún) con un porcentaje entre usuarios de la plataforma de apenas $16 \%$, significativamente menor a México y Europa. Esta escasa participación de estadounidenses podría deberse precisamente a que, siendo la principal fuente de turistas a Cancún, la comercialización de cuartos de hotel se realiza a través canales muy posicionados y los productos resultan igual o más accesibles y competitivos en comparación con los ofrecidos por las plataformas de alojamiento.

Al comparar el perfil sociodemográfico de los usuarios de plataformas entrevistados con lo manifestado por los anfitriones respecto a los huéspedes de Airbnb, la mayoría concuerdan en que sus huéspedes son turistas jóvenes entre 25 y 40 años, con nacionalidad europea (alemana, francesa y rusa), estadounidense, canadiense y sudamericana, con carreras universitarias y con alto nivel económico. 
Cuadro 4. Lugar de residencia de los entrevistados

\begin{tabular}{|llc}
\hline Región & País & $\%(\mathrm{n})$ \\
\hline & México & $34.8 \%(83)$ \\
\hline Europa & & $27.7 \%(66)$ \\
& Alemania & $5.9 \%(14)$ \\
& España & $4.2 \%(10)$ \\
& Francia & $3.4 \%(8)$ \\
& Italia & $3.4 \%(8)$ \\
& Otros países europeos & $10.9 \%(26)$ \\
\hline América del & Norte & $18.5 \%(44)$ \\
& Estados Unidos & $16 \%(38)$ \\
\hline Latinoamérica & Canadá & $2.5 \%(6)$ \\
& Argentina & $14.3 \%(34)$ \\
\hline Oceanía & Colombia & $6.7 \%(16)$ \\
\hline Asia & Otros países de Latinoamérica & $1.7 \%(4)$ \\
\hline
\end{tabular}

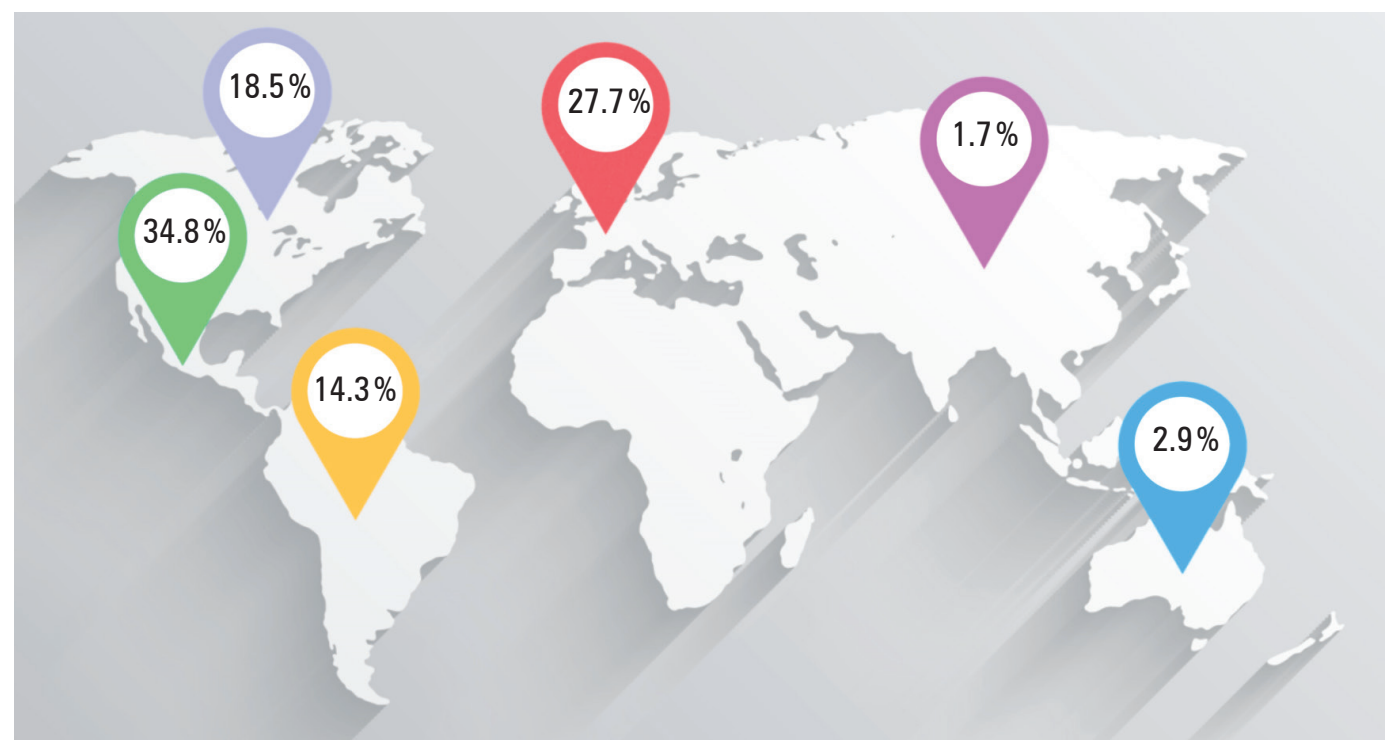

Fuente: elaboración propia con datos de las entrevistas a usuarios de Airbnb en Cancún.

Figura 3. Origen de los usuarios de Airbnb en Cancún 
En cuanto al comportamiento vacacional de los usuarios de Airbnb en Cancún, 89\% manifestó como motivo principal vacaciones y $10 \%$ lo repartió, en igual proporción, entre motivos laborales y de visita a familiares y amigos (cuadro 5). Predominan los grupos de amigos $(47 \%$ y y las parejas (24\%) que realizan un gasto por persona durante su viaje de 200 a 500 usd, mismo que planean en menos de un mes (50\%). Más de la mitad de los usuarios entrevistados dijo que era la primera vez que visitaba Cancún.

\section{CuADro 5. Comportamiento vacacional del sondeo}

\begin{tabular}{|c|c|c|c|}
\hline Variables & $\%(n)$ & Variables & $\%(n)$ \\
\hline \multicolumn{2}{|l|}{ Estadía en Cancún } & \multicolumn{2}{|l|}{ Motivo principal de viaje } \\
\hline$<$ de 3 noches & $55 \%(132)$ & 0cio/recreo/vacaciones & $89 \%(214)$ \\
\hline de 4 a 7 noches & $32 \%(77)$ & Negocios/trabajo & $5 \%(11)$ \\
\hline$>$ de 7 noches & $11 \%(26)$ & Visita familiares y amigos & $5 \%(11)$ \\
\hline$N / R$ & $1 \%(3)$ & $\mathrm{N} / \mathrm{R}$ & $1 \%(2)$ \\
\hline \multicolumn{2}{|c|}{ Tipo de habitación rentada } & \multicolumn{2}{|l|}{ Gasto por persona en el viaje } \\
\hline Habitación privada & $42 \%(101)$ & $<$ de 200 USD & $11 \%(26)$ \\
\hline Habitación compartida & $28 \%(66)$ & de 200 a 500 USD & $47 \%(112)$ \\
\hline Vivienda completa & $29 \%(70)$ & de 500 a 1000 usD & $19 \%(46)$ \\
\hline \multirow[t]{2}{*}{$\mathrm{N} / \mathrm{R}$} & \multirow[t]{2}{*}{$1 \%(1)$} & $>$ de 1000 USD & $14 \%(32)$ \\
\hline & & $\mathrm{N} / \mathrm{R}$ & $9 \%(22)$ \\
\hline \multicolumn{2}{|l|}{ Tipo de grupo } & \multicolumn{2}{|l|}{ Cantidad de visitas a Cancún } \\
\hline Amigos & $47 \%(112)$ & Primera vez & $56 \%(133)$ \\
\hline Pareja & $24 \%(57)$ & 2 a 3 veces & $36 \%(85)$ \\
\hline Familiares & $16 \%(37)$ & 4 a 5 veces & $5 \%(12)$ \\
\hline Solo & $13 \%(32)$ & Más de 6 veces & $3 \%(8)$ \\
\hline \multicolumn{2}{|l|}{ Tamaño de grupo (en pax.) } & \multicolumn{2}{|c|}{ Tiempo de planeación de viaje } \\
\hline 1 & $22 \%(52)$ & Menos de un mes & $50 \%(119)$ \\
\hline 2 & $33 \%(77)$ & Entre uno y seis meses & $32 \%(78)$ \\
\hline 3 & $14 \%(34)$ & Entre tres y seis meses & $11 \%(26)$ \\
\hline 4 & $14 \%(34)$ & Entre seis meses y un año & $5 \%(11)$ \\
\hline $5-7$ & $4 \%(10)$ & Más de un año & $2 \%(4)$ \\
\hline $\mathrm{N} / \mathrm{R}$ & $13 \%(31)$ & & \\
\hline
\end{tabular}

N/R: no respondió.

Fuente: Elaboración propia con base en las entrevistas realizadas. 
En cuanto a la estadía, la tendencia es claramente a una estancia corta -según resultados de moda (2) y mediana (3)-; también se registran casos de largas estancias, lo que parece representar un pequeño segmento de turismo residencial que aprovecha este canal para encontrar ofertas de alojamiento para estancias largas. La mitad de los usuarios de Airbnb entrevistados manifestaron que su estadía en Cancún fue de tres noches o menos (cuadro 5), resultado que difiere de la estadía promedio del sector hotelero tradicional, que es de cinco noches (Asociación de Hoteles de Cancún, 2016). Esta diferencia podría deberse a que el perfil del viajero Aribnb está más vinculado con turistas que realizan viajes largos con visitas a muchos destinos en su recorrido, en vez de utilizar el destino para permanecer toda su estadía asociada a la práctica -intensiva- de una actividad, como es disfrutar del sol y la playa.

Los resultados del sondeo concuerdan con lo expresado por la mayoría de los anfitriones de Airbnb en el grupo focal, quienes mencionaron que sus huéspedes de Airbnb se quedan una noche, para descansar y recuperarse del jet lag, y continúan hacia otros destinos de la Riviera Maya o de la Península de Yucatán. Por tal razón, algunos anfitriones redujeron su requisito de estancia mínima a una sola noche, afirmando "yo me di cuenta de que realmente había un mercado muy grande de la gente de una sola noche” (anfitrión 5).

Al indagar los motivos de los huéspedes en utilizar plataformas de alojamiento, la mayoría de los anfitriones concuerdan en que el principal es sentirse como local, realizando actividades propias del residente: ir a comer y comprar en lugares a los que asisten los locales y realizar las mismas actividades que ellos. La totalidad de los anfitriones coincide en el tema de la calidez de sentirse en una casa y conocer la cultura local-regional como motivo de elección de alojamiento. En este sentido, las palabras del anfitrión 5: "El perfil de Airbnb no es el de un hotel, es totalmente otra cosa".

Esto concuerda con los resultados del muestreo que indica que la opción de alojamiento más utilizada por los entrevistados (cuadro 5) es habitación privada en una vivienda compartida (42\%) frente a las opciones vivienda completa (29 \%) y habitación compartida (28\%).

CuADro 6. Tipo de alojamiento rentado según tipo de grupo

\begin{tabular}{lcccc} 
Tipo de grupo & \multicolumn{3}{c}{ Tipo de alojamiento rentado } & \\
& $\begin{array}{c}\text { Habitación } \\
\text { privada }\end{array}$ & $\begin{array}{c}\text { Habitación } \\
\text { compartida }\end{array}$ & $\begin{array}{c}\text { Vivienda } \\
\text { completa }\end{array}$ & Total \% (n) \\
\hline Solo & $50 \%(16)$ & $41 \%(13)$ & $9 \%(3)$ & $100 \%(32)$ \\
\hline Amigos & $34 \%(38)$ & $36 \%(40)$ & $30 \%(34)$ & $100 \%(112)$ \\
\hline Pareja & $70 \%(40)$ & $16 \%(9)$ & $14 \%(8)$ & $100 \%(57)$ \\
\hline Familia & $22 \%(8)$ & $11 \%(4)$ & $68 \%(25)$ & $100 \%(37)$ \\
\hline
\end{tabular}

Fuente: Elaboración propia con base en las entrevistas realizadas. 
La contratación de las distintas opciones presenta también una distribución bastante lógica según sus necesidades (cuadro 6): familias principalmente casas (68\%), parejas habitación sola (70\%), personas solas habitación sola o compartida, y amigos las tres opciones. Lo llamativo es que, aun cuando sea en un porcentaje menor, hay usuarios para las otras opciones en cada uno de los casos.

Otro aspecto relevante es el comportamiento del entrevistado sobre el uso de la plataforma de alojamiento. Del total de entrevistados más de la mitad ya tenía experiencia en su utilización; no obstante, para un amplio porcentaje (39\%) era la primera experiencia, es decir, es una moda y están experimentando con ella (cuadro 7).

La frecuencia de uso también es notable, aunque está por debajo de cuatro viajes anuales (54\%), que se calcula es la cantidad ordinaria de oportunidades de viajes que tienen las personas con acceso al turismo. Destaca que una de cada cuatro usa la plataforma más de seis veces, es decir, para cada viaje. Pero el dato más trascendente y predictor es que $96 \%$ manifiesta voluntad de usarla en el futuro, y que para $85 \%$ de los viajeros será su primera opción de viaje (cuadro 7), lo que puede estar indicando el potencial de crecimiento que aún tiene esta modalidad de contratación de hospedaje.

Los lugares visitados por los usuarios de la plataforma no son muy diferentes de los de turistas convencionales, como puede observarse en la figura 4. Una tercera parte no realiza salidas, lo que se explica en gran parte por las estancias más cortas, de una o dos noches.

La pregunta clave que siempre surge en torno a la discusión sobre las plataformas de alojamiento es si realmente son competencia del alojamiento comercial y, según los resultados, la respuesta es afirmativa. De los entrevistados, 58 \% consideró como opción al hotel, comparó alternativas, y la mayoría se decidió por la oferta de la plataforma (cuadro 7). Sin embargo, se requiere agregar otros datos, como el hecho de que a pesar de tener la experiencia de la plataforma en cada caso se siga considerando el hotel como posibilidad. Igualmente, aunque hace falta mayor análisis, vale la pena mencionar que la temporada a la cual corresponde el trabajo de campo registra altas tasas de ocupación hotelera en Cancún, cercanas a 88 \% (Secretaría de Turismo del Estado de Quintana Roo, 2017).

Una crítica recurrente a las plataformas es su falta de garantías legales y de seguridad, pero la valoración es alta, 92 \% afirmó no haber tenido complicaciones (cuadro 7). Al respecto cabe señalar que la lógica de operación de la economía colaborativa convierte a la reputación en el activo más importante tanto del usuario como del anfitrión; son las evaluaciones de ambos las que los mantienen en la plataforma y les brindan competitividad y al mismo tiempo garantizan la confianza y la seguridad.

Al tratar el tema de cómo brindar confianza en la plataforma, los anfitriones concuerdan en mencionar cuatro aspectos: las evaluaciones, la autodescripción del anfitrión, las fotos de los usuarios y su buena redacción, y comentaron: "A mí me encanta eso de que califiquen a los huéspedes y a los anfitriones, porque tienes una idea” (anfitrión 2) y "si no confías en poner una foto ¿cómo voy a invitarte yo, a mi casa?” (anfitrión 5). 


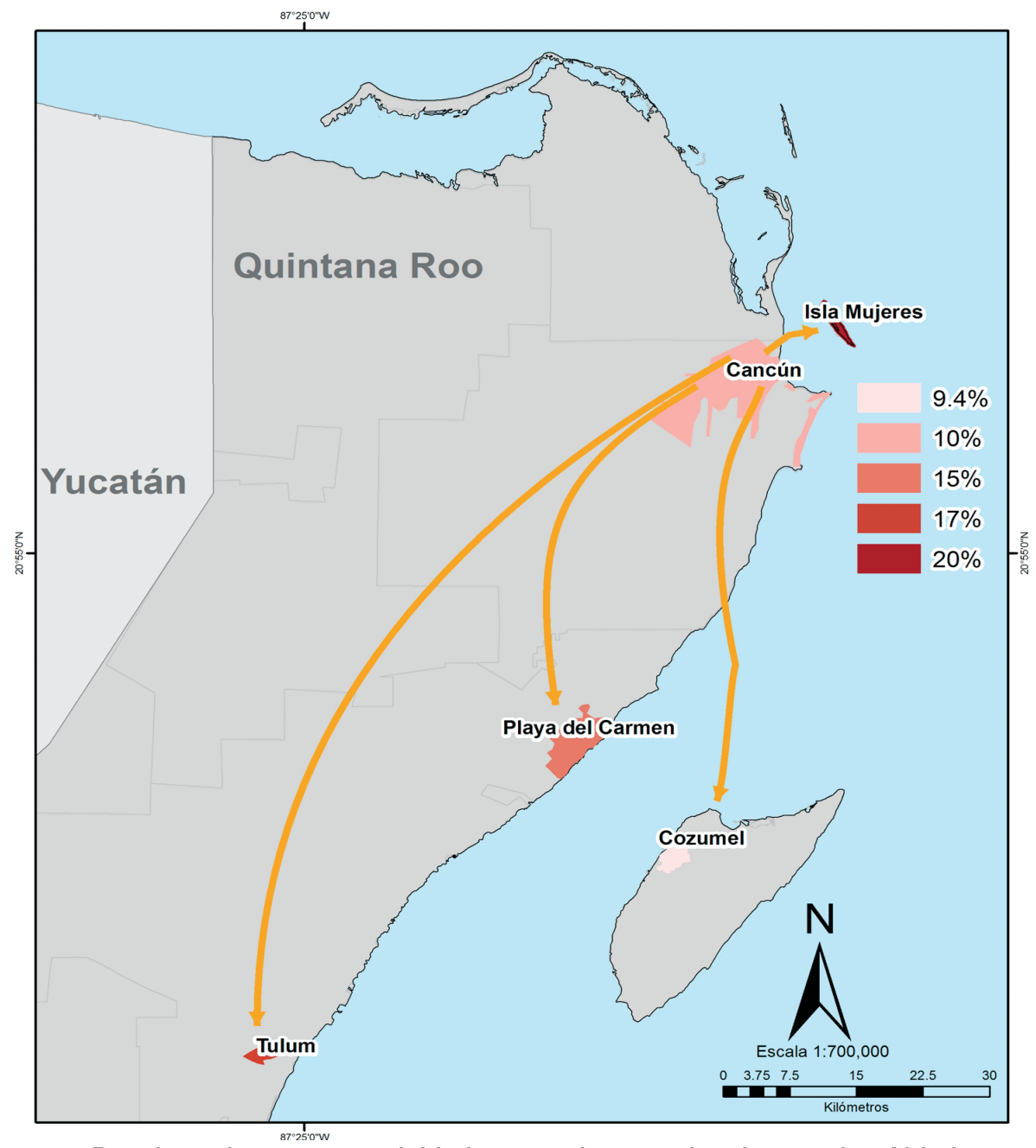

Desplazamiento para actividades complementarias de usuarios Airbnb

Fuentes: INEGI. MGM2013

Unicaribe. Recolección de datos.

Elaborado por Jonathan Salazar Santos

Marzo 2018

Figura 4. Lugares visitados en Quintana Roo por los usuarios de Airbnb

En la literatura y la publicidad se hace mucho énfasis en la experiencia de la convivencia con gente local y de "vivir como local" en el destino visitado; empero, al menos para el caso de Cancún, esto parece no ser el atributo más valorado por los usuarios (cuadro 8). Los tres primeros factores más valorados (precio, 80 \%; reputación web, 78 \%, y ubicación, $76 \%$ ) muestran un consumidor muy racional, contrario a lo que se idealiza. Esto coincide con la percepción expresada por algunos anfitriones participantes en el grupo focal, 
CuAdRo 7. Comportamiento del entrevistado en cuanto al uso de la plataforma Airbnb

\begin{tabular}{|c|c|c|c|}
\hline Variable & $\%(n)$ & Variable & $\%(n)$ \\
\hline \multicolumn{2}{|c|}{ Primera vez uso de plataformas } & \multicolumn{2}{|c|}{ Cantidad de veces en el último año } \\
\hline Sí & $39 \%(92)$ & 1 a 3 & $54 \%(79)$ \\
\hline \multirow[t]{3}{*}{ No } & \multirow[t]{3}{*}{$61 \%(146)$} & 4 a 6 & $18 \%(26)$ \\
\hline & & Más de 6 & $25 \%(36)$ \\
\hline & & No contestó & $3 \%(5)$ \\
\hline \multicolumn{2}{|c|}{ Uso de la plataforma en el futuro } & \multicolumn{2}{|c|}{ Consideró opción de hotel en este viaje } \\
\hline Sí & $96 \%(229)$ & Sí & $58 \%(139)$ \\
\hline No & $1 \%(2)$ & No & $39 \%(94)$ \\
\hline $\mathrm{N} / \mathrm{R}$ & $3 \%(7)$ & $\mathrm{N} / \mathrm{R}$ & $2 \%(5)$ \\
\hline \multicolumn{2}{|c|}{$\begin{array}{c}\text { Plataforma primera opción próximo } \\
\text { viaje }\end{array}$} & \multicolumn{2}{|c|}{$\begin{array}{l}\text { Inconveniente o incumplimiento al usar } \\
\text { plataforma }\end{array}$} \\
\hline Sí & $85 \%(203)$ & Sí & $7 \%(17)$ \\
\hline No & $11 \%(26)$ & No & $92 \%(219)$ \\
\hline $\mathrm{N} / \mathrm{R}$ & $4 \%(9)$ & $\mathrm{N} / \mathrm{R}$ & $1 \%(2)$ \\
\hline
\end{tabular}

N/R: no respondió.

Fuente: Elaboración propia con base en las entrevistas realizadas.

CuADRo 8. Factores de importancia y valoración relacionados con el hospedaje

\begin{tabular}{lcccc}
$\begin{array}{l}\text { Factores considerados al realizar } \\
\text { reservación }\end{array}$ & $\begin{array}{c}\text { Muy } \\
\text { importante }\end{array}$ & Importante & $\begin{array}{c}\text { Poco } \\
\text { importante }\end{array}$ & N/R \\
Ubicación & $76 \%(182)$ & $21 \%(51)$ & $1 \%(2)$ & $1 \%(3)$ \\
Convivencia con gente local & $49 \%(117)$ & $41 \%(98)$ & $9 \%(21)$ & $1 \%(2)$ \\
\hline Espacio a rentar & $52 \%(123)$ & $40 \%(96)$ & $7 \%(16)$ & $1 \%(3)$ \\
Reputación web del anfitrión & $78 \%(186)$ & $18 \%(43)$ & $2 \%(5)$ & $2 \%(4)$ \\
\hline Precio & $80 \%(191)$ & $17 \%(41)$ & $2 \%(4)$ & $1 \%(2)$ \\
Servicios & $47 \%(111)$ & $40 \%(96)$ & $12 \%(29)$ & $1 \%(2)$ \\
\hline
\end{tabular}

N/R: no respondió.

Fuente: Elaboración propia con base en las entrevistas realizadas.

quienes dijeron que al principio propiciaban mayor convivencia cultural e interacción, pero que con el paso del tiempo fueron disminuyendo las interacciones con sus huéspedes, dada su corta estancia en el destino o para propiciar mayor privacidad. 


\section{Conclusiones}

Los resultados de investigación sobre el uso de la plataforma Airbnb en Cancún permiten afirmar lo siguiente:

- La utilización de Airbnb como plataforma de alojamiento, tanto desde el punto de vista de los oferentes como de la demanda responde a fines de negocio; dejando de lado los principios del consumo colaborativo aplicados al turismo, donde se privilegia el compartir experiencias más que la faceta comercial.

- El perfil de los turistas hospedados a través de la plataforma corresponde totalmente a los denominados millenials, jóvenes entre 20 y 40 años, con alto nivel de estudios, y cuyos ingresos mensuales varían entre 300 y 1500 uSD, que son cazadores de oportunidades de ofertas, dada la escasa planificación del viaje, y que disponen de flexibilidad en materia de tiempo libre para viajar.

- En la oferta de alojamiento mediante Airbnb en Cancún participan variados actores, desde pequeños propietarios que rentan habitaciones en desuso de su propia vivienda hasta profesionales, empresas inmobiliarias e incluso pequeños hoteles del centro, que encuentran en la plataforma un medio eficaz para obtener ganancias e incluso clientes para su negocio. En este sentido, se puede afirmar que las plataformas de alojamiento sí son una competencia para ciertos sectores de alojamiento comercial, sobre todo el de menor categoría, ubicado en el área céntrica urbana del destino.

Se concluye que, para el caso de Cancún, las plataformas de alojamiento como Airbnb, donde media una remuneración por el servicio, se están convirtiendo en un nuevo mecanismo de comercialización directa entre el prestador del servicio y el turista.

Finalmente, resulta importante recomendar la realización de estudios comparados en otros destinos tradicionales de playa, donde las zonas urbanas sean contiguas a la turística y en destinos urbanos con atractivo colonial, donde el turista podría presentar otros comportamientos y hábitos de uso de la plataforma.

Es necesario también continuar el análisis sobre las diversas formas de regulación, aplicadas en otros destinos y las de aplicación potencial para Cancún, donde esta modalidad tiene incidencia en el mercado inmobiliario, en desarrollo urbano y usos de suelo, además de la ausencia de registros comerciales o turísticos. En este tema se requiere incluso analizar la efectividad regulatoria relativa al comercio electrónico que seguirá incrementándose. 


\section{Fuentes consultadas}

Airdna. (Mayo, 2017). Airbnb Market Report Cancun. Recuperado de https:/ /www.airdna.co/ Álvarez, I. (31 de marzo de 2016). La increíble historia de Airbn. Forbes, Business. Recuperado de http://forbes.es/business/8618/la-increible-historia-de-airbnb/

Asociación de Hoteles de Cancún. (Diciembre, 2016). Barómetro turístico de Cancún [Documento en formato digital para sus asociados].

Blanco, D. (1ำ de febrero de 2017). Cuatro mil al mes ganaron mexicanos en Airbnb. El Financiero. Recuperado de http://www.elfinanciero.com.mx/tech/mil-al-mes-ganaron-mexicanos-en-airbnb.html

Botsman, R. y Rogers, R. (2011). What's Mine is Yours: How Collaborative Consumption is Changing the Way We Live. Londres: Collins.

Dolnicar, S. (2018). Peer to Peer Accommodation Networks. Pushing the Boundaries. Londres: Good Fellow Publishers.

Gansky, L. (2010). The Mesh: Why the Future of Business is Sharing. Nueva York: Penguin.

Guillén, N. e Îñiguez, T. (2016). Acción pública y consumo colaborativo. Regulación de las viviendas de uso turístico en el contexto p2p. PASOS. Revista de Turismo y Patrimonio Cultural, 14(3), 751-768.

Karlsson, L. y Dolnicar, S. (2016). Someone's been sleeping in my bed. Annals of Tourism Research, 58, 159-162.

Oskam, J. y Boswijk, A. (2016). Airbnb: The future of networked hospitality businesses. Journal of Tourism Futures, 2(1), 22-42. Recuperado de https://doi.org/10.1108/ JTF-11-2015-0048

Pacheco, N. (2016). La web 2.0 como instrumento esencial en la economía colaborativa: auge de negocios de dudosa legalidad. Revista CESCO de Derecho de Consumo, 17, 76-84.

Reinhold, S. y Dolnicar, S. (2018). The sharing economy. En S. Dolnicar, Peer to Peer Accommodation Networks. Pushing the Boundaries (pp. 15-26). Londres: Good Fellow Publishers.

Secretaría de Turismo del Estado de Quintana Roo (2017) Indicadores turísticos. Enero-diciembre de 2016. Autor. Recuperado: https://qroo.gob.mx/sedetur/indicadores-turisticos.

Sosa, P., Martínez, C., Moncada, P. Beltrán, M. y Álvarez, V. (2015). Visitas de familiares y amigos en Cancún: impactos en una comunidad en construcción. En M. Nel-lo, B. Campos y A. P. Sosa. Temas pendientes y nuevas oportunidades en turismo y cooperación al desarrollo (pp. 156-165). Tarragona: Universidad Rovira Virgil/Universidad de Quintana Roo/Universidad del Caribe.

Zervas, G., Proserpio, D. y Byers, J. (Octubre, 2017). The rise of the sharing economy: Estimating the impact of Airbnb on the hotel industry. Journal of Marketing Research, 54(5), 687-705. Recuperado de https://doi.org/10.1509/jmr.15.0204 


\title{
El INICIO de IXTAPAN DE LA SAL COMO EMPORIO tURístico
}

\author{
Graciela Cruz JimÉnez \\ gracicj@hotmail.com \\ Centro de Investigación y Estudios Turísticos \\ Universidad Autónoma del Estado de México \\ Cecilia Cadena Inostroza \\ ccadena@cmq.edu.mx \\ El Colegio Mexiquense
}

\begin{abstract}
Este documento aborda los principales hechos correspondientes a la primera etapa del desarrollo turístico en Ixtapan de la Sal, uno de los destinos más importantes del Estado de México, cuya evolución está asociada con las aguas termales. El análisis está basado en el enfoque de redes de política pública y tiene un fuerte sustento en información documental y en entrevistas con actores vinculados con esa actividad. Los principales hallazgos evidencian asimetrías de poder entre los sectores público, social y privado en Ixtapan de la Sal durante el periodo analizado, por lo cual se concluye que los actores con mayores recursos de distinto tipo influyeron en el rumbo de este destino turístico.
\end{abstract}

Palabras clave: Ixtapan de la Sal, turismo, redes de política pública, evolución, destino.

\section{The StaRT OF IXTAPAN DE La SAL AS a tOURISM EMPORIOUM}

This document addresses the main events of the first development stage in Ixtapan de la Sal as a tourism destination where the local hot springs are associated to its evolution and make it one of the most important destinations in Estado de Mexico. This analysis is based on the approach of public policy networks, and it has a strong support in documentary information and interviews with actors related to this activity. The main findings show power asymmetries among the public, social, and private sectors of Ixtapan de la Sal during the analyzed period; therefore, it is concluded that those actors with the most resources influenced the development course of this tourism destination.

Keywords: Ixtapan de la Sal, tourism, policy networks, evolution, destination.

Fecha de recepción: 5 de abril de 2018. Fecha de aceptación: 7 de junio de 2018

CÓMO CITAR: Cruz, G. y Cadena, C. (2018). El inicio de Ixtapan de la Sal como emporio turístico. Dimensiones Turísticas, 2(3), 25-47. https://doi.org/10.47557/PKYS8544 


\section{Introducción}

$\mathrm{H}$

oy en día el turismo ha cobrado fuerza como una alternativa para contribuir al rescate y preservación de los recursos naturales y culturales de la comunidad receptora, bajo el supuesto de que beneficia tanto a sus habitantes como al propio visitante, al ofrecerle un destino más conservado en lo que respecta a su patrimonio natural, histórico y cultural.

Esta dinámica contrasta con la de décadas atrás, cuando el acento estaba puesto exclusivamente en la obtención de ganancias económicas, sin que ello signifique que esta práctica haya cambiado en su totalidad; todavía es común que los procesos decisorios favorezcan los intereses de los más poderosos en perjuicio de los pobladores y de su entorno.

Tal es el caso de Ixtapan de la Sal, uno de los principales sitios turísticos del Estado de México, donde la mayoría de los habitantes de su cabecera municipal dependen directa o indirectamente de esta actividad, que ha sufrido una transformación significativa con el correr de los años, que no podría explicarse sin entender su pasado, incluyendo a los actores que influyeron en el proceso.

En la década de los cuarenta del anterior siglo, el empresario Arturo San Román Chávez empezó a construir en ese lugar su emporio basado en un turismo de salud encaminado a la atención de problemas físicos a partir de las aguas termales. En la actualidad la oferta de Ixtapan de la Sal está concentrada en un parque acuático, un spa, el fraccionamiento turístico-residencial Grand Reserva y el hotel Ixtapan; todos estos servicios a cargo de los herederos de ese personaje.

Diversos factores contribuyeron en su conjunto a moldear el actual perfil turístico de la localidad: en un marco general, la reconfiguración del Estado mexicano, cuya apertura a la que hace alusión Porras (2012, p. 13) propició la redefinición en ciertos ámbitos de las funciones tradicionales de los actores gubernamentales y no gubernamentales. En ese contexto y en el ámbito local, se integraron asociaciones de prestadores de servicios turísticos y con ello aparecieron nuevos actores.

El avance en las telecomunicaciones y los cambios en la política turística también fueron determinantes en las relaciones que se gestaron entre diferentes personajes, las cuales influenciaron el proceso decisorio en ese destino. Son precisamente estos vínculos los que fundamentan el enfoque de redes de política pública (ERPP), que da sustento teórico al caso aquí expuesto.

Durante la primera etapa del desarrollo turístico de Ixtapan de la Sal fueron identificados dos cursos de acción; estos se conciben como los sucesos o eventos compuestos por distintos actos, cuyas características propiciaron relaciones entre diversos personajes, quienes con sus recursos, dependencias y lazos de cooperación lideraron las acciones turísticas.

Estos cursos de acción, que tuvieron lugar entre 1930 y 1979, corresponden respectivamente al arrendamiento del balneario de San Gaspar y a la confrontación por las aguas termales; este último es el más ríspido y propicio para el análisis, ya que incluye la disputa 


\section{G. Cruz Jiménez · C. Cadena Inostroza}

por los borbollones de Santa Catarina y la concesión de las aguas termales de San Gaspar, que fueron el centro de la oferta turística.

Para analizarlos y explicarlos, se presenta secuencialmente el sustento teórico de las redes de política pública, cuyo enfoque sirvió para guiar la investigación "El turismo como elemento de conflicto y acuerdo en las redes de política pública de Ixtapan de la Sal”, de la cual se deriva este artículo. Se aborda la metodología utilizada y se ofrece una panorámica general sobre Ixtapan de la Sal que sirve de contexto a los referidos cursos de acción relativos a su primera etapa de desarrollo turístico; de su descripción y análisis se derivan los resultados y las conclusiones.

\section{Las redes de política pública como base teórica}

En las últimas décadas ha crecido el interés entre la comunidad científica por el estudio de las políticas públicas; según Van Meter y Van Horn (2003, p. 99), constan de aquellas acciones efectuadas por individuos (o grupos) públicos y privados, tendientes a la consecución de objetivos previamente decididos a partir de un problema público. Este cobra tal categoría cuando las necesidades, intereses y proyectos son de alcance general (Aguilar, 2003, p. 29).

Por tanto, en un primer momento estas inquietudes corresponden a la agenda pública que, a diferencia de la gubernamental, se inclina a ser más general y abstracta. Los asuntos presentan una formulación genérica y aún se encuentran en su fase de formación de una problemática que afecta a un grupo considerable de personas (Montecinos, 2007, p. 328). Una vez que se fijan en la agenda de gobierno, el ente público genera una política para resolverlos.

Con base en ello y según Franco (2013, p. 88), las políticas públicas son acciones de gobierno con objetivos de interés público que surgen de decisiones sustentadas en un proceso, para la atención de problemas públicos específicos, en donde la ciudadanía participa en la definición de problemas y soluciones. Su mayor fortaleza analítica y disciplinaria (Hernández, 2015) radica en la posibilidad, a partir de este enfoque, de operacionalizar múltiples conceptos y estudiar muy diversos fenómenos sociales; el turístico sería uno de ellos.

En términos teóricos, estas políticas deben estar formadas por quienes participen de ellas, independientemente de que emanen de un ente público; sus amplios alcances relacionados con la participación, la democracia y la corresponsabilidad, entre otros elementos, les asignan un peso importante, pues de su implementación depende en gran medida la orientación que toma determinada acción. Sin embargo, se ha comprobado (Cruz, 2014; Cadena y Cruz, 2006) que son las interacciones entre personajes vinculados con esas políticas las que en realidad configuran sus resultados y no los lineamientos normativos bajo los cuales son diseñadas. Con base en este argumento, la hechura de las políticas responde a la interacción entre varios actores para asegurar la satisfacción de sus intereses (Klijn, 1997, p. 22). 
En estos aspectos está centrado el ERPP, el cual explica cómo a pesar de ciertos elementos que en teoría podrían favorecer o afectar determinadas acciones estas toman un rumbo diferente según la manera en que se relacionen los actores a partir de lo que Meny y Thoenig (1992, p. 103) denominan juego político: aquel que estos despliegan para hacer prevalecer sus propósitos y durante el cual ejercen sus recursos de distinta naturaleza para formar vínculos de cooperación o dependencia con otros, lo que genera una interacción positiva o negativa entre ellos. Esto influye en la conducción de decisiones y acciones, en este caso las turísticas (Cruz, Serrano-Barquín, Mejía, Mejía y Reza, 2010, p. 380). Por lo tanto, en las redes de política pública el análisis está enfocado en los actores que participan en su formación e implementación.

El esfuerzo intelectual y práctico ha de centrarse en sus condiciones de consenso, corrección y factibilidad en su formación, implementación, impacto y evaluación, en averiguar y depurar la manera en que ciertos problemas sociales o grupales devienen públicos y se insertan en la agenda de gobierno (Aguilar, 2007, p. 22). A la vez, el tipo de interdependencia y la convergencia o divergencia de intereses de los miembros que constituyen una red son los elementos a partir de los cuales Zabaleta (2006, pp. 47-48) clasifica estas redes en formales e informales; las primeras no establecen una organización clara (reglas, jerarquías, procedimientos, etc.), pero son capaces de formular políticas públicas mediante interacciones menos rígidas.

En tanto, las informales pueden surgir a partir de la presión de interés en torno a cierta política que busca influir en ella; estas redes se limitan a contactos entre los integrantes de diferentes organizaciones mediante interacciones informales -llamadas telefónicas, reuniones ad hoc, intercambio de información, etc.-. En ambos casos, la toma de decisiones es muy variada y dependerá en gran medida de la composición de la red (número y tipo de personajes, intereses y expectativas de cada uno); el tiempo de vida esperado de la red, el tipo y el número de funciones determinará si esta tenderá a formalizarse (Zabaleta, 2006, pp. 48, 54-55). En suma, estas redes son una representación abstracta de la realidad.

Además de la exploración documental sobre redes y políticas públicas, fueron revisados los postulados de las teorías interorganizacional y de ciencia política que sirven de base al enfoque con el que fue construido el marco teórico que soporta la investigación de la cual se deriva este artículo, el cual pone de relieve que el turismo representa, en términos investigativos, un área promisoria en el terreno político, pues alrededor de él se agrupan personajes públicos, sociales y privados con objetivos e intereses que bien pueden ser comunes o divergentes. Es a lo que Hernández (2015) llama actores heterogéneos, por tratarse de diversos tipos de autoridades, niveles de gobierno u origen de los recursos.

\section{El ERPP para el análisis de una realidad}

Con base en el ERPP fue desarrollada la investigación empírica siguiendo la propuesta metodológica de Cruz (2014), quien define como variables de análisis los objetivos, intereses, 


\section{G. Cruz Jiménez · C. Cadena Inostroza}

recursos, dependencia, cooperación e intensidad de interacción entre los participantes, en este caso, de la red que se formó durante los dos cursos de acción abordados.

Por tratarse de un periodo de análisis entre 1930 y 1979, la investigación tuvo un fuerte soporte documental, principalmente en archivos municipales y estatales. Además de aportar datos sobre aspectos importantes vinculados con el turismo, la información permitió identificar personajes cuya intervención fue relevante durante ese periodo; sin embargo, dado que la primera fase de desarrollo turístico de Ixtapan de la Sal tuvo lugar hace varias décadas, ninguno de ellos sobrevive. Por tanto, un segundo ejercicio consistió en seleccionar actores capaces de aportar información sobre estos, pero también datos más actuales en torno al destino.

Los informantes clave fueron el presidente municipal, el cronista, funcionarios municipales de la Dirección de Turismo, y pequeños y medianos hoteleros. Para abordarlos fueron diseñados guiones de entrevistas semiestructuradas con preguntas sobre las referidas variables (objetivos, intereses, recursos, dependencia, cooperación e intensidad de interacción entre los participantes en la red) que las vincularan con los personajes que tuvieron un papel preponderante durante los dos cursos de acción.

Los testimonios recabados fueron contrastados con la información documental a fin de confrontar las ideas, complementarlas o descartarlas, para lograr una interpretación más ajustada a la realidad. ${ }^{1}$ A partir de ello fueron diseñadas matrices relacionales cuyo análisis facilitó determinar la fortaleza o debilidad de los vínculos entre actores, que a su vez permitió establecer su influencia en la red y, por ende, en el proceso decisorio de Ixtapan de la Sal.

Las matrices fueron nueve por cada curso de acción; la primera tuvo un carácter meramente cualitativo, ya que concentró los objetivos e intereses de los actores objeto de estudio, así como el sector (público, social o privado) al que pertenecían. Esta matriz sirvió de base para las siguientes dos que, al igual que las restantes, tuvieron una naturaleza cuantitativa. Una abordó su compatibilidad de objetivos y la otra su compatibilidad de intereses. Para ambas fueron asignados los siguientes valores: compatibilidad alta +2 ; compatibilidad media +1; compatibilidad baja -1; compatibilidad nula -2 .

La cuarta matriz correspondió a los recursos puestos en juego por actor. Los valores asignados fueron: recursos altos +2 ; recursos medianos +1 ; recursos bajos -1 ; recursos nulos -2. La quinta analizó la dependencia entre actores, y los valores fueron: sin dependencia +2 ; dependencia baja +1; dependencia mediana -1 ; dependencia alta -2 .

Mediante la sexta matriz fue abordada la cooperación entre los integrantes de la red, a partir de los valores: cooperación alta +2; cooperación mediana +1; cooperación baja -1; cooperación nula -2 .

La séptima matriz concentró el promedio obtenido por actor en el curso de acción objeto de análisis; en la octava se colocaron los valores de ponderación por cada una de las

'En el cuerpo del texto, cuando se hace referencia por primera vez a un actor, se incluye su cargo y el nombre completo con las iniciales correspondientes, con las cuales se le identifica sucesivamente. 
variables de análisis correspondientes a las seis matrices relacionales. La novena matriz incluyó el factor de ponderación por variable de análisis, lo que arrojó el puntaje final por actor y sector.

Con esos resultados fue esbozado un modelo de red de política pública para esquematizar el predominio de sus participantes, así como el tipo e intensidad de relación entre sus integrantes, la cual se representa gráficamente en el apartado de resultados.

\section{Panorámica de Ixtapan de la Sal}

El municipio se localiza en la parte sur del Estado de México, a 135 kilómetros al suroeste de la Ciudad de México; colinda con cinco municipios mexiquenses y con el estado de Guerrero (H. Ayuntamiento de Ixtapan de la Sal, 2016, p. 11). El nombre de Ixtapan de la Sal es de origen náhuatl y significa "En la sal" o "Sobre la sal".

Desde la época prehispánica las aguas termales han representado un aspecto relevante en la cabecera municipal. Hacia 1394, los indígenas provenientes de las costas del Pacífico le informaron al emperador acerca de la existencia de agua caliente, pero, sobre todo, que al evaporarse el agua de los manantiales se formaba sal, artículo muy apreciado porque se comercializaba mediante trueque (Arizmendi, 1999a, p. 4).

Las propiedades terapéuticas del sitio se relacionaron con el temazcalli -casa de baño de vapor-, lo cual alentó las visitas de emperadores, con fines de reposo y descanso (Becerril, 1988, p. 23). Durante la Conquista, las autoridades virreinales fueron notificadas sobre la existencia de estas aguas y los beneficios físicos que generaban (Hernández, 2001, p. 47).

Iztapan tuvo un papel estratégico dentro de la Provincia de la Plata, como fue denominada la primera región minera de la Nueva España, conformada por cuatro comarcas: Temazcaltepec, Sultepec, Tasco y Zacualpan; a esta última pertenecía Ixtapan. Algunos factores que contribuyeron a tal situación fueron su cercanía con la ciudad de México y las minas de Zacualpan y Tasco; asimismo su fertilidad tanto para la agricultura como para la ganadería, y la producción de sal desde la época prehispánica que se comercializaba en la región (García, 2000, pp. 31, 53-54).

Con el paso de los años, en Ixtapan de la Sal se registró un flujo de metaleros y comerciantes españoles, mestizos e indios, proveedores de diversos productos, por lo cual las "ventas" o posadas tuvieron un papel preponderante como negocio de hospedaje (García, 2000, p. 61). Sin embargo, hacia 1860 en ocasiones no encontraban alojamiento en ninguno de los mesones de la región, que eran casas particulares acondicionadas (Hernández, 2001, pp. 52-53); por lo tanto, surgieron al menos tres casas de huéspedes para atender tanto esta demanda, como la necesidad de alimentación y descanso de los animales que transportaban cargamentos de oro y plata.

Los españoles vieron en el hospedaje un negocio alterno a la agricultura y la ganadería (González, 2004, p. 156); los permisos para estos establecimientos generalmente fueron otorgados a personajes ligados con la élite novohispana que tenían intereses en Ixtapan 


\section{G. Cruz Jiménez · C. Cadena Inostroza}

de la Sal; el primero del que se tiene constancia fue autorizado en 1576 a don Francisco Gómez de Saavedra (Ricaurte, 2001, pp. 65-66).

De lo anterior se concluye que, hasta ese momento, aunque eran apreciadas las propiedades de las aguas termales, no motivaron importantes desplazamientos para su aprovechamiento y, por lo tanto, tampoco produjeron algún efecto, como sí lo hizo la actividad comercial que alentó la aparición de sitios para el descanso de metaleros y vendedores, pero aún no para turistas. Hubo otros factores, como la construcción del ferrocarril (cuya estación estaba localizada en la población de Atlahuaca, cerca del vecino municipio de Tenango del Valle), que motivaron la instalación de más posadas entre 1860 y 1870 (Arizmendi, 1999b, p. 66). En esos años empezaba a gestarse de manera incipiente la oferta turística basada en el aprovechamiento de las aguas termales.

Es de resaltar que en las fuentes documentales existe una "laguna" de información de casi un siglo en materia de hotelería en este sitio, que abarca de 1870 a la segunda mitad del siglo xx, lo cual Ricaurte (2001, p. 71) atribuye a que en 1912 el archivo histórico municipal fue incendiado por un grupo de zapatistas durante la Revolución mexicana, de modo que no se cuenta con documentos anteriores a esa época.

Hasta antes de 1940 la economía del municipio estaba sustentada en las actividades primarias (Martínez, 1997, p. 63), a pesar de que una década atrás varios campesinos de las comunidades rurales comenzaron a migrar hacia la cabecera municipal para insertarse en actividades relacionadas con el turismo, ya fuera mediante empleos directos o indirectos asociados principalmente con el comercio (Ricaurte, 2001, pp. 77-79, 81, 103). Entre las décadas de los treinta y cuarenta, solo 1 \% de la población se dedicaba al turismo, pero en los cincuenta la cifra aumentó a 12 \% y observó un crecimiento continuo (Martínez, 1997, pp. $35,63)$.

En los últimos años, según el exalcalde Cesáreo Antonio Domínguez Díaz (CADD), 90 \% de la población de la cabecera municipal se ha beneficiado directa o indirectamente de esta actividad. De acuerdo con el Censo de Población y Vivienda (Instituto Nacional de Estadística y Geografía, 2010), la población de Ixtapan de la Sal asciende a 33541 personas; casi la mitad está concentrada en la cabecera municipal.

Además de su belleza paisajística derivada de una amplia variedad de especies vegetales, producto de su temperatura media anual de $17.9 \stackrel{\circ}{ }$ C, cabe señalar que Ixtapan de la Sal cuenta con recursos culturales, entre ellos el uso del barro y la madera para elaborar productos ornamentales y utilitarios, así como la preparación de dulces de pipián; también con algunos recintos religiosos como las parroquias de la Asunción de María y de Santa Ana Xocuca. Pese a este potencial, tales recursos no han sido capitalizados en su primera ni en su segunda fase de desarrollo turístico, para integrarlos como atractivos o productos turísticos.

Antes de alcanzar el rango de centro turístico por excelencia, la localidad observó una evolución turística; su primera etapa de desarrollo fue determinante en este proceso. 


\section{Primera etapa de desarrollo turístico}

\section{1 El arrendamiento del balneario de San Gaspar}

El primer curso de acción que tuvo una amplia influencia en esta etapa fue el arrendamiento del balneario de San Gaspar, pues sentó las bases para que, en años posteriores, sus aguas termales fueran concesionadas a uno de los personajes con mayor influencia en ese destino turístico: Arturo Alfredo San Román Chávez.

En 1850 un italiano construyó el primer balneario público en los borbollones de San Gaspar, el cual funcionó hasta 1910, cuando fue cerrado a causa de la Revolución (Arizmendi, 1999b, pp. 6-7). En aquel entonces, según el excronista Luis René Domínguez Arizmendi (LRDA), el gobierno municipal arrendaba el balneario y también administraba sus aguas termales.

Quizá debido a la falta de evidencia documental a la que se hizo referencia, el siguiente dato, sin que exista más información al respecto, corresponde a los años treinta, en que ese balneario fue arrendado a Erasmo Hernández, quien perteneció a una familia de políticos "a la buena o a la mala", por lo que, en su momento, al tener recursos (medianos), tanto económicos como políticos, obtuvo con cierta facilidad la renta del balneario (LRDA). Sin embargo, la seguridad de sus ingresos económicos dependía de mantener el contrato pactado con el gobierno municipal.

En 1931, a instancias del gobernador Filiberto Gómez, se realizó una campaña publicitaria del destino (Hernández, 2001, p. 53) y, un año después, el químico Rafael Ortiz Mena determinó que las aguas termales combatían el reumatismo articular, por lo cual eran útiles para diversos padecimientos (Castillo, 1995, p. 48); ambas acciones propiciaron que aumentara el flujo de personas que deseaban beneficiarse de estas. Flores (1987, pp. 32-34) da cuenta de ello cuando refiere que por el acceso principal a la cabecera municipal pasaba rumbo al balneario un gran número de enfermos a pie, con muletas o en carritos, con la esperanza de encontrar alivio para sus males en sus aguas milagrosas.

Casi al mismo tiempo, en medio del descontento de la población -por no ser oriundo del lugar-, el ayuntamiento de Ixtapan de la Sal le arrendó el inmueble al guanajuatense José Reynoso mediante un contrato avalado por el congreso estatal (H. Ayuntamiento de Ixtapan de la Sal, 1931), lo cual ocasionó conflictos sociales (Ricaurte, 2001, p. 72).

Entre 1913 y 1914 ese personaje fue subsecretario de Hacienda y Crédito Público y, más tarde, encargado del despacho. En el Constituyente de 1917 ocupó una curul por el Estado de México en Querétaro y después fue varias veces senador de la República. También se desempeñó como gobernador provisional de Guanajuato y luego se dedicó a negocios particulares, entre ellos el turístico en Ixtapan de la Sal.

Tales cargos no solo le brindaron soporte económico, además le permitieron afianzar relaciones en el ámbito federal, por lo que al tener altos recursos impuso su predominio y le fue concedido el arrendamiento. Él, al igual que Erasmo Hernández, pretendía afianzarse política y económicamente, lo cual él sí pudo concretar al imponer su supremacía. 
Se argumenta que, como diputado federal, José Reynoso llegó “ofreciendo las perlas de la Virgen" por el arrendamiento (LRDA).

Se infiere que las relaciones que formó en sus distintos cargos pudieron haber influido en uno de los objetivos del gobernador Filiberto Gómez: apoyar al empresario para que obtuviera este beneficio y así el mandatario recibiría su apoyo ante cualquier eventualidad que se registrara en Ixtapan de la Sal. Por lo tanto, fue bastante la cooperación entre ambos personajes, pero menor la dependencia del mandatario hacia el empresario, pues aunque se deduce que intercedió a su favor, José Reynoso no era el único aliado del que el Ejecutivo estatal pudo haber dispuesto para concretar su fin. Erasmo Hernández también tuvo una gran dependencia de las decisiones del gobernador para mantener la concesión, lo cual no logró.

Por otra parte, las relaciones que José Reynoso formó en sus anteriores cargos fueron decisivas para que el congreso local avalara el referido contrato de arrendamiento, por lo que a Erasmo Hernández no le quedó más remedio que acatar tal disposición, luego que el entonces alcalde Brignó Tovar le dirigiera un oficio, comunicándole que "por acuerdo de este Ayuntamiento, los baños termales propiedad de este municipio quedan por cuenta del arrendatario Sr. Ing. José J. Reynoso conforme al contrato que tiene celebrado este Ayuntamiento con el expresado". Como resultado, fue nula la compatibilidad de intereses entre José Reynoso y Erasmo Hernández, al igual que la cooperación entre ellos.

Asimismo, el hecho de que Reynoso ya tuviera cierto capital económico, producto de haber establecido el primer hotel en la cabecera municipal, habría influido en su objetivo de ampliar su oferta turística con la obtención del arrendamiento del balneario. Fue él quien gestionó la construcción de una vía para mejorar el acceso a la cabecera municipal, con lo cual se percibe cómo el objetivo de un actor para favorecer el desplazamiento hacia su negocio y consolidar su posición económica y política contribuyó al mejoramiento de caminos, aspecto que tuvo una repercusión más amplia, pues benefició además a otros sectores, como el comercial, y con ello se empezó a modificar el perfil de la localidad.

Al mismo tiempo, el ayuntamiento de Ixtapan de la Sal no era del todo autónomo sobre la renta del balneario, que también estaba supeditada -si no formalmente, sí en la prácticaal gobierno del Estado de México, lo cual reflejaría la alta dependencia de Reynoso hacia el mandatario estatal, cuya decisión acerca del arrendamiento habría sido la definitiva y no la de las autoridades ixtapenses.

El pago del arrendamiento del balneario representaba $15 \%$ sobre las entradas brutas al inmueble, cantidad que beneficiaba directamente al gobierno municipal (Arizmendi, 1999b, pp. 6-7), sin que esté claro en qué rubros fueron aplicados tales recursos. Desde entonces prevalecían prácticas de opacidad, pues aunque el secretario general de gobierno Francisco Carvajal le pidió al presidente municipal darle al Gobierno del Estado de México una copia del contrato de arrendamiento que suscribió con José Reynoso, el alcalde le respondió que "en esta presidencia no existe copia del contrato" (H. Ayuntamiento de Ixtapan de la Sal, 1932). 
El gobierno municipal en funciones en 1932 disponía de pocos recursos, por lo que su objetivo fue fortalecer sus finanzas mediante el porcentaje que le correspondía de ganancia sobre las entradas del inmueble, lo cual concretó gracias a Erasmo Hernández y a José Reynoso, quienes en su momento cumplieron su cometido de obtenerlo en renta, de ahí que los objetivos entre autoridades municipales y particulares tuvieron una alta compatibilidad.

En este mismo sentido, esos actores privados observaron una gran dependencia hacia las autoridades municipales para que les arrendaran el balneario; la dependencia del gobierno hacia ambos fue de la misma magnitud, pues requería rentar el inmueble a quien le garantizara $15 \%$ sobre las entradas brutas. Bajo este argumento los tres concretaron una alta cooperación, ya que mutuamente complementaron sus propósitos. A la vez, a pesar de que los intereses de estos tres personajes eran distintos, puesto que atendían a una naturaleza diferente, se complementaron y, por tanto, fueron de mediana compatibilidad.

En tal acción se refleja la configuración de relaciones de poder, pues en esta situación la concertación entre el gobierno de Ixtapan de la Sal con Erasmo Hernández y José Reynoso obedeció a la expectativa de las utilidades que cada uno de ellos calculó obtener y de ahí derivaron sus estrategias. En el caso del gobierno municipal de Ixtapan de la Sal en 1932, si bien sus recursos financieros eran bajos, disponía de altos recursos normativos, ya que él determinaba a quién le arrendaba el inmueble.

No obstante, en esa época las autoridades municipales estaban supeditadas a los designios de las autoridades estatales y federales, por lo cual eran susceptibles a que sus decisiones no fueran del todo autónomas; el gobierno ixtapense no fue la excepción en cuanto a una posible intromisión sobre quién sería el beneficiario con el arrendamiento, por lo que sus recursos políticos resultaron medianos. El correspondiente a la información fue alto, ya que disponía del conocimiento técnico para realizar la concesión.

Queda claro, en palabras de Aguilar (1992, pp. 29, 33-36), el protagonismo gubernamental que prevalecía. Como se ha demostrado, durante el presente curso de acción los actores centrales en términos reales fueron el gobierno municipal y los dos arrendatarios, independientemente de la intervención del gobernador para favorecer a uno de ellos. Destaca el hecho de que solo dos personajes hayan sido tenidos en cuenta para rentarles el balneario, aunque no se descarta que algunos prestadores del servicio de hospedaje, que para esa época sumaban alrededor de 20, hubieran manifestado su interés por arrendarlo, con lo cual se confirmaría que los dos actores privados con más recursos entonces, en especial financiero y político, resultaron beneficiados.

Es notable también la ausencia de personajes del sector social. A pesar de que había cierta inconformidad entre los habitantes de Ixtapan de la Sal por el arrendamiento del balneario a Reynoso, la magnitud de su descontento no fue importante; se deduce que en parte obedeció a que no estaban organizados, por lo cual sus quejas a título personal no prosperaron. Sin embargo, con el paso del tiempo, los sucesos empezaron a tomar una perspectiva diferente y la molestia del pueblo creció al sentir que era excluido de los beneficios derivados de las aguas termales, que jugó un papel relevante durante el segundo 


\section{G. Cruz Jiménez · C. Cadena Inostroza}

curso de acción que se plantea a continuación (la confrontación por las aguas termales), durante el cual se desarrollaron dos hechos significativos: la disputa por los borbollones de Santa Catarina y el arrendamiento del balneario de San Gaspar.

\section{La confrontación por las aguas termales}

\subsection{La disputa por los borbollones de Santa Catarina}

Desde los años treinta los habitantes de Ixtapan empezaron a manifestarse en contra de que personajes ajenos a la localidad fueran favorecidos con las aguas termales. Erasmo Hernández sí era oriundo de Ixtapan de la Sal, contrario al italiano del que se tiene la primera referencia sobre el arrendamiento del balneario; tampoco lo eran José Reynoso ni Arturo Alfredo San Román Chávez.

Poco después, en los cuarenta, el reclamo popular sobre los beneficios de este recurso alcanzó su punto más álgido, lo cual obligó a la intervención presidencial; como resultado, en un acuerdo firmado el 13 de junio de 1941, el mandatario federal Manuel Ávila Camacho estableció que los borbollones asentados en el barrio de Santa Catarina (conocidos como “El Borbollón de Santa Catarina” y "El Bañito) se reservaran para uso exclusivo y gratuito de los pobladores, por lo tanto, no se podrían entregar a ningún concesionario, ni dictarse medidas que limitaran el aprovechamiento total en su beneficio (Ricaurte, 2001, pp. 7375). El gobernador Isidro Fabela avaló tal disposición y ordenó construir un balneario en los borbollones de Santa Catarina, que eran utilizados de manera muy rudimentaria por los vecinos. Con ello se confirió a los ixtapenses el uso de este recurso, que tenía menores ventajas en cuanto a caudal y ubicación respecto a los de San Gaspar.

A Manuel Ávila Camacho le unía una "vieja y profunda amistad" con el gobernador Isidro Fabela que le rindió frutos importantes a este último (Hernández, 1998, pp. 61, 64). Esa relación se explica por el apoyo que Fabela -quien no pertenecía a la clase política local- dio al proyecto nacional de largo alcance del presidente que lo impuso en el cargo como una forma de evitar que permaneciera en el poder la élite tradicional involucrada en el asesinato del gobernador Alfredo Zárate Albarrán, hecho que ocasionó el descontento del mandatario federal, por lo cual respaldó a Fabela en la creación de su propio equipo de colaboradores para dar continuidad a la administración del político fallecido (Hernández, 1998, pp. 26, 40, 43, 59).

Gracias a la puesta en juego de sus altos recursos políticos, normativos, humanos y de información, el gobernador pudo concretar la disposición presidencial respecto a que ningún particular se beneficiara del uso de los borbollones de Santa Catarina; este decreto fue respaldado por el posterior dictamen de Isidro Fabela sobre el uso gratuito para la población. El gobernador tenía claro que la formación de un estado moderno solo podía alcanzarse, entre otras acciones, pacificando a los grupos, por lo que uno de sus principales propósitos fue abolir la violencia (Hernández, 1998, p. 66).

Aun cuando los objetivos de Isidro Fabela sobre los borbollones de Santa Catarina no buscaban en realidad atender los del pueblo, los habitantes resultaron beneficiados de las 
disposiciones oficiales, por ende, sus objetivos tuvieron una compatibilidad intermedia; no así sus intereses, cuya compatibilidad fue poca, dado que los del mandatario estatal estuvieron centrados en cuestiones totalmente ajenas a los suyos. Pese a ello, se generó de forma involuntaria una cooperación, aunque baja, entre estos dos actores, basada en su pretensión de que las aguas termales de Santa Catarina no fueran concesionadas a particulares.

El pueblo de Ixtapan de la Sal estuvo a expensas de las medidas que adoptó Isidro Fabela en torno a ese problema, por lo que su dependencia hacia él fue alta, aunque, a su vez, este también dependió del pueblo, pero en una proporción mediana, pues si continuaban sus manifestaciones de descontento se rompería el orden social y se pondría en riesgo su proyecto político y económico en ese municipio, por lo cual grupos inconformes con algún asunto podrían secundar el ejemplo de Ixtapan de la Sal.

Paralelamente, en 1941 llegó por primera vez a la localidad Arturo Alfredo San Román Chávez, quien ideó un gran centro turístico medicinal, pues "se dio cuenta de la bondad de sus aguas termales, su maravilloso clima y sus hermosos lomeríos” (Guadarrama, 2004). Desde entonces este personaje, con importantes vínculos con la clase política, empezó a tejer puentes que le permitieran cumplir su propósito de obtener en concesión las aguas termales de San Gaspar, lo cual suscitó la inconformidad entre los pobladores que reclamaban para ellos los beneficios de esas aguas.

Hacia 1944, durante este segundo curso de acción, el empresario San Román Chávez también gestionó la concesión de los borbollones de Santa Catarina, lo cual le permitiría posicionar económica y políticamente a su familia. Esta petición generó hostilidad entre el pueblo, pero además el gobierno municipal de 1944 entabló una disputa legal para que tal solicitud no prosperara.

El objetivo de las autoridades de Ixtapan de la Sal era que, con base en el referido dictamen gubernamental, los borbollones de Santa Catarina no fueran concesionados a particulares, lo que denota la nula compatibilidad de objetivos e intereses con el empresario, tanto por parte del ayuntamiento como de los ixtapenses; por el contrario, los objetivos de estos dos últimos actores fueron altamente compatibles, contrario a la baja compatibilidad de sus intereses, ya que los del gobierno eran conservar los ingresos derivados del uso de los borbollones, y los de la comunidad, seguir utilizando las aguas como un recurso colectivo.

Pese a ello, la cooperación entre ambos fue mediana, al igual que la dependencia del gobierno municipal hacia el pueblo, pues requería que los habitantes continuaran manifestando su inconformidad; de esta forma, las autoridades tenían un respaldo para presionar que se hiciera efectivo el citado decreto. Por su parte, el pueblo observó una alta dependencia hacia el ayuntamiento, porque el hecho de que esas aguas no pasaran a manos de San Román estribaba en que el gobierno ganara la querella que entabló en su contra. Esta disputa pudo seguir su curso pese a los bajos recursos financieros, normativos y humanos del ayuntamiento, el cual, sin embargo, ejerció en esta pugna sus medianos recursos políticos y de información. 


\section{G. Cruz Jiménez · C. Cadena Inostroza}

Por su parte, los ixtapenses lucharon por su cometido con pocas ventajas, ya que eran nulos sus recursos financieros, normativos y humanos y solo disponían de poca información acerca de los decretos presidencial y estatal. Salvo la intervención de la UDESIs, que, se infiere, era una Unión que reclamaba se le diera al pueblo el derecho de las aguas de San Gaspar y no a personas de manera ilegal, no existen más evidencias documentales ni testimoniales sobre la organización colectiva del pueblo. En contraparte, gracias a la presión que ejercieron estos actores, pudieron posicionar en la agenda presidencial su inconformidad por la inequitativa distribución de los beneficios derivados de las aguas termales, por lo que su recurso político fue mediano.

Aunque podría suponerse que el gobierno municipal defendió los derechos del pueblo como beneficiario de los borbollones de Santa Catarina, se deduce que su verdadero interés fue económico, pues si esas aguas hubieran sido concesionadas a particulares, las autoridades habrían dejado de percibir recursos por su administración y, en consecuencia, resultarían afectados sus verdaderos intereses. Este argumento se fortalece con el hecho de que, tras perder San Román la querella, el gobierno ixtapense elaboró años después, en 1956, el reglamento del Comité de Administración del balneario, con lo cual quedó como administrador formal tanto de los manantiales como de las recaudaciones por su uso, lo que le significó importantes ingresos adicionales respecto al monto que recibía por concepto de presupuesto federal y estatal (Ricaurte, 2001, pp. 90-91, 102; LRDA).

Se infiere que otro factor que influyó en que la solicitud de San Román Chávez no prospera fue que el gobernador calculó las repercusiones sociales de dar marcha atrás a las disposiciones que él mismo había decretado, lo cual contravendría sus objetivos políticos, por lo que decidió no respaldar, al menos en este caso, el propósito del empresario. Sin embargo, este ya había iniciado su juego político para beneficiarse de una acción más redituable que le garantizaría el monopolio de la oferta turística: la concesión de las aguas termales de San Gaspar.

\subsection{La concesión de las aguas termales de San Gaspar}

Al perder la disputa legal sobre los borbollones de Santa Catarina, Arturo San Román no pudo extender su oferta turística, ni acumular más riqueza y poder, pues el gobierno municipal es, hasta la fecha, el administrador de esos manantiales y los pobladores son los beneficiarios de su uso, aunque no de manera exclusiva, ya que, al construirse el balneario municipal en ese lugar, está abierto al público en general.

No obstante, el empresario tuvo éxito al obtener la concesión de arrendamiento del balneario de San Gaspar, que estaba en manos de José Reynoso, quien disponía de recursos financieros, políticos y normativos, pero que resultaron insuficientes comparados con los de San Román. El hecho de que Reynoso perdiera poderío en este curso de acción respecto al anterior corrobora que las redes no son idénticas en un proceso que en otro ante la diferencia de recursos de sus actores (Bressers, 1998, p. 85). 
No existen soportes documentales ni testimoniales de que Reynoso haya puesto algún tipo de resistencia frente a tal disposición que evidentemente le afectó, por lo que sus objetivos e intereses no resultaron compatibles con los de San Román ni con los del gobernador que apoyó al empresario, de ahí que fuera nula la cooperación entre el mandatario y José Reynoso, quien a su vez tampoco la tuvo con San Román ni con el pueblo.

A pesar de este triunfo de San Román, el más importante fue cuando gracias a sus relaciones con el gobernador Isidro Fabela (LRDA) obtuvo además la concesión de las aguas termales de San Gaspar, pues a partir de la explotación de este recurso amasó la fortuna que hoy en día administra su familia y que le permitió a él primero y luego a sus descendientes influir en el perfil turístico de Ixtapan de la Sal, al consolidar su emporio.

Una versión sobre el motivo de su influencia es que "por haber sido un importante 'talamontes' o maderero nacional, Arturo A. San Román estableció vínculos con la entonces Secretaría de Agricultura” (LRDA). A esta institución le correspondía legalmente otorgar la concesión de aguas termales, aunque, en la práctica, tal facultad la ejercía el presidente, en ese entonces Manuel Ávila Camacho. Se infiere que el gobernador Isidro Fabela intercedió ante su amigo el presidente a favor del empresario, quien a cambio de obtener este beneficio apoyaría directamente el proyecto del mandatario estatal, por lo cual fue alta la compatibilidad de objetivos e intereses de ambos, al igual que su cooperación.

El hecho de que el empresario estuviera a expensas de la intercesión de Fabela para ser favorecido con las aguas termales de San Gaspar hizo que dependiera de manera importante del Ejecutivo estatal, quien presuntamente habría exhibido una mediana dependencia por los supuestos beneficios económicos que obtuvo del empresario:

"Con dinero baila el perro" y así Isidro Fabela le concedió a Arturo Alfredo San Román Chávez la franquicia de explotación de las aguas termales de San Gaspar [LRDA].

Por lo tanto, los objetivos e intereses de ese particular tuvieron nula compatibilidad con los del gobierno municipal, que así dejó de administrar de forma definitiva el balneario que antes arrendaba; tampoco fueron afines con los del pueblo, el cual debió soportar una vez más que personas ajenas a la comunidad resultaran favorecidas con los mejores borbollones. Por consecuencia, los intereses de los ixtapenses y del ayuntamiento también se contrapusieron de algún modo con los de Fabela, que por una parte los benefició con la disposición correspondiente a los manantiales de Santa Catarina, pero no así en ese caso; esto refuerza lo que ya se había expuesto respecto a que sus intereses tuvieron una compatibilidad media.

En este marco, el gobernador puso nuevamente en juego sus altos recursos políticos, normativos, humanos y de información para favorecer al patriarca de los San Román, quien a su vez ejerció los suyos en materia financiera, política, humana y de información para obtener tal beneficio, que al ser de carácter normativo acrecentó sus recursos. Según Ricaurte (2000), esa concesión representa un monopolio sostenido mediante mecanismos de poder e influencia económica. 


\section{G. Cruz Jiménez · C. Cadena Inostroza}

Ya con la concesión de los borbollones de San Gaspar y luego de construir los inmuebles turísticos que le permitirían consolidar sus intereses, Arturo San Román necesitaba más apoyo y lo recibió una vez más de Isidro Fabela, quien recurrió a su fortaleza política al inaugurar el hotel, el balneario y el spa del inversionista. Aunque no está claro el tipo de apoyo que le brindó el mandatario estatal, se infiere que fue económico y político, acorde con los intereses del empresario, quien resultó el mayor beneficiado con las acciones emanadas del sector público.

El atractivo más importante en la localidad era su balneario, complementado por los servicios de hospedaje y del spa, que recibieron mayor afluencia gracias a la carretera federal Toluca-Ixtapan, cuyo funcionamiento en 1945 estuvo aparejado al decreto de Ixtapan de la Sal como zona turística, emanado también de la administración de Fabela. De acuerdo con Hernández (1998, p. 82), este vinculó el quehacer estatal con el proyecto económico nacional, y una de las acciones que puso en marcha para avanzar hacia ese fin fue su programa de carreteras.

A decir de los pobladores, San Román Chávez hizo una significativa aportación económica para la carretera con el propósito de fomentar el turismo hacia su hotel y balneario (Ricaurte, 2000, p. 83). Petronio Valencia Arizmendi (PVA), subdirector municipal de Turismo, señaló que previamente el empresario promovió la plantación de sauces llorones por donde después cruzó esta vía. ${ }^{2}$ De esa serie de acciones queda de manifiesto que aun cuando en cierto momento el objetivo del empresario resultó afectado por los decretos que evitaban la concesión de los borbollones de Santa Catarina a particulares, el respaldo que recibió posteriormente por parte de los gobiernos estatal y federal superaron en mucho las pérdidas por aquellas disposiciones oficiales.

De acuerdo con Luis Enrique Morán Noreña (LEMN), administrador de Bungalows Lolita; Benjamín Sotelo Domínguez (BSD), subgerente general de Hotel Villa Vergel, y PVA, ese beneficio le permitió allegarse de recursos políticos al vincularse con personajes de ese ámbito, sin que esté claro el origen de esas relaciones, presuntamente fomentadas con las casas que obsequió a gobernadores y presidentes.

El sentir de una parte de los prestadores de servicios sobre su actuación en la localidad se refleja en las palabras del propietario de un hotel de mediana categoría:

A él le debemos que Ixtapan esté así (en referencia a su perfil turístico); ahora los prestadores "cosechan lo que él sembró" [BSD].

El empresario murió en 1977 y con él aquel turismo de salud y descanso que promovió. Sus hijos Arturo y Roberto San Román Widerkehr, quienes ya también fallecieron, recibieron en herencia el balneario y el Hotel Ixtapan, respectivamente. El primero impulsó el parque acuático, hasta convertirlo en uno de los diez más importantes en el ámbito internacional y el principal motivo de visita a la localidad. El segundo participó de la tendencia

2 San Román Chávez fundó la Escuela de Arboricultura Práctica, donde se estableció el sistema de internado para alumnos de distintos municipios, cuyo primer fruto fue precisamente la mayoría de los árboles sembrados en ambos lados de la vialidad hasta llegar al municipio de Metepec (Guadarrama, 2004). 
hacia el turismo de negocios y con uno de sus herederos promovió la construcción del fraccionamiento turístico residencial Country Club Gran Reserva. Como impacto directo de todo ello, se transformó el perfil socioeconómico de la población (Ricaurte, 2000), hecho que corresponde a la segunda etapa de su desarrollo turístico (de 1980 a la fecha).

\section{Resultados}

El turismo, una de las principales actividades en Ixtapan de la Sal, fue el eje común en torno al cual convergieron, durante los dos cursos de acción abordados, personajes que definieron de manera individual o como grupos de interés sus objetivos, que no necesariamente estuvieron relacionados con esta actividad, pues en algunos casos más bien obedecieron a satisfacer -por medio de ella- sus intereses en particular de naturaleza política y de predominio económico; este último no en un sentido exclusivo de generar dividendos financieros, sino supremacía en el establecimiento de cotos de poder. Sin embargo, la consolidación de esos objetivos e intereses fueron los que finalmente moldearon el actual perfil turístico de Ixtapan de la Sal.

Tal complejidad de relaciones e interrelaciones entre unos y otros actores propició la formación de un red de política pública que se transformó de un curso de acción a otro y en la cual los intereses de sus participantes motivaron su actuación, así como las estrategias que desplegaron como parte de su juego político, entre ellas relaciones de cooperación con otros personajes con los que en ocasiones sus objetivos e intereses no convergieron por completo, pero que, al no contraponerse, pudieron establecer un vínculo que los benefició en forma recíproca, a veces en perjuicio de otros actores, no necesariamente los más débiles, aunque en términos generales así fue.

En los años treinta, una década antes del despegue turístico en Ixtapan de la Sal, el ayuntamiento estaba prácticamente relegado y subordinado a las políticas provenientes de los ámbitos federal y estatal, panorama que se mantuvo por años, sin que en la época actual el gobierno municipal haya logrado una verdadera autonomía, ni en lo financiero, ni respecto a la toma de decisiones, tanto en materia turística, como en lo general.

En la década de los cuarenta, la figura presidencial ejercía un papel predominante que se refleja en la red y que tuvo repercusiones vinculadas con el turismo; el ejemplo más representativo fue la concesión de aguas termales que obtuvo Arturo San Román Chávez, gracias a la intercesión del gobernador Isidro Fabela ante el presidente Manuel Ávila Camacho.

Aquí se corrobora el hecho de que la autoridad pública no ejerció su predominio para delinear políticas a favor del turismo, sino para propiciar las condiciones que permitieran a un particular iniciar, a partir de la explotación de las aguas termales, lo que más tarde se convertiría en un emporio.

Asimismo, prevalecieron asimetrías de poder entre los sectores público, social y privado en Ixtapan de la Sal, debido a que desde su inicio hubo condiciones de inequidad respecto a los intereses que estuvieron en juego a lo largo del periodo analizado. Esa condición obedeció a que no hubo un balance real en la participación y decisión de los 


\section{G. Cruz Jiménez · C. Cadena Inostroza}

integrantes de esos sectores y, por lo tanto, sus intereses no estuvieron representados de manera equitativa, lo cual condujo al desequilibrio en la toma de decisiones que favoreció a los más poderosos. Lo ocurrido en los cursos de acción examinados en esta primera etapa de desarrollo turístico siguió teniendo la misma lógica en la conducción gubernamental en las décadas posteriores y prevalece en la actualidad, cuestionan Vicente Lagunas Madrid, gerente de Villas de Belem; Enrique Pérez Nájera (EPN), gerente del Hotel Belisana; Javier Madrid Hernández (JMH), expresidente del Comité Ejecutivo Municipal del Partido de la Revolución Democrática; y Julio César Sergio Becerril (JCSB), excandidato a la alcaldía por el Partido Acción Nacional.

En ese sentido, otra de las mayores ventajas que obtuvo la familia San Román fue la concesión de la mayor parte del agua potable, cuyo volumen sobrepasa incluso la que recibe el gobierno municipal para abastecer a la población (incluidos los prestadores de servicios), lo cual le ha supuesto ventajas, en especial en época de sequía, que coincide con la temporada vacacional, según testimonios de Fidel López Ronces (FLR), exdirector del Organismo Público Descentralizado de Carácter Municipal para la Prestación de los Servicios de Agua Potable, Alcantarillado y Saneamiento de Ixtapan de la Sal (Odapas); Juan Morales Álvarez (JMA), auxiliar de Odapas; y Víctor Manuel Rodea Ruiz (VMRR), exdirector de Del Rey Inn Ixtapan de la Sal.

En suma, los actores que desplieguen un juego político basado en la compatibilidad de objetivos e intereses con otros integrantes, dispongan de mayores y mejores recursos, establezcan relaciones de cooperación que en su conjunto les permita desarrollar interacciones fuertes en la red, tendrán mayores posibilidades de influir en la orientación del proceso decisorio y, en consecuencia, podrán consolidar cierta política a su favor (Cruz, Serrano-Barquín y Zizumbo, 2010), como ocurrió en el caso de estudio.

En las figuras 1 y 2 se representa la red de política pública que se formó respectivamente en los cursos de acción "El arrendamiento del balneario de San Gaspar" y "La confrontación por las aguas termales". En ellos se aprecia cómo se transformó entre uno y otro curso, al integrar a diferentes actores, quienes ocuparon una posición en la red dependiendo de su influencia durante el proceso decisorio. También se observan las relaciones o inexistencia de ellas entre sus integrantes, al igual que la intensidad de su vínculo, sea negativo o positivo, de acuerdo con los intereses que se jugaron. 


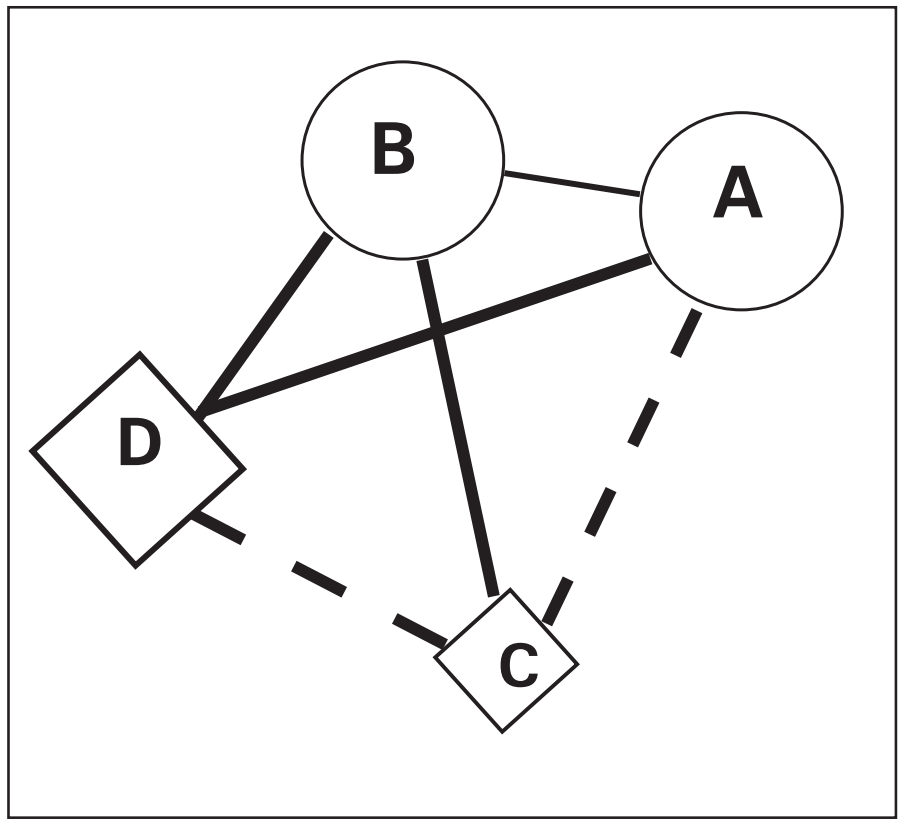

Fuente: Elaboración propia con base en la información de las variables analizadas

\section{Actores participantes en la red} de política pública:

A Filiberto Gómez, gobernador del Estado de México (1929-1933);

B Gobierno municipal 1932;

C Erasmo Hernández, arrendatario del balneario de San Gaspar;

D José Reynoso, arrendatario del balneario de San Gaspar.
Sectores en la red:

Público<smiles>c1ccccc1</smiles>

Privado

Tipo e intensidad de la relación:

Alta positiva

Alta negativa $\mathbf{-}-\boldsymbol{-}-\boldsymbol{-}$

Media positiva

Influencia de los actores en la red:

Influencia mediana<smiles>C1CCCCCC1</smiles><smiles>C1CC2CCC12</smiles>

Influencia baja

Figura 1. Red de política pública "El arrendamiento del balneario de San Gaspar" 


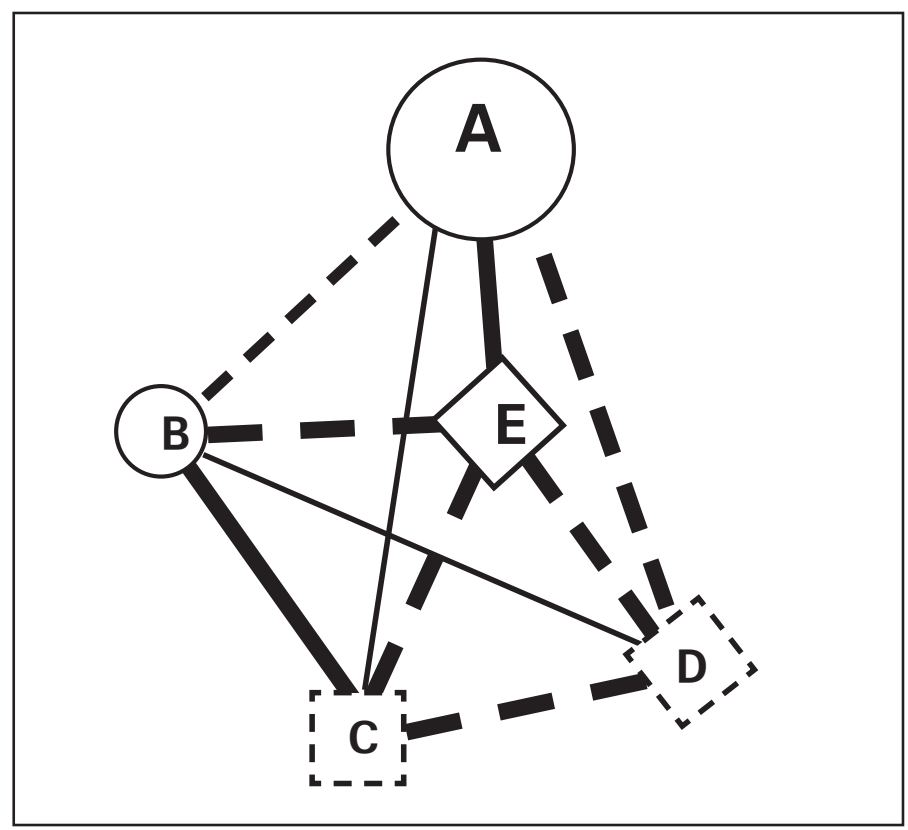

Fuente: Elaboración propia con base en la información de las variables analizadas

\section{Actores participantes} en la red de política pública:

A Isidro Fabela, gobernador del Estado de México (1942-1945);

B Gobierno municipal 1944;

C Pueblo de Ixtapan de la Sal;

D José Reynoso, arrendatario del balneario de San Gaspar en 1932;

E Arturo Alfredo San Román Chávez, arrendatario del balneario de San Gaspar y concesionario de las aguas termales de San Gaspar en 1947.

\section{Sectores en la red:}

Público $\bigcirc$ Social

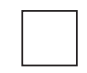

Privado

Tipo e intensidad de la relación:

Alta positiva

Alta negativa

Media positiva

Influencia de los actores en la red:

Influencia mediana

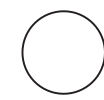

Influencia baja

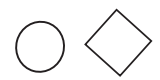

Influencia nula

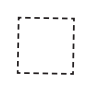

Figura 2. Red de política pública "La confrontación por las aguas termales" 


\section{Conclusiones}

Los supuestos teóricos del ERPP dieron posibilidades de abordar una realidad a partir de un complejo entramado de relaciones entre actores pertenecientes a diferentes sectores, cuya influencia contribuyó en gran medida a delinear el perfil turístico de Ixtapan de la Sal, donde fueron decisivos los dos primeros cursos de acción correspondientes a la primera etapa de su desarrollo en esta materia.

No obstante, el propio enfoque representa un desafío metodológico al ser limitada la producción académica en México sobre casos empíricos, en particular vinculados con el turismo, aunque paulatinamente se aprecian mayores esfuerzos en este sentido. Un aspecto más de este reto es que por ser las relaciones las que dan sustento a tal enfoque, su análisis para el caso abordado tuvo ciertas limitantes ante la ausencia física de los protagonistas del turismo en esa época.

El hecho de recurrir a otros personajes que aportaran su testimonio o la búsqueda documental podría hacer la información propensa a la subjetividad, lo que conlleva el riesgo de interpretaciones erróneas y, por ende, distorsionadas acerca de los hechos abordados; pese a ello, cuestiones como estas deben afrontarse para ampliar el panorama sobre los habituales estudios sustentados en aspectos lineales.

Cabe resaltar que, a pesar del uso de matrices relacionales, el resultado cuantitativo no siempre fue el más fiel a la realidad. Si bien el o los personajes que obtuvieron los puntajes más altos debieron ser interpretados en un primer momento como los más importantes en la red y, por tanto, los que ejercieron mayor influencia, no siempre fue así. Sus vastos recursos, nula o mínima conflictividad con otros participantes, fueron variables que les dieron un alto puntaje, aunque en realidad no hayan ejercido el mayor predominio.

De hecho, aquel que fue más influyente, no en términos cuantitativos sino reales, observó una marcada conflictividad con otros porque, como parte de su juego político, desplegó estrategias para hacer valer sus intereses muchas veces a costa del resto. No obstante, y como se argumentó a lo largo del documento y se constata en la representación gráfica de las redes correspondientes a los cursos de acción analizados, la constante en ambos fue la representación asimétrica de los distintos sectores y, en consecuencia, en la toma de decisiones.

Porras (2016, p. 91) argumenta que cuando las redes de política pública se conforman por actores o instituciones provenientes de varios sectores como del gobierno, la sociedad organizada o los mercados, y adquieren cierta capacidad para resistir las directrices del Estado, pueden ser consideradas redes de gobernanza (lo cual no sucedió en estos casos).

Son precisamente enfoques como el de la gobernanza los que también pueden apoyar análisis de naturaleza turística, actividad que por su multidimensionalidad, en ocasiones las políticas convencionales no alcanzan a darle respuesta. En este sentido se integran capacidades no gubernamentales en una nueva forma de gobernar, donde se observa la existencia de agentes privados, sociales y comunitarios capaces de autorregularse y resolver sus problemas. 


\section{G. Cruz Jiménez · C. Cadena Inostroza}

La gobernanza permite reflexionar sobre la participación local en el diseño, implementación y evaluación de las políticas públicas que conciernen al turismo (Roldán, Corbo y Castellucci, 2017, p. 17). Por tanto, en la medida en que sea posible la incorporación de los diferentes actores en un esquema equilibrado de participación, mayores serán las posibilidades de promover una práctica turística más efectiva.

\section{Fuentes consultadas}

Aguilar, L. (1992). Problemas públicos y agenda de gobierno. Estudio introductorio y edición (Antologías de Política Pública). México: Miguel Ángel Porrúa.

Aguilar, L. (2003). El estudio de las políticas públicas. Estudio introductorio y edición (Antologías de Política Pública). México: Miguel Ángel Porrúa.

Aguilar, L. (2007). El estudio de las políticas públicas (Antologías de Política Pública). México: Miguel Ángel Porrúa.

Arizmendi, L. (1999a). Monografía Municipal Ixtapan de la Sal, Gobierno del Estado de México. Toluca: Asociación Mexiquense de Cronistas Municipales.

Arizmendi, L. (1999b). Ixtapan de la Sal y su promoción como centro turístico 1945-1995 (Tesis de licenciatura en Turismo). Universidad Autónoma del Estado de México, Toluca.

Becerril, J. (1988). Los recursos geográficos y perspectivas para el desarrollo turístico de Ixtapan de la Sal (Tesis de licenciatura en Geografía). Universidad Autónoma del Estado de México, Toluca.

Bressers, H. (1998). The choice of policy instruments in policy networks. En D. Marsh, Comparing Policy Networks (pp. 85-105). Filadelfia: Open University Press.

Cadena, C. y Cruz, G. (2006). Políticas públicas municipales, relación de actores y desarrollo turístico en dos localidades del Estado de México (Documentos de Investigación, 113). Zinacantepec: El Colegio Mexiquense.

Castillo, R. (1995). Caracterización de la demanda turística que fluye al poblado de Ixtapan de la Sal (Tesis de licenciatura en Turismo). Universidad Autónoma del Estado de México, Toluca.

Cruz, G. (2014). El turismo como punto de conflicto y acuerdo en las redes de política pública. El caso de Ixtapan de la Sal, Estado de México. Zinacantepec: El Colegio Mexiquense.

Cruz, G., Serrano-Barquín, R. y Zizumbo, L. (2010). Redes de política pública y turismo en San Miguel Almaya. ¿Promotoras o limitantes del desarrollo local? Estudios y Perspectivas en Turismo, XIX(5), 792-811. Recuperado de http:/ / www.redalyc.org/ articulo.oa? id= 180717609012

Cruz, G., Serrano-Barquín, R., Mejía, C., Mejía, L. E. y Reza, J. (2010). Turismo y sustentabilidad; la complejidad del proceso decisorio en San Miguel Almaya. Ra Ximhai, VI(3), 379-392. Recuperado de http://www.revistas.unam.mx/index.php/rxm/article/ view $/ 24594$

Flores, A. (1987). Monografía municipal Ixtapan de la Sal. Toluca: Gobierno del Estado de México. 
Franco, J. (2013). Diseño de políticas públicas. México: IEXE Editorial.

García, J. (2000). Iztapan en el siglo xvı, Ixtapan de la Sal. En Cuadernos Municipales (pp. 31-70). Zinacantepec: El Colegio Mexiquense.

González, A. (2004). El anfitrión como actor social en el turismo. Reflexiones desde el caso de Ixtapan de la Sal, México. Revista de Ciencias Sociales, III(105), 155-168. Recuperado de https://revistacienciassociales.ucr.ac.cr/images/revistas/RCS105/ 10Gonzalez.pdf

Guadarrama. (2004). Arturo San Román. Ixtapan de la Sal, México.

H. Ayuntamiento de Ixtapan de la Sal. (1931). Archivo Histórico Municipal, Ixtapan de la Sal, sección Presidencia, vol. 2, exp. 1. Ixtapan de la Sal, México.

H. Ayuntamiento de Ixtapan de la Sal. (1932). Archivo Histórico Municipal, Ixtapan de la Sal, sección Presidencia, vol. 2, exp. 7. Ixtapan de la Sal, México.

H. Ayuntamiento de Ixtapan de la Sal. (2016). Atlas de Riesgos Municipal. Toluca: Coordinación General de Protección Civil del Estado de México. Recuperado de http:// ixtapandelasal.gob.mx/.../Atlas_IxtapanZdeZlaZSalZ2016...

Hernández, E. (2015). Análisis de redes sociales para el estudio de la gobernanza y las políticas. México: Centro de Investigación y Docencia Económicas.

Hernández, O. (2001). Impactos del boulevard turístico Ixtapan de la Sal Tonatico (Tesis de licenciatura en Turismo). Universidad Autónoma del Estado de México, Toluca.

Hernández, R. (1998). Amistades, compromisos y lealtades: líderes y grupos políticos en el Estado de México, 1942-1993. México: El Colegio de México.

Instituto Nacional de Estadística y Geografía. (2010). Censo de Población y Vivienda 2010. Recuperado de http://www.beta.inegi.org.mx/proyectos/ccpv/2010/

Klijn, E. (1997). Policy networks: An overview. En E. Kickert, E. Klijn y F. M. Koppenjan, Managing Complex Networks. Strategies for the Public Sector (pp. 14-34). Londres: Sage.

Martínez, J. (1997). El esquema laboral del turismo en Ixtapan de la Sal (Tesis de licenciatura en Turismo). Universidad Autónoma del Estado de México, Toluca.

Meny, I. y Thoenig, J. C. (1992). Las políticas públicas. Barcelona: Ariel.

Montecinos, E. (2007). Límites del enfoque de las políticas públicas para definir un problema público. Cuadernos de Administración, XX(33), 323-335. Recuperado de http://www.scielo.org.co/pdf/cadm/v20n33/v20n33a 14.pdf

Porras, F. (2012). Gobernanza y redes de política pública en espacios locales de México. México: Instituto de Investigaciones José María Luis Mora.

Porras, F. (2016). Gobernanza. Propuestas, límites y perspectivas. México: Instituto de Investigaciones José María Luis Mora.

Ricaurte, C. (2000). Sustentabilidad y turismo: el caso de Ixtapan de la Sal. El Periplo Sustentable, 3. Recuperado de www.uaemex.mx/plin/psus/rev3/ceditorial.html

Ricaurte, C. (2001). Turismo, sustentabilidad y gestión local en el municipio de Ixtapan de la Sal (Tesis de maestría en Estudios Socioeconómicos y Físicos del Turismo). Universidad Autónoma del Estado de México, Toluca.

Roldán, N., Corbo, Y. y Castellucci, D. (2017). Una aproximación al estado del arte en gobernanza y turismo, 2010-2015. En G. Cruz (coord.), Turismo y gobernanza. ¿En dónde estamos? Aproximaciones teóricas y empíricas (pp. 15-36). Universidad 


\section{G. Cruz Jiménez · C. Cadena Inostroza}

Autónoma del Estado de México. Recuperado de http://ri.uaemex.mx/handle/20.500.11799/67922

Van Meter, D. y Van Horn, C. (2003). El proceso de implementación de las políticas. Un marco conceptual. En L. Aguilar (ed.), La implementación de las políticas (Colección de Antología de las Políticas Públicas, pp. 99-124). México: Miguel Ángel Porrúa.

Zabaleta, D. (2006). Espacios multiorganizativos de políticas y conformación de redes de políticas en los municipios urbanos mexicanos. El caso de la política de protección y conservación del Centro Histórico de Morelia, Michoacán (Tesis de licenciatura en Administración Pública). El Colegio de México, México. 


\title{
EMPODERAMIENTO FEMENINO Y COMPETITIVIDAD: caso restaurante Tierra y Cielo, en San Cristóbal de Las Casas, Chiapas, México
}

\author{
Carlos Jesús González-Macías \\ cgonzalez@uacj.mx \\ Tomás Jesús Cuevas-Contreras \\ tcuevas@uacj.mx \\ IsABEL ZizALDRA-HERnÁNDEZ \\ izizaldr@uacj.mx \\ Universidad Autónoma de Ciudad Juárez
}

\begin{abstract}
El presente estudio de caso es un análisis de las acciones empresariales de empoderamiento femenino en la propietaria del restaurante Tierra y Cielo, en San Cristóbal de Las Casas. El liderazgo femenino marca su gestión en el establecimiento, al competir a partir de elementos sustentables que contribuyen en lo local-regional. El estudio gira en torno a la perspectiva de género, la competitividad y el desarrollo femenil en el ámbito de la gastronomía. La aproximación al tema es cualitativa, con base en el modelo tridimensional de Rowlands, mediante una entrevista a profundidad a la visionaria culinaria de Chiapas, así como la observación no participante y el sondeo a empleados de la empresa. En cuanto al análisis de los resultados, se realiza mediante el contraste de la tríada dimensional y los rasgos que potencian el empoderamiento femenino, los cuales definen redes semánticas, que puntualizan la evolución del empoderamiento y liderazgo en cuestión.
\end{abstract}

Palabras clave: Empoderamiento, competitividad, restaurante sustentable, estudio de caso, enfoque de género.

\section{FEMININE EMPOWERMENT AND COMPETITIVENESS: THE CASE of the Tierra y Cielo restaurant in San Cristóbal de las Casas, Chiapas, México}

This case study analyzes female empowerment through the entrepreneurial actions implemented by the owner of the Tierra y Cielo restaurant, in San Cristóbal de las Casas. Feminine leadership in this establishment is set by the local and regional competition performed with sustainable elements. The study revolves around gender perspective, competitiveness, and women's development in the field of gastronomy. There is a qualitative approximation to this topic based on Rowlands' three-dimensional model, through an in-depth interview with Chiapas' culinary visionary, as well as a non-participant observation, and questionnaires to the staff. The analysis of results is done by contrasting the dimensional triad and the traits enhancing female empowerment, which define semantic networks and identify the evolution of empowerment and leadership in question.

Keywords: Empowerment; competitiveness; sustainable restaurant; case study; gender focus.

Fecha de recepción: 26 de marzo de 2018. Fecha de aceptación: 11 de junio de 2018

CÓMO CITAR: González-Macías, C., Cuevas-Contreras, T. y Zizaldra-Hernández, I. (2018). Empoderamiento femenino y competitividad: caso restaurante Tierra y Cielo, en San Cristóbal de Las Casas, Chiapas, México. Dimensiones Turísticas, 2(3), 48-74. https://doi. org/10.47557/CLNR7199 


\section{Introducción}

\section{Antecedentes}

La actividad turística se comporta como un sistema complejo donde las propiedades del conjunto son diferentes de la mera suma de las partes, y se caracteriza por su sensibilidad ante fenómenos ajenos a los estrictamente económicos, la heterogeneidad de los servicios que abarca y la intensa interdependencia y amplitud de los sectores implicados directa o indirectamente. "Ya que el turismo no figura como una actividad productiva específica en la Clasificación Nacional de Actividades Económicas, este se encuentra desarrollándose, por tanto, a través de diversos sectores económicos" (Cobo Quesada, Hervé y Aparicio Sánchez, 2009, pp. 429-430), como el de los restaurantes.

Dentro de la actividad turística, el giro de restaurantes es el que más aperturas, traspasos y quiebras genera año con año. En la actualidad, las condiciones que preponderan en el mercado definen un ambiente sumamente competitivo para las empresas, en el cual una de las principales exigencias en la actividad empresarial es profesionalizarse a fin de ofrecer a los clientes, cada vez más conocedores y exigentes, un mejor servicio, calidad y, sobre todo, innovación (Durón, 2012, p. 15).

La industria restaurantera en México capta, en promedio, 28 \% del gasto efectuado por cada turista y visitante, nacional y extranjero, y aporta $3 \%$ al producto interno bruto nacional. Existen en territorio nacional 220000 establecimientos de alimentos y bebidas, de los cuales $4 \%$ pertenece al tipo de franquicia, nacional y transnacional, y el restante $96 \%$ lo conforma el segmento de restaurantes tradicionales (Cámara Nacional de la Industria de Restaurantes y Alimentos Condimentados [Canirac], 2014). "Aunque este segmento genera el $45 \%$ de las ventas totales de la actividad y el $56 \%$ de los empleos, es el más sensible y vulnerable a todos los problemas y movimientos de la economía nacional" (Durón, 2012, p. 5). Como indican Dressler y Varela (2016), todos los restaurantes influyen de manera importante sobre el mercado interno, así como también en el crecimiento económico de México; por ello, los índices de productividad y su impacto en la competitividad del sector toman gran relevancia.

Para lograr el éxito ante los competidores, se requiere desarrollar en los restaurantes habilidades y capacidades de servicio que combinen el sentido común, que muchos de los empresarios poseen, con la colaboración necesaria para alcanzar los resultados deseados al momento de realizar sus actividades; "esta filosofía básica puede resumirse de la siguiente manera: "hacer que las cosas sucedan"” (Franco, 2012, p. 73).

\section{Planteamiento del problema}

Tierra y Cielo, ubicado en la ciudad de San Cristóbal de Las Casas, Chiapas, en México, innova al ser el primer restaurante en el estado en obtener diversos premios, reconocimientos y distinciones de prestigio nacional e internacional. Esto gracias a las acciones realizadas por su propietaria y líder, que ha considerado apoyos para el reforzamiento de 
sus capacidades individuales en términos productivos dentro de la lógica de costo-beneficio (Román, 2000). Es así como se ha manifestado en el trabajo colectivo, al integrar específicamente a los pequeños productores de la comunidad como sus únicos proveedores, y a los integrantes de las comunidades indígenas como sus empleados. Este es su principal eje de acción, de manera que ha establecido una forma de trabajo significativa en el plano local. De tal suerte, resulta necesario el análisis de cómo se han llevado a cabo las actividades en el restaurante, pues en él se destacan elementos del ámbito sustentable, de colaboración y soporte a otras entidades.

Es cierto que esta clase de acciones no son frecuentes cuando se visualiza una operación de venta de alimentos y bebidas, pues resulta más común una gestión tipo occidental (proveedores institucionales, franquicias y cadenas, incorporación de manuales de operación estandarizados, entre otros). De modo que, al considerarse los diferentes actores e interesados en la gastronomía local, estas acciones incorporan un dinamismo inusitado y prácticamente inexistente.

El caso de Tierra y Cielo ofrece una vasta gama de oportunidades de generación de conocimiento para todos aquellos estudiosos del ámbito de la gastronomía con la incorporación de ingredientes locales, así como para el desarrollo de oportunidades para emprendedores con un enfoque diferenciado. Esta nueva forma de la gestión de operaciones en el caso de los restaurantes es significativa, gracias a los rasgos del empoderamiento femenino que se hacen presentes, a diferencia de la visión tradicionalista de dominio masculino, donde la administración de la cocina quedaba en manos homogéneas. Solo hay que recordar a Escoffier y otros más que han dejado su influencia por largo tiempo, desde la cocina francesa hasta la actualidad.

Por otra parte, la gran mayoría de los estudios del fenómeno de la gestión operativa de restaurantes cuenta con un enfoque cuantitativo (costos de operación, relación costo/ beneficio, presupuestos de ventas, etc.), mas no se han realizado estudios que permitan una cualificación de las actividades que se llevan a cabo en el día a día. Estas además influyen en el desarrollo de su actividad, como son estado de ánimo, estilo de liderazgo, percepciones, personalidades, prejuicios, condiciones del entorno, entre otras. De tal forma que esta influencia se encuentra presente en las tres dimensiones de Rowlands (1998) del empoderamiento femenino, identificadas en la propietaria.

Así, se cuestiona, por una parte, ¿cuál es el enfoque entre la competitividad y el empoderamiento que requiere el liderazgo femenino en el ámbito restaurantero?; por otra parte, ¿los procesos y conductas observados por la propietaria condicionan su gestión empresarial? y, además, ¿el liderazgo que ella desempeña es percibido como multifacético?

El objetivo general de la presente investigación dispone analizar las gestiones operativa y empresarial en el restaurante que permiten un nivel de competitividad sustentable a partir del empoderamiento femenino. En tanto, los objetivos específicos son: a) Explorar las acciones que impulsan la competitividad y sustentabilidad en el restaurante; b) Comprender los procesos, conductas y condiciones de la persona frente a las acciones empresariales; y c) Examinar la naturaleza multifacética de las acciones humanas en el liderazgo 


\section{J. González-Macías · T. J. Cuevas-Contreras · I. Zizaldra-Hernández}

femenino. Se destacan tres supuestos: 1. Las acciones de empoderamiento femenino impulsan la competitividad y sustentabilidad; 2. Los procesos y conductas condicionan las acciones empresariales; 3 . El liderazgo femenino es multifacético.

\section{Revisión de literatura}

La revisión se ha enfocado en el empoderamiento femenino, la competitividad y la innovación, y la relación entre ellos. Estas orientaciones permiten el escrutinio como visiones diferenciadas, ya que en el ambiente de la gastronomía ha predominado un punto de vista más masculino. De tal manera, se explora el matiz femíneo.

\subsection{Empoderamiento femenino}

El término empoderamiento femenino se utiliza desde la perspectiva colectiva de desarroIlar un cambio sustancial en la cultura de las sociedades actuales, sobre todo cuando se relaciona a la mujer con el uso del poder (León, 2007). De acuerdo con Erazo, Jiménez y López (2014, p .150):

El concepto sociopolítico de empowerment o empoderamiento se originó en Estados Unidos, durante los años sesenta, en los movimientos de derechos civiles, vinculados a ideologías sociales y políticas que revelan una opresión y reclaman la equidad y responde a las necesidades de generar cambios dentro de las relaciones de poder entre géneros.

El empoderamiento también puede entenderse como todo aquel proceso por el cual todos aquellos que no han tenido la oportunidad de tomar decisiones de vida estratégicas adquieren tal capacidad (Kabeer, 1999, p. 440). Para Montero (2003), el empoderamiento se presenta como ese proceso donde aquellas personas pertenecientes a una comunidad desarrollan de manera conjunta capacidades y recursos, propios y compartidos, para controlar su situación de vida, llevándolo a cabo de manera comprometida, consciente y crítica, transformando su entorno de acuerdo con la satisfacción de sus necesidades y aspiraciones, al mismo tiempo que se transforman a sí mismos.

Ahora bien, se debe incorporar a las mujeres como parte del necesario desarrollo de toda comunidad, fortaleciéndoles y favoreciéndoles el empoderamiento, ya que este concepto comprende no solo el proceso, sino también el resultado en el cual las mujeres obtienen un mayor control sobre los recursos intelectuales y materiales, desafiando con ello a la férrea ideología del patriarcado y la discriminación por género, que limita las oportunidades de las mujeres para tener acceso y desarrollarse en igualdad de condiciones en diversos ámbitos: político, social, económico y cultural, entre otros (Vázquez-Luna, Mortera, Rodríguez-Orozco, Martínez y Velázquez, 2013; Camberos, 2011; Casique, 2010). Si bien el empoderamiento ha sido una tendencia masculina entre el poder y la violencia, ahora en los países desarrollados esta idea sucumbe ante el movimiento feminista orientado a un marco capitalista equilibrado, 
fomentando a través de él la participación activa y formal de las mujeres en la economía (Lino, 2013; Buendía-Martínez y Carrasco, 2013; Matthaei, 2010).

Por lo anterior, el empoderamiento femenino es producto de una evolución personal experimentada por la mujer. Dentro de este nuevo contexto global permeado de influencias de diversos universos culturales, la mujer posee el derecho de empoderarse a sí misma. Ya no le es posible entender el hecho de dar poder a otras personas sin que sea aceptado el hecho de que ella también puede detentar ese poder. La mujer logra, entonces, un verdadero empoderamiento, plenamente reconocido dentro de la estructura social en la cual interactúa y que, por ende, la valora (Sáez, Valor-Segura y Expósito, 2012).

A pesar de que para la mujer ha sido difícil conseguir tal reconocimiento de su derecho de empoderarse, sí se ha podido abrir espacios y darse posibilidades para que este proceso se lleve a cabo; de ahí la importancia de crear conciencia de la discriminación de género y del compromiso de las organizaciones como agentes facilitadores de este (Zapata, Townsend, Rowlands, Alberti y Mercado, 2002).

Ante este entorno existen distintos ejemplos de empoderamiento (Erazo, Jiménez y López, 2014; Zapata et al., 2002) que afirman que la autogestión comunitaria ha sido exitosa a través del aprovechamiento de los recursos de los cuales dispone y desarrolla la mujer, que han marcado la diferencia entre el enfoque masculino. Luego entonces, su intervención social no es solo la antesala del equilibrio que debe de existir en la gestión empresarial.

En el presente estudio de caso se incorpora el concepto de empoderamiento femenino desarrollado por Rowlands (1998), quien distingue entre condición y posición de las personas y establece qué condición se refiere al estado material en el cual se encuentran: su condición económica, su nivel de educación y capacitación, su carga de trabajo, su acceso a la tecnología, y la posición supuesta de la ubicación social y económica de las mujeres respecto a los hombres.

Con base en su planteamiento, Rowlands (1997) define el empoderamiento como todo ese conjunto de procesos psicológicos que cuando se presentan y son desarrollados por la persona o el grupo los capacitan para desenvolverse y actuar dentro de su entorno de una manera en la cual su acceso al poder se incrementa y los posibilita a utilizarlo en varias formas. En este mismo orden de ideas, amplía la definición del concepto al resumir:

el empoderamiento es un conjunto de procesos que pueden ser vistos en las dimensiones individual, colectiva y de las relaciones cercanas, centrado alrededor del núcleo de desarrollo de confianza, la autoestima, el sentido de la capacidad individual o grupal para realizar acciones de cambio y la dignidad [Rowlands, 1996, p. 230].

Por otra parte, plantea que los intereses de las personas no son homogéneos y determina la diferencia entre intereses prácticos y estratégicos. Los primeros corresponden a los que se derivan del hecho de que a las mujeres les son asignados ciertos roles por la división sexual del trabajo y normas hegemónicas de género (por ejemplo, educación, pobreza, entre otros), mientras que los segundos tienen como fin cambiar la subordinación de la mujer (su ubicación social), buscando una sociedad más igualitaria. Rowlands acota 
que para que estos últimos intereses puedan ser abordados "es necesario ver las dinámicas de poder de género" (1998, p. 214).

La autora en cuestión crea un modelo a partir de las dinámicas de poder de género: "poder sobre", que es la habilidad para que una persona o un grupo haga algo en contra de sus deseos, esto es, un poder de suma negativa: para que uno gane, el otro debe perder. El segundo es un "poder para", que es el poder que tienen las personas para estimular las actividades de otros; luego, el "poder con", un poder sumatorio de poderes individuales; y, finalmente, el "poder desde dentro", aquel que reside en cada individuo; estas tres últimas clases las denomina de suma positiva, donde todos los involucrados ganan.

A partir de los argumentos anteriores, se deduce que el empoderamiento femenino puede ser modificado en tres dimensiones: la dimensión personal, que consiste en desarrollar el sentido del ser, la confianza y las capacidades individuales; la dimensión de las relaciones cercanas, relativa a desarrollar la habilidad para negociar e influenciar la naturaleza de las relaciones del ámbito cotidiano; y la dimensión colectiva, donde se trabaja en conjunto con otros para lograr un mayor impacto y cambios significativos.

El empoderamiento femenino, asimismo, debe ser más que la simple apertura al acceso para la toma de decisiones, debe incluir también procesos que permitan a las mujeres tener la capacidad de percibirse a sí mismas como aptas para ocupar los espacios de toma de decisiones y usar esos espacios de manera efectiva. Así, los procesos de autogestión se encauzan y dirigen sus esfuerzos a desarrollar una lucha contra el paternalismo, edificando entonces, sobre las fuerzas ya de por sí existentes en la persona o grupo social, todas sus capacidades para "potenciarlas" y aumentar las fuerzas preexistentes (Erazo et al., 2014).

\subsection{Competitividad e innovación}

La competitividad puede entenderse como todos aquellos resultados provenientes de la creación y desarrollo de innovaciones y procesos tecnológicos de los actores protagonistas que se desenvuelven dentro de un determinado contexto, llámense estos empresas, instituciones u organizaciones, las cuales permanecen ligadas a las actividades de transformación técnica u organizacional (Bianco, 2007). Debido a esto, los encargados de las empresas deben estar siempre a la vanguardia de la información y procedimientos para sobresalir competitivamente en el mercado. Según Manucci (2010, p. 95):

la competitividad es el resultado de un juego de posiciones y movimientos necesarios para mantener el protagonismo (personal, grupal o corporativo) en la dinámica del entorno actual. No tiene que ver con la fuerza, el tamaño o el poder material, sino con la capacidad de interacción para ser percibidos y valorados en el contexto de actores volátiles y reglas del juego variables.

Los aspectos que conforman el conocimiento en las empresas ponen de manifiesto que todos aquellos atributos importantes, tales como la flexibilidad y la capacidad innovadora que se crean y desarrollan dentro de ellas, se visualizan en la actualidad como prioritarios y esenciales para generar competitividad en los mercados (La Rovere y Hasenclever, 
2010). Lo anterior tiene su razón de ser debido a que los negocios familiares conforman el grupo predominante de empresas que contribuyen significativamente a la creación de empleos, a la generación de ingresos y a satisfacer necesidades en ciertos mercados que son poco atractivos para las grandes organizaciones (Hernani y Hamann, 2013).

Dentro de esta conceptualización, destacan las aportaciones de Porter (1990, 2004), quien define la competitividad sobre la base de las ventajas competitivas mediante un "diamante" dinámico, determinado tanto por las condiciones de oferta, demanda, estructura de las propias empresas y su entorno, como por las relaciones con sus proveedores y clientes.

Porter (1985) explica cómo una empresa puede crear y sostener una ventaja competitiva que le dé diferenciación, con la cual buscará que su producto o servicio sea percibido como algo "único" en las distintas dimensiones que son valoradas por los posibles clientes. Afirma que la estrategia de diferenciación le da a la empresa habilidades y recursos necesarios mediante una gran aptitud para la comercialización e ingeniería del producto, además de un instinto creativo e innovador.

La Rovere y Hasenclever (2010) mencionan que el debate sobre la capacidad innovadora de las empresas familiares surge del hecho de que ellas son diferentes al respecto, ya que tal capacidad no es fácilmente adquirida debido al carácter tácito, acumulativo y localizado del conocimiento técnico y científico que se debe generar. Por ello es necesario para la empresa utilizar el proceso de aprendizaje para la toma de decisiones como estrategia fundamental en la adquisición de conocimiento y la construcción de ventajas que la ayuden a ser competitiva en el mediano y largo plazo (Pérez y Cortés, 2007).

El estudio de la competitividad de las empresas familiares ha sido aproximado, según Saldívar González, García Rivera, Valenciana Moreno y Roa Rivera (2012), desde dos enfoques. Primero, desde el externo: el entorno macroeconómico, donde las empresas tienen poca injerencia en la solución de la problemática que enfrentan, dado que no han podido desarrollar una capacidad de reacción competitiva, pues los recursos que poseen son escasos. Segundo, desde el interno: todos los problemas derivados de la propia gestión de las empresas y del sector económico al que pertenecen y en el que compiten. De acuerdo con Millán y Marín (2014), existe una estrecha relación entre la competitividad y las decisiones que se toman, debido al impacto en todos los involucrados y cómo abordan las cuestiones prioritarias para la empresa.

\subsection{Empoderamiento femenino y competitividad}

Al relacionar el empoderamiento femenino de Rowlands (1998) con la competitividad descrita por Porter (1990), se observa que las líneas teóricas de estas variables conciben a la gestión empresarial realizada por una mujer como un activo valioso, pero protegerlo dentro de la empresa se torna complicado. Como en cualquier persona, cuando esta permanece en la empresa el activo también, pero al irse a su casa se lo lleva, reservándoselo para sí misma. 
En la actualidad, cada vez es más común recurrir al concepto de empoderamiento con referencia a la mujer, por ello, el tipo de gestión y el liderazgo relacionados con el fenómeno de estudio se orientan a permitir el acceso de las mujeres a los recursos y a la toma de decisiones, tanto individuales como colectivas, y a conseguir que ellas se perciban a sí mismas capaces y legítimas para ocupar un espacio en la toma de decisiones (Erazo et al., 2014).

Sin embargo, los factores que componen las dimensiones del empoderamiento en el entorno de la empresa, ya sea interno o externo, son, por naturaleza, inciertos. Empero, si estos se tratan de forma concreta como un activo de ella, le proporcionarán certeza, volviéndose un apoyo para tomar riesgos con menor incertidumbre, y ayudándole a enfocar sus habilidades en innovar y permanecer competitiva. De ese modo, tales factores se convierten en activos intangibles y deben ser valorados a la par de los activos materiales de la empresa, ya que le brindan ventajas competitivas importantes.

El empoderamiento de una mujer empresaria, según Hernani y Hamann (2013), se fundamenta en la creación de valor por medio de actividades que promuevan el uso y aprovechamiento de tecnologías disponibles y un enfoque en el desarrollo económico, ambos encaminados a un mejor posicionamiento competitivo. Los acuerdos de cooperación que ella promueva entre los involucrados responden a la importancia general de este tipo de estrategias en el mundo empresarial. La cooperación adquiere incluso mayor relevancia en las empresas, debido a su clara naturaleza sistémica, donde todos los agentes intervienen

y deben unir esfuerzos para lograr un mejor servicio y la satisfacción final del cliente (Cobo Quesada et al., 2009).

\subsection{Contexto de San Cristóbal de Las Casas, Chiapas, México}

La frontera sur de México se encuentra comprendida en un territorio de aproximadamente 965 kilómetros. La apertura comercial México-Centroamérica, en lo que se refiere a su estructura productiva del sector rural de Chiapas, ha tenido efectos de alcance en el mediano y largo plazo que han podido modificar la estructura agrícola. El acercamiento de México al istmo centroamericano ha constituido una posibilidad para el desarrollo de las economías (Villafuerte, 2011).

Las principales ciudades son Tuxtla Gutiérrez, Tapachula de Córdova y Ordóñez, San Cristóbal de Las Casas, Ocosingo, Comitán de Domínguez y Palenque. Cabe puntualizarse que el fenómeno de la pobreza alimentaria en Chiapas se extiende en una amplia franja de municipios rurales cuya población se halla dispersa en el territorio. Tal como lo señala el diagnóstico gubernamental:

La pobreza se encuentra mayormente extendida en las zonas rurales que urbanas, ocho de cada diez chiapanecos en poblaciones rurales se encuentran en pobreza extrema, cuyo gasto en consumo es inferior a la línea de pobreza alimentaria o canasta básica, mientras que en las zonas urbanas la cifra es de cinco pobres por cada diez habitantes [Centro de Estudios para el Desarrollo Municipal y Políticas Públicas, 2014]. 
Aunado al grado de dispersión poblacional presente en la entidad, su accidentada orografía dificulta la adecuada provisión de servicios básicos, como agua, drenaje y electricidad, hecho que sin duda afecta principalmente a las localidades rurales, pero que ocurre de igual manera en las principales poblaciones, como Tuxtla Gutiérrez y San Cristóbal de Las Casas, las cuales muestran bajos grados de marginación, a diferencia del resto de la entidad. Por otra parte, un segmento importante de los habitantes de estas localidades dispersas en el territorio está formado por diferentes grupos étnicos, que históricamente han padecido graves rezagos en educación, salud, alimentación, y viven en situaciones de exclusión social.

Comitán de Domínguez, San Cristóbal de Las Casas, Tapachula y Tuxtla Gutiérrez han funcionado como ejes del desarrollo regional en Chiapas, y desde la década de 1990 han venido experimentando un crecimiento más rápido que el resto de las poblaciones de la entidad, lo cual ha traído consigo problemas asociados con la concentración poblacional urbana: competencia por el espacio, alto índice de especulación del suelo, deterioro ambiental y proliferación de asentamientos irregulares.

Es decir, el crecimiento demográfico de San Cristóbal de Las Casas se disparó durante la década de 1970; su población creció a una tasa media anual de 5.04\% entre 1970 y 1980, se incrementó a 5.7 en el decenio 1980-1990, y su ritmo se aceleró en el periodo 1995-2010, cuando la principal ciudad de los Altos de Chiapas creció a una tasa media anual de $6.22 \%$ (Instituto Nacional de Estadística y Geografía, 2015), hasta llegar a concentrar 166460 habitantes.

Esta tendencia de la urbanización de San Cristóbal se explica en gran medida por el aumento de actividades ligadas a los servicios para el turismo, la expansión de la burocracia gubernamental, y la creación de centros de investigación y de educación superior en los últimos 40 años, según el Instituto de Población y Ciudades Rurales (2013). Asimismo, San Cristóbal de Las Casas exhibe un rango de complejidad urbana mayor que el resto de las ciudades importantes del estado, cuya tendencia de crecimiento es bastante moderada.

De acuerdo con la Canirac (2014): “En materia de empleo el sector de alojamiento temporal y de preparación de alimentos y bebidas (Sector 72) continúa siendo el sector líder en generación de empleo y autoempleo dentro de los servicios no financieros". En este sentido, la Canirac indica que la actividad restaurantera en Chiapas se encuentra representada por 19052 establecimientos, lo que significa $3.7 \%$ del total nacional.

De los restaurantes en San Cristóbal de Las Casas, el dato contemplado es del giro de alimentos, el cual representa un total de 212 establecimientos. Pero para efectos de la orientación del manuscrito, no se tuvieron en cuenta: taquerías y torterías, bares, piano bar, discotecas y salones de baile. En el cuadro 1 se consideran 184 establecimientos.

Tierra y Cielo forma parte del $65 \%$ de los establecimientos ubicados en el centro que cuenta con cocina regional de Chiapas a la carta. Se sitúa en una casona del Centro Histórico de San Cristóbal de Las Casas (véase figura 1), donde: 
CuadRo 1. Distribución de servicios de preparación de alimentos en San Cristóbal de Las Casas

\begin{tabular}{lccl}
\multicolumn{1}{c}{ Establecimientos } & Cantidad & Porcentaje & \multicolumn{1}{c}{ Observaciones } \\
\hline Cafeterías & 31 & 17 & Servicio semipersonalizado \\
Comida internacional & 20 & 11 & Servicio personalizado \\
\hline Comida rápida & 12 & 7 & Autoservicios \\
\hline Fondas y cocinas económicas & 2 & 1 & Servicio semipersonalizado \\
\hline Restaurantes & 119 & 65 & Servicio personalizado \\
\hline Total & 184 & 100 & \\
\hline
\end{tabular}

Fuente: Elaboración propia con base en Trujillo Rincón (2015).

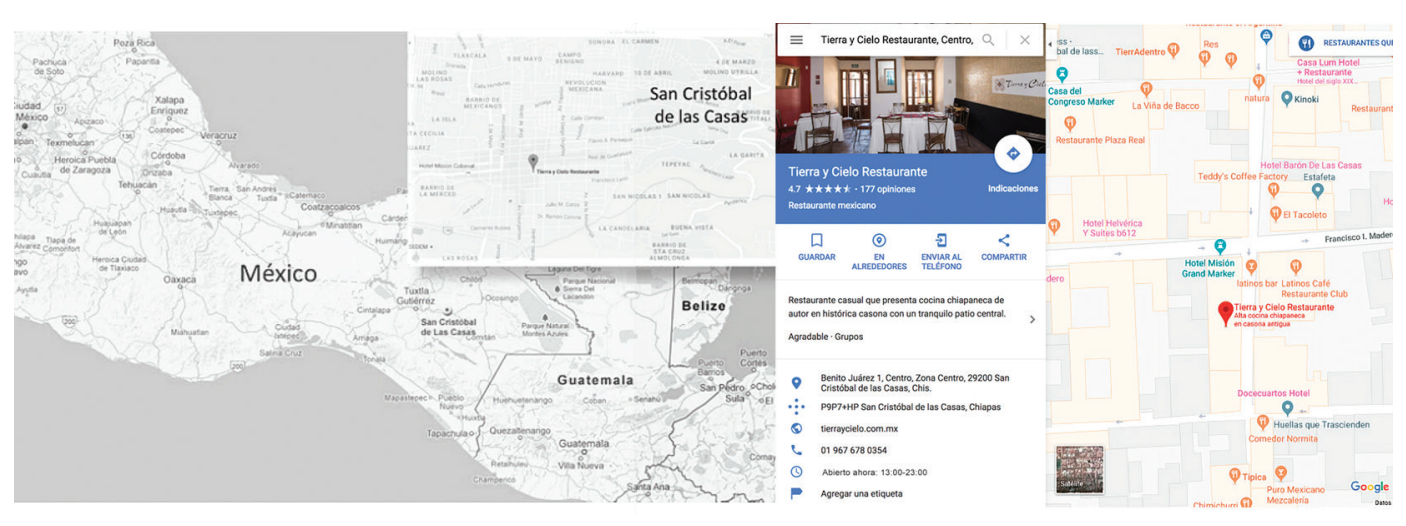

Fuente: Elaboración propia con base en https://www.google.com/maps/ y http://www.vivesancristobal.com/mapas-de-san-cristobal-de-las-casas/

Figura 1. Mapa de ubicación en San Cristóbal: Tierra y Cielo

[se] capitaliza la riqueza cultural, tradiciones y recursos naturales de Chiapas. Fundado en enero de 2007, como parte del proyecto de Tesis de la chef chiapaneca (su propietaria), quien es egresada del Centro de Estudios Superiores de San Ángel, CESSA. La chef busca hacer de la cocina chiapaneca un producto gastronómico turístico, donde se promueven la sustentabilidad y el comercio justo mediante el apoyo a productores, artesanos, colaboradores y proveedores locales. Tierra y Cielo es reconocido como el mejor restaurante del estado de Chiapas. Entre sus galardones destacan el Premio Nacional de Calidad 2015 y el reconocimiento del Conservatorio de la Cultura Gastronómica de México 2017 [www.tierraycielo.com.mx].

El restaurante cuenta con cuatro reconocimientos nacionales (véase cuadro 2), independientemente de que su propietaria cultiva el desarrollo sustentable, al promover la gastronomía local, el consumo responsable, y se esfuerza por fortalecer la economía local 
para transformarla en bienestar comunitario para San Cristóbal de Las Casas. Tierra y Cielo ha sido reconocido como el mejor restaurante de Chiapas por la Guía México Gastronómico 2017, así como en 2016, entre los 120 mejores restaurantes del país. Además del Reconocimiento del Conservatorio de la Cultura Gastronómica de México 2017, en el Foro Mundial de la Gastronomía.

Cuadro 2. Premios y distinciones al restaurante Tierra y Cielo

\begin{tabular}{|c|c|c|}
\hline Premio & Institución & Comentarios \\
\hline $\begin{array}{l}\text { Premio Nacional del Emprendedor } \\
\text { en la categoría de “Mujer } \\
\text { Emprendedora” } 2014\end{array}$ & $\begin{array}{l}\text { Entregado por el presidente de la República } \\
\text { Enrique Peña Nieto }\end{array}$ & Premio nacional \\
\hline $\begin{array}{l}\text { Finalista en el Premio Nacional de } \\
\text { Calidad } 2013\end{array}$ & & Distinción \\
\hline $\begin{array}{l}\text { Reconocimiento Nacional por } \\
\text { Buenas Prácticas Sustentables } 2012\end{array}$ & $\begin{array}{l}\text { Entregado por la Canirac y Unilever Food } \\
\text { Solutions, agosto de } 2012\end{array}$ & $\begin{array}{l}\text { Reconocimiento } \\
\text { nacional }\end{array}$ \\
\hline $\begin{array}{l}\text { Reconocimiento de la Asociación } \\
\text { Mexicana de Mujeres Empresarias } \\
\text { AMMJE Delegación San Cristóbal }\end{array}$ & Enero de 2011 & $\begin{array}{l}\text { Reconocimiento } \\
\text { nacional }\end{array}$ \\
\hline $\begin{array}{l}\text { Premio a la Juventud "Javier Ruiz } \\
\text { Bonifaz" }\end{array}$ & $\begin{array}{l}\text { Entregado por el Club Rotario de San } \\
\text { Cristóbal de Las Casas, septiembre de } 2010\end{array}$ & $\begin{array}{l}\text { Reconocimiento } \\
\text { estatal }\end{array}$ \\
\hline $\begin{array}{l}\text { Reconocimiento a Mujeres } \\
\text { Empresarias de Chiapas } 2010\end{array}$ & $\begin{array}{l}\text { Entregado por el secretario de Turismo } \\
\text { Juan Carlos Cal y Mayor, octubre de } 2010\end{array}$ & $\begin{array}{l}\text { Reconocimiento } \\
\text { estatal }\end{array}$ \\
\hline $\begin{array}{l}\text { Premio al Mérito Empresarial } \\
\text { Restaurantero “José Peza Fragoso" } \\
\text { de Cocina Regional }\end{array}$ & $\begin{array}{l}\text { Entregado por el expresidente de la } \\
\text { República Felipe Calderón Hinojosa en el } \\
50 \text { aniversario de la Canirac, noviembre de } \\
2008\end{array}$ & Premio nacional \\
\hline
\end{tabular}

Fuente: Elaboración propia con base en http://www.tierraycielo.com.mx/

\section{Metodología}

Es un estudio cualitativo, con una aproximación a los procesos de empoderamiento femenino y toma de decisiones que implica acciones empresariales y, por tanto, de naturaleza multifacética en el comportamiento humano que no proporcionan esencialmente datos cuantitativos. La utilización de nuevos modelos explicativos propicia que nuevas metodologías emerjan, y el estudio de caso, en ese sentido, se debe tener en cuenta como una metodología que aborda los fenómenos contemporáneos dentro de la realidad de su contexto, donde lo ilimitado de este no es visible de manera precisa, por lo que tiene que ser aproximado desde diversas fuentes de evidencia (Villarreal y Landeta, 2010; Arias, 2003; Yin, 1989). Esto permite una mejor aproximación a los procesos, conductas y condiciones de la mujer frente a la gestión en ambientes competitivos, como el de los restaurantes. 


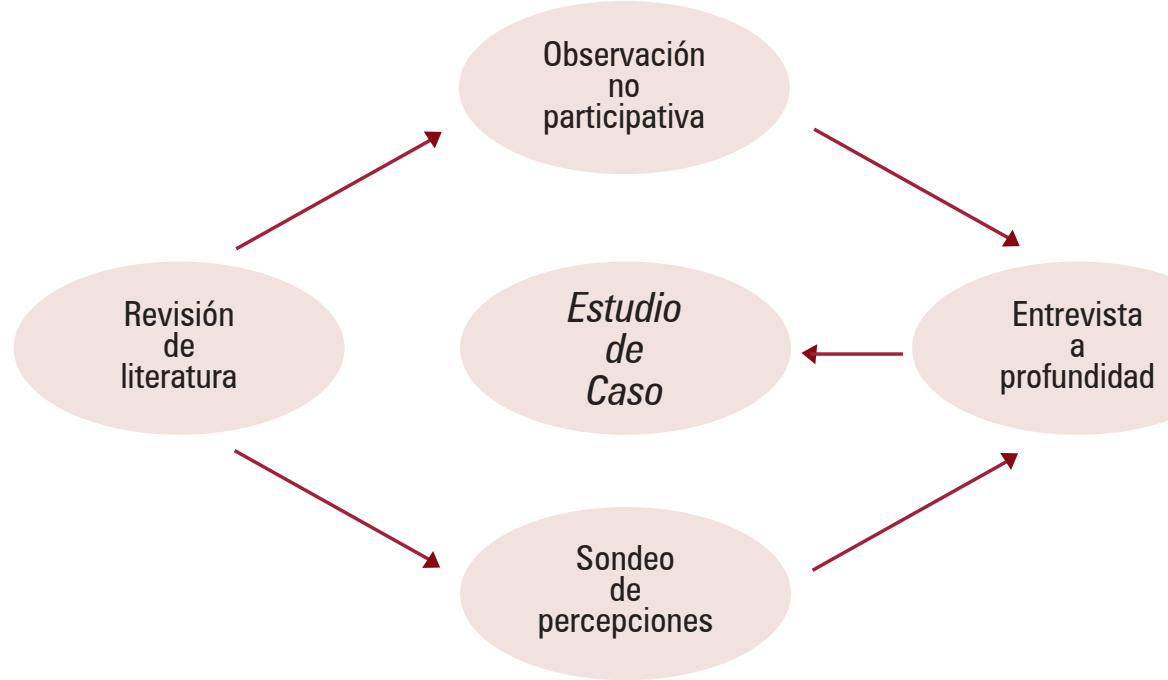

Fuente: Elaboración propia.

Figura 2. Aproximación metodológica del estudio de caso de Tierra y Cielo

Se utiliza como técnica de investigación una entrevista semiestructurada con la informante clave: su propietaria, quien ha sobresalido en el estado de Chiapas por contar con una visión culinaria destacada en la comida regional, ya que, con un enfoque sustentable en el restaurante Tierra y Cielo, ha logrado involucrar los rasgos representativos de la cultura chiapaneca.

En este sentido, el método de Rowlands (1998), con la tríada de las dimensiones y los rasgos que inhiben o potencian el empoderamiento (véase cuadro 3), se aplica en la entrevista a profundidad con un guion de 20 preguntas. El apartado sobre el tema "A. Dimensión personal" cuenta con seis preguntas; el del tema "B. Dimensión colectiva”, con ocho; y el del tema "C. Dimensión de las relaciones cercanas", con cinco. Los comentarios vertidos por la entrevistada se contrastan con las bases presentes de la tríada.

El análisis de los datos se realiza mediante el software Atlas.ti, en un análisis de redes semánticas, el cual facilita la elaboración de tramas entre los códigos identificados y sus vínculos, de manera que puedan visualizarse de forma gráfica las relaciones encontradas, apoyadas con la observación no participante.

Además, se tiene un sondeo entre los empleados del restaurante, con comentarios de su percepción sobre las acciones de gestión realizadas por la propietaria, los cuales se contrastan en busca de convergencias, se examinan mediante la red semántica y se relacionan con las tres dimensiones de Rowlands. Es decir, el análisis parte de cuatro niveles de influencia cercana a partir de su apreciación. 
CuAdro 3. Tríada del empoderamiento femenino de Rowlands

Tríada del

empoderamiento

femenino

Perspectiva

Está compuesta por la capacidad de la mujer para realizar acciones para el cambio, la identidad y la comprensión de su condición para alcanzar el empoderamiento y el desarrollo del sentido del ser y la confianza. Sostiene que la adquisición de conocimientos denota un rostro de empoderamiento, ya que permite acrecentar las habilidades para formular ideas y opiniones, participar e influir en nuevos espacios, otorgándoles mayores oportunidades de análisis y actuación.

Tiene un comportamiento similar al observado en la dimensión personal de acuerdo con la narrativa de la persona entrevistada, pero manifiesta una presencia en la comunidad, toda vez que a partir de sus acciones se está fomentando la participación y la organización colectiva.

Establece que esta es una consecuencia inevitable de la sinergia entre las dimensiones personal y colectiva de la mujer, y señala que es el área más difícil de cambiar debido a las resistencias que provocan en los participantes (familia, empleados, clientes, etc.) las expectativas de cambios empresariales.

Fuente: Elaboración propia con base en Rowlands (1998).

\section{Resultados y discusión}

Los resultados son producto de los comentarios vertidos durante la entrevista a profundidad, con respecto a las tres dimensiones de Rowlands, las cuales se han identificado con códigos presentes, o sea, la orientación del mensaje, y se interpretan en una red semántica.

\subsection{Primera: Dimensión personal}

La dimensión personal, de acuerdo con Rowlands (1998), está compuesta por la capacidad de la mujer para realizar acciones para el cambio, la identidad y la comprensión de su condición a fin de alcanzar el empoderamiento y el desarrollo del sentido del ser y la confianza. Sostiene que la adquisición de conocimientos denota un rostro de empoderamiento, ya que permite acrecentar las habilidades para formular ideas y opiniones, participar e influir en nuevos espacios, otorgándoles mayores oportunidades de análisis y actuación.

En este aspecto, es considerado como un componente de esta dimensión personal el conocimiento y las habilidades que posee la propietaria, así como el soporte que estas puedan aportar al restaurante. Dentro del conocimiento que la entrevistada manifestó poseer sobre el carácter empresarial dentro de su restaurante, es de remarcarse que pareciera estar plenamente apropiado como ayuda, apoyo y beneficio para ella en todas sus actividades. Lo anterior infiere un rasgo incipiente que posiblemente le permita integrarse 
a un proceso de empoderamiento, para posteriormente lograr los resultados deseados, como es la competitividad (véase figura 3).

a) Sobre la adquisición de conocimientos y habilidades, el liderazgo lo demuestra la propietaria con sus acciones de empoderamiento fundamentadas en la creación de valor en Tierra y Cielo, como indican Hernani y Hamann (2013), y su relación con la competitividad. Así lo señalan sus declaraciones, y se identifican los siguientes códigos semánticos: sociedad familiar, emprendimiento (idea de negocios), colaboración, gestión, socios familiares y capacitación.

La propietaria refiere que su entrada a la universidad a estudiar cocina fue por gusto y se reafirmó al llevar un proyecto que más tarde se fortalecería. Así, las condiciones de sociedad familiar y emprendimiento (idea de negocios) lo manifiestan:

Tierra y Cielo fue al principio mi proyecto de tesis, yo estudié la licenciatura en Hotelería en la Ciudad de México, y al principio funcionaba como un hotel, la casa es de mi familia, de mis papás, y con mis hermanos hicimos una sociedad para arrancar el hotel Tierra y Cielo, y ahora pues está el concepto de una hotelería más básica, porque todo ha evolucionado a lo largo de este tiempo, porque cuando iniciamos éramos básicamente un hotel de cuatro estrellas, y ahora es un restaurante gourmet de cocina internacional. Y ya poco a poco ha ido cambiando. Somos cinco socios, mis cuatro hermanos y yo, y la propiedad es de mis papás, todos somos parte de la familia.

Igualmente la líder muestra el interés por el emprendimiento mediante la colaboración y la gestión:

además he trabajado mucho con consultoría, siempre me ha gustado estar trabajando con cualquier idea que siento que me ayuda, y que sea un reto, que si voy a participar en el Premio Nacional del Emprendedor, pues eso implica que yo debo de tener al día mis reportes de ventas, de mercadotecnia, de recursos humanos, de medio ambiente, de participación en festivales y en congresos.

Y sostiene la condición de socios familiares y la capacitación constante al enfatizar las certificaciones logradas para mantener la calidad y servir como ejemplo para otras empresas.

b) Sobre las acciones emprendidas para el cambio, la identidad y la comprensión de su condición, en la entrevista se identifican los siguiente códigos semánticos: visión de cambio, colaboración, identidad, sustentabilidad, emprendimiento, capacitación, gestión.

La entrevistada reseña la importancia de los premios recibidos a partir de 2008 relacionados con la comida artesanal y las tradiciones, ante un compromiso con la Canirac local. De manera que:

para 2010 lanzamos el proyecto de la alta cocina regional, la que es de Chiapas, y para 2011, empezamos a trabajar otros distintivos, que es el del programa Cambia, es un programa dedicado al medio ambiente, y a fomentar esta parte de la empresa verde, empresa responsable, y al trabajar con eso. 


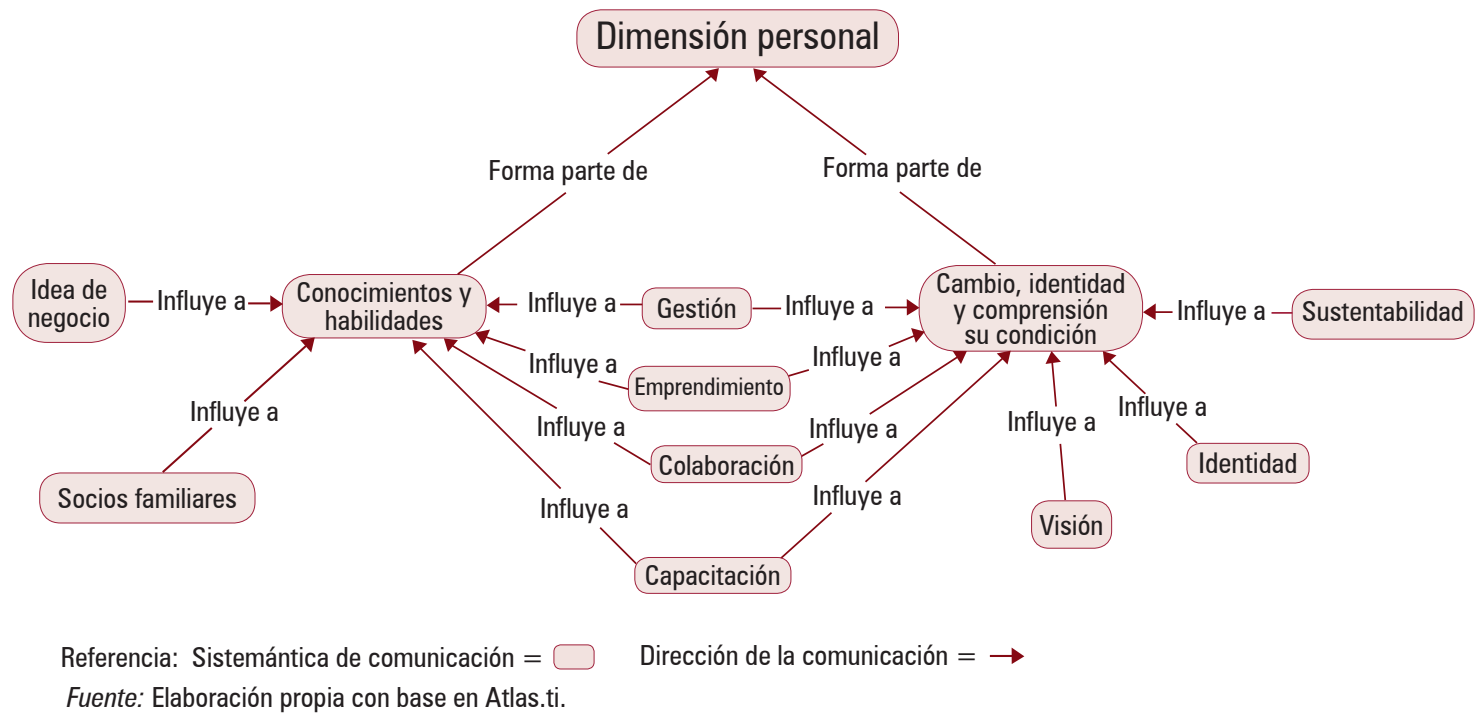

Figura 3. Red semántica de la dimensión personal

Así, la condición de emprendimiento, capacitación y gestión se manifiesta en el logro que revela la chef:

en 2014 [...] nos dieron el Premio Nacional del Emprendedor, pero ha sido un camino que hemos ido recorriendo poco a poco, adaptarse a estos distintivos y también tenemos las certificaciones, que para mí han sido muy importantes desde que estaba en la escuela, lo importante que es trabajar con higiene, con calidad, con normas, con procesos, porque así me enseñaron a estudiar.

La posición de la trayectoria de capacitación, identidad, gestión, se refrenda en su discurso de la comida regional y el trabajo con las cooperativas que se afianzan con las certificaciones y los distintivos de calidad. Como lo acota:

ahora tenemos como pilar a la comida regional, es lo principal de nuestro menú, a través del trabajo con las cooperativas, pero tenemos también la parte de calidad que para nosotros es muy importante manejar mejores procesos y cada vez tener más certificaciones y más distintivos que nos ayuden a ser mejores.

La alocución continúa en términos de calidad y la referencia al carácter chiapaneco, al utilizar insumos locales y regionales, evitando productos estandarizados internacionalmente (de cadena de supermercados, con productos congelados). De manera que el emprendimiento, la gestión y la capacitación están presentes:

Que cuando la gente piense en venir a Chiapas, piense en venir a Tierra y Cielo, y que eso se pueda compartir, y que tampoco sea eso de una moda.

La figura 3 acerca de la red semántica de la dimensión personal sintetiza el escenario: a) sobre la adquisición de conocimientos y habilidades, y b) sobre las acciones emprendidas para el cambio, la identidad y la comprensión de su condición. 


\subsection{Segunda: Dimensión colectiva}

Dentro de la dimensión colectiva del empoderamiento mencionada por Rowlands (1998), se identifica un comportamiento similar al observado en la dimensión personal, de acuerdo con la narrativa de la entrevistada. Aunado a ello, se manifiesta una presencia participativa dentro de la comunidad, toda vez que a partir de sus acciones se está fomentando la participación y la organización colectiva.

Se considera que lo anterior se debe a que las acciones realizadas por la propietaria sirven de apoyo a las redes constituidas por los pequeños productores para enfrentar sus condiciones de extrema pobreza (redes que fundamentalmente operan a través de intercambios), y fortalecen la participación comunitaria mediante, por ejemplo, proyectos productivos colectivos, además de que fomenta contactos con los empresarios de la ciudad y de otras localidades.

A partir de la observación no participante, se percibe una diferencia de opinión entre la chef y las instituciones gubernamentales, pues existe inconformidad con las políticas públicas existentes. En este sentido, manifiesta que el gobierno no está fomentando la actividad restaurantera dentro de la comunidad, ni tampoco promueve la unidad para la creación de proyectos productivos $u$ otras alternativas colectivas que eventualmente permitieran el beneficio socioeconómico en la comunidad (véase figura 4).

a) Sobre el fomento a la participación, se detectan los siguientes códigos semánticos: identidad, proveeduría local, promoción, compromiso social, colaboración, visión de cambio, competitividad, capacitación.

Los códigos semánticos se encuentran entrelazados; es así como la entrevistada, a partir de la identidad, la proveeduría local y la promoción, explica:

entonces me da mucho gusto que cocineros mexicanos estén en las listas de los mejores exponentes del mundo, están utilizando ingredientes de Ocosingo, de los Altos de Chiapas, de Tascalate, entonces ya le están dando esta promoción a los productos chiapanecos, y es la fórmula de llevar la cocina de Chiapas hacia las mejores cocinas de México.

Continúa con su exposición, remarcando el compromiso social de su parte, en cuanto al apoyo a los artesanos y las cooperativas, en el sentido de reflejarlo al visitante de San Cristóbal. Esto es, lograr, en el ámbito de gobierno estatal, programas de apoyo para mejorar su calidad de vida. La sensibilización a los entornos de gobierno mediante el restaurante ha cambiado al paso del tiempo, como lo comenta. Ahora se cuenta con:

el sistema de encuesta a clientes, es una parte muy importante que nos permite ver en qué estamos fallando, o en qué estamos diciendo cosas distintas, porque a veces no es que falles, sino que los clientes esperan algo diferente a lo que tenían en su mente antes de venir a Tierra y Cielo. 
La visión de cambio, a partir de la propietaria, se ha modificado en el transcurso de la operación del hotel-restaurante/restaurante-hotel, y explica que los cambios se han dado del servicio personalizado tradicional con comida regional, a innovaciones no solo en el servicio sino en los platillos tradicionales con el apoyo regional:

la clave está en hacer las cosas con calidad, con este arraigo a nuestras raíces y con este apoyo a nuestros productores y a nuestros colaboradores, a nuestros proveedores, que ya son nuestros colaboradores. Nosotros queremos que mucha gente se sume a lo que hacemos.

b) Sobre el fomento a la organización colectiva, en la entrevista se reflejan los siguientes códigos semánticos, que interactúan en el discurso: colaboración, compromiso social, calidad, identidad, capacitación, promoción, gestión, visión de cambio y sustentabilidad.

La consultada, en términos de inclusión, habla de "nosotros", al mencionar el trabajo de colaboración con la Canirac y la Confederación Patronal de la República Mexicana (Coparmex) en el proyecto llamado Marca Chiapas. La idea se configura en términos de calidad y compromiso social, sin dejar de insistir en la identidad:

empiezo a trabajar con cooperativas, con asociaciones, con los tianguis de cocina que hay cercana, con esa parte de ver cómo nosotros podemos promover a los pequeños productores de Chiapas, capacitarlos también, para que puedan acceder a la marca Chiapas, que es una marca estatal, que certifica a estos productores que tienen cierta calidad, y sobre todo les ayuda a trabajar con una manera en la que ellos puedan distribuir a restaurantes, puedan facturar y ser empresas formales.

El trabajo de los artesanos y de los productores lo tiene en la visión y misión de Tierra y Cielo: el bordado de San Juan Chamula, el cacao de Choconuztlo, el queso bola de Ocosingo, o el pescado de La Encrucijada; detrás de cada producto están las familias chiapanecas. Y considera la visión de cambio mediante la colaboración:

Ya cosas más generales, tomamos las decisiones en conjunto con los hoteleros, los restauranteros, en redes de empresarios, con las asociaciones, con las cámaras, participando directamente en las mesas y en los consejos, porque me interesa, porque estoy convencida de que para cambiar algo tienes que participar.

En este orden de ideas, el restaurante es un enclave en la sociedad, el cual transmite con elocuencia mediante el empoderamiento femenino:

queremos que sea una empresa líder que promueva Chiapas, que la gente que piense en Chiapas, piense en venir a Tierra y Cielo, pero que también al final Tierra y Cielo sea punta de lanza en muchas cosas, como el programa ambiental, como con las alianzas con los productores, como con el trabajar con las comidas de las comunidades cercanas, como promover a las zonas protegidas de la biosfera.

La figura 4 en torno a la red semántica de la dimensión colectiva comprime los conceptos a) sobre el fomento a la participación y b) sobre el fomento a la organización colectiva y 
las directrices en la posición colectiva. Asimismo, incorpora consideraciones concurrentes con Millán y Marín (2014), pues se asocian con la competitividad, ya que se ha logrado una toma de decisiones de manera conjunta. Esta situación impacta en los involucrados y en su posición en condiciones prioritarias para la organización.

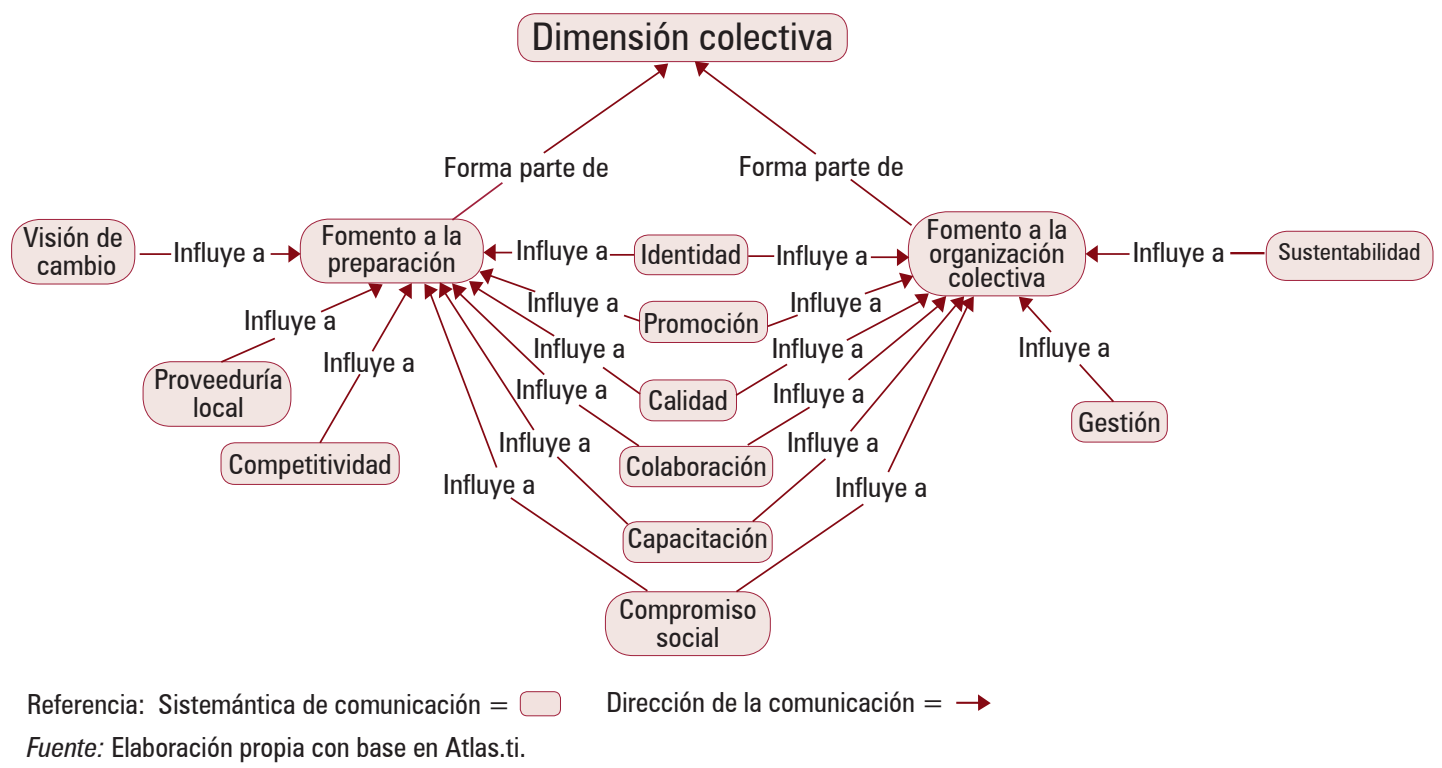

FiguRA 4. Red semántica de la dimensión colectiva

\subsection{Tercera: Dimensión de las relaciones cercanas}

En cuanto a esta tercera dimensión del empoderamiento, concerniente a las relaciones cercanas, Rowlands (1998) establece que esta es una consecuencia inevitable de la sinergia entre las dimensiones personal y colectiva de la mujer. Además, señala que es el área más difícil de cambiar debido a la resistencia que provocan en los participantes (familia, empleados, clientes, etc.) las expectativas de cambios empresariales.

La entrevistada revela que ha experimentado cambios sustanciales en las relaciones con su pareja, familiares, empleados y clientes, entre otros, a partir de su evolución como empresa en busca de ser más competitiva. Las respuestas dadas y sus opiniones giran en torno a que este (el restaurante) es una ayuda y un beneficio para todos los involucrados. Los testimonios dejan entrever que tampoco se han producido conflictos importantes por parte de estos respecto al fin que se debe perseguir y que, por el contrario, lo que domina es un discurso de comprensión y condescendencia. Este hecho es un indicador de la gestión empresarial de la entrevistada, y al tiempo que puede favorecer su empoderamiento, también lo inhibe fundamentalmente al reproducir en el discurso y en la práctica las principales premisas de las normas hegemónicas de género (véase figura 5). 
a) Sobre las relaciones con su familia, se identifican los siguiente códigos semánticos: gestión, emprendimiento, sociedad familiar, colaboración, identidad, recursos y visión de cambio.

En la entrevista se comenta sobre el bien familiar, en términos de gestión, emprendimiento y sociedad familiar. La responsabilidad recae en sí misma, lo que implica dificultad, compromiso y libertad:

luego por el bien familiar decidimos que nada más yo iba a llevar la dirección de la empresa, y me quedé haciendo todo prácticamente sola, y fue muy complicado, muy difícil, pero también es algo que te da el poder elegir, el tener la libertad de tomar cada decisión, el no pedir permiso, y hacer algo, y entonces pues ha sido muy bueno.

La sociedad familiar exige, pero al definir una estructura de trabajo la directora distribuye la carga de responsabilidad y otorga condiciones de identificación con la empresa. De esta manera, los colaboradores (familia y empleados) se cautivan con su labor:

depende mucho de tener claro la función de cada uno, qué es lo que hace cada quien y que eso se respete, y también como empresario ver si puedes o no trabajar con alguien más, si estás dispuesto a tomar decisiones en conjunto, a tener muy clara también la parte del dinero, de cómo se reparte y cuándo se reparte, y todo implica si todos le apuestan a que la empresa siga creciendo.

b) Sobre las relaciones con los empleados y otros involucrados, se cuenta con los siguientes códigos semánticos: identidad, colaboración, compromiso social, capacitación, calidad, promoción, gestión, recursos y sin apoyo gubernamental.

Acerca de la relación con los empleados y otros involucrados, la directora apunta que es una elección estatal, es decir, 95 \% de los trabajadores son chiapanecos, en especial de comunidades cercanas a San Cristóbal, que por lo general hablan algún dialecto:

Yo misma he elegido un perfil de gente con la que estoy acostumbrada a trabajar, por ejemplo, en la cocina trabajo con señoras, a veces tengo algunos jóvenes que hacen prácticas, pero por lo general no. Con los hombres al revés, para los meseros que sean jóvenes, porque a los señores les costaba trabajo, no querían cambiar, toda la vida le he hecho así, nunca lo he hecho mal, no voy a caer en esta parte de que no íbamos por el mismo camino, pero con los chavos que están estudiando, que tienen ganas, que quieren sacar un dinero extra para terminar sus estudios.

$Y$ afirma:

entonces también trabajamos esta parte de capital humano, en donde se certifiquen con los mismos distintivos que nosotros tenemos, y más que se certifiquen ellos, gente que entró de ayudante y ahora son baristas, tenemos gente que ganó "El capitán de meseros del siglo xxi", y gente que ha hecho carrera dentro de la empresa, pero que también ha hecho carrera en Chiapas.

El compromiso de la chef se encuentra en la colaboración, promoción, compromiso social, y capacitación constante: 
una persona que tenía conmigo siete años ya fue a representar a Chiapas en cocina tradicional, hace 15 días, al Foro Mundial de la Cocina Mexicana, en Puebla, entonces ella realmente no sabía nada de cocina tradicional, ella era una indígena que entró a trabajar conmigo de lavalozas, luego subió a ayudante, luego subió a cocinera, luego fue atendiendo recetas, algunas recetas las creamos en conjunto, las trabajamos, y ahora fue a representar a Chiapas como cocinera tradicional del estado.

Su gestión se encuentra presente en las reuniones de trabajo con su equipo de colaboradores, pues las vicisitudes, desde la visión de cambio social, se ubican en las jefaturas de área y el gestor de calidad, de modo que las decisiones se toman al interior del grupo de forma conciliatoria. Pero en el entorno externo es diferente y exhibe:

estas leyes o estándares que hay por parte del gobierno no están bien estructuradas ni tampoco están a favor de los empresarios restauranteros de simplificarles las cosas o que te motiven a hacerlo negocio informal cuando ya te cansaste.

La figura 5 agrupa las condiciones de la dimensión de las relaciones cercanas: a) sobre las relaciones con su familia, y b) sobre las relaciones con los empleados y otros involucrados. En la figura también se observan estrategias de gestión de personal que fortalecen esta dimensión como se indica: "se desean trabajadores con disposición laboral, además que susciten calidad en el servicio, también la empresa deberá corresponder a dicho esfuerzo y la satisfacción de necesidades a los trabajadores, al propiciar calidad de vida” (Varela Juárez, Cuevas Contreras y Salmerón Manzanares, 2015, p. 67).

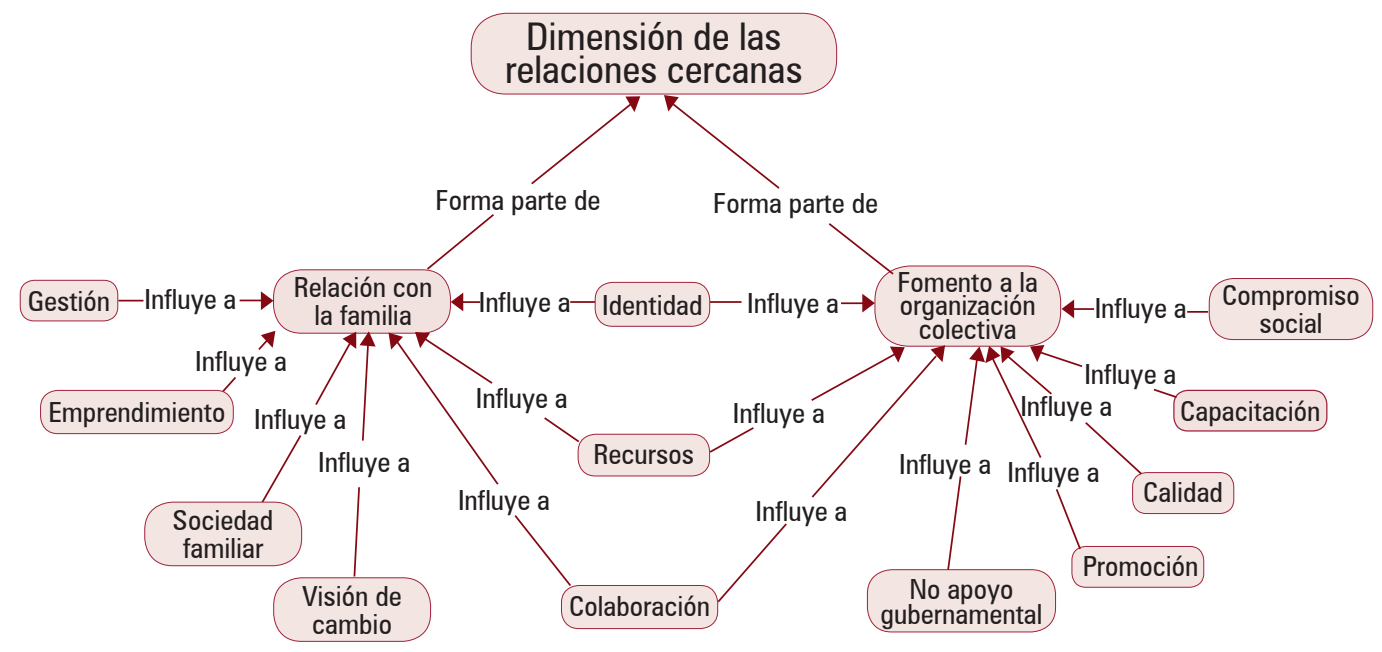

Referencia: Sistemántica de comunicación =

Dirección de la comunicación $=\rightarrow$

Fuente: Elaboración propia con base en Atlas.ti.

Figura 5. Red semántica de la dimensión de las relaciones cercanas 
El sondeo entre los empleados del restaurante (figura 6) refleja su percepción sobre las acciones del empoderamiento femenino. Los comentarios presentan convergencias en las tres dimensiones de Rowlands, en la red semántica.

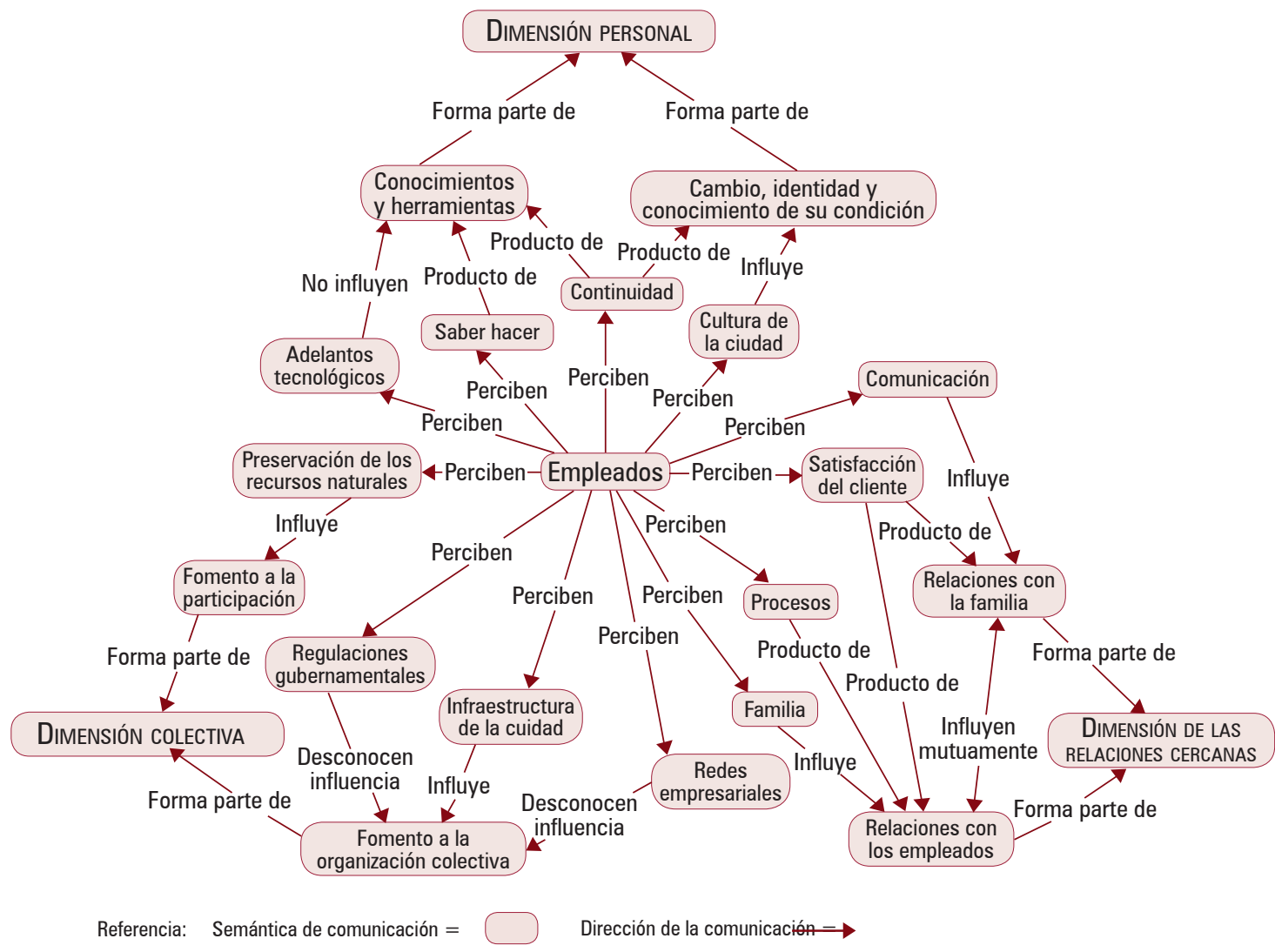

Fuente: Elaboración propia con base en Atlas.ti.

Figura 6. Red semántica de los comentarios de empleados

El cuadro 4 presenta los códigos identificados en los comentarios vertidos por los empleados; asimismo se incorpora la interpretación, la cual permite el vínculo entre su percepción y las dimensiones (personal, colectiva y de relaciones cercanas).

La mirada de los empleados (figura 7) es significativa ante su percepción del empoderamiento femenino y su liderazgo. Esta mirada se plasma en 12 códigos de interpretación vertidos en los comentarios. En este sentido, el análisis parte de cuatro niveles de influencia semántica y su cercana a partir de su apreciación.

El primer nivel de análisis se encuentra configurado por 12 posiciones semánticas $y$, de esta forma, estimula el segundo nivel con enfoques en: 1) Infraestructura de la ciudad; 2) Preservación de los recursos naturales; 3) Cultura de la ciudad; 4) Saber hacer; 5) Adelantos tecnológicos; 6) Redes empresariales; 7) Regulaciones gubernamentales; 8) Satisfacción del cliente; 9) Procesos; 10) Continuidad; 11) Familia; y 12) Comunicación. 


\section{J. González-Macías · T. J. Cuevas-Contreras · I. Zizaldra-Hernández}

Mientras, el tercer nivel emerge de derecha a izquierda: 1) Conocimientos y habilidades; 2) Cambio, identidad y conocimiento de su condición; 3) Relaciones con la familia; 4)

CuAdro 4. Comentarios de los empleados sobre la gestión de la propietaria

\begin{tabular}{|c|c|}
\hline Códigos semánticos & Interpretación \\
\hline Infraestructura de la ciudad & $\begin{array}{l}\text { Percepción de adecuado aprovechamiento de la infraestructura que } \\
\text { brinda la ciudad. Influye para el fomento de la organización colectiva. }\end{array}$ \\
\hline $\begin{array}{l}\text { Preservación de los recursos } \\
\text { naturales }\end{array}$ & $\begin{array}{l}\text { Percepción de que los procesos no contaminan el medio ambiente. } \\
\text { Esto influye al fomento a la participación. }\end{array}$ \\
\hline Cultura de la ciudad & $\begin{array}{l}\text { Percepción de lucha y trabajo por una ciudad muy propensa } \\
\text { culturalmente para la actividad restaurantera. Esto influye en el } \\
\text { cambio, la identidad y el conocimiento de su condición. }\end{array}$ \\
\hline Saber hacer & $\begin{array}{l}\text { Percepción de un dominio del saber hacer de las actividades } \\
\text { del restaurante. Esto es producto de todos sus conocimientos y } \\
\text { habilidades. }\end{array}$ \\
\hline Adelantos tecnológicos & $\begin{array}{l}\text { Percepción de que los adelantos tecnológicos no son necesarios para } \\
\text { brindar buen servicio y excelentes platillos. Estos no influyen en sus } \\
\text { conocimientos y habilidades. }\end{array}$ \\
\hline Redes empresariales & $\begin{array}{l}\text { Percepción de } 40 \% \text { de conocimiento de convenios con proveedores } \\
\text { locales y el restante } 60 \% \text { de los empleados manifestó desconocerlo. } \\
\text { Esto es un desconocimiento de la influencia sobre el fomento a la } \\
\text { organización colectiva. }\end{array}$ \\
\hline $\begin{array}{l}\text { Regulaciones } \\
\text { gubernamentales }\end{array}$ & $\begin{array}{l}\text { Percepción de } 85 \% \text { de desconocimiento sobre las regulaciones } \\
\text { gubernamentales y de } 15 \% \text { que no ayudan. Esto es un } \\
\text { desconocimiento de la influencia en el fomento a la organización } \\
\text { colectiva. }\end{array}$ \\
\hline Satisfacción del cliente & $\begin{array}{l}\text { Percepción de un excelente servicio al cliente. Esto es producto de las } \\
\text { relaciones estrechas con familia y empleados. }\end{array}$ \\
\hline Procesos & $\begin{array}{l}\text { Percepción de adecuados procesos. Esto es producto de las } \\
\text { relaciones estrechas con empleados. }\end{array}$ \\
\hline Continuidad & $\begin{array}{l}\text { Percepción de continuidad del restaurante. Esto es producto de } \\
\text { los conocimientos y habilidades, así como del cambio, identidad y } \\
\text { conocimiento de su condición. }\end{array}$ \\
\hline Familia & $\begin{array}{l}\text { Percepción de un ambiente de familia. Esto influye sobre las relaciones } \\
\text { con los empleados. }\end{array}$ \\
\hline Comunicación & $\begin{array}{l}\text { Percepción de excelente comunicación. Esto influye en las relaciones } \\
\text { con los empleados. }\end{array}$ \\
\hline
\end{tabular}

Fuente: Elaboración propia. 


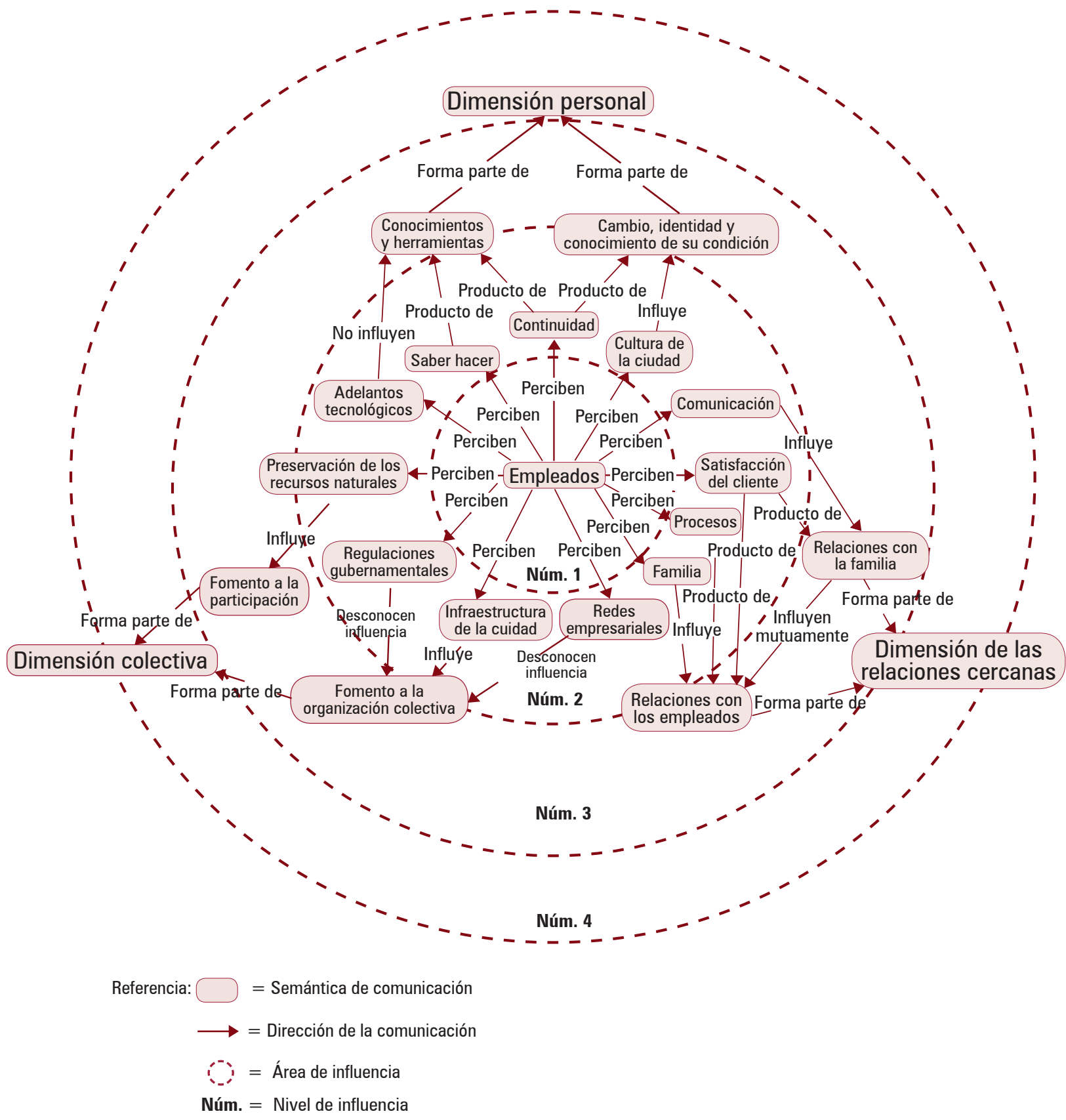

Fuente: Elaboración propia con base en Atlas.ti.

Figura 7. Mirada de los empleados en Tierra y Cielo 
Relaciones con los empleados; 5) Fomento a la organización colectiva; y 6) Fomento a la participación. De hecho, es revelador el manejo de niveles de influencia. En el cuarto nivel, la dimensión personal coincide con la mirada de los empleados, y se engarza, mediante los conocimientos y habilidades, con el cambio, identidad y conocimiento de su condición. Estas son interacciones relacionadas con adelantos tecnológicos, saber hacer, continuidad y cultura de la ciudad.

Por su parte, el fomento a la organización y la participación colectiva estimulan la dimensión colectiva, acompañados de la relación familiar y de los empleados, además del producto de preservación, apoyo en regulaciones, infraestructura de la ciudad y redes empresariales, en cuanto a cómo las relaciones cercanas se encuentran a una distancia similar de la familia, los procesos, la satisfacción del cliente y la comunicación, mediante la relación con los empleados y la familia.

A pesar de que la colaboración gubernamental es exigua, este escenario resulta motivante, de manera que las alianzas estratégicas son de vital importancia (Olguín Negrete, Cuevas Contreras y Loera Anchondo, 2016; Leguísamo Guevara, 2016). Esta situación cohesiona a los actores, y el ánimo de colaboración y cooperación se respalda.

\section{Conclusión}

Frente a las acciones de empoderamiento femenino y su liderazgo, el ambiente de los restaurantes ha sido un enclave en su desarrollo. En este contexto, el enlace entre competitividad y sustentabilidad se compromete con lo glocal, pues el mercado actual no solo está en la globalización, sino en una intensa competencia para mantener la ventaja competitiva (Dressler y Varela, 2004). Así, lo femenino, ante el reto de un liderazgo empresarial, se enfoca en el desarrollo de procesos comunitarios, que establecen una estrategia frontal contra las carencias (Erazo et al., 2014). Y se alza con acciones multifacéticas al observar respeto a los integrantes sociales, mediante lo legal y la acentuación en la colaboración y la cooperación de los familiares y empleados.

El restaurante Tierra y Cielo, en el centro de la ciudad de San Cristóbal de Las Casas, Chiapas, cuenta con una excelente apariencia externa, rodeado de un ambiente de la época colonial y las calles anexas limpias en general, pero con banquetas muy reducidas, y ruidosos alrededores por la noche. El edificio en donde se ubica tiene buen mantenimiento, pues, aunque es antiguo, se ve renovado y adaptado con instalaciones adecuadas, considerando la conciliación entre el hotel y el restaurante como parte de los servicios que se brindan a los visitantes. De manera que los espacios son reducidos, pero con un patio para mesas y sillas, adornado con artesanías, plantas y flores de la región, en donde se percibe la influencia femenina. Mientras, el estacionamiento es una ventana de oportunidad de mejora, ya que se encuentra retirado del establecimiento, y aunque se localiza en el centro de la ciudad, tiene lugar para pocos vehículos.

La impronta en el restaurante se refleja también en los productos locales y los elementos de identidad cultural, y se demuestra la imagen de liderazgo femenino. Esta huella 
es tangible en las condiciones internas, que superan la imagen externa, al contar con un ambiente que invita a departir, aun y lo limitante del espacio. Sus instalaciones están cuidadas, limpias y muy coloridas. Con mobiliario apropiado y cómodo, además de una adecuada presentación. Aportando un lugar acogedor y cálido, a manera de hogar. El ambiente del área de espera reafirma el toque femenino, al utilizar adornos y productos típicos (decoración floral y artesanías de la región) y de marca propia a la venta.

Las tres dimensiones exploradas de la propuesta de Rowlands (1998) en lo personal, colectivo y de las relaciones cercanas son patentes en los procesos y conductas condicionantes de acciones empresariales femeninas. El interior del restaurante confirma su administración sustentable, con un montaje conveniente de una casona de principios del siglo xx. Aunque la decoración es austera, se enfoca en resaltar las tradiciones y la cultura local, con un menú equilibrado incluso en los precios de los platillos. La recepcionista es amable, simpática, agradable, y ubica a los comensales donde estos lo solicitan. Está apoyada con el personal de servicio (mesero), que es agradable, considerado, y está informado del menú. Entonces se aprecia el compromiso, al brindar atención esmerada, explicación de los platillos y recomendaciones sobre bebidas. De tal modo, se demuestra un liderazgo en la gestión, al reclutar personal técnicamente responsable y comprometido con su entorno.

Los tiempos del servicio son acordes al menú, con platillos originales y porciones adecuadas. Sin espera prolongada, entre la orden y la llegada de platillos y bebidas. El periodo más largo corre al ordenar el platillo principal, sin embargo, se requiere mayor presencia de la propietaria en el área de servicio, ya que su atención haría más placentera la estancia. Aunque los tiempos son adecuados, es recomendable dedicarle un tiempo especial a la llegada y a la salida de los comensales. Actualmente, el cobro y la despedida se realizan con una amabilidad genérica. En el transcurso de la experiencia se acompaña con música en vivo, lo que confiere distinción al lugar, atribuible a las comisiones existentes.

Por último, el posicionamiento ganado en un ecosistema tradicionalmente masculino, pero cada vez más llano, que se beneficia con su accesibilidad a las incursiones del empoderamiento femenino, se encuentra presente en la gestión de Tierra y Cielo, el cual se reafirma con su perspectiva empresarial competitiva e innovadora.

\section{Fuentes consultadas}

Arias, M. (2003). Metodologías de investigación emergentes en economía de la empresa. Papers Proceedings, 17, 19-28.

Bianco, C. (Marzo, 2007). ¿De qué hablamos cuando hablamos de competitividad? (Documento de Trabajo, núm. 31). Centro de Estudios sobre Ciencia, Desarrollo y Educación Superior.

Buendía-Martínez, I. y Carrasco, I. (2013). Mujer, actividad emprendedora y desarrollo rural en América Latina y el Caribe. Cuadernos de Desarrollo Rural, 10(72), 21-45.

Camberos, M. (2011). Empoderamiento femenino y políticas públicas, una perspectiva desde las representaciones sociales de género. Entramado, 7(29), 40-53. 
Canirac. (2014). Dimensiones de la Industria Restaurantera. Cifras de la Industria Restaurantera para maximar su potencial económico. México: Autor/Instituto Nacional de Estadística y Geografía. Recuperado de http://canirac.org.mx

Casique, I. (2010). Factores de empoderamiento y protección de las mujeres contra la violencia. Revista Mexicana de Sociología, 72(1), 37-71.

Centro de Estudios para el Desarrollo Municipal y Políticas Públicas. (2014). Ciudades rurales sustentables: referentes para la formulación del Plan Maestro. Tuxtla Gutiérrez: Universidad Autónoma de Chiapas.

Cobo Quesada, F. B., Hervé, A. y Aparicio Sánchez, M. S. (2009). El sistema turístico en clave de marketing relacional: el factor relacional. Anuario Jurídico y Económico Escurialense, XLII, 419-442.

Dressler, G. y Varela, R. (2004). Administración de recursos humanos. Enfoque latinoamericano. México: Pearson Educación.

Durón, C. (2012). El restaurante como empresa. México: Trillas.

Erazo, M., Jiménez, M. y López, C. (2014). Empoderamiento y liderazgo femenino; su papel en la autogestión comunitaria en el corregimiento El Hormiguero-Valle del Cauca. Avances en Psicología Latinoamericana, 32(1), 149-157.

Franco, A. (2012). Administración de la empresa restaurantera. México: Trillas.

Hernani, M. y Hamann, A. (2013). Percepción sobre el desarrollo sostenible de las MyPE en Perú. Revista de Administración de Empresas, 53(3), 290-302.

Instituto de Población y Ciudades Rurales. (2013). Programa de ciudades rurales sustentables. Tuxtla Gutiérrez: Gobierno del Estado de Chiapas.

Instituto Nacional de Estadística y Geografía. (2015). Sistema Automatizado de Información Censal. Recuperado de http://www.inegi.org.mx

Kabeer, N. (1999). Resources, agency, achievements: Reflections on the measurement of women's empowerment. Development and Change, 30, 435-464.

La Rovere, R. y Hasenclever, L. (2010). Innovación, competitividad y adopción de tecnologías de la información y de la comunicación en pequeñas y medianas empresas: algunos estudios de caso sobre Brasil. Río de Janeiro: Universidad Federal de Río de Janeiro, Instituto de Economía.

Leguísamo Guevara, M. R. (Enero, 2016). Economía popular y solidaria para el mejoramiento del comercio justo de productos de cacao de aroma. Caso: Asociación Artesanal de Mujeres Emprendedoras San Plácido - Portoviejo (Tesis de magíster en Gestión para el Desarrollo Local Comunitario). Pontificia Universidad Católica del Ecuador, Escuela de Trabajo Social.

León, M. (2007). Poder y empoderamiento de las mujeres. Bogotá: Tercer Mundo Editores.

Lino, S. (2013). Víctima, detective y femme fatale: En busca de estrategias de empoderamiento femenino ante la inmigración en la novela negra española. L'érudit Franco-Espagnol, 4, 65-85.

Manucci, M. (2010). Contingencias. 5 desafíos de cambio para una nueva década. Bogotá: Norma.

Matthaei, J. (2010). Más allá del hombre económico: Crisis económica, economía feminista, y la economía solidaria. Cayapa, Revista Venezolana de Economía Social, 10(19), 65-80.

Millán, S. y Marín, M. (2014). Competitividad de las empresas familiares del sector alimentos de tipo gourmet de la ciudad de Ensenada, Baja California. Global Conference on Business and Finance Proceedings, 9(1), 1055-1060. 
Montero, M. (2003). Teoría y práctica de la psicología comunitaria. Buenos Aires: Paidós.

Olguín Negrete, B. R., Cuevas Contreras, T. J. y Loera Anchondo, E. (2016). Colaboración entre lo público y lo privado en la imagen del destino de Hermosillo Sonora. CULTUR: Revista de Cultura e Turismo, 10(3), 6-21.

Pérez, J. y Cortés, J. (2007). Barreras para el aprendizaje organizacional: Estudio de casos. Pensamiento y Gestión, 22, 256-282.

Porter, M. (1985). Competitive Advantage: Creating and Sustaining Superior Performance. Nueva York: Free Press.

Porter, M. (1990). The Competitive Advantage of Nations. Nueva York: Free Press.

Porter, M. (2004). Ventaja competitiva. México: CECSA.

Román, L. (2000). Acumulación de la pobreza y política social. En L. Valencia et al. (coords.), Los dilemas de la política social, ¿cómo combatir la pobreza? México: Amaroma Ediciones.

Rowlands, J. (1996). Empowerment Examined: An Exploration of the Concepts and Practice of Women's Empowerment in Honduras, in Questioning Empowerment. Working with Women in Honduras (Tesis doctoral). Universidad de Durham, Departamento de Geografía.

Rowlands, J. (1998). Empoderamiento y mujeres rurales en Honduras: un modelo para el desarrollo. En M. León (comp.), Poder y empoderamiento de las mujeres (pp. 213245). Bogotá: Tercer Mundo Editores.

Sáez, G., Valor-Segura, I. y Expósito, F. (2012). ¿Empoderamiento o subyugación de la mujer? Experiencias de cosificación sexual interpersonal. Psychosocial Intervention, 21(1), 41-51. Recuperado de http://dx.doi.org/10.5093/in2012v21n1a9

Saldívar González, S. J., García Rivera, B. R., Valenciana Moreno, N. y Roa Rivera, R. O. (2012). Competitividad y gestión de las Pymes. Global Conference on Business and Finance Proceedings, 7(2), 1152-1156.

Trujillo Rincón, J. (Noviembre, 2015). Pymes más competitivas para la creación de más empleos. Análisis de la cadena de valor del sector turístico de San Cristóbal de Las Casas, Chiapas, México. Organización Internacional del Trabajo. Recuperado de http://www.ilo.org

Varela Juárez, R., Cuevas Contreras, T. y Salmerón Manzanares, S. (2015). Efectos de la propina en la socioeconomía y en el ser humano. Noésis, 24(número especial 1), 49-68. Recuperado de http://www.revistanoesis.net/47-es-1/4/

Vázquez-Luna, D., Mortera, D., Rodríguez-Orozco, N., Martínez, M. y Velázquez, M. (2013). Organización comunitaria de mujeres: del empoderamiento al éxito del desarrollo rural sustentable. La Ventana, 23, 262-288.

Villafuerte, D. (2011). Integraciones comerciales en la frontera sur. México: Universidad Nacional Autónoma de México.

Villarreal, O. y Landeta, J. (2010). El estudio de casos como metodología de investigación científica en dirección y economía de la empresa: Una aplicación a la internacionalización. Investigaciones Europeas de Dirección de la Empresa (IEDEE), 16(31), 3-52.

Yin, R. K. (1989). Case Study Research. Design and Methods (Applied Social Research Methods Series, vol. 5). Sage: Londres.

Zapata, E., Townsend, J., Rowlands, J., Alberti, P. y Mercado, M. (2002). Las mujeres y el poder: contra el patriarcado y la pobreza. Montecillo: Cole 


\title{
Signos distintivos en comunidades ruRales de Baja California Sur, MÉXICO: UNA ESTRATEGIA PARA IMPULSAR EL TURISMO RURAL
}

\author{
Alba E. GÁmez \\ agamez@uabcs.mx \\ EDUARDO JUÁREZ \\ lalo@uabcs.mx \\ Departamento Académico de Economía \\ Universidad Autónoma de Baja California Sur \\ José Alfredo Guevara-Franco \\ jguevara@uabcs.mx \\ Departamento Académico de Ciencia \\ Animal y Conservación del Hábitat \\ Universidad Autónoma de Baja California Sur
}

En este artículo se ofrece una reflexión sobre las posibilidades que da la figura de signos distintivos a alimentos para potenciar el turismo rural en San Miguel y San José de Comondú, dos localidades serranas aisladas que conforman Los Comondú, uno de los oasis de mayor importancia en la parte sur de la península de Baja California, en el noroeste de México. En ambas comunidades, los productos agropecuarios representan un valor significativo para la economía familiar. Sin embargo, es preciso replantear sus procesos de organización y de producción para revalorar el patrimonio gastronómico, así como cuidar la inocuidad de los productos. Esto prepararía a los pobladores locales para incursionar en nuevos nichos de mercado e incorporar valor agregado a productos ya existentes, lo que a la vez apoyaría las iniciativas de turismo rural en la zona.

Palabras clave: México, alimentos, signos distintivos, turismo rural.

\section{DistinCTIVE SIGNS IN RURAL COMMUNITIES OF}

\section{Baja California Sur, Mexico: a strategy to promote rural tourism}

This paper reflects on the possibilities given to food products by distinctive signs or trademarks to strengthen rural tourism in San Miguel and San José de Comondú area, two geographically isolated mountain towns that form Los Comondú, one of the most important oases in the southern part of the Baja California peninsula. Agricultural products are a key asset for the economy of families in the region; however, the organization and production processes should be reconsidered for the revaluation of their gastronomic heritage including the improvement of measures related to food safety. These strategies would prepare the local population to venture into new market niches and add value to the existing food products, and at the same time, it could support rural tourism initiatives in the region.

Keywords: Mexico, distinctive signs, food, rural tourism. 
E n este artículo se ofrece un análisis respecto a las posibilidades de reactivación económica ligadas al empleo de signos distintivos en la producción de alimentos en zonas rurales remotas, que fortalezcan las economías locales y permitan elevar el nivel de vida de sus habitantes, usando el caso de las localidades de San Miguel y San José de Comondú (Los Comondú), ubicadas en Baja California Sur, en el noroeste mexicano. Los signos distintivos, como marca colectiva (MC) y denominación de origen (Do), presentan una dimensión que supera el ámbito meramente económico para entroncar con aspectos sociales y culturales, y son considerados un factor importante que contribuye al desarrollo rural de regiones periféricas, aprovechando el potencial de nichos de mercado para estos productos (Granados y Álvarez, 2004).

En particular, el uso de las gastronomías locales asociado al turismo es entendido como un mecanismo benéfico de diversificación de las actividades productivas locales, en la medida en que no las sustituya sino que las complemente (Millán Vázquez de la Torre y Agudo, 2010). De esa manera, las posibilidades de empleo e ingreso ayudan a evitar la expulsión demográfica y la falta de desarrollo, que afectan a una vasta proporción de las comunidades rurales. Además, la reevaluación del patrimonio gastronómico puede desplegar efectos positivos sobre la conservación de los recursos naturales en las zonas rurales al estimular su buen aprovechamiento, toda vez que en ellos se basa la preparación de alimentos.

Por ejemplo, se adelanta que las Do permiten una mejor conservación de las especies de razas y variedades criollas, al rescatar elementos como su antigüedad y su significado patrimonial natural y cultural, en comparación con los sistemas intensivos y modernos de producción. De alguna forma, podría considerarse que la Do mantiene colecciones in situ, sin proponérselo. Es así que, en Europa, las indicaciones geográficas (IG) de alimentos y las Do se estiman importantes por sus efectos ambientales, como la conservación del paisaje, del suelo y de las especies nativas originales (Millán Vázquez de la Torre y Agudo, 2010).

En el caso de Baja California Sur, su aislamiento geográfico y naturaleza geológica han favorecido la existencia de pequeños valles delimitados por cañadas. En ellos, comunidades aisladas mantienen una riqueza gastronómica centenaria ligada a actividades agropecuarias sostenidas desde la época de la presencia jesuita en la región durante los siglos XVII y XVIII. De ese tiempo se conservan, entre otros elementos patrimoniales, una misión de piedra, acequias, y el sistema de huertas y ganadería aún en funcionamiento. Varios productos podrían ser potenciales candidatos de protección legal en Los Comondú, lo cual favorecería abonar a la conservación de especies de valor cultural y ambiental, y proteger un patrimonio común en esas localidades. Sin embargo, es necesario reducir la heterogeneidad en la calidad de los productos, y generar estudios de ubicación geográfica, calidad e inocuidad como estrategias de intervención que estén anclados, por ejemplo, al turismo rural (Guevara, Juárez, Gámez y Rojas, 2013). Lo anterior permitiría ofrecer alternativas de reactivación para esa zona económicamente deprimida y rescatar modos de vida con un alto valor cultural.

Las comunidades de San Miguel y San José de Comondú están enclavadas en la sierra La Giganta, a una distancia de 130 kilómetros de Ciudad Constitución, cabecera del 


\section{A. E. Gámez · E. Juárez · J. A. Guevara-Franco}

municipio de donde dependen administrativamente estos poblados. A mitad de 2011 se concluyó el tramo carretero que comunica a Los Comondú con la localidad de Francisco Villa, ubicada a 37 kilómetros de distancia de los dos poblados. Justo ahí está la intersección con una carretera que conduce a La Purísima y a San Isidro, hacia el norte, y a Ciudad Insurgentes, hacia el sur. En este último asentamiento, la ruta se entronca con la carretera transpeninsular, eje de las comunicaciones por tierra de la entidad.

San Miguel y San José se encuentran separados entre sí por un camino vecinal de tres kilómetros de distancia, dentro de una cañada de 16 kilómetros de longitud que tiene una superficie de 88 hectáreas, deshabitada en su mayor parte. La zona cuenta con un arroyo superficial, el arroyo Comondú, que se nutre del agua que brota de varios manantiales repartidos a lo largo de su recorrido. Los Comondú son, literalmente, un oasis en el semidesierto sudcaliforniano; un socioecosistema valioso no solo ambiental sino culturalmente. El arroyo Comondú forma un humedal que fue designado sitio Ramsar el 2 de febrero de 2008 por su alto valor ecosistémico, el cual hospeda a siete especies de aves y 18 de reptiles bajo algún estado de protección en la NOM-059-SEMARNAT-2001, y es sitio de descanso para especies migratorias (Breceda, Galina y Cortés, 2010).

La estructura productiva en estas comunidades descansa en el sector primario: las dos actividades que le dan viabilidad a sus economías son la ganadería y la agricultura. Cabe mencionar que, en San Miguel de Comondú, la producción agrícola es más importante que la ganadería, porque el suelo es menos salino, lo que permite una mayor fertilidad y mejores cosechas; en el caso de San José, la ganadería (y la producción de queso) representa la actividad sobresaliente. Sin embargo, en ambas comunidades coexisten otras prácticas productivas que complementan el ingreso de sus habitantes, como la fabricación de dulces regionales, vino, y algunas artesanías que venden a los visitantes (Gámez, 2013). Asimismo, los programas gubernamentales de apoyo rural constituyen una fuente monetaria significativa en la forma de programas de empleo temporal y capacitación para la conservación ambiental y el desarrollo local (Peninsular Digital, 2011).

En los últimos años, el gobierno estatal ha promovido el turismo en las zonas serranas ligado a la producción artesanal del vino misional, a la confitería con frutas locales, a las figuras del oasis y el rancho sudcaliforniano. Los mecanismos han sido la organización de festivales del vino, los apoyos a fondo perdido para la elaboración de alimentos y la construcción de cabañas, la construcción de vías de comunicación y el mantenimiento de la infraestructura en la zona central de los dos pueblos, así como el financiamiento para la investigación a través de las convocatorias de fondos mixtos (Gámez, 2013; Coordinación General de Desarrollo Sustentable, 2015). Tales iniciativas, acompañadas de algunos esfuerzos privados, han derivado en resultados heterogéneos respecto al turismo rural: hay un hotel, que promociona un museo, con habitaciones dobles y sencillas, servicio de internet, cocineta equipada, aire acondicionado y televisión por cable, además de alguna otra oferta de alojamiento en cabañas y de servicios de alimentos; ciclismo de montaña; caminata; cabalgatas; exhibiciones y festivales de tradiciones locales; pero lejos están aún la activación de las huertas o la integración de las actividades primarias y productos 
artesanales tradicionales en una oferta turística consolidada. Con todo, el discurso del potencial turístico de los oasis sigue siendo incluido en la política pública estatal (Consejo Nacional de Ciencia y Tecnología, 2018).

Esta investigación ofrece una reflexión sobre las posibilidades que pudieran surgir para los productores artesanales de San Miguel y San José de Comondú a partir de la incorporación de valor agregado a productos agropecuarios ya existentes, como el queso de cabra y el vino misional; lo que a la vez apoyaría las iniciativas de turismo rural en la zona. Esa reflexión se basa en el trabajo de campo realizado por los autores en Los Comondú entre 2012 y 2013, que incluyó el análisis de cepas de ambos productos, y en subsecuentes visitas de investigación en 2014 y 2016, las cuales derivaron en la observación de los procesos productivos y festivales del vino y de la fruta; en entrevistas a rancheros productores de queso en ambas comunidades, y de vino en San Miguel, así como a pobladores participantes en las actividades de alojamiento y preparación de alimentos, también en esta última localidad.

El texto está dividido en tres partes tras esta introducción. La primera expone una revisión del turismo rural como elemento de dinamización económica en zonas apartadas; la segunda se refiere a las oportunidades económicas que ofrecen los signos distintivos para la comercialización de productos y servicios artesanales; la tercera aborda las características del queso de cabra y del vino misional de Los Comondú, productos que podrían comercializarse con signos distintivos como el de una mc. También se incluyen algunas consideraciones finales sobre los elementos que habría que contemplar para aprovechar las condiciones de ventaja que poseen los productos agropecuarios artesanales de Los Comondú en términos de la aceptación que tienen entre los consumidores del estado, y del reconocimiento de su valor cultural asociado con la cultura ranchera sudcaliforniana y del oasis.

\section{El turismo rural como una alternativa de dinamización en zonas apartadas}

Uno de los sectores de mayor dinamismo en la estructura económica mundial es el turismo, de manera que se ha convertido en un factor importante en cuanto mecanismo para la diversificación económica y la captación de divisas. En el ámbito internacional, en los primeros cuatro meses de 2018, el arribo de turistas creció 6 \% con relación al año anterior, superando las expectativas de 4 \% que contemplaba la Organización Mundial de Turismo para 2018 (Organización Mundial de Turismo, 2018). Los recursos generados de ese crecimiento significaron el equivalente a $30 \%$ de las exportaciones mundiales de servicios, y casi $70 \%$ para los países en desarrollo en este mismo rubro, lo que lo ha constituido en fuente principal de ingreso para estos países.

Sin embargo el turismo, por lo general identificado con su vertiente "tradicional" (esto es, masificado, del cual el tipo de sol-playa es representativo), está sujeto a "filtraciones" 
económicas asociadas con la repatriación de ganancias, y a dos factores estrechamente relacionados: la especulación con el precio de la tierra y el cambio de uso del suelo para fines de explotación turística (Dávila López, 2014; Brenner y Aguilar, 2002). Esto suele tener efectos adversos sobre los ecosistemas de las regiones donde se inserta (Ibarra Núñez, Gámez y Ortega-Rubio, 2018) y sobre las sociedades ahí establecidas; si bien, en este último sentido, se ha registrado dualidad en torno a las percepciones de tales afectaciones (Monterrubio, Osorio y Benítez, 2018).

Con base en esas consideraciones, acompañar el análisis de las actividades turísticas desde una perspectiva económica, medioambiental y de las relaciones sociales es relevante, en especial respecto a comunidades pequeñas (Mckercher y Du Cros, 2002; Rosas Mantecón, 2006). De tal modo, pueden plantearse formas alternas para aprovechar el potencial turístico en un marco de respeto del medio natural, orientando políticas públicas dirigidas a las actividades del sector turístico en apoyo de proyectos productivos en y para las comunidades locales. Es en este contexto que, en las últimas décadas, ha surgido una corriente para promover y practicar turismo, así como ofrecer servicios turísticos de una manera diferente de la masiva. Ello ha dado cabida a una amplia diversidad de formas de realizar actividades turísticas no convencionales, que incluyen la apreciación de atractivos naturales y manifestaciones culturales con un bajo impacto ambiental y cultural.

Así, la tendencia creciente a experimentar entornos distintos de los urbanos ha propiciado la diversificación de actividades turísticas ligadas a lo cultural (formas de vida, costumbres, alimentos) en las zonas rurales. Aunque el turismo rural no es nuevo, su novedad en la actualidad reside en las características de los turistas (mayor conciencia ambiental e ingreso, demanda de mejor calidad, entre otros factores); lo cual requiere de estrategias para convertir los recursos (naturales, patrimoniales) en productos turísticos (García Henche, 2005, p. 115). Sin embargo, usar esos recursos garantizando el desarrollo de las comunidades rurales y conservando la autenticidad de las experiencias, productos y servicios rurales precisa resaltar el vínculo entre las personas, los lugares y los productos (Vandecandelaere y Abis, 2012).

Pese a lo anterior, con frecuencia son poco conocidos por la población y por los potenciales prestadores de servicios los mecanismos dirigidos a implementar las actividades para concretar su realización. Algunos de los problemas más relevantes al respecto son el bajo nivel de conocimiento del mercado potencial, de nociones de administración, de las formas de comercialización de los productos turísticos, de acceso a financiamiento y de capacitación. La creación y fortalecimiento de micro y pequeñas empresas orientadas al turismo rural permitiría incidir en el desarrollo turístico regional y sentar las bases para un crecimiento que reduzca las externalidades negativas vinculadas con los modelos turísticos tradicionales.

Las asociaciones de pequeñas empresas o de pequeños productores alrededor de algún producto o servicio, como la preparación de alimentos, se ha convertido en una estrategia favorable al desarrollo local (Vandecandelaere y Abis, 2012). En ese contexto, una medida (que no necesariamente requiere de certificación) son las rutas gastronómicas o 
alimentarias, que se desligan de los restaurantes. Una ruta gastronómica es definida como "un itinerario que permite reconocer y disfrutar de forma organizada el proceso productivo agropecuario, industrial y la degustación de la cocina regional considerada una expresión de la identidad cultural regional” (Barrera y Bringas Alvarado, 2009, p. 5). Pero las rutas alimentarias no debieran ser una trivialización turística de la cultura rural, sino un instrumento para el desarrollo de los territorios rurales, de modo que se integren los establecimientos agropecuarios, las agroindustrias y los restaurantes con una visión compartida del desarrollo y con normas de calidad que atiendan tanto al orden sanitario como a la autenticidad de la propuesta.

De acuerdo con Barrera y Bringas Alvarado (2009, p. 47), la construcción de las rutas alimentarias requiere de acciones y políticas que favorezcan el turismo de los alimentos, pero también que tomen en consideración elementos relevantes como: a) sensibilización de la población local en torno al valor de esos alimentos; b) promoción de una vinculación más activa entre los clúster de alimentos y bebidas, y los de turismo; c) desarrollo de productos turísticos memorables; d) un sistema de calidad para la oferta garantizando la inocuidad de los alimentos y la autenticidad de la propuesta; e) marcas de calidad referenciadas en origen y medidas de protección para los alimentos con identidad; f) capacitación, creación y desarrollo de asociaciones de la ruta; g) diseño y puesta en marcha de un plan estratégico con un plan de inversiones; h) investigación y desarrollo de un inventario de los recursos.

Sin duda, la organización alrededor de signos distintivos o de estrategias de comercialización como las rutas gastronómicas no solo involucra la realización de un plan de negocios, sino de un programa de desarrollo rural que tenga en cuenta, como inicio, la voluntad de participación de las comunidades rurales (Sauvage y Gámez, 2013), así como los efectos ambientales y sociales de la transformación productiva asociada con el turismo gastronómico rural. De otra manera, los esquemas de fomento público o privado difícilmente serán exitosos, o lo serán, aunque con una distribución desigual de los beneficios.

\section{Las posibilidades económicas de los signos distintivos}

En el comercio, la propiedad intelectual de los productos en general, y de las marcas en particular, confiere ventajas competitivas a los productores y brinda certidumbre al consumidor sobre los artículos que adquiere. Las formas de protección de los productos son distintas y variadas: Estados Unidos utiliza Do fundamentalmente para vinos, y mc para el resto de los productos; en Europa se suele emplear IG, MC, Do y marcas certificadas, dependiendo de los productos de que se trate; y en México se usa con más frecuencia mc y Do.

Así, a través del Instituto Mexicano de la Propiedad Industrial (IMPI), los derechos de propiedad industrial protegen dos rubros de creaciones en México: los signos distintivos y las invenciones. "Los Signos Distintivos son todos aquellos símbolos, figuras, vocablos o expresiones que se utilizan en la industria o en el comercio para distinguir un producto, servicio o establecimiento, de otros de su misma especie, clase o actividad en el mercado" 
(Instituto Mexicano de la Propiedad Industrial, 2016, p. 11), y reciben protección mediante las marcas, avisos y nombres comerciales, y las Do.

La Do es el nombre de un país, una región o un lugar determinado, que se usa para designar a un producto originario, cuyas cualidades y características se deben exclusivamente al medio geográfico, incluidos factores naturales como geografía, clima o materia prima, y factores humanos como mano de obra, arte, ingenio y tradición, entre otros (Granados y Álvarez, 2004; Secretaría de Economía, 2018). En nuestro país, los gobiernos estatales, municipales o las asociaciones de productores pueden solicitar tal protección, pero cuando se otorga a una Do, el titular es el Estado mexicano.

De 1997 a 2018, las Do mexicanas llegaron a 16, entre ellas cinco destilados (tequila, mezcal, bacanora, sotol y charanda), ocho productos agrícolas (mango Ataulfo del Soconusco de Chiapas, café de Veracruz, café de Chiapas, chile habanero de la Península de Yucatán, chile de Yahualica, vainilla de Papantla, cacao de Grijalba y arroz del estado de Morelos), dos artesanías (maderas y productos de Olinalá, y cerámica de Talavera) y joyería de Ámbar de Chiapas (Instituto Mexicano de la Propiedad Industrial, 2018a). Así, en México, productos con Do como el tequila, o algunos quesos como el Cotija y el Adobera, son elaborados en entornos geográficos muy particulares, y sus características gastronómicas son mundialmente conocidas.

Sus objetivos son, entre otros, establecer normas o un código de prácticas o reglamento de uso para generar sistemas de trazabilidad, verificación y control a fin de garantizar calidad y conformidad; otorgar al producto un valor agregado que se ve reflejado en el precio; favorecer su uso y aprovechamiento y generar ganancias económicas importantes en la comercialización y exportación de los productos; impedir la competencia desleal en la forma de imitaciones o falsificaciones; crear un efecto de derrama económica, incluso en el ámbito turístico; difundir entre consumidores y comercializadores el producto y su calidad; identificar las características del producto y evaluar si tiene posibilidades en los mercados internos y externos.

El registro de las $\mathrm{MC}$ se otorga a petición de agrupaciones formalmente constituidas que reúnan a productores, fabricantes, prestadores de servicios, organizaciones o grupos de personas legalmente establecidos. Al día de hoy, el IMPI ha concedido 174 registros de Mc a asociaciones o sociedades en el país, que distinguen productos agroalimentarios, artesanías, cerámicas, sombreros, ropa y muebles, entre otros (Instituto Mexicano de la Propiedad Industrial, 2018b), en función del:

origen geográfico, el material, el modo de fabricación u otras características comunes de los bienes y servicios de las distintas empresas que utilizan la marca colectiva. El propietario de la misma puede ser una asociación de la que son miembros esas empresas o cualquier otra entidad, ya sea una institución pública o una cooperativa [Organización Mundial de la Propiedad Intelectual, s. f., s. p.].

A diferencia de la Do, que permite a los consumidores conocer la procedencia geográfica de los productos identificados con ella -así como que la calidad proviene de esa 
procedencia-, las mc dan a conocer a los consumidores que los que productos y/o servicios de quienes pertenecen a una misma agrupación comparten determinadas características. En ese sentido, reducen las desventajas en la comercialización que suelen enfrentar los pequeños productores, y les proporcionan un marco para la cooperación. Dado que el establecimiento de normas, criterios y una estrategia común es indispensable para el registro de las Mc, la Organización Mundial de la Propiedad Intelectual (s. f.) resalta su beneficio como instrumento de desarrollo local.

Sin embargo, estudios sobre casos incluso emblemáticos del uso de signos distintivos en México, como el queso Cotija, muestran que las figuras de protección legal no resuelven del todo la indefensión de los productores artesanales. Por ello, se ha adelantado la necesidad de que los marcos legales e institucionales mexicanos se adecuen a las diferentes condiciones de los campesinos y artesanos del país (Barragán López, 2016, pp. 107-108). Es decir, la protección que ofrecen los signos distintivos no está orientada a atender la naturaleza especial de los productos y servicios derivados de las creaciones y tradiciones indígenas o artesanales del país; ni el contexto institucional favorece su aplicación adecuada. Esa situación pone a las comunidades y a su patrimonio en condiciones de vulnerabilidad ante imitadores e industrias consolidadas.

Más aún, la integración a los esquemas de mercado del patrimonio comunitario (indígena o artesanal), como el alimentario, ha sido cuestionada sobre la base de que la valoración (para la comercialización) implica una apropiación cultural; y, por consecuencia, es un ejercicio de poder que no necesariamente queda bajo el control de los propietarios originales. De ese modo, la conexión entre las políticas de desarrollo y los alimentos no es directa y corren el riesgo de ser exotizados, trivializados y descontextualizados (Contreras, Ramírez de la 0 y Thomé Ortiz, 2016, pp. 329-330).

Esa preocupación es compartida en el marco europeo, en la medida en que los proyectos de desarrollo local (rural) anclados en el sector turístico promueven la dependencia económica de un modelo global basado en la diferenciación espacial en zonas productivas y áreas de recreación. En esa perspectiva, la especialización de regiones rurales españolas en el turismo (gastronómico, rural) es señalado como una tendencia hacia el "monocultivo" (Aguilar Criado, Merino Baena y Migens, 2003), con los riesgos que tal especialización conlleva en términos de dependencia y artificialidad.

Lo anterior contempla retos relevantes, para las comunidades en general, al momento de aprovechar las posibilidades y reducir las deficiencias de los signos distintivos para una efectiva protección legal y conservación de los patrimonios. No obstante, como destaca Rinaldi (2017) en el caso de la comida y la gastronomía, las salidas a ese conflicto dependen del tipo de política pública que se promueva, del tipo de estrategias de desarrollo que se realicen, del tipo de turistas que se atraiga y, en especial, del reconocimiento de que los elementos presentes en el territorio o en la comunidad deben ser considerados como un sistema y no como componentes individuales, desligados entre sí. 


\section{A. E. Gámez · E. Juárez · J. A. Guevara-Franco}

\section{Alimentos y bebidas con potencial de signos distintivos en Los Comondú}

Por su alto dinamismo, el turismo en Baja California Sur ha moldeado la economía estatal, y su relevancia no solo se refleja en el propio crecimiento de las esferas de alojamiento, alimentación y bienes inmuebles, sino que ha transformado el paisaje, los patrones migratorios y las relaciones sociales. Una de las razones de ello puede ser que, en un contexto de aridez y prácticamente nula actividad industrial, se ha difundido la percepción de que los beneficios del turismo sobrepasan sus consecuencias negativas. De manera paralela, aunque Sudcalifornia tiene 40 \% de su territorio bajo alguna categoría de protección, el conflicto entre las cuestiones ambientales y el crecimiento turístico no se ha abordado de forma integral (Ibarra Núñez et al., 2018). Efectos como el desmonte, la escasez de agua, el congestionamiento urbano y sus derivaciones son visibles desde ahora (Moreno Gómez, 2016) y, lo más probable, es que se exacerben en el futuro inmediato.

Asimismo, el aprovechamiento y difusión de los aspectos culturales regionales (como la gastronomía) es incipiente, ${ }^{1}$ no habiendo sido suficientemente integrado a la oferta turística, en especial en las comunidades rurales. Pese a ello, hay un área de oportunidad aprovechable considerando una tendencia positiva de los hogares estadounidenses - de donde se alimenta predominantemente el sector turístico sudcaliforniano- a participar en actividades culturales (Consejo de Promoción Turística de México, 2008).

En el caso de Baja California Sur, se pueden identificar más de 25 productos alimentarios frescos o procesados que tienen características diferenciales y que son reconocidos por los consumidores locales por su origen geográfico de algunas zonas del estado. De ellos, al menos cinco son derivados lácteos, cuatro derivados cárnicos, cinco frutas procesadas, dos frutas frescas, cuatro platos preparados, dos bebidas alcohólicas y, al menos, dos dulces típicos; esto sin considerar granos y tubérculos que forman parte de la gastronomía del rancho sudcaliforniano (Guevara-Franco, 2018). El sistema contemporáneo de ranchos proviene de los asentamientos estimulados por los misioneros jesuitas en su proceso de evangelización y colonización de la península de Baja California en el siglo xVII. En un contexto de aridez y aislamiento, misioneros y rancheros se establecieron junto a las escasas fuentes superficiales de agua, lo cual transformó la demografía de la región por la extinción de los indígenas, y del paisaje con las misiones y la construcción de los oasis (Cariño, 2001).

Los Comondú constituye uno de los oasis de mayor tamaño y mejor conservado de los 184 presentes en la península de Baja California (Arriaga y Rodríguez-Estrella, 1997), y es representativo de la historia, problemática y potencialidad de estos sistemas (Tenza, Pérez, Martínez-Fernández y Giménez, 2017). La población total de los dos núcleos de población asociados al oasis -San José y San Miguel de Comondú-, así como de los ranchos

Existen varias obras dedicadas a la representación visual de la naturaleza sudcaliforniana; dentro de las muy escasas sobre gastronomía, véase Macías Gómez (2015). 
aledaños, es de 257 habitantes (Secretaría de Desarrollo Social, 2013). En torno al oasis se organiza un sistema tradicional de ganadería extensiva de ganado bovino y caprino. Empero, en años recientes, desde la política pública se ha estimulado la actividad turística rural como un mecanismo de dinamización económica (Gámez, Angeles y Juárez, 2013; Ivanova, Gámez, Domínguez y Ramírez, 2013).

El principal ingreso de los productores en San Miguel y San José de Comondú (en esta última localidad se ubica una misión jesuita) es la venta de queso seco salado, seguida por la venta de cabrito y becerro. Sin embargo, sus factores más limitantes son la vulnerabilidad ante el alargamiento de las épocas de sequía, el alto intermediarismo, el abigeato, la depredación, así como la falta de organización de los productores, de financiamiento y de canales adecuados de comercialización. A ello se añade la ausencia de parámetros de calidad e inocuidad en el sector primario que permita a los productores locales competir en el mercado y que alienten la transformación agroindustrial. De los productos elaborados en la región destacan el queso, los dulces y algo de vino, que complementan los ingresos en esas economías casi de autosubsistencia.

La caprinocultura es una actividad rural socioeconómicamente importante en Baja California Sur, de la cual dependen directa e indirectamente cientos de familias. La producción de queso blanco oreado de cabra se realiza a pie de rancho. La elaboración del queso seco de cabra comprende los pasos básicos de clarificación, cuajado, salado, desuerado, y prensado en moldes fabricados con madera de la región. La leche proviene de cabras, principalmente, de la raza Nubia y sus cruzas con Saanen, Toggenburg y Alpina, adaptadas mejor a climas secos y alimentadas en su mayoría con vegetación silvestre. El queso se deja orear por alrededor de 15 días, y la falta de condiciones de refrigeración en la zona explica las altas concentraciones de sal para conservar el producto (Tapia Rendón, 2013).

Este queso es bien identificado por los consumidores locales, por su localización geográfica, como queso seco de Los Comondú, debido a que su producción se restringe al oasis conformado por las dos poblaciones sudcalifornianas mencionadas. Este queso es sensorialmente preferido por el consumidor por su sabor, olor y apariencia general. No obstante, su calidad microbiológica es baja, toda vez que es preparado con leche cruda de cabra, sin pasteurizar. En la actualidad, el queso se comercializa a través de intermediarios y, en su mayoría, es enviado a Sinaloa, Sonora y Jalisco. Este producto es poco conocido en las ciudades de Baja California Sur y no está disponible en restaurantes ni hoteles de los corredores turísticos del estado.

La organización de productores alrededor de la defensa de la calidad del producto en el marco normativo e institucional puede acelerar el registro y protección del "queso seco de cabra de Los Comondú”. Dadas las condiciones locales, ello mejoraría la rentabilidad de quienes lo producen, pero se requeriría de estudios de caracterización física-química, organoléptica y microbiológica que definan con claridad los métodos de producción y las características que dieran lugar, por ejemplo, a una mc; lo cual podría ser un ejercicio más realizable en el corto plazo que, por ejemplo, una Do. Asimismo, haría procedente que los productores locales se organizaran para regular la presentación y comercialización del queso. 


\section{A. E. Gámez · E. Juárez · J. A. Guevara-Franco}

Otro producto con potencial de mc es el vino misional, elaborado a partir de una variedad de uva conocida por los pequeños vitivinicultores artesanales de la región como "misional”. Esta se asocia con la uva que se utilizaba para la preparación del vino de consagrar en las misiones jesuitas, aunque no se sabe a ciencia cierta el tiempo de existencia de este producto. Solo algunos vestigios de equipos como prensas, filtros y fermentadores realizados a base de piel bovina en un marco de madera indican que se elabora tradicionalmente (Guevara et al., 2013).

Hoy en día, se empieza a reconocer la calidad del producto y, alrededor del vino, se Ileva a cabo un festival del vino misional de Los Comondú, que se extiende a otros oasis aledaños, y en sus ediciones ha tenido la participación de sommeliers de España y México. Esto se ha convertido en un atractivo turístico y toda la oferta (si bien es pequeña) es vendida a turistas y visitantes a los poblados, e incluso en ocasiones es distribuida al menudeo en la ciudad de La Paz. El producto es sensorialmente atractivo y se puede comparar con otros vinos jóvenes de calidad; pero, pese a que tiene una calidad organoléptica bien definida, la alternativa de constituirse en un producto de Mc o de Do implica determinar, en principio, si el producto no representa un riesgo para la salud. Ello, a la vez, requiere destacar su inocuidad y las mejores características fisicoquímicas. Los vinos jóvenes, de crianza, son bebidas alcohólicas de acuerdo con la NMX-V-012-1986, por lo cual la cantidad de alcohol debe estar bien especificada para el consumidor mediante una etiqueta en una mejor forma de presentación.

Es necesario, entonces, plantearse algunas estrategias que mejoren la calidad e inocuidad del producto y eleven la producción de uva mediante la implementación de prácticas de producción agrícola y la reducción de riesgos de contaminación durante las etapas fenológicas del cultivo. La recomendación es que se realice un diagnóstico en este rubro, donde se determinen las características de la variedad de uva, las mejores prácticas agronómicas, se clasifiquen los viñedos y se haga un inventario de las cepas y, en su defecto, se busquen alternativas para incrementar el número de cepas.

Asimismo, se debe capacitar en el uso del agua, y ofrecer cursos sobre manejo vegetativo del cultivo, buenas prácticas agrícolas y tratamiento poscosecha de la uva, así como sobre prácticas de higiene en la elaboración del vino y factores que afectan su calidad y métodos de producción. En cuanto a la infraestructura, es menester desarrollar proyectos para el establecimiento de pequeñas bodegas que cumplan con los requisitos de higiene en la elaboración del producto. Respecto al queso de cabra, han de tomarse medidas similares. De ser de interés, se puede apoyar investigación que determine los microorganismos benéficos que favorecen la fermentación y así distinguir un cultivo iniciador de la fermentación del vino y del queso para esa pequeña región.

Como se ha indicado, en ambas comunidades el queso de cabra y el vino misional son productos con un valor significativo para la economía familiar en la región. Sin embargo, pese a que la producción de queso de cabra está más generalizada que la de vino misional, es esta en la que se ha centrado la política de promoción de turismo rural en la zona. Además, a casi ocho años de iniciada una explícita política de aprovechamiento turístico del 
pasado misional en Los Comondú, los resultados son aún ambiguos y sigue siendo preciso replantear sus procesos de organización y de producción para revalorar el patrimonio gastronómico, así como cuidar la inocuidad de los productos.

En todo caso, independientemente de proceder a la organización de productores alrededor de una mc u otro signo distintivo, un elemento prioritario es garantizar la inocuidad de los productos locales. Tanto el queso como el vino son productos conocidos, ya comercializados y que, de cierta forma, han sido patrimonializados a través de una larga historia de producción artesanal y de las iniciativas de turismo rural en Los Comondú y en zonas similares de los últimos años.

\section{Conclusiones}

Algunos alimentos, como el queso de cabra y el vino misional producidos en zonas rurales serranas en Baja California Sur, ofrecen una oportunidad para aprovechar productos agroalimentarios tradicionales a fin de mejorar las condiciones de vida de las poblaciones locales, ya que se encuentran vinculados con tradiciones de producción artesanal, con zonas geográficas específicas, y tienen características de alta calidad sensorial. El aislamiento geográfico y la conformación del territorio por grandes cañadas y valles delimitados unos de otros mantienen una riqueza gastronómica centenaria que se ha conservado desde la época misional. Sin embargo, para formalizar su aprovechamiento a través de signos distintivos y potenciar sus posibilidades de comercialización, aún es necesario reducir la variabilidad de productos, y generar estudios de ubicación geográfica, calidad e inocuidad, así como estrategias de intervención para ligar esos esfuerzos a un turismo rural incipiente.

Pese a la existencia de políticas de fomento del turismo rural y de comercialización de los productos locales en Los Comondú desde hace casi una década, no se ha avanzado en el mejoramiento de las condiciones con que se realiza su oferta. En particular, destaca la importancia de establecer esquemas de capacitación a los productores locales para un manejo adecuado de los alimentos en todo su proceso. La finalidad de esto es que los estudios que se realicen tengan una aplicación efectiva, lo cual implica identificar a los integrantes del sector interesados en desarrollarlas, además de ubicar las fuentes de apoyos diversos para la puesta en práctica de esas actividades alternativas. En este sentido, a partir de investigaciones sobre el manejo pecuario y agrícola, se pueden realizar mejoras a los procesos productivos, así como garantizar la inocuidad alimentaria y la conveniencia de procesos de certificación en beneficio de los productores y comunidades locales. Esto tendría que ir aparejado de capacitación y conocimiento en el tema turístico, y de mecanismos para enfrentar los efectos socioculturales que van asociados con la introducción del turismo en la vida de las comunidades y las familias.

Algunas recomendaciones que pueden adelantarse son llevar a cabo estudios que determinen la calidad tecnológica, sensorial y microbiológica, que aseguren su inocuidad. Ningún plan de comercialización o de establecimiento de rutas alimentarias será realmente viable si en el lugar no se cambian las formas como se realiza la producción. Entre otros 


\section{A. E. Gámez · E. Juárez · J. A. Guevara-Franco}

factores esto se relaciona con: a) las prácticas productivas (falta de inocuidad); b) la actitud de los productores y pobladores respecto a sus formas de organización, capacitación, y percepción de su patrimonio (tanto tangible como intangible); y c) el tipo de intervención efectuada por los diferentes niveles de gobierno.

Revisar el marco legal y la organización de los signos distintivos, como Do y Mc, y adecuarlo a las características de los productos sudcalifornianos, puede ser una estrategia para facilitar las posibilidades de mc de productos de Los Comondú. En México existe experiencia incluso con productores pequeños que puede ser compartida. Por otro lado, la promoción y apropiación de las marcas por parte de los consumidores fortalecería la concientización de los productores respecto a la importancia de valorar y diferenciar sus productos con base en la calidad, su origen y tradición. Esto bien podría contribuir al fortalecimiento del incipiente turismo rural en la zona.

Las características ecosistémicas de Los Comondú hacen poco factible incrementar en una escala masiva la producción y comercialización de sus productos agropecuarios. Empero, el turismo rural ligado a rutas alimentarias en pequeña escala o eventualmente en mc permitiría rescatar la idea de aprovechar la calidad de productos como el queso y el vino, a través de estudios de laboratorio sobre sus condiciones e inocuidad. Además, es pertinente promover una política de desarrollo rural que integre la conformación histórica y sociocultural de ambas comunidades, las relaciones con el exterior y la influencia de agentes extralocales, las condiciones en que se realizan las actividades económicas, los usos de recursos clave como el agua, y la cultura productiva local. Un esquema de fortalecimiento productivo integral que permita el desarrollo y empoderamiento de la propia comunidad puede ser potenciado con un aprovechamiento alterno de los recursos locales. Dado que Los Comondú no son un caso aislado en la búsqueda de opciones para el cumplimiento de esos objetivos, un esquema así podría extrapolarse a comunidades rancheras y de oasis similares en el resto del estado.

\section{Fuentes consultadas}

Aguilar Criado, E., Merino Baena, D. y Migens, M. (2003). Cultura, políticas de desarrollo y turismo rural en el ámbito de la globalización. Horizontes Antropológicos, 9(20), 161183. Recuperado de https://dx.doi.org/10.1590/S0104-71832003000200009

Arriaga, L. y Rodríguez-Estrella, R. (1997). Los oasis de la península de Baja California. La Paz, Baja California Sur: Centro de Investigaciones Biológicas del Noroeste.

Barragán López, E. (2016). Entre oportunidades y obstáculos. Lo que devela el proceso de inserción del queso Cotija artesanal en la economía formal. EntreDiversidades. Revista de Ciencias Sociales y Humanidades, 7, 84-111.

Barrera, E. y Bringas Alvarado, O. (2009). La ruta de la sal prehispánica de Zapotitlán Salinas, una estrategia de desarrollo comunitario basada en los alimentos con identidad local. Cultura, Tecnología y Patrimonio, 4(7), 33-48.

Breceda, A., Galina, P. y Cortés, P. (2010). Estrategias de conservación para los oasis de Baja California: un estudio de caso. Taller de Dunas Costeras y Humedales: Futuro y 
Conservación. Comisión Nacional de Áreas Naturales Protegidas, 2 de septiembre, San José del Cabo, Baja California Sur. Recuperado de http://ramsar.conanp.gob. $\mathrm{mx} /$ talleres.php

Brenner, L. y Aguilar, A. G. (2002). Luxury tourism and regional economic development in Mexico. The Professional Geographer, 54(4), 500-520. doi:10.1111/00330124.00346

Cariño, M. (2001). La oasisidad, núcleo de la cultura sudcaliforniana. Gaceta Ecológica, 60, 57-69.

Consejo de Promoción Turística de México. (2008). Análisis del mercado internacional del turismo de cultura 2007. México: Autor.

Consejo Nacional de Ciencia y Tecnología. (2018). Fondo Mixto CONACYT-Gobierno del Estado de Baja California Sur. Convocatoria BCS-2018-01 "Desarrollo e Localidades Serranas de Baja California Sur". Demanda Específica Demanda BCS-2018-01-01 Programa de Desarrollo Sustentable de las Localidades Serranas de Baja California Sur. Recuperado de https://www.conacyt.gob.mx/index.php/el-conacyt/ convocatorias-y-resultados-conacyt/convocatorias-fondos-mixtos-contituidos / convocatorias-fondos-mixtos-constituidos-baja-california-sur/convocatorias-abiertas-fondos-mixtos-constituidos-baja-california-sur / 18-01-fomix-bcs / 17870-fomix-bcs-18-01-dem-espec/file

Contreras, D. J., Ramírez de la O, I. L. y Thomé Ortiz, H. (2016). Entre el desarrollo económico y la apropiación cultural. Apuntes para el debate sobre la valorización de alimentos emblemáticos. Estudios Sociales, 47(25), 327-347.

Coordinación General de Desarrollo Sustentable. (2015). Proyecto estratégico de desarrollo sustentable oasis sudcalifornianos. La Paz, Baja California Sur: Gobierno del Estado de Baja California Sur. Recuperado de https://docplayer.es/11480713-Proyecto-estrategico-de-desarrollo-sustentable-oasis-sudcalifornianos.html

Dávila López, A. (2014). Centros Integralmente Planeados (CIPs) en México. Las piezas del proyecto turístico de FONATUR. VI Seminario Internacional de Investigación en Urbanismo, Barcelona-Bogotá, junio 2014. Recuperado de https://upcommons.upc. edu/bitstream/handle/2099/15985/075_BCN_Davila_Arturo.pdf

Gámez, A. E. (ed.). (2013). Opciones de desarrollo en el oasis de Los Comondú, Baja California Sur, México. México: Instituto Sudcaliforniano de Cultura/Universidad Autónoma de Baja California Sur/Consejo Nacional de Ciencia y Tecnología.

Gámez, A. E., Angeles, M. y Juárez, E. (2013). Turismo y emprendedurismo en regiones rurales de México: una crítica al rol del capital social en el desarrollo local. El caso del oasis de Los Comondú. TURyDES. Revista de Investigación en Turismo y Desarrollo Local, 6(14). Recuperado de http://www.eumed.net/rev/turydes/14/turismo-regiones-rurales-mexico.pdf

García Henche, B. (2005). Características diferenciales del producto turismo rural. Cuadernos de Turismo, 15, 113-133.

Granados, L. y Álvarez, C. (2004). Estudio introductorio sobre la viabilidad de las denominaciones de origen de los productos agroalimentarios en Costa Rica a partir de la experiencia en la Comunidad Autónoma de Galicia. Revista Gallega de Cooperación Científica Iberoamericana, 10, 9-19. 


\section{A. E. Gámez · E. Juárez · J. A. Guevara-Franco}

Guevara, J., Juárez, E., Gámez, A. E. y Rojas, M. (2013). Los Comondú: opciones de agregación de valor a los productos locales. En A. E. Gámez (ed.), Opciones de desarrollo en el oasis de Los Comondú, Baja California Sur, México (pp. 181-208). México: Instituto Sudcaliforniano de Cultura/Universidad Autónoma de Baja California Sur/ Consejo Nacional de Ciencia y Tecnología.

Guevara-Franco, A. (2018). Documento de trabajo [mimeo]. La Paz, Baja California Sur: Universidad Autónoma de Baja California Sur, Departamento Académico de Ciencia Animal y Conservación del Hábitat.

Ibarra Núñez, E., Gámez, A. E. y Ortega-Rubio, A. (2018). Impacto territorial del turismo en Zonas Prioritarias para la Conservación y Ecosistemas Prioritarios de Baja California Sur, México. Sociedad y Ambiente, 6(17), 33-58.

Instituto Mexicano de la Propiedad Industrial. (2016). Guía del usuario para el Registro de Marcas, Avisos y Publicación de Nombres Comerciales. México: Autor. Recuperado de https://www.gob.mx/cms/uploads/attachment/file/54262/GDU_Marcas.pdf

Instituto Mexicano de la Propiedad Industrial. (2018a). Servicios que ofrece el IMPI, Marcas, Denominaciones de Origen e Indicaciones Geográficas. México: Autor. Recuperado de https://www.gob.mx/impi/acciones-y-programas/servicios-que-ofrece-el-impi-marcas-denominaciones-de-origen-e-indicaciones-geograficas

Instituto Mexicano de la Propiedad Industrial. (2018b). Ventajas de contar con una marca-colectiva. Recuperado de https://www.gob.mx/impi/articulos/ventajas-de-contar-con-una-marca-colectiva

Ivanova, A., Gámez, A., Domínguez, W. y Ramírez, E. (2013). Turismo sustentable y desarrollo local en el oasis de los Comondú. En M. Cariño, A. Breceda, A. Ortega y L. Castorena (eds.), Evocando al edén: conocimiento, valoración y problemática del oasis de los Comondú (pp. 481-516). Barcelona: Icaria.

Macías Gómez, B. E. (2015). Gastronomía de los zafiros. Arte que surge del mar y el desierto de Sudcalifornia. México: Instituto Sudcaliforniano de Cultura.

Mckercher, B. y Du Cros, H. (2002). Cultural Tourism. The Partnership between Tourism and Cultural Heritage Management. Nueva York: The Haworth Hospitality Press.

Millán Vázquez de la Torre, M. G. y Agudo, E. M. (2010). El turismo gastronómico y las Denominaciones de origen en el sur de España: Oleoturismo. Un estudio de caso. Pasos. Revista de Turismo y Patrimonio Cultural, 8(1), 91-112. Recuperado de http:// www.pasosonline.org/Publicados/8110/PS0110_8.pdf

Monterrubio, C., Osorio, M. y Benítez, J. (2018). Comparing enclave tourism's socioeconomic impacts: A dependency theory approach to three state-planned resorts in Mexico. Journal of Destination Marketing \& Management, 8, 412-422.

Moreno Gómez, G. (2016). Capacidad de carga urbana y análisis espacio-temporal del crecimiento de La Paz, B.C.S., México (Tesis de maestría en Ciencias Sociales con orientación en Desarrollo Sustentable). Universidad Autónoma de Baja California Sur, La Paz.

Organización Mundial de la Propiedad Intelectual. (s. f.). Las marcas colectivas. Recuperado de http://www.wipo.int/sme/es/ip_business/collective_marks/collective_marks.htm

Organización Mundial del Turismo. (2018). Notas metodológicas de la base de datos de estadísticas de turismo, edición 2018. Madrid: Autor. 
Peninsular Digital. (21 de diciembre de 2011). Invierte gobierno 13.5 mdp en oasis Mulegé. Peninsular Digital. Recuperado de http://peninsulardigital.com/municipios/ invierte-el-gobierno-13-5-mdp-en-oasis-de-mulege/63429

Rinaldi, C. (2017). Food and gastronomy for sustainable place development: A multidisciplinary analysis of different theoretical approaches. Sustainability, 9(10), 1748. doi: $10.3390 /$ su9101748

Rosas Mantecón, A. (2006). Turismo y patrimonio: realidades y espejismos de una promesa. En L. Arizpe (ed.), Retos culturales de México frente a la globalización (pp. 473-497). México: Porrúa.

Sauvage, A. y Gámez, A. E. (2013). Desarrollo, identidad cultural y turismo en los oasis de Baja California Sur, México. Pasos. Revista de Turismo y Patrimonio Cultural, 11(1), 159-172.

Secretaría de Desarrollo Social. (Julio, 2013). Catálogo de Localidades. Resumen municipal. Municipio de Comondú. Recuperado de http://www.microrregiones.gob.mx/catloc $/$ Default.aspx?tipo=clave\&campo $=$ mun\&valor $=03$

Secretaría de Economía. (2 de julio de 2018). México cuenta con 16 denominaciones de origen. Recuperado de https://www.gob.mx/se/articulos/mexico-cuenta-con-16-denominaciones-de-origen

Tapia Rendón, N. A. (2013). Caracterización de la calidad tecnológica e inocuidad del queso seco de cabra producido en el oasis de San Miguel y San José de Comondú, BCS (Tesis de médico veterinario zootecnista). Universidad Autónoma de Baja California Sur, Departamento de Zootecnia, La Paz.

Tenza, A., Pérez, I., Martínez-Fernández, J. y Giménez, A. (2017). Understanding the decline and resilience loss of a long-lived social-ecological system: Insights from system dynamics. Ecology and Society, 22(2), 15. Recuperado de https://doi.org/10.5751/ ES-09176-220215

Vandecandelaere, E. y Abis, S. (2012). Food, tourism and regional authorities. En Mediterra (pp. 423-442). París: Presses de Sciences Po. 


\title{
¿QUÉ OPINAN NUESTROS TURISTAS? \\ UN ANÁLISIS TEMÁTICO EN TRIPADVISOR SOBRE ATRACTIVOS TURÍSTICOS DE LA CIUDAD DE GUANAJUATO
}

\author{
Rafael Guerrero RodríGuez \\ r.guerrero-rodriguez@ugto.mx \\ MónICA Pérez SánCHeZ \\ moniperez@ugto.mx \\ Departamento de Gestión y Dirección de Empresas \\ Universidad de Guanajuato \\ Ilia Alvarado Sizzo \\ ialvarado@igg.unam.mx \\ Instituto de Geografía \\ Universidad Nacional Autónoma de México
}

El objetivo central de esta investigación fue analizar las principales temáticas incluidas en las opiniones sobre algunos de los atractivos turísticos más importantes de la ciudad de Guanajuato, México. A través de la revisión de su contenido en el foro digital TripAdvisor, se intentó comprender mejor la manera en que los viajeros comunican sus experiencias identificando lo que les es más significativo en los lugares que visitan. El hallazgo más relevante se refiere a que los grupos de turistas nacionales y extranjeros presentan una tendencia muy similar en la valoración de sus experiencias. La información de este trabajo puede ser útil para identificar los elementos que contribuyen a construir esas percepciones.

Palabras clave: Guanajuato, atractivos, opiniones, TripAdvisor, turismo.

\section{What do OUR tourists think? A thematic analysis on TripAdvisor ABOUT TOURIST ATTRACTIONS IN THE CITY OF GUANAJUATO}

The main objective of this research was to analyze the main themes included in the opinions about some of the most important tourist attractions in the city of Guanajuato, Mexico. Based on a content review in the TripAdvisor digital forum, it was attempted to better understand the way visitors communicate their experiences identifying the most meaningful elements in the places they visit. The main finding is related to the similar trend among domestic and international tourists when valuing their experience. The information of this study can be useful to identify the elements that contribute to building these perceptions.

Keywords: Guanajuato, attractions, opinions, TripAdvisor, tourism. 


\section{Introducción}

$\mathrm{E}$ n los últimos años, los avances tecnológicos en el área del turismo han desempeñado un papel cada vez más relevante en lo que se refiere tanto a la gestión turística de los destinos como al proceso de decisión de los viajeros. La adopción de internet y la Web 2.0 como principal medio de comunicación han permitido que los viajeros contemporáneos tengan más foros de expresión y comunicación donde todos los días se dejan millones de registros digitales relacionados con reseñas sobre productos, servicios, destinos y atractivos turísticos.

Estas referencias de información digital son conocidas en la literatura como opiniones on-line de viaje (oov) y se han convertido en un factor determinante dentro de la construcción de la experiencia turística en sus diferentes fases: inspiración, ejecución del viaje y rememoración. Esta literatura se ha extendido a lo largo de los últimos 15 años, cubriendo distintos enfoques teóricos vinculados con temáticas como: construcción de la imagen del destino (Marine-Roig, 2017), percepciones y comportamiento del visitante (Lopes, Kastenholz y Abrantes, 2015; Nilashi et al., 2018), mejoras en la calidad de los servicios (Egresi, 2017; Kim y Park, 2017; Zhang y Vásquez, 2014), planeación turística (Baka, 2016; Pongwat, 2017; Wilson, Murphy y Fierro, 2012) y diseño de experiencias turísticas (Barreda y Bilgihan, 2013; Pantano, Priporas y Stylos, 2017). Esta información, en la mayoría de las ocasiones, tiene más peso dentro de las decisiones de viaje, ya que goza de mayor credibilidad y reputación que aquella que difunden las fuentes oficiales, debido a que se percibe como el "consejo experto" de una persona que ya vivió aquello que se piensa comprar o consumir (Chua y Barnerjee, 2013; Coursaris, Van Osch y Albini, 2017; Filieri, Alguezaui y McLeay, 2015; Groth, Constantini y Schlögl, 2017; Jeacle y Carter, 2011; Lee, Hu y Lu, 2018). En ese sentido, se ha vuelto una práctica común para las personas acudir a estas fuentes de información antes de tomar una decisión de viaje, las cuales influyen de manera directa en ella (Zeng y Gerritsen, 2014).

El objetivo principal de este trabajo fue analizar la información contenida en las oov vinculadas con algunos de los atractivos turísticos más relevantes de la ciudad de Guanajuato, México. A través de la revisión del contenido de las opiniones escritas por los visitantes a este destino turístico, se intentó comprender mejor la manera en que estos perciben su experiencia de viaje al identificar aquellos elementos que les son más o menos agradables en los atractivos que visitan. Para este fin, se tomó como principal referencia el foro mundial digital más importante relacionado con reseñas de viaje: TripAdvisor. Esta plataforma concentra actualmente una gran cantidad de referencias personales asociadas con evaluaciones sobre establecimientos de alojamiento, alimentación, entretenimiento, transporte, atractivos turísticos y recomendaciones en general sobre qué hacer en determinados destinos de acuerdo con las preferencias y gustos de los viajeros. En el caso de Guanajuato, TripAdvisor agrupa un total de 26 atractivos dentro de su categoría "Monumentos y lugares de interés", mismos que cuentan con un número diverso de opiniones tanto de visitantes nacionales como extranjeros. 
Por ello, se estudiaron las narrativas y temáticas que se refieren a aquellos atractivos que gozaron de mayor interés por parte de los viajeros y usuarios de esta plataforma, registrando una cantidad considerable de reseñas (por lo menos más de 500). A partir de la revisión del contenido de las oov sobre estos atractivos, se identificaron aspectos positivos y negativos percibidos por los visitantes en estos espacios, así como las temáticas dominantes al reflexionar, comunicar y evaluar su experiencia. Se piensa que esta información es bastante útil no solo para conocer las percepciones reales de los viajeros a la ciudad de Guanajuato, sino también para identificar y proponer áreas de mejora dentro de la gestión turística de estos atractivos.

Como ejemplos de investigaciones relacionadas con la que aquí se presenta se pueden mencionar las de Compagnone (2017), De Ascaniis y Gretzel (2013), De Ascaniis y Cantoni (2014, 2017), Dellarocas (2003), Gretzel (2006, 2007), Gretzel y Yoo (2008), Hennig-Thurau, Gwinner, Walsh y Gremler (2004), McKenzie y Adams (2018), Owens (2012), Vásquez (2012) y Xiang y Gretzel (2010). En ellas se señala como un parteaguas la aparición de la Web 2.0 en el campo de la comunicación humana, misma que hizo posible una mayor interacción entre los usuarios de internet y que posteriormente dio origen a la multiplicación de los llamados contenidos generados por el usuario (CGU). El surgimiento de los cGU puede entenderse como el proceso de democratización de la web, donde las personas vieron la oportunidad de crear nuevos foros de expresión y comunicación tanto sincrónica como asincrónica, de forma digital. En este sentido, las plataformas digitales que permiten la generación de cGU han crecido de manera exponencial, atrayendo la atención y participación activa de millones de personas todos los días (Facebook y Twitter son los ejemplos de plataformas digitales más representativos de esta tendencia). Asimismo, estos estudios resaltan el papel de los cGu en el campo del turismo, en particular en el caso de las oov, las cuales se han convertido en un elemento influyente dentro de la construcción de la experiencia y las decisiones de viaje. Con base en diferentes propuestas metodológicas (el análisis de discurso, el análisis de contenido, el análisis argumentativo, el análisis de frecuencia estadística, entre otros), estos trabajos han examinado lo que se comenta en diversos foros digitales especializados en turismo, abriendo el debate sobre la pertinencia de establecer estrategias de monitoreo de información a fin de tener mayor comprensión de cómo se construyen las percepciones individuales a partir de la comunicación de experiencias de viaje. A pesar de que este tipo de investigaciones no son tan recientes dentro de la literatura existente, en el caso de México, desafortunadamente, aún no hay información suficiente asociada con este tema que permita visualizar mejor la naturaleza y las características de este fenómeno social. Por esa razón, la realización de este tipo de estudios en el contexto mexicano se considera pertinente y necesaria para intentar cerrar la brecha de conocimiento en este campo.

El artículo se encuentra organizado en cinco secciones, incluyendo esta introducción. La segunda sección se refiere a la contextualización teórica de este estudio. La tercera describe la propuesta metodológica aquí adoptada respecto al proceso de recolección y análisis de la información. La cuarta presenta los resultados principales derivados del 
proceso de investigación. La última sección está constituida por las conclusiones y algunas recomendaciones tanto para la gestión turística de algunos de los atractivos estudiados como para la identificación de alternativas para futuras investigaciones similares.

\section{CGU y 00V y su relevancia para las prácticas del turismo contemporáneo}

En el proceso de toma de decisión para llevar a cabo un viaje y visitar algunos sitios en el destino elegido, no hay duda de que la recomendación personal o el "boca a boca" sigue siendo un factor determinante. Con el vertiginoso desarrollo tecnológico que el mundo ha experimentado en las últimas dos décadas, el significado de "boca a boca" se ha diversificado hacia ámbitos presenciales y virtuales. La existencia y proliferación de foros digitales en la Web 2.0 ha dado origen a nuevas prácticas de comunicación que han sido ampliamente adoptadas por los usuarios de internet. Lo anterior quiere decir que, a partir de la creación de estos espacios de expresión digital, las personas han expandido sus posibilidades de opinar libremente sobre variados asuntos que son del interés de los usuarios, incluyendo al turismo. Los cGu son esos registros creados por los usuarios en los diversos foros digitales existentes en internet con el propósito que otros usuarios puedan saber esa información, beneficiarse de ella y/u opinar sobre su utilidad y validez. De Ascaniis y Cantoni (2017) señalan que los usuarios confían cada vez más en la información que generan otros usuarios para tomar decisiones importantes como qué comprar, a dónde ir, qué visitar, etc. Dellarocas (2003) menciona tres razones por las cuales los usuarios confían en ella: 1) la información vertida no posee ningún fin comercial o de lucro; 2) la información refleja una experiencia vivida que convierte al autor en "experto calificado"; y

3) los intereses entre quien escribe y lee son comunes, por lo cual se desarrolla un vínculo de entendimiento natural.

Las oov pueden ser consideradas una variante especial de cGU. Este tipo de comunicación se caracteriza por hacer referencia a experiencias de viaje en foros digitales especializados en turismo. Algunos ejemplos de este tipo de foros digitales son City Guides, Dopplr, Foursquare, Gogobot, Google Reviews, Lonely Planet, Minube, Touristeye, Trippy Tripwolf, Twigmore y TripAdvisor. En ellos, los usuarios registran sus experiencias y construyen argumentos escritos a favor o en contra de los lugares que visitan. Es importante apuntar que la disponibilidad de esta información ha crecido exponencialmente y se ha vuelto un factor de referencia especial a la hora de planificar las visitas en los destinos turísticos. Un reporte de Google (2014) acerca de factores de decisiones de viaje señala que un importante número de personas hace una investigación exhaustiva previa a su viaje acerca de dónde y cómo quieren realizarlo. Este proceso de investigación incluye la determinación de lugares de visita en el o los destinos seleccionados, y es en esta fase donde las oov se convierten en un factor determinante para seleccionar o descartar sitios por visitar. La influencia que tienen las valoraciones positivas y/o negativas, así como la construcción colectiva de advertencias y recomendaciones, hace que estos foros se vuelvan una fuente de referencia 
primordial para los viajeros. Google (2014) estimaba que al menos $74 \%$ de turistas que viajan por motivos de descanso o placer, revisan oov relacionadas con la oferta de transporte, hospedaje, alimentación, entretenimiento y lugares de interés turístico.

Como se puede apreciar en la figura 1, el proceso de decisión de viaje consiste en seis etapas claramente distinguibles: inspiración, planeación, comparación, compra, viaje y aquella después del viaje. De acuerdo con la literatura especializada, las oov pueden tener influencia dentro de las decisiones de los viajeros a lo largo de las primeras cinco etapas, y en la última, como medio de expresión y comunicación con otros posibles interesados.

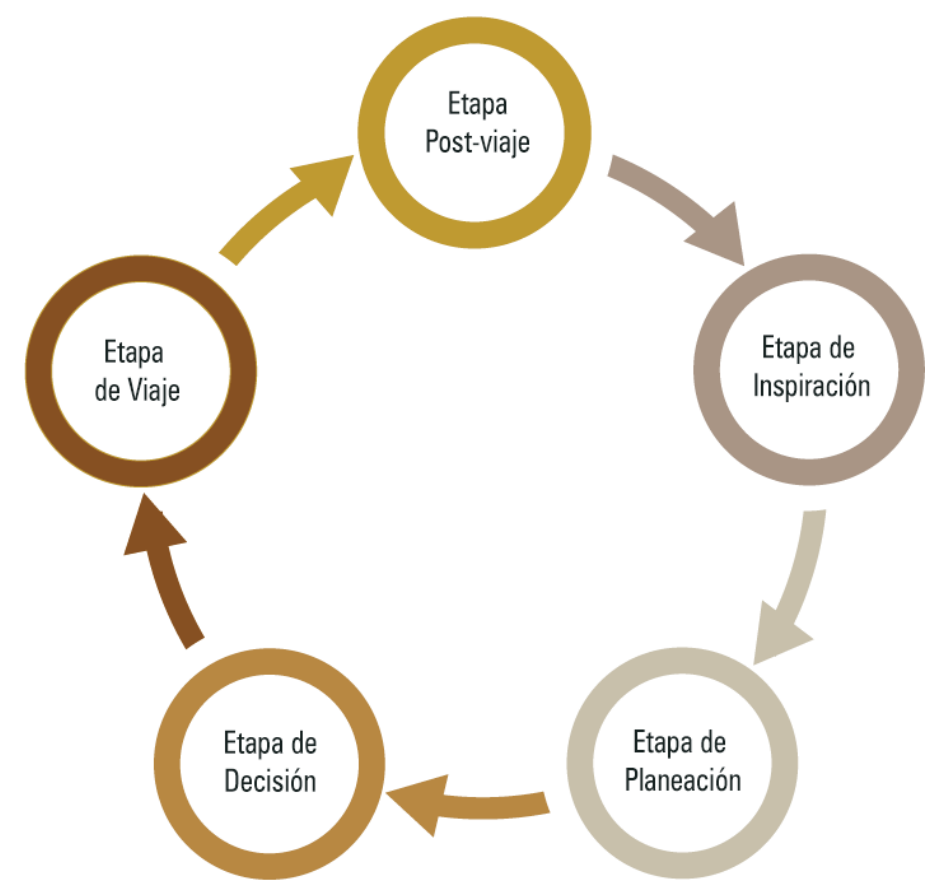

Fuente: Elaboración propia.

Figura 1. Modelo de proceso de decisión de viaje

Antes de finalizar este apartado, cabe indicar que los cGu y, en particular, las oov representan una mirada a la percepción individual en la construcción subjetiva de la experiencia turística. Una exploración de esas experiencias implica revisar la construcción de las narrativas y los significados que se le adscriben a las vivencias registradas. A diferencia de lo que se reporta en entrevistas o encuestas, este proceso reflexivo-argumentativo tiene la principal característica de ser voluntario, y no tiene un mayor objetivo práctico que el de contribuir a una determinada comunidad, en este caso virtual. A pesar de las críticas sobre la validez y representatividad de estos constructos para analizar la realidad turística de los destinos, atractivos, servicios, etc., lo cierto es que estos textos representan un tipo de información que difícilmente podría extraerse con otro tipo de métodos o técnicas de 
recolección. En otras palabras, se reconocen las limitaciones asociadas con este tipo de información, sin embargo, ello no quiere decir que su análisis carezca de valor teórico o práctico tanto para el entendimiento de la experiencia de viaje como para la gestión turística.

\section{Metodología}

El objetivo de esta investigación fue recolectar y analizar información digital contenida en las oov en el sitio web relacionado con reseñas de viaje conocido como TripAdvisor. Tomando como principal referencia los elementos que componen el modelo de la teoría de la comunicación propuesto por Roman Jakobson en 1960 (emisor, mensaje, receptor, contexto, código y canal), el interés de este estudio se centró en conocer de manera primordial las características tanto del emisor como del mensaje en este peculiar canal. El contexto se encuentra definido exclusivamente en el ámbito del turismo (información acerca de atractivos turísticos), el canal en el ámbito digital (oov en TripAdvisor), mientras que el código está definido con el lenguaje escrito dentro de las oov. Dado que la publicación de oov en sitios como TripAdvisor es "abierta" a todos los interesados en un tema en particular, el elemento del modelo conocido como "receptor" en este caso es por naturaleza indefinido y se entiende que serían usuarios de la web con una intención potencial de viaje. Con objeto de clarificar el diseño metodológico propuesto en esta investigación, se tomaron como referencia las siguientes preguntas:

\section{1. ¿Qué información se recolectó?}

Información digital alojada en el sitio web TripAdvisor relacionada con las siguientes variables: opiniones sobre atractivos turísticos de la ciudad de Guanajuato, género, edad, procedencia, evaluación numérica del atractivo (1-5), idioma de la opinión, dispositivo utilizado y fecha de publicación. El criterio principal para la selección de atractivos a estudiar en esta investigación fue que contaran con un número superior a las 500 opiniones archivadas. Se identificaron diez atractivos turísticos que cumplieron con ese criterio (véase cuadro 1). En total se recolectaron 10462 opiniones derivadas de esos atractivos. La temporalidad de las opiniones comprende un horizonte del año 2003 al 2018.

\section{2. ¿Cuándo se hizo la recolección y análisis de la información?}

La recolección de información se llevó a cabo durante abril, mayo y junio de 2018. Toda la información recogida se integró en una base de datos digital homogeneizada y preparada para su posterior tratamiento en la fase de análisis. El trabajo de análisis se realizó durante junio, julio y agosto de 2018. El presente escrito refleja los primeros resultados de este ejercicio de investigación. 
Cuadro 1. Atractivos turísticos de estudio

\begin{tabular}{|lc|}
\hline Atractivo & $\begin{array}{c}\text { Número de oov } \\
\text { recolectadas }\end{array}$ \\
\hline Alhóndiga de Granaditas & 930 \\
\hline $\begin{array}{l}\text { Basílica Colegiata de Nuestra Señora de } \\
\text { Guanajuato }\end{array}$ & 560 \\
Callejón del Beso & 1360 \\
\hline Jardín Unión & 1134 \\
\hline Mercado Hidalgo & 600 \\
\hline Museo Diego Rivera & 698 \\
\hline Museo de las Momias & 1650 \\
\hline Monumento al Pípila & 1620 \\
\hline Teatro Juárez & 1010 \\
\hline Universidad de Guanajuato & 900 \\
\hline
\end{tabular}

\section{3. ¿Cómo se realizó el análisis de la información recolectada?}

El proceso de análisis consistió en: 1) cuantificación por variable; 2) división de opiniones positivas y negativas; 3) división de grupos de opiniones nacionales y extranjeras; 4) identificación de temáticas dominantes por grupo de origen; 5) generación de inferencias; y 6) identificación de principales resultados y generación de conclusiones. Como referencia de este tipo de estudios, se revisó el de De Ascaniis y Cantoni (2017). En esta investigación se identifican y clasifican las temáticas de las oov aplicando un procedimiento iterativo para la definición de categorías hasta llegar a una saturación. En la figura 2 se explica de manera gráfica el procedimiento de análisis.

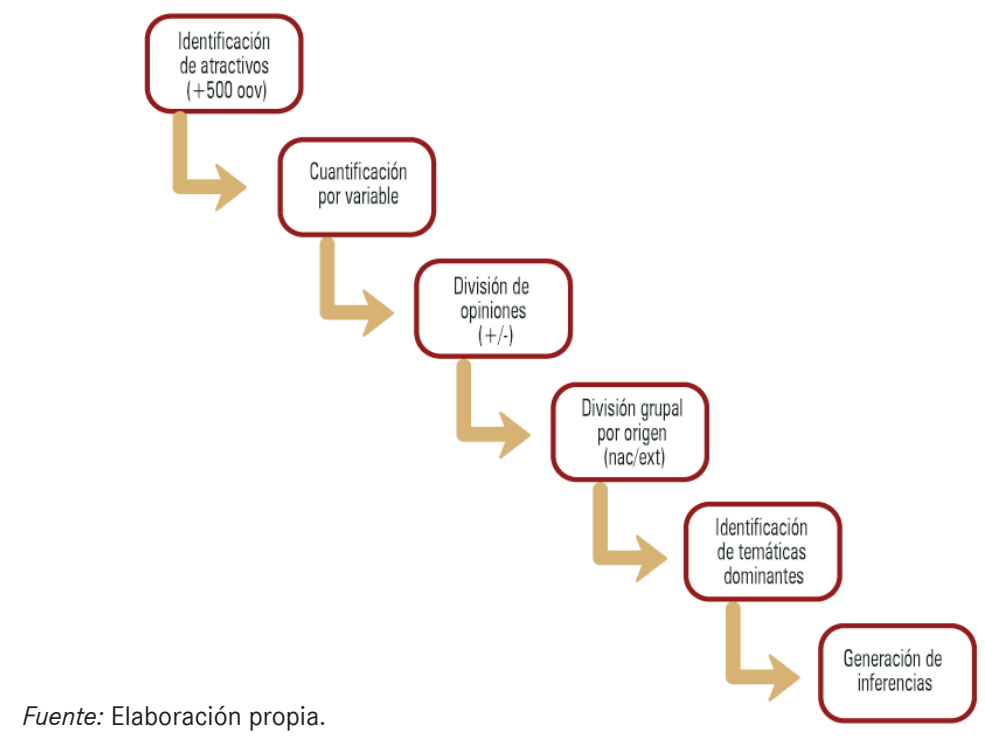

Figura 2. Procedimiento de análisis de las 00V 
Es importante mencionar que, para el análisis de las opiniones y la concentración de las temáticas, no se consideró la evolución de las opiniones a través de los años. Esta decisión se basó en el hecho de que el mayor número de opiniones se concentra en un horizonte relativamente corto (2013-2018), así como de que el número final de opiniones recolectadas no es lo suficientemente amplio en algunos años para un ejercicio de esta naturaleza.

\section{Resultados y discusión}

Por cuestiones de espacio y de propósito de este artículo, solo se muestran algunos de los resultados generales derivados de este proceso de investigación, siguiendo la lógica de la estrategia de análisis.

\subsection{Cuantificación global por variable}

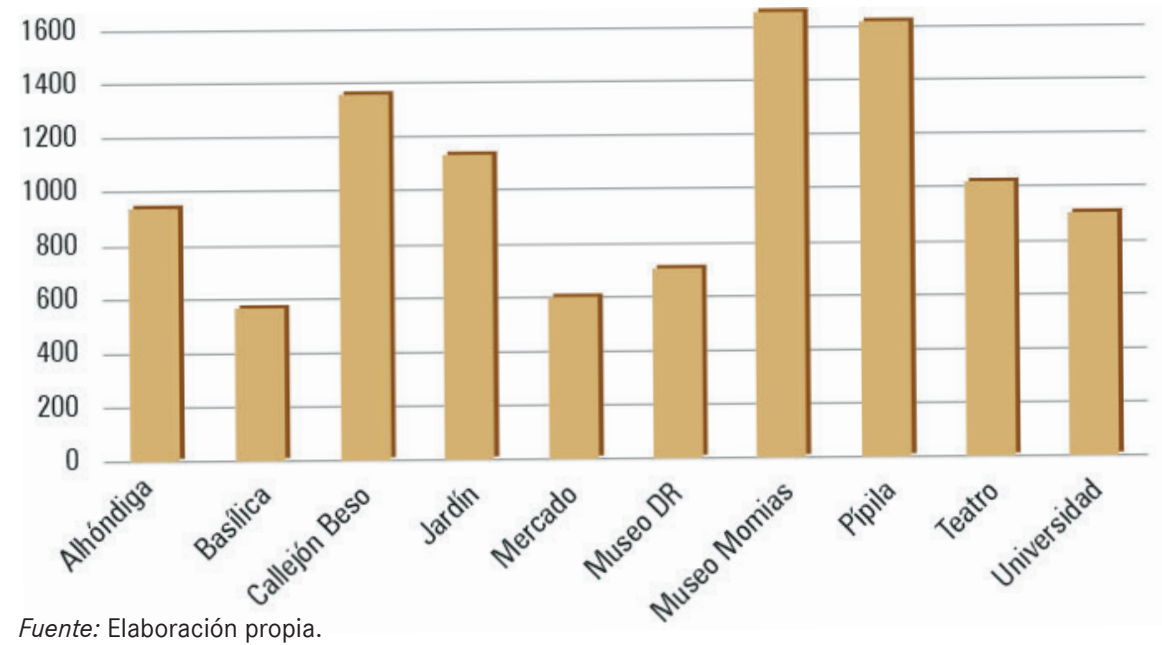

Figura 3. Número de opiniones por atractivo

En la figura 3 se puede observar la distribución del total de las oov por atractivo. AqueIlos que cuentan con un mayor número de opiniones fueron el Museo de las Momias, el Monumento al Pípila y el Callejón del Beso. En contraste, los que registraron una menor cantidad de ellas fueron la Basílica, el Mercado Hidalgo y el Museo Diego Rivera.

Con respecto a la distribución de las opiniones por el género de su autor, el masculino fue ligeramente superior, registrando $54 \%$, mientras que el femenino obtuvo $46 \%$.

Por otro lado, en la figura 4 se puede apreciar la distribución de la participación de las opiniones por edad. Así, el grupo mayoritario de autores se concentra en el rango de los 20 a los 55 años. El promedio de edad global es de 40.11 años, la mediana de 38 años, y la edad mínima de 15 años, en tanto que la máxima reportada fue de 81 años. 


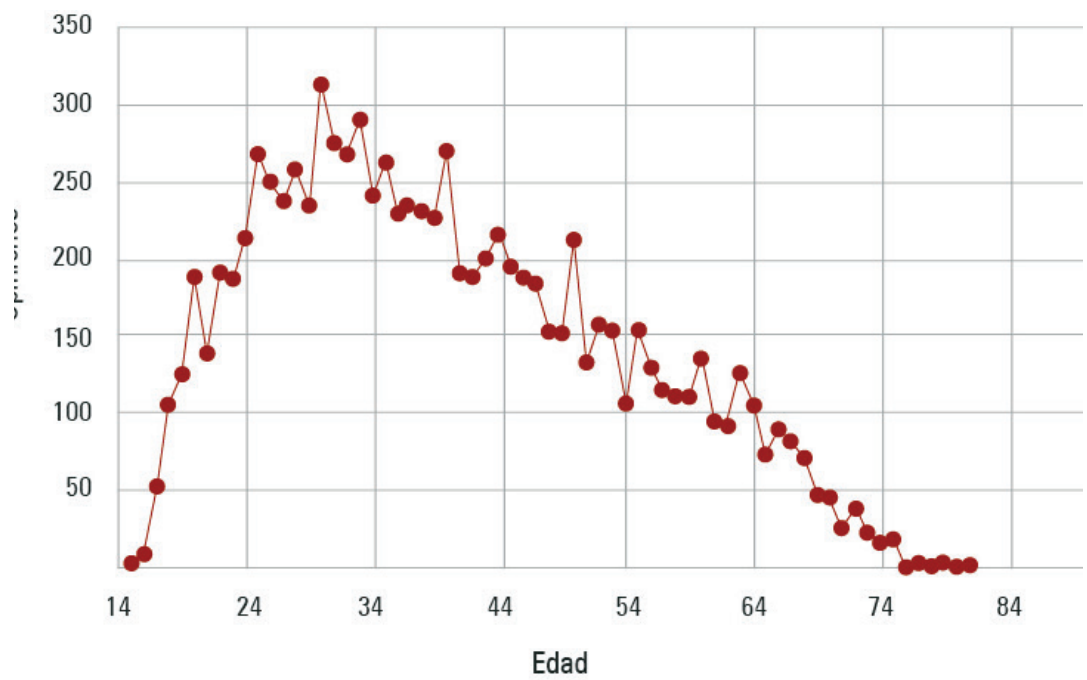

Fuente: Elaboración propia.

FiguRa 4. Participación por edad

La figura 5 muestra la distribución global de las evaluaciones obtenidas en los diez atractivos analizados. Como se puede observar, la mayor parte de las evaluaciones de la experiencia en el atractivo se concentra en Bueno (4) y Muy bueno (5). Por ende, se puede explicar que la media se sitúa en 4.253 y la mediana en 4. Aun así, no se puede ignorar el hecho de que aproximadamente $19 \%$ de las opiniones se ubica en un espectro de evaluación negativo (se consideran todas las evaluaciones que están en el rango 1-3).

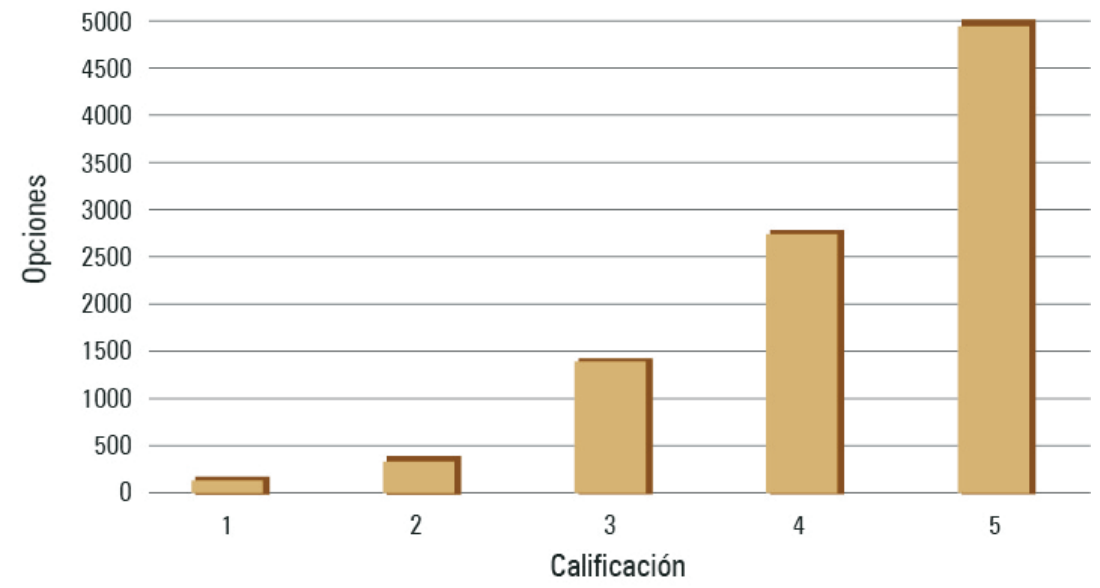

Fuente: Elaboración propia.

FIgURA 5. Evaluación global 
Por su parte, la figura 6 exhibe el origen geográfico de las opiniones. Como se puede apreciar, el país que domina el origen de las opiniones es México, y en segundo lugar se encuentra Estados Unidos. Otros países de importancia en América son Argentina, Brasil y Canadá. Es interesante ver en esta representación la gran diversidad de naciones donde se reporta el origen de los usuarios, desde Asia, Europa Central, Norte de África, Oceanía y Sudáfrica.

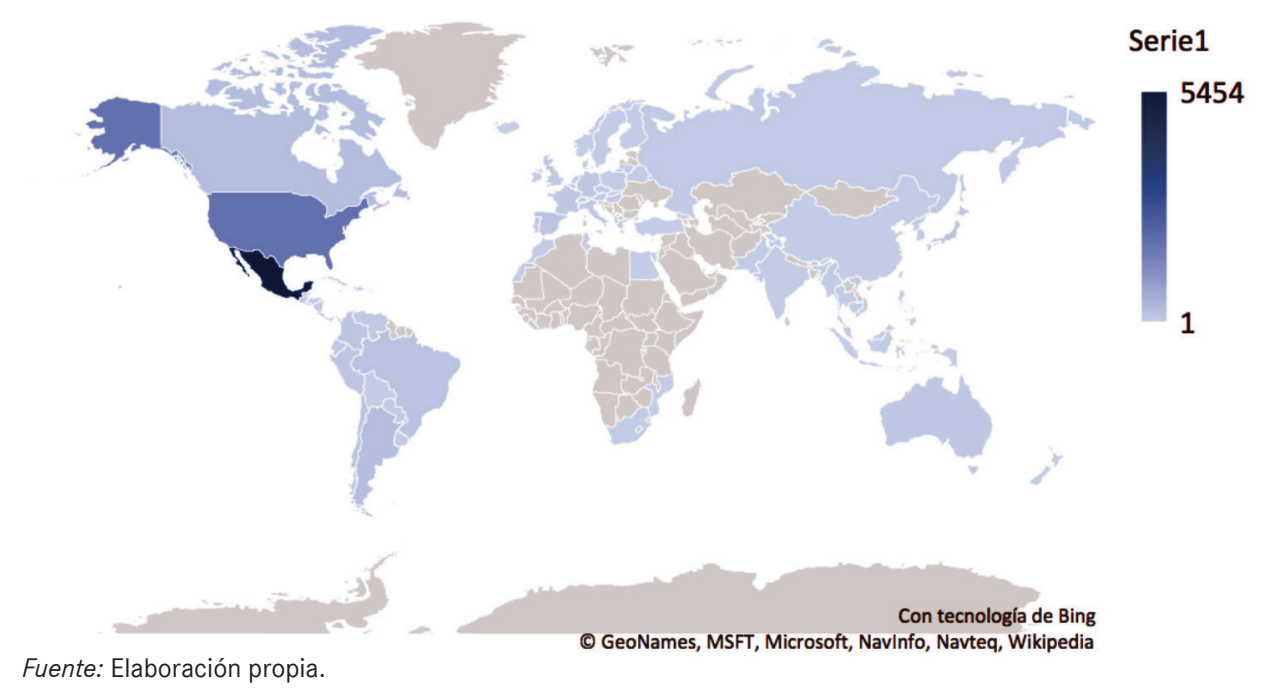

Figura 6. Concentración nacional de las 00v

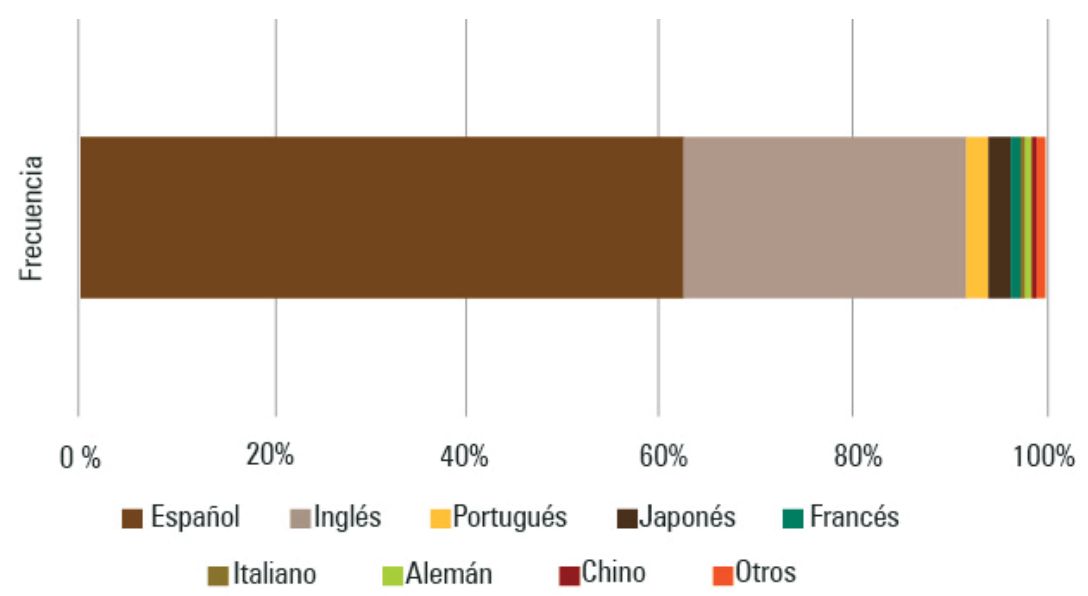

Fuente: Elaboración propia.

Figura 7. Distribución de idiomas de las oov 
En la figura 7 se pueden ver los idiomas dominantes de las opiniones registradas y relacionadas con los diez atractivos analizados. En concordancia con la figura 7 (origen nacional de opiniones), el idioma predominante es el español, seguido del inglés. Otros idiomas con menor frecuencia en los registros son el portugués y el japonés. Cabe señalar la gran diversidad de idiomas que compone el grupo de análisis. Para analizar las opiniones que estaban escritas en idiomas con otro tipo de alfabeto y estructura gramatical (por ejemplo, coreano, neerlandés, ruso, turco y urdu), se utilizó el traductor automático de TripAdvisor. Se reconoce que esta herramienta tiene limitaciones importantes en la generación exacta de la traducción, sin embargo, gracias a ella se pudieron extraer las ideas generales y algunos significados de los textos.

En relación con la distribución de opiniones por tipo de dispositivo utilizado durante su creación, destaca que $71 \%$ de los participantes haya empleado una computadora personal o de escritorio tanto para acceder al foro como para generar la opinión. El uso de los dispositivos móviles registró el restante $29 \%$.

La figura 8 muestra el número de opiniones globales en los diez atractivos por año. Es relevante destacar que TripAdvisor fue creado en el año 2000, y, como se puede ver, su uso para la valoración y opinión de los atractivos turísticos en Guanajuato fue marginal hasta el 2012. De acuerdo con los datos recolectados, el año con una mayor cantidad de opiniones y evaluaciones acerca de estos atractivos fue 2016, registrando una disminución importante similar a las cifras obtenidas en 2015.

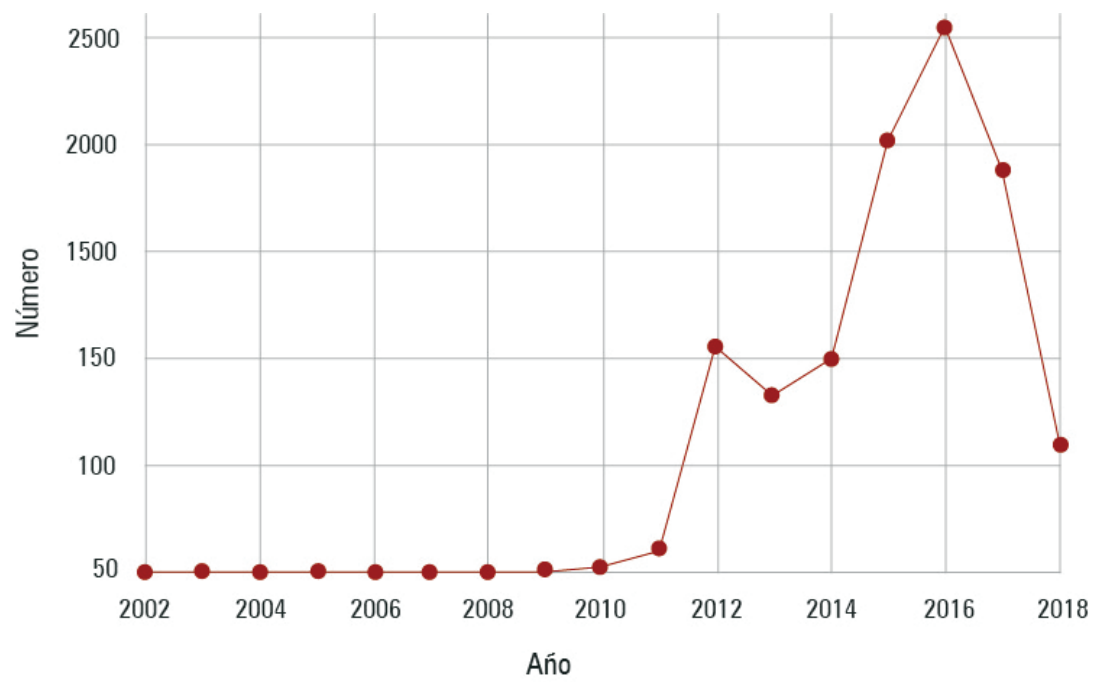

Fuente: Elaboración propia.

FiguRA 8. Evolución de aportaciones 
Por último, en lo que se refiere a resultados globales por variable, en la distribución de los participantes de acuerdo con su procedencia (nacional o extranjera) resulta interesante que el grupo nacional domina ligeramente la estadística (54\%), pero el grupo extranjero también está ampliamente representado (46\%). Lo anterior es fundamental para comprender los resultados que se presentan a continuación.

\subsection{Opiniones positivas y negativas por grupo de origen}

Uno de los principales intereses de esta investigación era analizar si existía una diferencia importante en la forma de evaluar la experiencia en los atractivos turísticos por grupo de origen (nacional y extranjero). Una de las hipótesis que se tenía al inicio de la investigación era que, considerando la falta de información en un idioma diferente del español en los distintos atractivos de la ciudad, ello se vería claramente reflejado en las opiniones por parte de los visitantes extranjeros, y en ese mismo sentido deberían apuntar las evaluaciones, es decir, presentando una tendencia negativa. Sin embargo, a partir de los resultados obtenidos y expuestos en la figura 12 se puede observar que tanto las valoraciones positivas como las negativas muestran una tendencia bastante similar en ambos grupos. Los resultados inclusive parecen coincidir con el grado de participación observado en la figura 11. En ese aspecto, a partir de los datos obtenidos se puede decir que no existe una diferencia definitiva en la valoración de las experiencias en los atractivos seleccionados por parte de los grupos estudiados y se refuta la hipótesis.

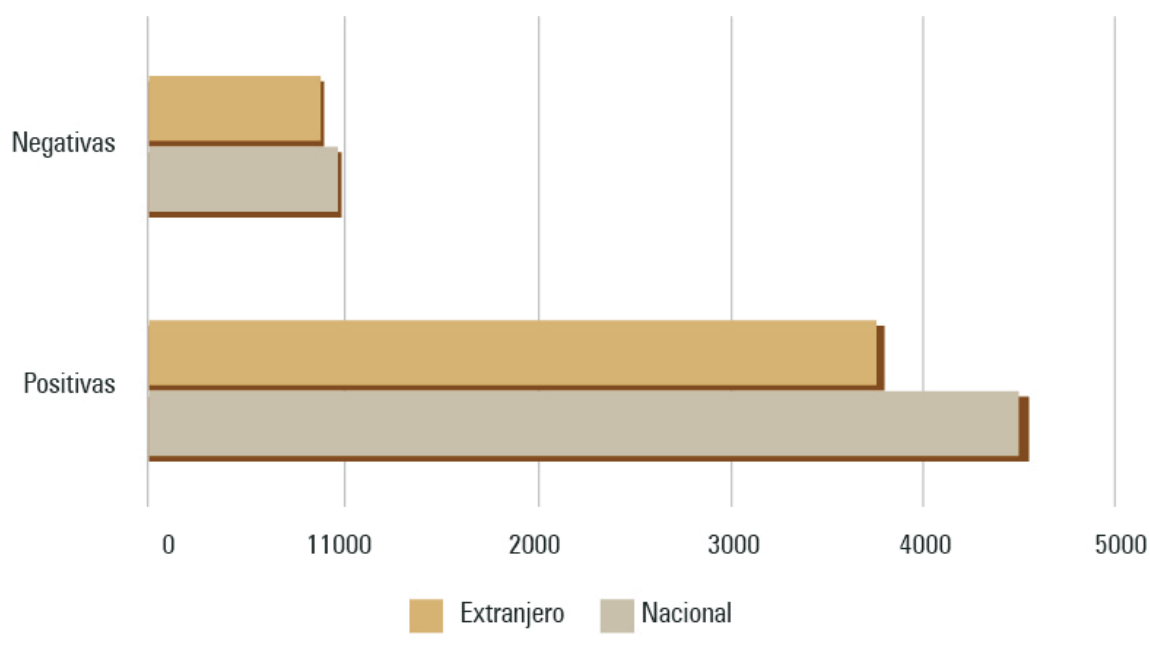

Fuente: Elaboración propia.

Figura 9. Valoración por grupo de origen 
Como ya se explicó previamente, por cuestiones de espacio y de propósito se decidió presentar en este documento solo los resultados relacionados con las temáticas globales negativas por grupo de interés (nacional y extranjero). Lo anterior obedece al objetivo de centrar la discusión en posibles recomendaciones prácticas de gestión turística, en especial para aquellos atractivos que han sido calificados predominantemente de manera negativa. A continuación se abordan la valoración y las temáticas dominantes encontradas en este segmento.

\subsection{Calificaciones negativas globales grupo nacional}

Con respecto a la calificación global en el grupo considerado como "turistas nacionales" es importante mencionar que en esta investigación se agrupó como calificación negativa a los números 1, 2 y 3, en la escala de polaridad prevista por TripAdvisor (1-5). Con base en esta adecuación en el tratamiento de los datos, se identificó un total de 971 opiniones, donde 7.5 \% correspondió a la peor calificación, “1”, 15 \% a la segunda peor, “2”, y una mayor proporción (76.5 \%) a la "3".

En la figura 10 se puede ver el desglose de las 971 opiniones negativas por atractivo turístico reportado. Según se puede apreciar, los atractivos que obtuvieron una mayor cantidad de opiniones negativas fueron el Museo de las Momias y el Callejón del Beso. El Monumento al Pípila y el Mercado Hidalgo se encuentran por debajo, en tanto que los restantes atractivos no presentan un número importante de evaluaciones negativas. Un punto a destacar en estos resultados es que el atractivo turístico denominado "Teatro Juárez" exhibe el menor número de opiniones negativas de acuerdo con los datos obtenidos.

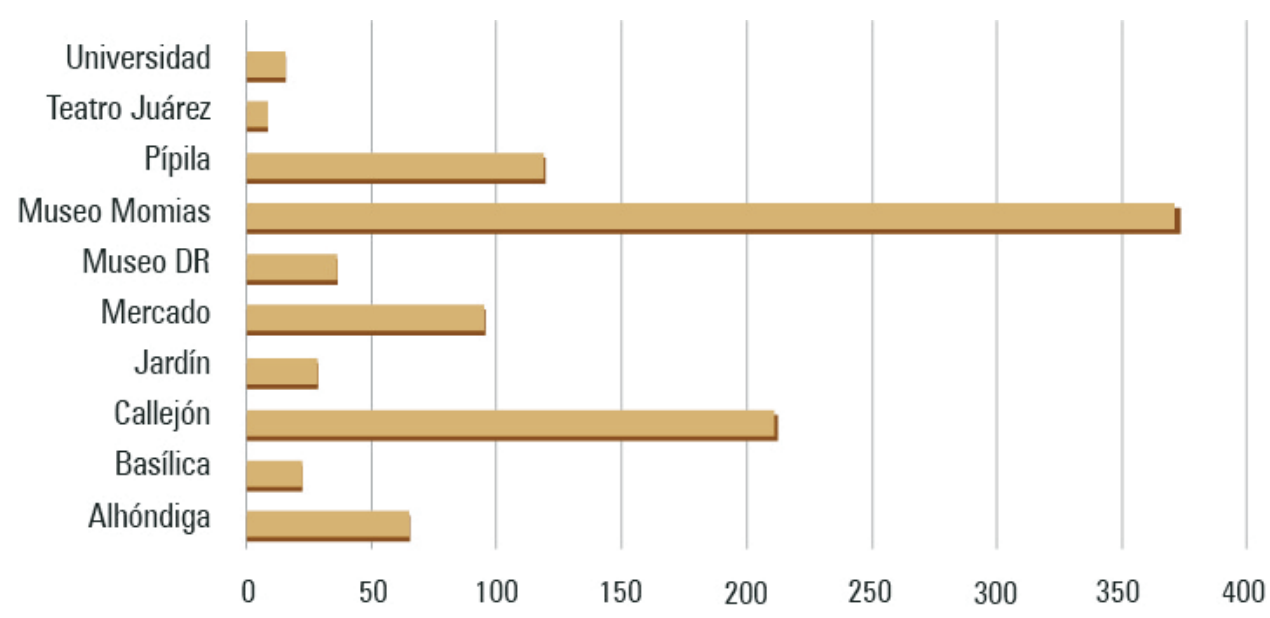

Fuente: Elaboración propia.

FIGURA 10. 00V negativas por atractivo grupo nacional 


\subsection{Temáticas dominantes en atractivo turístico grupo nacional}

Otro de los intereses principales de esta investigación era identificar, además de las evaluaciones numéricas, las temáticas dominantes dentro de las oov. A manera de ejemplo, en el cuadro 2 se muestran las temáticas encontradas en orden de importancia en uno de los atractivos peor evaluados para el grupo de turistas nacionales (Museo de las Momias). A pesar de ser uno de los atractivos principales de la ciudad y un poderoso imán de visitantes, también parece ser un sitio donde la experiencia turística no está cumpliendo con las expectativas de los interesados. El cuadro se divide en tres grandes apartados: temática, etiquetas y relevancia. Esta última fue estimada de acuerdo con el número de repeticiones dentro de las oov. En este sentido, a mayor repetición, mayor relevancia estimada.

\section{Cuadro 2. Temáticas negativas dominantes en el Museo de las Momias}

\begin{tabular}{llc}
\multicolumn{1}{c}{ Temática } & \multicolumn{1}{c}{ Etiquetas } & Relevancia \\
$\begin{array}{l}\text { Descripción de atributos físicos } \\
\text { o simbólicos relacionados con el } \\
\text { atractivo }\end{array}$ & $\begin{array}{l}\text { Condición de los cuerpos, poca información } \\
\text { alrededor de la colección, cuestionamiento } \\
\text { ético de exhibición, renovación necesaria, datos } \\
\text { históricos insuficientes, espacio pequeño de } \\
\text { exhibición, poca iluminación, temperatura alta, } \\
\text { aglomeración de visitantes en salas }\end{array}$ & \\
$\begin{array}{ll}\text { Recomendaciones prácticas de } \\
\text { visita }\end{array}$ & $\begin{array}{l}\text { Difícil acceso, poco espacio de estacionamiento, } \\
\text { taxi como principal medio de transporte, uso de } \\
\text { guías de sitio obligatorio, tiempo de visita corto, } \\
\text { imposible adquirir boletos anticipadamente, nada } \\
\text { extraordinario que ver }\end{array}$ & Media \\
$\begin{array}{l}\text { Identificación de potenciales } \\
\text { riesgos que pudieran afectar } \\
\text { de manera negativa la visita al } \\
\text { atractivo }\end{array}$ & $\begin{array}{l}\text { Cobro excesivo por servicios básicos, tiempo } \\
\text { de espera excesivo en temporada vacacional, } \\
\text { condiciones no adecuadas para la espera, } \\
\text { desorden en filas, no apto para ciertos públicos }\end{array}$ & Alta \\
$\begin{array}{l}\text { Reflexiones/recuentos personales } \\
\text { que reflejan emociones } 0 \\
\text { sentimientos experimentados } \\
\text { durante la visita }\end{array}$ & $\begin{array}{l}\text { Morbo, miedo, curiosidad, ansiedad, temor, terror, } \\
\text { inseguridad, incertidumbre, incredulidad, tristeza }\end{array}$ & Baja \\
$\begin{array}{l}\text { Información de algún aspecto del } \\
\text { destino en general }\end{array}$ & $\begin{array}{l}\text { Atractivo recomendado pero prescindible, } \\
\text { contexto circundante en malas condiciones, } \\
\text { suciedad, inseguridad, comercio fijo e informal sin } \\
\text { orden, promotores no controlados }\end{array}$ & Baja \\
\hline
\end{tabular}

Fuente: Elaboración propia. 
Es importante hacer notar que la intención principal del cuadro 2 es mostrar de manera condensada las temáticas generales abordadas en las 372 oov negativas encontradas en este atractivo en particular.

\subsection{Calificaciones negativas globales grupo internacional}

Se identificaron 875 opiniones, donde 8 \% correspondió a la peor calificación, “1”, 15 \% a la segunda peor, "2", y una mayor proporción (77 \%) a la "3". Si se comparan estos resultados con la calificación global en el grupo considerado como "turistas nacionales", se podrá observar que la tendencia es muy parecida entre ambos grupos.

Por otro lado, en la figura 16 se puede ver el desglose de las 875 opiniones negativas por atractivo turístico reportado. De forma similar al grupo de "turistas nacionales", los atractivos que obtuvieron una mayor cantidad de opiniones negativas fueron el Museo de las Momias y el Callejón del Beso. Este es un hallazgo importante en esta investigación, pues descarta la hipótesis inicial de alguna diferencia sustancial entre ambos grupos de turistas estudiados. Otro hallazgo se refiere a que el atractivo turístico denominado "Teatro Juárez" fue el lugar que recibió la menor cantidad de evaluaciones negativas también para este grupo.

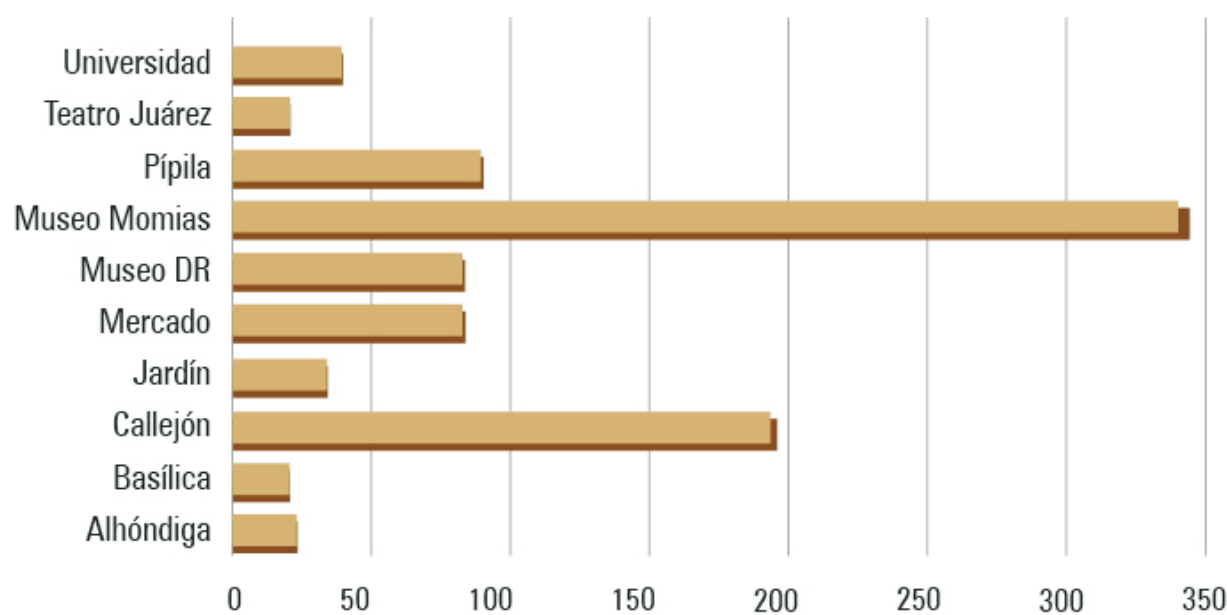

FigURA 11. oov negativas por atractivo grupo internacional

\subsection{Temáticas dominantes en un atractivo turístico (grupo extranjero)}

Otro ejemplo de temáticas dominantes en un atractivo se puede observar en el cuadro 3. En esta ocasión se muestran los resultados para el segundo atractivo peor evaluado: el CaIlejón del Beso. Al igual que el Museo de las Momias, este sitio es un imán importante para los visitantes de la ciudad debido a su gran reconocimiento. Hay que destacar que este atractivo turístico posee características muy diferentes de las del Museo. El atractivo del sitio se basa en la construcción de una narrativa romántico-trágica alrededor del callejón 
muy similar a la de Romeo y Julieta en Italia. Además de ello, los turistas suelen tomarse fotografías en el lugar como parte de la práctica de viaje asociada con él. Por sus condiciones físicas y de espacio, este atractivo genera grandes aglomeraciones de personas.

Cuadro 3. Temáticas negativas dominantes en el Callejón del Beso

\begin{tabular}{|c|c|c|}
\hline Temática & Etiquetas & Relevancia \\
\hline $\begin{array}{l}\text { Descripción de atributos físicos } 0 \\
\text { simbólicos relacionados con el atractivo }\end{array}$ & $\begin{array}{l}\text { Narrativa sin sustento, espacio reducido } \\
\text { de visita, contenido e información } \\
\text { limitada, organización deficiente en la } \\
\text { visita, propósito mayormente comercial, } \\
\text { imagen descuidada, baja diferenciación } \\
\text { respecto de otros paisajes de la ciudad }\end{array}$ & Alta \\
\hline Recomendaciones prácticas de visita & $\begin{array}{l}\text { Atractivo prescindible, evitar visitar en } \\
\text { temporada vacacional, evitar visitar en } \\
\text { formato grupal (estudiantina), limitación } \\
\text { de información en idioma diferente del } \\
\text { español, evitar oferta comercial informal }\end{array}$ & Alta \\
\hline $\begin{array}{l}\text { Identificación de potenciales riesgos que } \\
\text { pudieran afectar de manera negativa la } \\
\text { visita al atractivo }\end{array}$ & $\begin{array}{l}\text { Acceso restringido, tiempo de espera } \\
\text { excesivo, mantenimiento necesario, } \\
\text { cobros informales no previstos, ausencia } \\
\text { de gestión pública del atractivo }\end{array}$ & Media \\
\hline $\begin{array}{l}\text { Reflexiones/recuentos personales que } \\
\text { reflejan emociones o sentimientos } \\
\text { experimentados durante la visita }\end{array}$ & $\begin{array}{l}\text { Visita sin sentido, pérdida de tiempo, } \\
\text { poco entendimiento, incredulidad, } \\
\text { relación esfuerzo-expectativa } \\
\text { inequitativa, valor histórico y/o } \\
\text { paisajístico no identificado }\end{array}$ & Media \\
\hline $\begin{array}{l}\text { Información de algún aspecto del destino } \\
\text { en general }\end{array}$ & $\begin{array}{l}\text { Inseguridad, transporte público limitado, } \\
\text { señalética insuficiente, condiciones de } \\
\text { entorno }\end{array}$ & Baja \\
\hline
\end{tabular}

Al igual que el cuadro 2, el objetivo del cuadro 3 es exponer de manera condensada las temáticas generales abordadas en las 195 oov negativas registradas en este atractivo.

\subsection{Limitaciones}

Antes de concluir el artículo, es preciso señalar sus limitaciones. En primer lugar, este escrito únicamente presenta los resultados globales de las oov y no de manera particular por atractivo. En segundo lugar, en este estudio solo se hace un análisis del grupo de opiniones negativas de forma global e identificación de temáticas de modo particular. Se seguirá trabajando en la base de datos para presentar los resultados de las opiniones positivas y la identificación de temáticas en el nivel particular. Otra limitación se refiere a la falta de un 
análisis por tipo de variable demográfica. Igualmente, se espera seguir trabajando en los datos analizando las diferencias entre variables (por ejemplo, género, edad, procedencia, etc.) respecto de las valoraciones (variable dependiente). Una limitación adicional es que no se separó a los usuarios que tienen la categoría de viajeros expertos de los que no en la plataforma, para realizar un análisis acerca del promedio y extensión de sus valoraciones y textos. Quizá este análisis también podría arrojar información interesante considerando que un viajero experto tiene mayores elementos tanto para la valoración de la experiencia como para la construcción de argumentos consistentes. Finalmente, una limitación adicional se refiere a la ausencia de un análisis más profundo de los contenidos en las evaluaciones relacionado con la identificación de las funciones comunicativas de los argumentos. Sin duda, esta información ayudaría a entender mejor los significados de las experiencias y los aspectos implícitos sobre las intenciones de las opiniones.

\section{Conclusiones y recomendaciones}

Este documento presenta algunos resultados generales del proceso de investigación relacionado con el análisis de oov en atractivos turísticos de la ciudad de Guanajuato. Para ello se recolectó y examinó información proveniente del foro digital de viaje conocido como TripAdvisor. En esta oportunidad se revisaron las oov de los diez atractivos turísticos principales de este destino, y el análisis en este documento se centró en las oov negativas por parte del grupo de turistas nacionales y extranjeros. Aunque es cardinal decir que, del total de oov recolectadas (10 462), las evaluaciones negativas solo representan $17 \%$. Un hallazgo importante de esta investigación es que las valoraciones negativas exhiben una tendencia muy similar en ambos grupos de turistas (nacional y extranjero), incluyendo el hecho que los dos atractivos peor valorados en ambos casos fueron el Museo de las Momias y el Callejón del Beso. De igual manera, se incluyeron ejemplos de los resúmenes de las temáticas dominantes dentro de las oov negativas para ambos grupos de turistas en estudio (nacional y extranjero). Para cada uno de ellos se escogió un atractivo, se presentaron los temas más mencionados en los textos recolectados y se estimó su relevancia a partir de la repetición en los textos de las opiniones. Derivado de este análisis, se pueden identificar algunas recomendaciones simples de gestión turística para estos atractivos.

En el caso del Museo de las Momias, se considera prioritario atender la construcción de una propuesta museográfica diferente, de tal forma que se pueda incorporar información más relevante acerca de la colección. Del mismo modo, se debe atender la generación de información dentro del museo para permitir la visita autónoma tanto para visitantes nacionales como para extranjeros que en este momento es imposible realizar. Otra recomendación está vinculada con unificar en el costo general de acceso los servicios complementarios como sanitarios, permisos de fotografía y otros relacionados. Finalmente, se recomienda trabajar en un modelo ex ante de planificación de la visita. Lo anterior permitiría organizar los flujos de turistas de mejor forma y evitar los problemas de aglomeraciones y experiencias poco agradables que se reflejan en valoraciones y opiniones negativas. 
Respecto al Callejón del Beso, se considera prioritario implementar un modelo de administración de visita mejor organizado. La manera espontánea de atender a los concurrentes parece afectar claramente la experiencia de visita. Considerando el poco espacio disponible y el control inexistente de los flujos de visitantes, se sugiere que el municipio trabaje en la construcción de una propuesta que pueda beneficiar a todos los interesados alrededor de este atractivo, manteniendo un balance entre los intereses públicos y privados. Se recomienda de manera prioritaria mejorar la imagen del sitio pues, derivado de lo mencionado en las oov, esta parece afectar la percepción positiva de los visitantes. Otra posible recomendación para este sitio se refiere a considerar la unificación de una narrativa oficial tanto para visitantes nacionales como extranjeros, ya que, al parecer, existen grandes discrepancias y vacíos según lo reportado en las oov. Lo anterior va aunado con la creación de contenidos independientes, sobre todo con miras a mejorar la experiencia en el lugar para el grupo de turistas extranjeros. A este grupo en particular, de acuerdo con las oov, se le dificulta comprender el valor histórico-patrimonial-paisajístico debido a la ausencia de información en un idioma diferente del español. En ese sentido, habrá que contemplar la generación de contenidos en los atractivos principales en diferentes formatos (físicos y digitales) por lo menos en idioma inglés, por considerarlo como la lingua franca de los tiempos modernos y del turismo mundial. Por último, se sugiere poner atención en el control de la oferta informal tanto de guías de turistas como la comercialización de artículos varios en el lugar. En este atractivo no es difícil encontrar a muchos menores deambulando en el sitio, ofreciendo servicios de información o venta de mercancía variada. La existencia de esta oferta, en muchas ocasiones, puede actuar en detrimento de la experiencia de visita de acuerdo con lo reportado en las oov. En ese aspecto, se debe poner atención en la creación de un marco administrativo y regulatorio adecuado que permita controlar ese fenómeno en beneficio de los visitantes y residentes.

Aunque las recomendaciones incluidas en esta sección se reconocen como generales, se espera que la información presentada en todo el documento pueda contribuir a identificar áreas de oportunidad para mejorar la gestión turística de los atractivos turísticos de la ciudad de Guanajuato. Se considera indispensable el monitoreo constante de la información alojada en foros digitales como TripAdvisor por parte del municipio y los administradores de los atractivos con miras a mejorar la visita y la experiencia turística en general.

\section{Agradecimiento}

Se reconoce el apoyo de la Universidad de Guanajuato a través del financiamiento al proyecto "Análisis de opiniones acerca de atractivos turísticos en un foro de viaje digital. El caso de la ciudad de Guanajuato en TripAdvisor", en la Convocatoria Institucional para el Mejoramiento de la Capacidad Académica 2018. 


\section{Fuentes consultadas}

Baka, V. (2016). The becoming of user-generated reviews: Looking at the past to understand the future of managing reputation in the travel sector. Tourism Management, $53,148-162$.

Barreda, A. y Bilgihan, A. (2013). An analysis of user-generated content for hotel experiences. Journal of Hospitality and Tourism Technology, 4(2), 263-280.

Chua, A. y Banerjee, S. (2013). Reliability of reviews on the internet: The case of trip advisor. Lecture Notes in Engineering and Computer Science, 1, 453-457.

Compagnone, M. (2017). Storytelling in TripAdvisor reviews / Le storytelling dans les commentaires de TripAdvisor. Synergies Italie, 13, 81-91.

Coursaris, C., Osch, W. van y Albini, A. (2017). What drives perceptions of review trustworthiness in electronic word-of-mouth: An experimental study of TripAdvisor. Atas da Conferencia da Associacao Portuguesa de Sistemas de Informacao, 17, 111-126.

De Ascaniis, S. y Cantoni, L. (2014). Artistic and religious experiences in online travel reviews about Saint Paul outside the walls. Ponencia presentada en International Conference on Tourism, Limassol, Chipre, 160-173.

De Ascaniis, S. y Cantoni, L. (2017). Online visit opinions about attractions of the religious heritage: An argumentative approach. Church, Communication and Culture, 2(2), 179-202.

De Ascaniis, S. y Gretzel, U. (2013). Communicative functions of online travel review titles. A pragmatic and linguistic investigation of destination and attraction OTR titles. Studies in Communication Sciences, 13, 156-165.

Dellarocas, C. (2003). The digitization of Word-Of-Mouth: Promise and challenges of online feedback mechanisms. Management Science, 49(10), 1407-1424.

Egresi, I. (2017). Tourists' satisfaction with shopping experience based on reviews on TripAdvisor. Tourism, 65(3), 330-345.

Filieri, R., Alguezaui, S. y McLeay, F. (2015). Why do travelers trust TripAdvisor? Antecedents of trust towards consumer-generated media and its influence on recommendation adoption and word of mouth. Tourism Management, 51, 174-185.

Google. (2014). The 2014 Traveler's Road to Decision. Google Travel Study. Ipsos MediaCT.

Gretzel, U. (2006). Consumer generated content: Trends and implications for branding. e-Review of Tourism Research (eRTR), 4(3).

Gretzel, U. (Febrero, 2007). Role and Impact of Online Travel Reviews. Texas A\&M University, Laboratory for Intelligent Systems in Tourism. Disponible en https://www.TripAdvisor.com/pdfs/OnlineTravelReviewReport.pdf

Gretzel, U. y Yoo, K. (2008). Use and impact of online travel reviews. En P. O'Connor, W. Höpken y U. Gretzel (eds.), Information and Communication Technologies in Tourism (pp. 35-46). Viena y Nueva York: Springer.

Groth, A., Constantini, G. y Schlögl, S. (2017). Perception of source credibility within touristic virtual communities: A cross-generational examination. Lecture Notes in Computer Science, 10290, 435-492.

Hennig-Thurau, T., Gwinner, K. P., Walsh, G. y Gremler, D. D. (2004). Electronic Word-ofMouth Via Consumer-Opinion Platforms: What motivates consumers to articulate 
themselves on the internet? Journal of Interactive Marketing, 18(1), 38-52.

Jakobson, R. (1960). Linguistics and poetics. En T. A. Sebeok (ed.), Style in Language (pp. 350-377). Cambridge: міт Press.

Jeacle, I. y Carter, C. (2011). In TripAdvisor we trust: Rankings, calculative regimes and abstract systems. Accounting, Organizations and Society, 36(4-5), 293-309.

Kim, W. y Park, S. (2017). Social media review rating versus traditional customer satisfaction: Which one has more incremental predictive power in explaining hotel performance? International Journal of Contemporary Hospitality Management, 29(2), 784-802.

Lee, P., Hu, Y. y Lu, K. (2018). Assessing the helpfulness of online hotel reviews: A classification-based approach. Telematics and Informatics, 35(2), 436-445.

Lopes, R., Kastenholz, E. y Abrantes, J. (2015). Perceptions and behaviours towards online travel reviews. En G. Fernandes, A. Sardo, J. A. Martins y A. Melo (coords.), Innovation, Management and Education in Tourism and Hospitality: Applied Research (pp. 23-29). Guarda: Instituto Politécnico da Guarda.

Marine-Roig, E. (2017). Measuring destination image through travel reviews in search engines. Suistainability, 9(8), 1-18.

McKenzie, G. y Adams, B. (2018). A data-driven approach to exploring similarities of tourist attractions through online reviews. Journal of Location Based Services, 12(2), 94118.

Nilashi, M., Ibrahim, O., Yadegaridehkordi, E., Samad, S., Akbari, E. y Alizadeh, A. (2018). Travelers decision making using online review in social network sites: A case on TripAdvisor. Journal of Computational Science, 28, 167-179.

Owens, T. (2012). Tripadvisor rates Einstein: Using the social web to unpack the public meanings of a cultural heritage site. International Journal of Web Based Communities, 8(1), 40-56.

Pantano, E., Priporas, C. y Stylos, N. (2017). "You will like it!" using open data to predict tourists' response to a tourist attraction. Tourism Management, 60, 430-438.

Pongwat, A. (Diciembre, 2017). An investigation of tourism information on destination management organization websites as the pull factor: A case study of health and wellness tourism information. International Conference on Software, Knowledge Information, Industrial Management and Applications, SKIMA.

Vásquez, C. (2012). Narrativity and involvement in online consumer reviews: The case of TripAdvisor. Narrative Inquiry, 22(1), 105-121.

Wilson, A., Murphy, H. y Fierro, J. (2012). Hospitality and travel: The nature and implications of user-generated content. Cornell Hospitality Quarterly, 53(3), 220-228.

Xiang, Z. y Gretzel, U. (2010). Role of social media in online travel information search. Tourism Management, 31, 179-188.

Zeng, B. y Gerritsen, R. (2014). What do we know about social media in tourism? A review. Tourism Management Perspectives, 10, 27-36.

Zhang, Y. y Vásquez, C. (2014). Hotels' responses to online reviews: Managing consumer dissatisfaction. Discourse, Context and Media, 6(1), 54-64. 


\title{
Interrogantes sobre producciones y publicaciones académicas en turismo
}

\author{
Questions on tourism academic production
}

\author{
Noemí Wallingre \\ Licenciatura en Turismo y Hotelería \\ Universidad Nacional de Quilmes, Argentina \\ nwallingre@unq.edu.ar \\ nwallingre@yahoo.com.ar
}

D esde las últimas décadas, los profesionales que se desempeñan en los ámbitos académicos, sin distinción disciplinar, están obligados, tal como expresa De Ambrosio (2018), a "publicar o perecer”, condición que les permitirá continuar o quedar fuera de ese sistema. Plantea que el clima de época fomenta lo irracional y una lógica orientada a la productividad -académica- a toda costa, incluso bajo riesgo de que los resultados sean débiles o erróneos, lo que deriva en una carrera encaminada hacia la cantidad y velocidad en que se produce; también a la superespecialización que, entre otros aspectos, debido a su enorme magnitud, impide estar al tanto de todo lo que se publica. Todo ello en desmedro de colocar el acento en la calidad y profundidad y en lograr aportes reales para que las publicaciones visualicen y contribuyan con el avance de los procesos educativos y científicos. Respecto de la hiperespecialización, Edgar Morín (1999), el padre de la teoría de la complejidad, permite reforzar que la misma impide ver tanto lo global (que fragmenta en parcelas), como lo esencial (que disuelve); además de tratar correctamente los problemas particulares que solo pueden plantearse y pensarse en un contexto, porque los problemas esenciales nunca son parcelados y los problemas globales son cada vez más esenciales.

De Ambrosio (2018) indaga sobre si los mecanismos indicados hacen que la ciencia funcione mejor, se explote todo el potencial creativo de las disciplinas, o si únicamente alimenta la máquina burocrática de producir papers o, quizá, solo sea una industrialización de la producción del conocimiento que genera cierto aburguesamiento que conspira contra las ideas creadoras; todo dependiente de un sistema de fondos, becas, subvenciones y ascensos en la carrera de investigador.

De esta manera, se transitan tiempos en los cuales quienes se dediquen a la investigación tienen que saber vender su idea y centrarse en la cantidad más que en la calidad de lo que producen y publican, hacerlo en tiempo récord y dentro de plazos cortos, muchas veces supeditados a las temáticas que requieren los sistemas de financiación (agencias gubernamentales, universitarias, privadas). Los científicos, y sus proyectos, son evaluados, básicamente, a partir de la cantidad de trabajos publicados y también por donde publican, ya que hay rankings de revistas de mayor o menor renombre o prestigio.

Para el caso de América Latina, Cantoral (2007) señala que, en la década de los setenta del siglo xx, las políticas universitarias latinoamericanas no planteaban a sus profesores 
la necesidad de publicar como requisito de permanencia, reconocimiento o promoción. En cambio, la universidad de los años ochenta, y sobre todo de los noventa, basó su modelo de desarrollo en la evaluación de los logros de los profesores, de los grupos de investigación y de los índices institucionales asociados con la productividad. El requisito para otorgar reconocimientos o promociones ha sido, desde entonces, fundamentalmente la publicación. Dice el autor que es así como en esos años se estableció la máxima: no hay nada peor que no publicar. Indica que, con los cambios en las formas de evaluar el mérito académico, se ha ido consolidando una nueva variante que apunta: sí hay algo peor que no publicar, es publicar y que nadie te lea (o te cite). Esta postura deja entrever que la región se adhiere a las tendencias y lineamientos globales vigentes.

\section{¿Y en el turismo cómo estamos?}

Si bien puede pensarse que las exigencias descritas recaen particularmente en quienes se dedican a investigar en el marco de las ciencias duras, tal situación se extiende, generaliza y comprende también a las ciencias humanas y sociales, y a aquellos campos de estudio de menor trayectoria en el tiempo, donde se incluye al turismo.

El estudio del turismo ha atravesado diferentes etapas evolutivas (desde finales del siglo XIX), así como distintas corrientes ideológicas y epistemológicas para su pensamiento -conviene resaltar que, al respecto, aún no existe un verdadero consenso-, que, sin duda, inciden en las temáticas de investigación y en las producciones académicas que se publican. Además, su abordaje científico transitó y transita los enfoques interdisciplinares, multidisciplinares o transdisciplinares, entre los cuales se entrelazan miradas encontradas con postulados más o menos favorables hacia uno u otro, dependiendo, en particular, de la formación disciplinar de quien se exprese.

De cualquier modo, todo ello ha contribuido a avanzar en la construcción del conocimiento del turismo, campo disciplinar que aún sigue siendo de desarrollo reciente respecto de otros más antiguos. Hay que rescatar que la búsqueda de la cientificidad del turismo continúa y permite despojar los estudios y los análisis de la subjetividad, de los preconceptos, de los mitos y hasta de la fantasía. Y porque, en todo caso, se puede generar conocimiento vulgar caracterizado por ser normalmente superficial, subjetivo y acrítico, a diferencia del conocimiento científico que es objetivo y reproducible (porque es un proceso que permite que otros investigadores arriben a iguales resultados) y sistemático (porque se trata de conocimientos ordenados lógicamente empleando procedimientos técnicos, que además deben contar con un método) (Schlüter, 2000).

Actualmente, y siguiendo los lineamientos globales, quienes se dedican a la investigación y al estudio del turismo quedan también comprendidos en los desafíos de publicar o desaparecer, y los sistemas universitarios y de investigación evalúan el desempeño de sus docentes-investigadores en gran parte a partir de su nivel de productividad en las publicaciones.

Ahora bien, en el turismo ¿qué tipo de investigación se produce y publica?: ¿fundamental o teórica, que propone nuevos conceptos y marcos referenciales? o ¿aplicada, más 
pragmática y empírica?; ¿sobre qué tipologías o temáticas se investiga y publica?; ¿la investigación que se realiza se focaliza en la calidad y profundidad de sus resultados?; ¿aporta verdaderos avances en los procesos científicos del turismo?

Al intentar dar respuesta a esos interrogantes, surgen puntos de vista diferenciales según los autores. Véanse solo algunos. Para Tribe (cit. en Panosso Netto, 2011), existen tres temáticas claras de investigación en turismo: los negocios, las ciencias sociales y la crítica. Castillo Nechar y Panosso Netto (2010), basados en otros autores, observan que un alto porcentaje de los estudios en turismo son descriptivos, de estadística descriptiva, de corte económico y de impactos socioculturales, los que prevalecen por sobre los de carácter académico (teórico-conceptual). Tribe distingue además dos grupos muy claros en la investigación del turismo: los interesados en las cuestiones empresariales del turismo y los interesados en cuestiones no empresariales (ambientales, sociales u otras). César Dachary (2005) focaliza los referentes de la investigación contemporánea en turismo en los cambios de la sociedad y el trabajo, en las nuevas dimensiones del tiempo y el espacio, en las nuevas tecnologías y la magia del turismo, en el turismo como modelo de desarrollo y de recolonización, en una nueva geografía del turismo, en el ambiente y las nuevas opciones del turista y la cultura. Cuando alude a las tipologías de su investigación rescata, por un lado, los estudios micro, incluyendo como temas particulares los del mercado-perfil del turista; como temas vinculados al turismo, los impactos y la contaminación, y los temas compartidos con el turismo como la moda y la seguridad. Por otro lado, los estudios macro, diferenciándolos, según el universo, en corredor, país, región, comarca; según el proceso, en transición de zonas aisladas o marginales, creación de polos; según el tema dominante, en naturaleza, historia, cultura; según la estrategia de desarrollo, en sustentable, viable económicamente; y, según el mundo, en rural o urbano.

Por su parte, Pearce (2003) plantea que la mayoría de las orientaciones adoptadas en la investigación turística no está vinculada entre sí (anteriores y actuales), dando lugar a una producción muy atomatizada; la mayor parte fue realizada en forma individual o en pequeños equipos (limitadas competencias y recursos) centrándose en sectores específicos (transporte, alojamiento, atractivos, demanda, otros); se produjo muy poca investigación sistemática (que comprenda múltiples aspectos y dimensiones) y atrajo investigadores de una gran variedad de disciplinas, así como también que hay poca investigación multidisciplinar. Cuando se refiere a las orientaciones futuras de la investigación del turismo, alude a las tendencias de una mayor dispersión geográfica de los nuevos destinos, muchos en desarrollo y otros en franco crecimiento, lo cual concibe nuevos temas a investigar y cree, por lo tanto, que son necesarias nuevas preguntas que permitan orientarlos. Sostiene que las posibles respuestas estarán producidas con mayor claridad en la dirección a seguir y sustentada en la pregunta ¿cómo se logra?, y ensaya tres posibilidades: la amplitud geográfica (enfoques supranacionales, nacionales, regionales, locales), la integración de los marcos de actuación (claros y analíticos que permitan soluciones más integradas) y los desarrollos teóricos y metodológicos (generar bases conceptuales -teoría y método-). 
Para Ortega, Rodríguez y Cobo (2003), la investigación del turismo se viene realizando desde hace mucho tiempo por diferentes instituciones, asociaciones o empresas vinculadas con la actividad. La menos conocida es la promovida por las empresas, porque no tiene por finalidad ser difundida, sino constituirse en el motor para obtener un conocimiento propio que les permita adoptar acciones o estrategias futuras; en cambio, la que tiene su origen en las instituciones (universitarias, asociaciones, otras) está más abierta a la difusión.

Esta última perspectiva alude a que la investigación no necesariamente debe concentrarse en los niveles académicos; más bien hay que reconocer el conocimiento tácito producido por las empresas, la administración pública, las organizaciones no gubernamentales y los centros independientes que pueden incorporar diversos intereses y, por lo tanto, los temas de investigación variarán dependiendo de quienes los promuevan y realicen. Sin embargo, la construcción ideológica y epistemológica tiene su centro en los ámbitos y niveles académicos y es desde donde se genera la mayoría de las publicaciones. Dicho de otro modo, la transferencia del conocimiento construido se realiza desde estos últimos.

Otra aportación a tener en cuenta es que mayoritariamente las publicaciones en turismo, por lo menos en Latinoamérica, se sostienen en la investigación empírica y basada en análisis de casos, en general de pequeña escala (territorial, empresarial, gubernamental), y son muy escasos los aportes teóricos y metodológicos. Además, en muchas oportunidades, es posible observar determinadas inconsistencias o falta de solidez metodológicas en su desarrollo. A su vez, los aportes son producidos por profesionales de una enorme diversidad de disciplinas - que abarcan desde la economía hasta la antropología, por citar dos extremos-, cada uno de los cuales realiza un abordaje a partir de su formación de grado desde donde orienta la investigación, y desde un desconocimiento generalizado de las reales construcciones, complejidades y conceptos del turismo. Por lo tanto, sus resultados son influenciados por otros campos disciplinares que imposibilitan captar la complejidad del tejido del turismo en su conjunto.

\section{Una mirada futura sobre las producciones y publicaciones académicas en turismo}

Retomando a De Ambrosio (2018) sobre su postura sostenida en la necesidad de "publicar o perecer", este plantea que, en el ámbito universal, se está intentando buscar otras opciones, al punto de proponerse una llamada "ciencia lenta" (slow science) impulsada por algunos filósofos y emparentada con otros fenómenos slow vigentes en el mundo. Tiende, según el autor, a que la producción científica deje de lado la búsqueda de resultados cuantitativos y tenga una visión más macro del para qué se hace ciencia, quién usará los resultados en cada caso y con qué intencionalidad. Para esta perspectiva, de lo que se trata es que los procesos científicos sean políticos, en el mejor sentido de esa palabra, y que la creatividad se libere de las presiones productivistas. El autor cita al biólogo e investigador 
Alberto Kornblihtt, quien pone el énfasis en lo que debiera ser la base de toda práctica científica: curiosidad y libertad, y explica que la misión de un científico es investigar sobre la base de preguntas que no han sido aún respondidas, para obtener hallazgos y nuevas conclusiones. Entiende que, en este proceso, es necesario hacer públicas las conclusiones para que otros científicos las lean, las verifiquen, las comenten, las refuten, las critiquen. 0 se inspiren para iniciar o continuar sus propias investigaciones. Es decir: publicar debe ser la consecuencia de haber encontrado algo, y no un fin en sí mismo.

Desde este interesante planteamiento, y retomando algunos interrogantes ya expuestos, en el campo de estudio del turismo es pertinente indagar sobre:

- $\quad$ si se está haciendo ciencia teórica o aplicada;

- qué temáticas se están produciendo y publicando;

- qué tipo de artículos o textos se escriben y publican (investigación, didácticos, ensayos, revisión);

- si se conoce lo que otros profesionales están publicando, en particular sobre la temática que es de nuestro interés;

- si cuando se cree que se está innovando, se verifica que no se esté repitiendo a otros autores;

- si las producciones que se publican contribuyen a mejorar/ampliar los procesos de enseñanza-aprendizaje y la investigación; si permiten la transferencia a las organizaciones empresariales, gubernamentales, y a la sociedad en su conjunto;

- si se producen nuevos desarrollos teóricos, métodos y nuevas técnicas para apuntalar los avances;

- si prevalece la calidad y la profundidad de los resultados por sobre la cantidad.

Tender hacia una sólida construcción en el avance de la investigación en turismo continúa siendo una necesidad porque es un pilar fundamental para fortalecer no solo el campo disciplinar sino también la actividad. Además, hay que preguntarse sobre qué tipo de artículos priorizan en sus publicaciones las revistas académicas especializadas en turismo; si son equitativas en sus elecciones, si se valora la calidad y profundidad de los resultados. Otra preocupación que se presenta es si no se estará -de tanto privilegiar las publicaciones en papers- descuidando las publicaciones de buenos libros de textos que históricamente han nutrido -y deberían seguir haciéndolo- los procesos integrales de enseñanza-aprendizaje, y de la investigación del turismo.

Asimismo, desde los ámbitos académicos se debe tener presente que no solo hay que investigar para instrumentar la realidad (mercado y Estado), sino también con el propósito de construir bases sólidas para una epistemología del turismo. Como la investigación aplicada prevalece ampliamente por sobre la investigación teórica en cuanto generadora de ideas o teorías, esta última debería tener una mayor promoción institucional.

Para finalizar, es pertinente buscar respuestas a los interrogantes planteados y, de ser necesario, revisar y redefinir el camino transitado para que permita construir una visión de 
futuro en concordancia con los desafíos que en el campo de estudio del turismo se presentan. De lo contrario, no se legarán grandes y nuevas contribuciones, y solo se seguirá cumpliendo con los parámetros cuantitativos de producción que las distintas organizaciones requieren.

\section{Fuentes consultadas}

Ambrosio, M. de. (11 de marzo de 2018). La ciencia, víctima del "publicar o perecer". La Nación. Recuperado de https://www.lanacion.com.ar/2115347-la-ciencia-victima-del-publicar-o-perecer

Cantoral, R. (Noviembre, 2007). ¿Publicar o perecer, o publicar y perecer? Relime, 10(3), 311-313.

Castillo Nechar, M. y Panosso Netto, A. (2010). Epistemología del turismo. Estudios críticos. México: Trillas.

César Dachary, A. (2005). La construcción del paradigma del turismo: un camino interdisciplinario. Congreso La creatividad en el turismo para el nuevo milenio [CD]. Universidad Nacional del Comahue, Neuquén.

Morín, E. (1999). Los siete saberes necesarios para la educación del futuro. Buenos Aires: Ediciones Nueva Visión.

Ortega, E., Rodríguez, B. y Cobo, F. (2003). La investigación del turismo a través de las tesis doctorales. Un análisis comparativo entre España, Estados Unidos y Francia. En E. Ortega (coord.), Investigación y estrategias turísticas (pp. 65-90). Madrid: Thomson.

Panosso Netto, A. (2011). Filosofía do turismo. Teoría e epistemología (2 ${ }^{a}$ ed.). São Paulo: Aleph.

Pearce, D. (2003). Orientaciones actuales y futuras en la investigación turística. En E. Ortega (coord.), Investigación y estrategias turísticas (pp. 91-106). Madrid: Thomson.

Schlüter, R. (2000). Investigación en turismo y hotelería. Buenos Aires: Centro de Investigaciones y Estudios Turísticos. 
Reseña

Maribel Osorio y Nora L. Bringas Rábago (Coords.) Turismo residencial en México. Comportamientos socio-espaciales

México: El Colegio de la Frontera Norte, 2017

Álvaro López López
lopuslopez@yahoo.com.mx
Instituto de Geografía
Universidad Nacional Autónoma de México

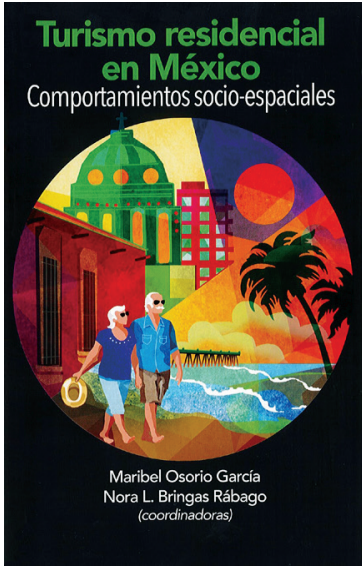

$T$ urismo residencial en México. Comportamientos socio-espaciales, coordinado por Maribel Osorio García y Nora L. Bringas Rábago, viene a llenar un vacío en la comprensión crítica de la realidad del turismo residencial en México que, pese la fuerte compenetración que tiene con el sector financiero-inmobiliario, los transportes y las comunicaciones locales, nacionales y globales, se ha analizado poco en el ámbito académico mexicano.

En esta obra de 245 páginas, publicada por El Colegio de la Frontera Norte en octubre de 2017, participan tres científicas y un científico del más alto nivel académico: especialistas en abordajes del turismo. El volumen tiene cuatro extensos capítulos (cuyos títulos completos se indican párrafos abajo): el primero, de Raquel Huete Nieves y Alejandro Mantecón Terán, es un análisis de orden teórico-conceptual, y los otros son estudios de caso: sobre el Corredor Costero Tijuana-Rosarito-Ensenada (Cocotren) se desarrolla la investigación de Nora Bringas; la de Maribel Osorio García es acerca de Malinalco, y la de Ana Pricila Sosa Ferreira, sobre Puerto Morelos.

El libro es una muestra representativa del fenómeno del turismo residencial en México, pues se hace una valoración de sitios ubicados en los litorales Pacífico (Cocotren) y Atlántico (Puerto Morelos), en donde es fuerte la presencia de turistas extrarregionales, y del interior del país (Malinalco), con dominancia de turistas regionales. En general hay una coincidencia entre los diferentes estudios de que el turismo residencial no es un proceso, sino el resultado de la interacción de varios procesos que tiene que ver, entre otras cosas, con la movilidad, la transformación del espacio geográfico, la lógica empresarial y el alojamiento de viviendas privadas.

Se ha convenido ampliamente en la literatura generada por organismos oficiales del turismo que el propio turismo se asocia con la presencia temporal de individuos en un espacio que no es el de su residencia y con fines recreativos, pero sabemos que esa definición se ha quedado muy corta para explicar el complejo fenómeno del turismo en todas sus aristas. Así, ¿cómo se puede interpretar el hecho de que los turistas sean propietarios de inmuebles en el sitio que visitan? O incluso, ¿realmente es un turista quien llega a una propiedad suya en calidad de visitante por largos periodos, o más bien es un migrante? ¿Qué implicaciones socioterritoriales tiene desentrañar el fondo de estas preguntas? El

CÓMO CITAR: López, A. (2018). Reseña del libro Turismo residencial en México. Comportamientos socio-espaciales. Dimensiones Turísticas, 2(3), 117-120. https://doi.org/10.47557/WTPM1394 
y las autoras de este libro se esfuerzan en plantear la plataforma de análisis y presentar resultados de investigación.

En el capítulo 1, “El turismo residencial: Revisión y crítica de un concepto”, Raquel Huete Nieves y Alejandro Mantecón Terán aluden a que el turismo residencial es una categoría difícil, pues se trata de migraciones situadas en la esfera del ocio y no del trabajo (que es lo común), lo que origina formas de movilidad residencial; aunque es un fenómeno muy anterior, los primeros estudios formales surgieron en España en los años setenta del siglo pasado, debido a que este país fue uno de los más impactados por el arribo de turistas ricos de otras naciones que aprovecharon las desigualdades regionales desfavorables a España para comprar otra residencia, de ahí que hayan sido (y sigan siendo) estudios de corte marxista y con una obra prolija desde los geógrafos y la geografía en donde se refirió a las segundas residencias como un proceso de colonización.

Entre los principales problemas que se han reconocido del turismo residencial está el hecho de que incentiva la terciarización de la economía, una suerte de hipertrofia de lo agrario a favor de los servicios; en este capítulo, y también en los subsecuentes, se revela y discute que esto se debe a que el turismo residencial, con frecuencia, se enclava en territorios agrarios y muchas veces áreas naturales, y la población local es "aspirada" o "atraída" por las inversiones inmobiliarias, de modo que el sector servicios crece en detrimento del primario, sin que el sector industrial logre desarrollarse, por lo cual estas economías suelen ser muy vulnerables.

También se discute que el abordaje teórico y empírico del turismo de segundas residencias puede ser analizado desde dos perspectivas que suelen contraponerse: los estudiosos provenientes de países ricos, en especial los anglosajones, tienden a examinar el fenómeno desde el punto de vista de sus connacionales, lo que hace que tengan marcos explicativos imprecisos; en cambio, los académicos que viven en los sitios donde hay segundas residencias discuten el fenómeno desde diferentes realidades, pero privilegiando conocer los procesos de transformación del espacio y los impactos diversos a partir de las vivencias directas.

Se subraya que el turismo residencial se fundamenta en el hecho de que en los niveles internacional y regional hay una división internacional del trabajo que hace que la población de los centros del capital se dirija a las nuevas periferias del placer en busca de una nueva vida en espacios distintos de los rutinarios. Así, cuando el turismo residencial se enclava en poblaciones más pobres, aunque en entornos paisajísticos considerados bellos, se presenta un fenómeno de mercantilización, masificación, fragmentación de los espacios, vulgarización de lo ecológico y lo sociocultural que, paradójicamente, fue el motivo de atracción. Tan pronto llegan los turistas-migrantes buscan participar de un entorno de afinidades y establecen una red de apoyo emocional y práctico. Aunque haya voluntad de acceder a la cultura local y al idioma, suele aplazarse o anularse porque se crean comunidades culturales comunes y la cultura local puede hablar el idioma de los turistas externos.

Debido a que los perfiles de los turistas de segundas residencias son diferentes de los sitios visitados, transforman las realidades locales; por ejemplo, si su percepción es 
que es inseguro el ámbito local, amurallan, establecen linderos físicos y culturales, y la apreciación de privatización aumenta. Con esto se genera una fragmentación del espacio, se reduce la movilidad que antes tenían los locales, caso muy común en las playas de México, en donde la población local se ve limitada a acceder a los ámbitos de influencia de las segundas residencias. A veces el miedo hace que los fuereños limiten la movilidad, pero también ocurre por la ostentación social que lleva a una marcada idea de propiedad y restricción de las porciones de propiedad. Esta situación puede ocasionar una autoexclusión de los locales.

El territorio de las segundas residencias es una lucha de poderes subordinados y dominantes y ello influye en lo que cada uno obtiene. La apropiación de espacios naturales por parte de inmobiliarias y de dueños de residencias representa un símbolo de riqueza ante comunidades locales que, con el apoyo de los propios gobiernos, motivan la exclusión. Mientras mayor sea la desigualdad de la región receptora (con relación a los espacios de donde provienen los turistas), los problemas que derivan de las segundas residencias se agudizarán; la exclusión también complica la gestión de los recursos públicos. Estos planteamientos teóricos fungen como telón de fondo en los capítulos subsecuentes.

En el capítulo 2, "El turismo residencial en el Corredor Costero Tijuana-Rosarito-Ensenada en Baja California: Surgimiento, características e imaginarios”, Nora L. Bringas Rábago expone que la característica predominante del sitio de estudio es que es una frontera altamente diferenciada, con fuertes inequidades entre uno y otro lado de la línea. Se reflexiona sobre el surgimiento del turismo y su evolución, los contrastes de la urbanización entre las porciones de segundas residencias y las localidades urbanas y rurales, además de los perfiles de los turistas residenciales y los imaginarios que alimentan el turismo residencial.

La atracción del Cocotren se sustenta en el paisaje costero y el clima mediterráneo, así como en la idea de la tranquilidad, con el plus de la cercanía de un ambiente transfronterizo agitado entre Tijuana y San Diego, en donde las telecomunicaciones y los transportes permiten un fuerte intercambio transfronterizo. Cabe anotar que Bringas Rábago considera el hecho de que el Cocotren ha tenido éxito como sitio de segundas residencias por las características de las poblaciones implicadas y sus ingresos: migrantes estadounidenses, jubilados, mayores de 45 años, con un poder adquisitivo mayor que los turistas nacionales y mucho mayor que la población local, con lo cual los extranjeros tienen posición de privilegio dentro de los turistas; para ellos es mucho más fácil adquirir una segunda residencia del lado mexicano -la cual sería mucho más cara del lado estadounidense-, con los beneficios de la frontera y la proximidad a su residencia principal.

Puesto que la demanda antecedió a la oferta, el crecimiento urbano litoral fue anárquico; así, alternan los sitios que la autora denomina como "planeados" y los "no planeados" y que se aprecian en uno y otro caso en los centros turísticos, los trailer parks y los sectores de comunidades locales. A esta complejidad se suman los efectos de la burbuja inmobiliaria que se dio hace unos años en esta zona, que dejó sectores en cierto abandono y viviendas inconclusas. Otro fenómeno interesante es que muchos extranjeros estadounidenses 
con propiedades en el Cocotren tienen orígenes mexicanos, con lo cual hay cierto vínculo cultural, situación que la autora discute como una particularidad relevante y que incide en la construcción de imaginarios.

En el capítulo 3, "El turismo residencial en Malinalco, Estado de México. Análisis crítico desde la posmodernidad", Maribel Osorio García argumenta (a diferencia de lo que ocurre en Tijuana-Rosarito-Ensenada y Puerto Morelos) que los turistas residenciales de Malinalco no son extranjeros, ya que en gran medida provienen de las urbes cercanas, en especial de la Ciudad de México y Toluca. Los propietarios pertenecen a grupos nacionales de alto poder adquisitivo; pueden adquirir la vivienda a través de inmobiliarias o por autoconstrucción. Osorio García detecta, por un lado, procesos de elitización de los territorios, pero, por el otro, de precarización de la vivienda.

Sin duda, al igual que en los otros dos lugares analizados en este libro, se advierten afectaciones al medio ambiente y socioculturales. También Osorio García dice que hubo un proceso de terciarización de la economía, empero, es importante señalar que, a diferencia de los otros sitios, aquí ha habido una historia muy antigua y arraigada a la cultura y al patrimonio locales, lo que ha aminorado la fuerte penetración cultural, aunque, como la autora indica, entre los jóvenes locales se observa una mayor tendencia al cambio y a la adaptación de los nuevos patrones culturales incorporados por los turistas residenciales.

Además, la autora evidencia la existencia de dos grupos de turistas de segundas residencias: por una parte, individuos de una élite intelectual, y, por la otra, individuos de élites políticas y económicas. Los primeros buscan mayor interacción con la comunidad local, pues perciben que es una forma de acercarse a las raíces culturales de las que están ajenos en las ciudades, mientras que los políticos y empresarios no tienen ni buscan ese tipo de aproximaciones.

En el capítulo 4, "Turismo residencial en Puerto Morelos: Reflexiones sobre sus características", Ana Pricila Sosa Ferreira dice que en Puerto Morelos ocurre una situación socioespacial muy diferente a dos casos anteriores de estudio en cuanto al abordaje del turismo de segundas residencias, pues las comunidades locales valoran este fenómeno más en sentido positivo, debido a que ha sido tan avasallador el modelo turístico de Cancún, que Puerto Morelos se ve como un destino alternativo por su baja densidad, el libre acceso a la playa, una comunidad cohesionada y efectiva que lucha por defender el manglar y el litoral. En tanto, los turistas valoran este espacio frente a la masificación de Cancún. Sin embargo, se detecta una fuerte presión por parte de los inversionistas inmobiliarios, dado que se observa un fuerte potencial turístico de mayor densidad.

Al final, en las conclusiones, las autoras de los tres estudios empíricos realizan un ejercicio comparativo en dos sentidos: por un lado, contrastan la plataforma teórica del libro con los resultados de campo, $y$, por el otro, confrontan las evidencias que resultaron de los estudios de caso entre sí, lo cual hace posible cerrar la lectura de forma muy enriquecedora, pues permite al lector forjarse un punto de vista más depurado acerca de la complejidad del turismo de segundas residencias en México. 


\section{Foro de Creatividad, Innovación y Competitividad en Turismo}

\section{ENTRE LA REALIDAD EMPRESARIAL Y LA ACADEMIA}

\author{
Sonia Guadalupe \\ Zermeño Flores \\ soniagpez@gmail.com \\ Universidad Estatal \\ de Sonora
}

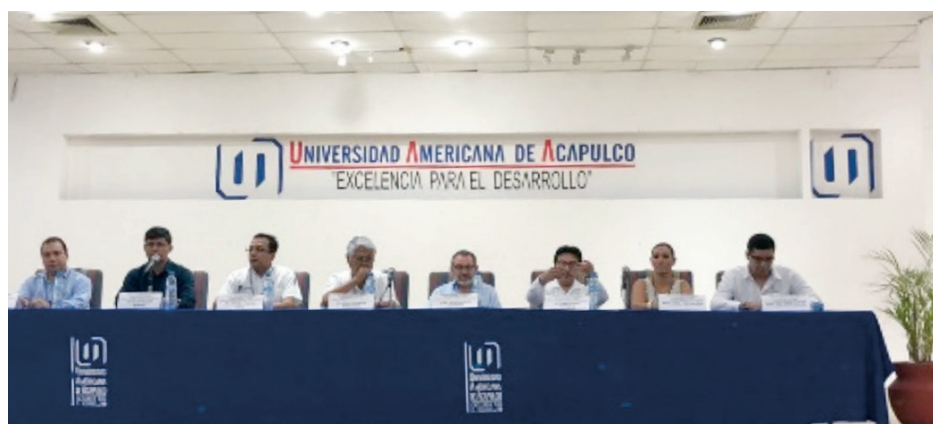

a Universidad Americana de Acapulco (UAA) se constituyó como sede y anfitriona del encuentro académico denominado Foro de Creatividad, Innovación y Competitividad en Turismo: Entre la Realidad Empresarial y la Academia, el cual contó con la gestión de su rector, maestro Mario Mendoza Castañeda, y el apoyo del maestro Javier Saldaña Almazán, rector de la Universidad Autónoma de Guerrero (UAGro). Ambas instituciones avalaron la visión de los organizadores: el doctor Tomás Cuevas Contreras, líder del Cuerpo Académico UACJ-CA-31, Estudios sobre Turismo y Tiempo Libre, de la Universidad Autónoma de Ciudad Juárez, Chihuahua (UACJ), y actual presidente del Centro de Investigación en Creatividad, Innovación y Competitividad (CiCiC), y su homólogo el doctor Sergio Salmerón Manzanares, presidente de la Asociación de Posgraduados del Estado de Guerrero (APG), profesores-investigadores que se han dado a la tarea de unir a académicos con perfil multidisciplinario, con la finalidad de fortalecer los saberes a través de la diversidad, la ciencia y la difusión de conocimiento tanto en la sociedad, como en el gobierno y la empresa.

El foro se desarrolló los días 7 y 8 de junio de 2108 en Acapulco de Juárez, Guerrero, México. Se planteó como objetivo reunir a la academia, el gobierno y la empresa para reflexionar sobre tópicos de interés ante las condiciones y tendencias del mercado, el patrimonio cultural, 


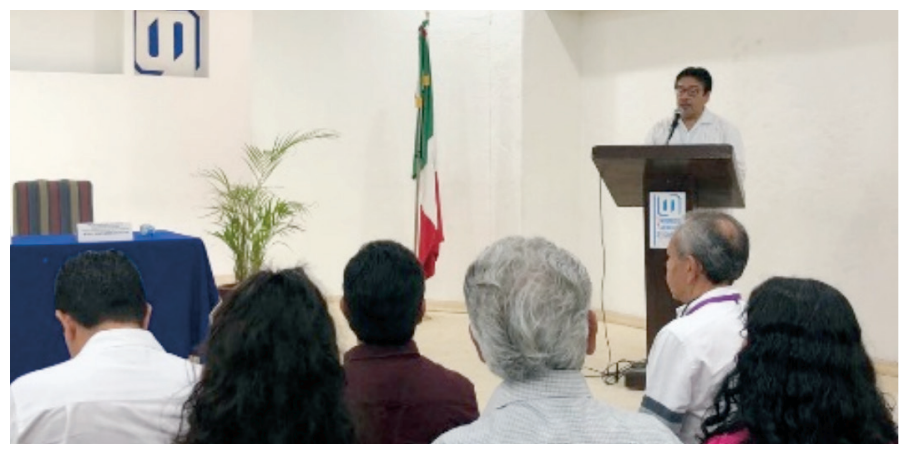

el turismo médico, la gastronomía y las nuevas tecnologías. Contó con la asistencia de más de 200 personas: académicos, investigadores, estudiantes de pregrado, posgrado, doctorado, especialistas, miembros de organismos de la sociedad civil, empresarios, representantes de gobierno y público en general, provenientes de los estados de Guerrero, Quintana Roo, Estado de México, Chihuahua y Sonora, principalmente.

El foro se organizó con el formato de conferencia magistral y paneles de discusión para, al final, permitir preguntas y/o aportaciones del auditorio. Las temáticas abordadas el jueves 7 de junio fueron 1) desarrollo turístico y sustentabilidad: indicadores de resiliencia de destinos turísticos ante huracanes, e información para la competitividad; 2) incorporación de los observatorios turísticos en la política pública de México y 3) turismo médico.

La conferencia magistral de apertura: "Indicadores de resiliencia de destinos turísticos ante huracanes: información para la competitividad", estuvo a cargo del doctor Oscar Frausto Martínez de la Universidad de Quintana Roo, quien subrayó la necesidad de planear las políticas públi- cas de los destinos turísticos desde el ámbito de los ecosistemas, la biodiversidad y las contingencias ambientales, a partir de la generación de indicadores en contextos de resiliencia que permitan contar con información para la toma de decisiones de los sectores público y privado.

La segunda conferencia: "Incorporación de los Observatorios Turísticos en la política pública de México", del matemático Ariel Juárez Morales, director general de Integración de Información Sectorial de la Secretaría de Turismo, versó sobre la importancia de los observatorios en la producción de información de datos duros para la toma de decisiones en la actividad turística, gastronómica u otras actividades económicas. De esta manera, se puso de relieve que los observatorios son una herramienta para gestionar la información científica sobre el turismo y proporcionar un eje de análisis a los organismos públicos y privados relacionados con el sector, con el afán de que estos puedan afrontar sus decisiones de actuación a partir de una base científica sólida.

Por otro lado, la conferencia denominada "Turismo médico", dictada por el maestro Seyed Rezvani, director general 


\section{S. G. Zermeño Flores}

de Mundo Imperial, reconoció el mérito del turismo médico como una actividad cada vez más prometedora y de alto crecimiento internacional. Precisó que, de acuerdo con ProMéxico, México se ubica en el segundo lugar mundial de este tipo de turismo y que, en 2017, se atendió a 1.2 millones de pacientes, lo cual reportó ingresos por 6000 millones de dólares. Por lo anterior, se expuso la posibilidad de impulsar un polo de desarrollo turístico médico y de bienestar en el estado de Guerrero. Con base en estos antecedentes, se hizo referencia al proyecto Princess Hospital, que se construirá en una extensión de 15000 metros cuadrados y que contará con un centro de diagnóstico integral, consulta externa, quirófanos, cirugía ambulatoria, área de medicina física y rehabilitación, hemodiálisis, departamento de radiología e imagen, laboratorio clínico, fisiología cardiopulmonar, además de urgencias, una unidad de terapia intensiva y cuidado intermedio, todo lo cual se complementará con un área de asistencia a adultos mayores con servicios de salud y esparcimiento que cumpla con los estándares internacionales.

El viernes 8 de junio tuvieron lugar las conferencias: 4) Turismo gastronómico patrimonio de la humanidad; 5) Colaboración entre lo público y lo privado: Condición de la imagen del destino de Hermosillo, Sonora y 6) El conocimiento emergente del turismo.

La primera conferencia fue dictada por la conocida chef Susana Palazuelos, quien se enfocó en la gastronomía tradicional mexicana y su impacto en la alimentación internacional, así como su relevancia en el desarrollo del turismo gastronómico en nuestro país. Por otro lado, relató su vida de trabajo a lo largo de los años, sus libros y experiencias en el área de eventos gastronómicos.

Los trabajos continuaron con la conferencia "Colaboración entre lo público y lo privado: Condición de la imagen del destino de Hermosillo, Sonora", a cargo del doctor Tomás Cuevas Contreras, quien se refirió a la importancia de las oficinas de congresos y convenciones (ocv) como entes dedicados a la promoción turística, y precisó que son uno de los actores o stakeholders que mantienen coordinación con otros grupos, como las agrupaciones de hoteleros, cámaras empresariales, prestadores de servicios turísticos, oficinas gubernamentales, academia y sociedad, es decir, con agrupaciones de los ámbitos público y privado que participan en la comunicación de una imagen sólida de un destino turístico.

El último trabajo del foro estuvo a cargo del doctor Marcelino Castillo Nechar, de la Universidad Autónoma del Estado de México (UAEM), quien ofreció la conferencia magistral "El conocimiento emergente del turismo", durante la cual puso énfasis en la creación de nuevos enfoques de investigación en el área de las ciencias sociales y humanidades. Asimismo, profundizó en la necesidad de observar al turismo como una ciencia con requerimientos de métodos sistemáticos basados en una epistemología de soporte, esto es, como un área de la filosofía del conocimiento. De esta forma, reflexionó sobre las implicaciones epistemológicas en la investigación turística con la finalidad de construir y producir conocimiento del turismo, avanzando en procesos teóricos metodoló- 
gicos que aporten criterios de fundamentación filosófica en el área del turismo y gesten condiciones para una investigación crítico-reflexiva aunada a la reflexión filosófica y el análisis pragmático de los fenómenos de estudio.

En conclusión, por sus aportes, el foro contribuyó a la instauración de un espacio de reflexión del fenómeno del turismo desde la perspectiva de la innovación, la creatividad y la competitividad, la cual se encuentra inmersa no solo en la operación de la actividad, sino en la acción colegiada, académica y de investigación, además de conformar un eslabón entre las empresas y el gobierno. Este intercambio de experiencias enriqueció el conocimiento que dinamizará la actividad y su desarrollo socioeconómico desde una orientación académica, con aportaciones de los prestadores de servicios turísticos privados, los entes gubernamentales y la sociedad en general. 


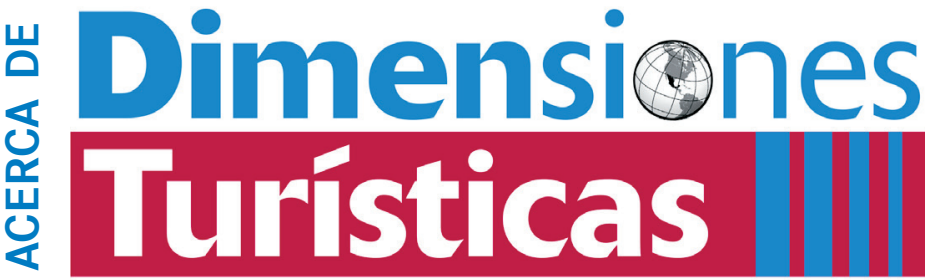

\section{POLÍTICAS}

\section{Enfoque y alcance}

Dimensiones Turísticas es una publicación científica, digital y de distribución gratuita que publica y difunde trabajos originales de investigación que abordan temáticas turísticas en México y en otros contextos internacionales. Dimensiones Turísticas se especializa en el estudio de los distintos procesos sociales, culturales, económicos, políticos, ambientales y territoriales vinculados con la actividad turística a través de investigaciones analíticas, críticas y reflexivas desde una perspectiva inter y multidisciplinaria con el propósito de difundir los principales hallazgos de investigación tanto entre la comunidad académica, como con el sector gubernamental, empresarial y la sociedad en su conjunto.

Su objetivo es constituirse en un espacio que permita exponer nuevos enfoques, teorías, metodologías, estudios, experiencias y hallazgos de investigación que posibiliten avanzar en la construcción y difusión del conocimiento acerca del turismo, así como contribuir al enriquecimiento de debates actuales sobre la investigación turística.

\section{Políticas de sección}

Dimensiones Turísticas publica textos inéditos de carácter científico que analicen teorías, metodologías o procesos sociales, culturales, económicos, administrativos, políticos, ambientales y territoriales vinculados con la actividad turística desde una perspectiva inter y multidisciplinaria. Se publicarán tres tipos de trabajos: artículos, notas críticas y reseñas bibliográficas.

Artículo: Se refiere a trabajos originales que expongan los principales hallazgos teóricos, empíricos o metodológicos de investigaciones concluidas o en curso que analicen desde distintas disciplinas procesos vinculados a la actividad turística.

Notas críticas: Es una reflexión académica sobre temas actuales o avances de investigación.

Reseña: Es un texto breve que refiere o analiza publicaciones en formato físico o electrónico recientes que aborden temáticas de turismo o de investigación. El Comité editorial será el responsable de sugerir los libros a reseñar. 


\section{Proceso de evaluación por pares}

Los trabajos académicos serán sometidos a un proceso de evaluación anónima por pares. Las notas críticas serán sometidas al mismo proceso de evaluación que los artículos. Las publicaciones reseñadas no deberán tener una fecha de publicación mayor a dos años anteriores al año de envío de la propuesta.

Debido al proceso editorial anónimo, los datos de autores/as como adscripción, currículo sucinto, dirección electrónica y postal figurarán en una hoja aparte. Los trabajos serán sometidos a la revisión de un comité de expertos para avalar la calidad científica y deberán enviarse en su versión final y completa, ya que no se permitirán modificaciones posteriores una vez iniciado el proceso de evaluación.

El proceso para la revisión blindada de artículos es el siguiente:

Recepción del manuscrito y aviso de recepción al autor en un plazo no mayor a 72 horas. Posteriormente, inicia el proceso que consta de las siguientes fases:

1. Primera fase: Envío de la propuesta al Comité editorial para realizar una pre-evaluación de la calidad del manuscrito, la pertinencia temática y la conformidad de las normas editoriales. El manuscrito podrá ser aceptado o rechazado por el Comité, que basa su decisión en criterios de calidad académica, aportación al campo científico y a la temática y normatividad. Si el manuscrito es aceptado, pasa a la segunda fase; en caso contrario, se envía un aviso de rechazo al/la autor/a.

2. Segunda fase: en caso de que el pre-dictamen sea favorable, el manuscrito anónimo se enviará a dos evaluadores/as externos/as, con especialidad en la línea de investigación, temática o materia de la propuesta. En caso de contar con dictámenes contradictorios, el manuscrito se envía a un tercer evaluador/a, también especialista, cuya decisión será determinante para el dictamen final.

Los dictámenes podrán tener los siguientes resultados:

1. Dictamen positivo: indica un resultado favorable; el manuscrito puede ser evaluado como:
a) Publicar sin cambios;
b) Publicar cuando se hayan cumplido con modificaciones menores;
c) Publicar una vez que se haya efectuado una revisión a fondo.

2. No publicable: El manuscrito se rechaza de forma definitiva.

En caso de que el dictamen final solicite cambios o modificaciones, los/as autores/as disponen de cuatro semanas para incorporarlos y volver someter el manuscrito para su revisión. La revisión la realiza el Comité editorial. Si los cambios se incorporan adecuadamente, el manuscrito se acepta finalmente; si se considera que no se han hecho las modificaciones requeridas se pedirá a los/las autores/as que revisen su propuesta y se contará con un 
plazo no mayor a dos semanas para incorporar los cambios solicitados. Si los cambios se incorporan, será aceptado para su publicación; si los cambios no se incorporan en este segundo periodo, el manuscrito se rechaza.

Para que las propuestas sean enviadas al Comité editorial deberán cumplir con las normas editoriales de AMIT (APA 6). En caso contrario, serán devueltas a los/las autores/as para que ajusten sus propuestas a las Directrices.

Una vez aceptado el trabajo para su publicación, los/as autores/as conceden a la Dimensiones Turísticas los derechos de los artículos publicados, conservando sus derechos morales conforme lo establece la Ley de derechos de autor

\section{Frecuencia de publicación}

Dimensiones Turísticas es una publicación semestral. Se publica en junio y diciembre La convocatoria para recepción de trabajos se mantiene abierta durante todo el año.

\section{Política de acceso abierto}

Dimensiones Turísticas brinda un acceso abierto y gratuito al contenido de sus investigaciones con la finalidad de difundir y garantizar un intercambio amplio y directo del conocimiento generado.

Dimensiones Turísticas no cobra cuotas por el envío, gestión o publicación de los trabajos enviados a evaluar.

\section{Derechos de los/las autores/as}

Los/las autores/as serán responsables únicos de las ideas, afirmaciones y opiniones expresadas en su texto, por lo que la revista no asume responsabilidad alguna en este sentido. Los/las autores/as conserva/n sus derechos morales conforme lo establece la Ley de derechos de autor. Dimensiones Turísticas autoriza la reproducción de su material a través de medios magnéticos, electrónicos y de reprografía siempre y cuando no se alteren los contenidos, sea sin fines de lucro y se cite la fuente completa.

\section{DIRECTRICES PARA AUTORES/AS}

Los trabajos serán sometidos a evaluación por un comité de expertos. Todas las propuestas pasarán por un proceso editorial que se desarrollará en varias fases, por lo que es necesario que la presentación de los manuscritos siga una serie de normas que faciliten la edición y eviten el retraso de la publicación.

1. Los trabajos que se envíen a Dimensiones Turísticas para su publicación deberán ser originales y académicos, no haber sido publicados en otros medios impresos, ni electrónicos. Tampoco deberán haber sido sometidos de manera simultánea a otras 
revistas u órganos editoriales. Deberán atender de manera estricta la presente guía para autores.

2. Los trabajos deberán enviarse en su versión final y completa, ya que no se admitirán modificaciones posteriores una vez iniciado el proceso de evaluación.

3. Dimensiones Turísticas publicará tres tipos de trabajos: artículos, notas críticas y reseñas bibliográficas.

4. Todos los trabajos serán revisados para verificar que se ajusten estrictamente a la presente guía para autores. En caso contrario se remitirán a los/las autores/ as para que realicen los ajustes correspondientes. Una vez establecido que el trabajo cumple con los requisitos solicitados por la revista, será enviado a dos árbitros, quienes determinarán en forma anónima:

a) Dictamen positivo: indica un resultado favorable; el manuscrito puede ser evaluado:

- Publicar sin cambios;

- Publicar cuando se hayan cumplido con modificaciones menores;

- Publicar una vez que se haya efectuado una revisión a fondo.

b) No publicable: El manuscrito se rechaza de forma definitiva.

5. En caso de discrepancia entre ambos resultados, el texto será enviado a un tercer árbitro, cuyo dictamen será determinante para decidir si se acepta o no. Los resultados del proceso de evaluación serán inapelables en todos los casos.

6. Los trabajos enviados por académicos/as adscritos/as a alguna institución serán sometidos a consideración de árbitros externos a la misma.

7. Los dictámenes serán enviados a los/las autores/as oportunamente.

8. Los trabajos enviados deberán estar escritos de manera clara, sencilla y bien estructurada, omitiendo la redacción en primera persona, ya sea en singular o plural (yo o nosotros).

9. Los párrafos adoptarán el estilo de párrafo moderno (sin sangría).

10. Los trabajos podrán estar escritos en español o en inglés.

\section{Requisitos para los artículos}

1. Todos los trabajos deberán estar escritos en el programa Word 2011 o anterior, en hojas tamaño carta, en una sola faz, a espacio y medio y con márgenes de tres centímetros. Tipo de letra Times New Roman de 12 puntos.

2. La extensión mínima del artículo será de 20 cuartillas y la máxima de 30 cuartillas tamaño carta, a espacio y medio, incluyendo resumen, cuadros, gráficos y figuras (mapas, ilustraciones, diagramas, fotografías) y bibliografía.

3. En la primera página deberá aparecer el título del trabajo (redactado en alta y bajas, en negritas y en español e inglés), que deberá ser breve y referir claramente 
el contenido. Enseguida se incluirá un resumen en español e inglés (abstract) con una extensión máxima de 600 caracteres, en el que se destaque el objetivo, la relevancia del análisis, el método utilizado, los principales resultados o hallazgos más relevantes. Es responsabilidad del autor proveer una traducción correcta del resumen. Asimismo, se requieren cinco palabras clave en español e inglés (key words). Se sugiere que estas palabras sean: una geográfica, dos disciplinarles y dos temáticas, con su respectiva traducción al inglés o español que permitan identificar el contenido del artículo. Enseguida se presenta el texto principal y las referencias.

4. El texto deberá organizarse como sigue (los títulos de secciones son indicativos, las propuestas pueden llevar otro título, pero respetar los contenidos):

a) Título

b) Resumen (español e inglés) y palabras clave en ambos idiomas

c) Introducción

d) Cuerpo del trabajo: antecedentes, metodología, resultados, discusión y/o hallazgos.

e) Conclusiones

f) Bibliografía

5. Los títulos o subtítulos deberán diferenciarse entre sí, para ello se recomienda el uso del sistema decimal progresivo, cuidando que la numeración de los subtemas o secciones no sea excesiva o mayor a dos órdenes (2., 2.1, 2.1.1, 2.1.2).

6. Las siglas y acrónimos deberán ser claramente definidos en su primer uso en el texto.

7. No se aceptan abreviaturas.

8. Todas las referencias a material previamente publicado y a fuentes estadísticas deberán estar identificadas en el texto utilizando el sistema de citas autor y fecha de APA 6, anotando entre paréntesis el primer apellido del autor/a o autores, seguido del año de publicación y página(s) de referencia precedida(s) por las letras p. o pp. Por ejemplo: (Hiernaux, 2010, p. 63) o (Hiernaux y Osorio, 2015, pp. 231-235).

9. Las notas de pie de página deberán ser las estrictamente necesarias, estar numeradas sucesivamente en números arábigos y estar situadas a pié de página. Se utilizarán sólo para hacer comentarios puntuales o aclaraciones del autor y no para referencias bibliográficas. Deberán presentarse con letra Times New Roman de 9 puntos evitando anexos o apéndices.

10. Los cuadros, tablas y gráficos deberán incluir información estadística concisa, en formato de hoja de cálculo, preferiblemente en Microsoft Excel. Igualmente deberán colocarse en formato editable en el lugar propuesto en el documento, con el título colocado en la parte superior del objeto, con tipología Times New Roman 10 puntos y con su respectiva fuente de referencia colocada en la parte inferior. 
11. Las figuras deberán respaldarse en un archivo aparte, en formato de imagen jpeg (.jpg) o tiff (.tif) con una resolución de 300 dpi y preferentemente en color y un archivo por cada objeto. También deberán colocarse en formato editable en el lugar propuesto en el documento, con el título colocado en la parte superior de la figura, con tipología Times New Roman 10 puntos y con su respectiva fuente de referencia colocada en la parte inferior.

12. Tanto los cuadros, tablas, gráficos y demás figuras serán numerados con el sistema arábigo (cuadro 1, 2, 3, etc.). Las fotografías son consideradas como figuras (figura 1, 2, 3, etcétera). Estas últimas deberán manejarse en formato JPG a 300 dpi como mínimo y deberán especificar como pie de foto, el autor y el año en que fueron tomadas, con tipología Times New Roman 10 puntos y con su respectiva fuente de referencia, colocada en la parte inferior.

13. Cada archivo debe ir titulado en primer lugar por el tipo de objeto, su número consecutivo y la página en que queda ubicado (graf1p8.jpg; mapa1p15.tif; fig1p12. jpg; fig2p16.xls; etcétera). En el cuerpo del texto deberá incluirse cada objeto en el lugar correspondiente en formato editable.

14. La bibliografía se incluirá al final del artículo ordenada alfabéticamente por autor, incluyendo exclusivamente las obras citadas en el cuerpo del texto como libros, capítulos de libros, artículos en revistas digital o impreso, notas periodísticas, archivos de Internet, películas, entre otros.

\section{Requisitos para las notas críticas}

1. Las notas críticas son reflexiones sobre temas de actualidad o avances de investigación. Deberán tener una extensión mínima de ocho cuartillas tamaño carta y un máximo de diez, a espacio y medio, en Times New Roman de 12 puntos, con márgenes de tres centímetros.

2. Las notas críticas serán seleccionadas por el Comité Editorial de la revista considerando su calidad, originalidad en el análisis, actualidad y pertinencia temática.

3. Las notas críticas deberán atender las mismas indicaciones con respecto al título (bilingüe), así como para citar referencias y bibliografía.

\section{Requisitos para las reseñas bibliográficas}

1. Las reseñas deben referirse a libros relevantes publicados dentro de los dos años anteriores a la fecha de publicación de la revista y su extensión máxima deberá ser de cuatro páginas tamaño carta, a espacio y medio, en Times New Roman de 12 puntos, con márgenes de tres centímetros en todos los lados. 
2. La reseña deberá contener la referencia completa de la obra (formato APA 6), seguida de los comentarios de quien hace la reseña y los datos de identificación (nombre y apellidos, adscripción institucional y correo electrónico).

3. Las reseñas deberán atender las mismas indicaciones con respecto al título (bilingüe), así como para citar referencias y bibliografía.

Normas para citar las referencias bibliográficas

Las referencias a fuentes consultadas deberán incluirse al final en orden alfabético, sin distinguir el tipo de fuente y en formato APA 6.

\section{Artículos y publicaciones periódicas impresas}

Apellido, A. A., Apellido, B. B. y Apellido, C. C. (Año). Título del artículo (en redondas). Nombre de la revista (en cursivas), volumen(en cursivas)(número), pp.-pp.

Ejemplo:

Bertoncello, R. (2002). Turismo y territorio otras prácticas, otras miradas. Aportes y Transferencias, 6(2), 29-50.

\section{Artículo y publicaciones digitales o electrónicas}

Apellido, A. A., Apellido, B. B. y Apellido, C. C. (Año). Título del artículo (en redondas). Nombre de la revista (en cursivas), volumen(en cursivas)(número), pp.-pp. Recuperado de www.direcciónelectrónica.com

Ejemplo:

Valcuende del Río, J. M. (2012). Turismo y poblaciones indígenas: Espacios, tiempos y recursos. Scripta Nova. Revista Electrónica de Geografía y Ciencias Sociales, XVI(410), 2855. Recuperado de http://www.raco.cat/index.php/ScriptaNova/issue/view/18634

\section{Artículo con DoI}

Apellido, A. A., Apellido, B. B. y Apellido, C. C. (Año). Título del artículo (en redondas). Nombre de la revista (en cursivas), volumen(en cursivas)(número), pp.-pp. Dol: XXX-YYYY Ejemplo:

Valcuende del Río, J. M. (2012). Turismo y poblaciones indígenas: Espacios, tiempos y recursos. Scripta Nova. Revista Electrónica de Geografía y Ciencias Sociales, XVI(410), 28-55. Dol: $1138-9788$

\section{Libros}

Apellido, A. A. (Año). Título (en cursivas). Ciudad, País: Editorial.

Ejemplos:

Santana, A. (1997). Antropología y Turismo. ¿Nuevas hordas, viejas culturas? Barcelona, España: Ariel. 
Casez, G. (1992a). Fondements pour une géographie du tourisme et des loisirs. París, Francia: Bréal Editions.

Casez, G. (1992b). Tourisme et tiers-monde, un bilan controversé. París, Francia: L'Harmattan (Tome II).

\section{Libros con editor, compilador o coordinador:}

Apellido, A. A. (Ed.). (Año). Título (en cursivas). Ciudad, País: Editorial.

Ejemplo:

Vera Rebollo, J. F. (coord.). (2011). Análisis territorial del turismo y planificación de destinos turísticos. Valencia, España: Tirant Lo Blanch.

\section{Versión electrónica o digital de libro impreso:}

Apellido, A. A. (Año). Título (en cursivas). Editorial. Recuperado de www.direcciónelectrónica.com

Ejemplo:

Ascanio, A. (2013). Economía del turismo [e-book]. Ediciones de la U.

\section{Capítulo de libro:}

Apellido, A. A. y Apellido, B. B. (Año). Título del capítulo (en redondas). En A. A. Apellido (Ed.), Título del libro (en cursivas) (pp. nn-nn). Ciudad, País: Editorial.

Ejemplos:

Luka, N. (2011). Del espacio al lugar y al paisaje cultural: segundas residencias a orillas de ríos y lagos en Canadá central. En T. Mazón, R. Huete y A. Mantecón (eds.), Construir una nueva vida. Los espacios del turismo y la migración residencial (pp. 2146). Santander, España: Milrazones.

Salvat, J., Meritxell, S. y Olmos, P. (1998). Evaluación del potencial turístico: las montañas de Prades. En J. Oliveras y S. Antón (eds.), Turismo y planificación del territorio en la España de fin de siglo (pp. 107-115). Tarragona, España: Universitat Rovira I Virgili.

\section{Videos, grabaciones y otros soportes digitales:}

Apellido, A. A. (Productor) y Apellido, B. B. (Director). (Año). Título (en cursivas) [Película cinematográfica]. País de origen: Estudio.

Ejemplo:

Secretaría de Turismo de México (2015). Compendio estadístico del turismo en México 2016 [disco compacto]. México: Sectur.

\section{Videos, podcast y otras fuentes en línea:}

Apellido, A. A. (día, mes, año). Nombre del programa o evento (en cursivas) [Tipo de archivo]. Recuperado de www.direcciónelectrónica.com 
Ejemplo:

Boehm, P. (26 de noviembre de 2014). La entrevista de Herta Müller en Hay Festival Cartagena 2013 [Audio en podcast]. Recuperado de http://programas.cooperativa.cl/ unanuevamanana/

\section{Páginas web}

Apellido, A. A. (Año). Título de la página web (en cursivas). Recuperado de www.direcciónelectrónica.com

Ejemplo:

Instituto Nacional de Estadística y Geografía (INEGI) (2014). Cuenta Satélite del Turismo (CST) de México. Recuperado de http://www.beta.inegi.org.mx/app/biblioteca/ficha. html?upc $=702825060640$

\section{Simposios y conferencias}

Apellido, A. y Apellido, B. (mes, año). Título de la presentación (en redondas). En A. Apellido del Presidente/organizador del Congreso (Presidencia), Título de/ simposio (en cursivas). Simposio dirigido por Nombre de la Institución Organizadora, Lugar.

Ejemplo:

Ibáñez, R. (noviembre, 2013). Retos en materia de turismo y sustentabilidad en pequeñas localidades costeras de Baja California Sur (BCs). En 7mo. Congreso Internacional de la Academia Mexicana de Investigación Turística. Academia Mexicana de Investigación Turística y Universidad Autónoma de Chiapas, San Cristóbal de Las Casas, Chiapas, México.

\section{Tesis}

Apellido, A. (Año). Título de la tesis (en cursivas) (Tesis de [grado]). Nombre de la Institución, lugar de presentación.

\section{Ejemplo:}

Gaxiola Aldama, R. (2010). Turismo sexual masculino y las prácticas sociales de uso del espacio urbano en la ciudad de Tijuana (Tesis de doctorado en Ciencias Sociales con especialidad en Estudios Regionales). El Colegio de la Frontera Norte, Tijuana, Baja California, México.

\section{Comunicaciones personales y entrevistas}

Si bien las comunicaciones personales (correos, cartas privadas, memorandos, entrevistas telefónicas) deberán aparecer referidas en el cuerpo del texto según lo sugerido por las normas APA 6, no se incluyen en las referencias bibliográficas, por no considerarse fuentes consultables. 


\section{ENVÍos}

Los trabajos podrán enviarse atendiendo cualquiera de las dos opciones:

1. Enviar el archivo digital del trabajo a la dirección: amit.dimentur@gmail.com, asegurándose de eliminar las referencias de autoría y filiación.

2. Subir el archivo digital del trabajo directamente en el siguiente enlace: www.amiturismo.org/envio-de-articulo

\section{Información adicional}

1. Para asegurar el anonimato, además del texto completo del artículo o reseña, es necesario enviar en hoja independiente o capturar directamente en el siguiente enlace www.amiturismo.org/envio-de-articulo

- Tipo de colaboración

- Título de la colaboración.

- Nombre completo del/la autor/a.

- Correo electrónico del/la autor/a.

- Institución y dependencia de adscripción.

- Dirección postal

- País

2. Currículo abreviado de el/la autor/a o autores/as (máximo 600 caracteres), que incluya el último grado académico y la institución donde obtuvo el grado, ocupación actual, líneas de investigación y título de los últimos tres trabajos publicados.

Lista de comprobación de preparación de envíos

Como parte del proceso de envío se requiere que los autores indiquen que el mismo cumple puntualmente con las siguientes características:

1. Que la propuesta no ha sido publicada previamente, ni se ha enviado simultáneamente a otra revista.

2. Que el fichero enviado está en formato Microsoft Word.

3. Que se han añadido direcciones web para las referencias donde sea posible.

4. Tipografía Times New Roman a 12 puntos para el texto y de 10 para títulos de cuadros, gráficas y figuras y para notas de pie de página el tamaño es 9.

5. Texto interlineado a espacio y medio.

6. Que el texto cumple con los requisitos bibliográficos y de estilo indicados en la presente Guía para autores. 
Los trabajos que no cumplan con estas indicaciones pueden ser devueltos al/la autor/a, quien podrá enviar de nuevo su manuscrito siempre y cuando cumpla con los puntos solicitados.

Aviso de derechos de autor

- Los/as autores/as conceden a Dimensiones Turísticas el permiso para que su material se difunda en la revista y medios magnéticos, electrónicos y fotográficos. Los derechos de autor de los artículos publicados en Dimensiones Turísticas son cedidos a la Academia Mexicana de Investigación Turística, A.C. (AMIT) tras la aceptación del original para que éste se publique y distribuya en versión electrónica; asimismo, los/las autores/as conserva(n) sus derechos morales conforme lo establece la Ley de derechos de autor.

- El/la autor/a principal recibirá una forma de Declaración de originalidad y cesión de derechos de autor que deberá firmar y remitir a Dimensiones Turísticas (amit.dimentur@gmail.com) conjuntamente con la versión final del trabajo. Será su responsabilidad obtener la firma y consentimiento de los/las demás autores/as si los hubiere.

- Por otra parte, los/as autores/as podrán usar el material de su artículo en otros trabajos o libros publicados por ellos mismos, con la condición de citar a Dimensiones Turísticas como la fuente original de los textos.

- Es responsabilidad de los/las autores/as obtener por escrito la autorización correspondiente para todo aquel material que forme parte de su artículo (Vg. fotografías o mapas satelitales) y que se encuentre protegido por la Ley de derechos de autor.

\section{Declaración de privacidad}

Los nombres y direcciones de correos administrados por Dimensiones Turísticas se usarán exclusivamente para los fines declarados por la revista y no estarán disponibles para ningún otro propósito u otra persona.

\section{OTROS}

\section{Declaración de ética}

Dimensiones Turísticas suscribe el código de conducta del cope (Committee on Publication Ethics), que adopta las siguientes recomendaciones de la Guía de buenas prácticas revisada y aprobada por el COPE en 2011: 
- La dirección de la revista y demás miembros del equipo editorial son responsables de garantizar un proceso de evaluación anónimo entre autores y evaluadores. La información sobre el manuscrito se mantendrá en estricta confidencialidad y sólo se informará a autores/as responsables de la propuesta y al equipo editorial.

- La dirección de la revista mantendrá anónima la identidad de los/as evaluadores/as.

- Dimensiones Turísticas se compromete a elegir evaluadores/as calificados/as según la temática y con capacidad probada para evaluar de forma ética y profesional, evitando conflictos de intereses.

- Dimensiones Turísticas cuidará la calidad académica y ética de la comunicación con los/las evaluadores/as, cualquier falta, descortesía o mala conducta de un/a dictaminador/a será revisada y la revista se compromete a no recurrir a evaluadores/as que realicen tales prácticas.

- Las propuestas serán sometidas a dictamen considerando su contenido intelectual, sin sesgos ni discriminación de edad, género, creencias políticas o religiosas y respetando la libertad de expresión.

- Las decisiones editoriales de aceptación o rechazo estarán basadas en la importancia, originalidad y claridad del manuscrito, en la validez del estudio científico y en su vínculo con la línea editorial de la revista. El/la directora/a sólo podrán revocar propuestas o contribuciones en caso de que se identifiquen problemas serios con las mismas, como plagio, faltas éticas, entre otras, aunque estuvieran previamente aprobadas para su publicación.

- En caso de ser necesario y estar comprobado, Dimensiones Turísticas puede hacer públicas cuestiones de mala conducta vinculadas a la investigación y a las propuestas incluyendo prácticas de plagio y duplicidad por parte de los/as autores/as.

- La dirección de la revista y el Consejo editorial recomiendan a sus revisores/as el uso de software para detectar plagios (Turnitin, Paper Rater, Viper, entre otros).

En cuanto a los/las evaluadores/as, éstos deberán comprometerse a lo siguiente:

Revisar las propuestas de forma confidencial y no utilizar la información de la revisión para otros fines distintos a la evaluación del trabajo.

- Informar a la dirección de la revista en caso de existir algún conflicto de cualquier tipo (de interés o vinculado con la metodología, contenidos o procedimientos de la investigación, los/las evaluadores/as deberán informar a la dirección).

- Informar a la dirección de la revista cuestiones de mala ética vinculadas a la investigación y a las propuestas incluyendo prácticas de plagio y duplicidad por parte de los/as autores/as.

En cuanto a los/las autores/as, éstos deberán comprometerse a lo siguiente:

- Las propuestas son responsabilidad de quien sustenta la autoría; los/las autores/ as se comprometen a someter obras académicas inéditas y originales elaboradas 
por ellos mismos. Las propuestas no deberán ser sometidas a otros procedimientos editoriales ni haber sido objeto de plagio, falsificación o manipulación.

- Todo material no producido por quien sustenta la autoría, deberá estar claramente citado de acuerdo a las normas de Dimensiones Turísticas.

- Los/las autores/as tienen la obligación de no incurrir en falsificación de participación de autoría, por lo que deberán equilibrar su participación a fin de que no aparezcan autorías o colaboraciones fantasmas. 